\title{
WestVirginiaUniversity
}

THE RESEARCH REPOSITORY @ WVU

Graduate Theses, Dissertations, and Problem Reports

2002

\section{Modeling trade and environmental interactions}

\author{
Haixiao Huang \\ West Virginia University
}

Follow this and additional works at: https://researchrepository.wvu.edu/etd

\section{Recommended Citation}

Huang, Haixiao, "Modeling trade and environmental interactions" (2002). Graduate Theses, Dissertations, and Problem Reports. 1586.

https://researchrepository.wvu.edu/etd/1586

This Dissertation is protected by copyright and/or related rights. It has been brought to you by the The Research Repository @ WVU with permission from the rights-holder(s). You are free to use this Dissertation in any way that is permitted by the copyright and related rights legislation that applies to your use. For other uses you must obtain permission from the rights-holder(s) directly, unless additional rights are indicated by a Creative Commons license in the record and/ or on the work itself. This Dissertation has been accepted for inclusion in WVU Graduate Theses, Dissertations, and Problem Reports collection by an authorized administrator of The Research Repository @ WVU.

For more information, please contact researchrepository@mail.wvu.edu. 


\title{
MODELING TRADE AND ENVIRONMENTAL INTERACTIONS
}

\author{
Haixiao Huang
}

Dissertation submitted to the Davis College of Agriculture,

Forestry and Consumer Sciences

at West Virginia University

in partial fulfillment of the requirements

for the Degree of

Doctor of Philosophy

in

Natural Resource Economics

\author{
Walter C. Labys, Ph.D., Chair \\ Subhayu Bandyopadhyay, Ph.D. \\ Jerald J. Fletcher, Ph.D. \\ Timothy T. Phipps, Ph.D. \\ Peter V. Schaeffer, Ph.D. \\ Morgantown, West Virginia \\ 2002
}

Keywords: Trade and Environment, Simultaneous Equations, Chinese

Environmental Economics

Copyright 2002 Haixiao Huang 


\title{
ABSTRACT \\ Modeling Trade and Environmental Interactions
}

\author{
Haixiao Huang
}

Interactions between trade and the environment have been studied extensively as a reaction to the pressure that the accelerated pace of globalization is placing on environment and trade. Distinguishing itself from previous studies, this research addresses issues, methods and policy implications concerning the interrelationship between trade and environment first in a comprehensive literature survey, and then focuses on a modeling analysis on the interactions between trade and the environment in China.

The literature review provides a perspective on received and future research by employing a dual approach: not only are major issues concerning trade and environment analyzed, but also progress in the methods necessary to examine those issues is assessed. In both parts, the attempt has been to suggest new possibilities for research and policy goals.

To investigate the interactions between trade and the environment in the Chinese case, a nonlinear simultaneous equations trade and environment model (TEM) is developed. The theoretical framework of the TEM is an expansion of Dean's (1999) fourequation model by adding international trade and foreign direct investment relationships. This model can be used not only to analyze the trade impact of an environmental policy and the environmental impact of trade, but also to identify the sources of those influences. In addition, the nonlinear specification of the relationship between emissions and economic scales allows for an explicit test of the environmental Kuznets curve.

The TEM is estimated with a Chinese provincial panel data set. The empirical results suggest that there may indeed have existed a tradeoff between economic growth and environmental protection in China's development. That is, increased trade and rapid economic growth may have led to more pollution emissions on the one hand, while environmental policies may have led to reduced economic growth and reduced trade on the other. Policy alternatives to mitigate these negative impacts are also explored here. 


\section{ACKNOWLEDGMENTS}

I am most indebted to Dr. Walter C. Labys, my advisor and committee chairman, for his caring guidance, active involvement, and constant assistance throughout my $\mathrm{PhD}$ study as well as my dissertation research. I would also like to thank other committee members, Dr. Jerald J. Fletcher, Dr. Timothy T. Phipps, Dr. Peter V. Schaeffer, and Dr. Subhayu Bandyopadhyay for their encouragement, insightful suggestions, detailed criticisms, and support. Their help has proven important to the successful completion of this dissertation.

I wish to thank Dr. Zhiping Le, Nanchang University, Dr. Xingshan Zhu, China's State Development Planning Commission, and Dr. Shubo Xu, Rensselaer Polytechnic Institute, for helping me to collect Chinese provincial macro data, and Dr. Hua Wang, the World Bank, for providing me with the Chinese provincial environmental data.

Finally, I also wish to thank my parents, brothers, and sisters for their encouragement and support. Particularly, I would like to express my appreciation and love to my wife Peng Jia and my daughter Fan Huang for their support, patience, and help. To Peng and Fan, this dissertation is dedicated. 


\section{TABLE OF CONTENTS}

ABSTRACT ii

ACKNOWLEDGMENTS

LIST OF TABLES viii

LIST OF FIGURES ix

CHAPTER

1. INTRODUCTION 1

1.1 Purpose 1

1.2 Background 3

1.3 Methodology 6

$\begin{array}{ll}1.4 \text { Contribution } & 7\end{array}$

1.5 Outline for the Study 9

2. ISSUES CONCERNING ECONOMIC INTERACTIONS

BETWEEN ENVIRONMENT AND TRADE 11

2.1 Introduction 11

2.2 Macroeconomic Impact 13

2.2.1 Impacts on national income $\quad 13$

2.2.2 Impacts on employment 14

2.2.3 Impacts on other economic variables $\quad 15$

2.2.4 Impacts on balance of trade and payments $\quad 16$

2.2.5 Impacts on sustainable development 17

2.3 Patterns of Trade and Comparative Advantage 18

2.3.1 Patterns of world trade in environmentally sensitive goods 18

2.3.2 Comparative advantage 20

2.4 Terms of Trade 23

2.4.1 Impacts of emissions standards in one country 23

2.4.2 Impacts of pollution taxes in one country 24

2.4.3 Transnational pollution case 25

2.5 Patterns of Production and Consumption 27

2.5.1 Adjustments in production sectors 27

2.5.2 Impacts on production $\quad 28$

2.5.3 Impacts on consumption $\quad 30$

2.6 Linkages between Trade, Environment and the Economy 31

2.6.1 Conflicts between trade policy and environmental policy 31

2.6.2 Transnational pollution and trade $\quad 33$

2.6.3 Natural resources and trade $\quad 35$

2.6.4 Hazardous substances and trade $\quad 36$

2.6.5 Global warming and trade $\quad 37$

2.7 Pollution Redeployment to Developing Countries 39

2.7.1 National environmental policy and capital mobility $\quad 39$ 
2.7.2 Environmentally-induced industrial relocation $\quad 40$

2.8 Environmental Degradation 44

2.8.1 Trade and the global environment 44

2.8.2 Trade-induced environmental degradation $\quad 47$

2.9 Factor rewards $\quad 50$

2.9.1 Capital and labor rewards $\quad 50$

2.9.2 Resource rewards 53

2.10 Conlusions $\quad 54$

3. METHODS OF ANALYZING INTERACTIONS BETWEEN ENVIRONMENT AND TRADE 57

3.1 Problems of measuring trade and environmental interactions 57

3.2 Computable General Equilibrium Models 58

3.2.1 Market CGE models 58

3.2.2 Non-market CGE models $\quad 61$

3.3 International Trade Models 63

3.3.1 The Heckscher-Ohlin model 63

3.3.2 Empirical trade models $\quad 66$

3.4 Input-Output Models 68

3.4.1 Basic I-O models 68

3.4.2 Trade and I-O models $\quad 69$

3.4.3 Environment and I-O models $\quad 72$

3.5 Welfare Models 74

3.5.1 Welfare analysis and impact measurement 74

3.5.2 Welfare analysis of gains from trade 75

3.5.3 Welfare analysis of environmental policy 76

3.5.4 Welfare model applications $\quad 76$

3.6 Game-Theoretic Models 79

3.6.1 Cooperative game theoretic models 79

3.6.2 Non-cooperative game theoretic models 81

3.7 Optimization Models 83

3.7.1 The search for optimal trade and environmental policy 83

3.7.2 Lack of applications $\quad 84$

3.8 Spatial Analysis and GIS Models $\quad 85$

3.8.1 Spatial analysis $\quad 85$

3.8.2 GIS model theory $\quad 86$

3.8.3 GIS model applications $\quad 87$

3.9 Econometric Time Series Models 89

3.9.1 Trade and environment linkages over time $\quad 89$

3.9.2 Potential model applications $\quad 90$

3.10 Conclusions 91

4. MODELING TRADE AND THE ENVIRONMENT 92

4.1 Introduction 92

4.2 Model Theory and Equations 97 
4.2.1 The production function including emissions and trade $\quad 97$

4.2.2 Emissions demand and supply $\quad 99$

4.2.3 trade and foreign direct investment 101

4.3 Interactions between Trade and the Environment 104

$\begin{array}{ll}\text { 4.4 Model Application } & 112\end{array}$

4.4.1 China as an Appropriate Case Study 112

4.4.2 The present environmental status and regulations 113

4.4.3 Interface between trade and the environment $\quad 120$

$\begin{array}{ll}4.5 \text { Model Specification } & 121\end{array}$

$\begin{array}{lr}4.6 \text { Conclusions } & 132\end{array}$

5. MODEL ESTIMATION AND APPLICATION 134

$\begin{array}{ll}5.1 \text { Introduction } & 134\end{array}$

$\begin{array}{ll}5.2 \text { Data Sources } & 134\end{array}$

$\begin{array}{ll}5.3 \text { Model Identification } & 136\end{array}$

$\begin{array}{ll}5.4 \text { Model Estimation } & 144\end{array}$

5.4.1 2SLS estimation results 146

5.4.2 2SLS estimation results with fixed effects 157

5.4.3 2SLS estimation results with random effects 161

$\begin{array}{ll}\text { 5.4.4 Which estimation method works best } & 162\end{array}$

$\begin{array}{ll}5.5 \text { Model Validation } & 165\end{array}$

5.5.1 Linear Specification $\quad 165$

5.5.2 Estimation results from a reduced sub-period 166

5.5.3 Estimation results with exclusion of three municipalities 167

5.5.4 Dynamic response and characteristics 168

5.6 Empirical Relationship between Trade and Environment 168

$\begin{array}{ll}\text { 5.6.1 Introduction } & 168\end{array}$

$\begin{array}{ll}\text { 5.6.2 Environmental impacts of trade } & 170\end{array}$

$\begin{array}{ll}\text { 5.6.3 Trade impact of an emissions charge } & 172\end{array}$

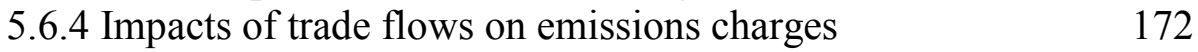

5.6.5 Impacts of an emissions charge on FDI 173

$\begin{array}{lr}5.7 \text { Model Simulation } & 175\end{array}$

$\begin{array}{ll}\text { 5.7.1 Introduction } & 175\end{array}$

$\begin{array}{ll}\text { 5.7.2 Simulation Procedure } & 177\end{array}$

$\begin{array}{ll}\text { 5.7.3 Deterministic Solution } & 181\end{array}$

5.7.4 Stochastic Error Solution $\quad 190$

5.7.5 Stochastic Error and Coefficient Solution 191

$\begin{array}{ll}5.8 \text { Conclusions } & 192\end{array}$

6. POLICY IMPLICATIONS AND CONCLUSIONS 198

$\begin{array}{ll}6.1 \text { Introduction } & 198\end{array}$

$\begin{array}{ll}\text { 6.2 Major Findings } & 198\end{array}$

$\begin{array}{ll}6.3 \text { Policy Implications } & 201\end{array}$

$\begin{array}{ll}6.4 \text { Conclusions } & 204\end{array}$

$\begin{array}{ll}\text { REFERENCES } & 207\end{array}$ 
APPENDIX A: Flowgraph Analysis and Comparative Statics Results

APPENDIX B: EViews Codes for 2SLS, 2SLS with Fixed Effects and EC2SLS

APPENDIX C: 2SLS Fixed Effects Estimation Results

APPENDIX D: EC2SLS Estimation Results

APPENDIX E: Linear Model 2SLS Results

258

APPENDIX F: 2SLS Results with Data from 1987-1993

264

APPENDIX G: 2SLS Results with Exclusion of Three Municipalities

270

Vita

276 


\section{LIST OF TABLES}

Table 2.1 Issues Concerning Economic Interactions between

Environment and Trade

Table 3.1 Methods for Analyzing Interactions between Environment And Trade

Table 4.1 Major Economic Indicators of China, 1980-1998

Table 4.2 China's Total Exports by Main Categories, 1980-1998 115

Table 4.3 China's Total Imports by Main Categories, 1980-1998 116

Table 4.4 Energy Consumption in China, 1980-1998 118

Table 4.5 Variable Definition and Coefficient Assumption 123

Table 5.1 List of Variables and Data Sources 137

Table 5.2 Summary Statistics of Variables (1987-1995) 140

Table 5.3 TEM Specification 141

Table 5.4 2SLS Estimates When Industrial Wastewater Included 147

Table 5.5 2SLS Estimates When Industrial Waste Gas Included 153

Table 5.6 2SLS Estimates When Industrial $\mathrm{SO}_{2}$ Emissions Included 155

Table 5.7 2SLS Estimates When $\mathrm{CO}_{2}$ Included 158

Table 5.8 2SLS Estimates When Industrial Particle Emissions Included 159

Table 5.9 2SLS Estimates When Industrial Dust Included 160

Table 5.10 System Determinant Results 171

Table 5.11 Impacts of Trade on Emissions 171

Table 5.12 Impacts of an Emissions Charge on Trade $\quad 171$

Table 5.13 Impacts of Trade on Emissions Charges 174

Table 5.14 Impact of an Emissions Charge on FDI 174

Table 5.15 List of Simulation Scenarios 180

Table 5.16 Means and Deviations of Baseline Solutions In Industrial Wastewater Pollution (IWW) Case 182

Table 5.17 Means and Deviations of Baseline Solutions In Industrial Waste Gas Emissions (IGE) Case 183

Table 5.18 Deterministic Baseline Solution (DBS) vs. Stochastic Baseline Solution (SBS) In Industrial Wastewater Pollution (IWW) Case 184

Table 5.19 Deterministic Baseline Solution (DBS) vs. Stochastic Baseline Solution (SBS) In Industrial Waste Gas Emissions (IGE) Case

Table 5.20 Deterministic Simulation Results when Industrial Wastewater (IWW) Included

Table 5.21 Deterministic Simulation Results when Industrial Gas Emissions (IGE) Included

Table 5.22 Stochastic Error Simulation Results when Industrial Wastewater (IWW) Included

Table 5.23 Stochastic Error Simulation Results when Industrial Gas Emissions (IGE) Included

Table 5.24 Stochastic Error Coefficient Simulation Results when Industrial Wastewater (IWW) Included

Table 5.25 Stochastic Error Coefficient Simulation Results when Industrial Gas Emissions (IGE) Included 


\section{LIST OF FIGURES}

Figure 4.1 The Environmental Kuznets Curve $\quad 102$

Figure 4.2 Interactions between Trade and the Environment 106

Figure 5.1 Map of China 


\section{Chapter 1}

\section{INTRODUCTION}

\subsection{Purpose}

There exists an increasingly large body of literature on the interactions between trade and the environment, both in determining how growth in trade and changes in trade regimes affect the environment and in determining how stricter environmental regulations and enforcement affect trade. This has greatly increased the level and scope of our understanding of the issues involved and challenges they pose to policy makers. Frequently, however, one finds that the existing literature is limited because the relations between trade and the environment are complicated and causality, let alone simultaneity, is difficult to establish. In theory, trade could either improve a country's environmental quality or aggravate a country's environmental problems. Likewise, strict environmental regulations could be either a detrimental or a beneficial factor to a country's competitiveness in international markets. The analysis of such impacts provides important insights into the complicated interrelationships between trade and the environment. But what is the nature of these relationships for a particular country and how quantitatively important are these impacts? This is simply unknown in many cases due to the absence of necessary quantitative and empirical research. There is no doubt by most professionals that there is an increasingly greater need for more country-specific empirical research. This research attempts to help fill this gap focusing on an application to the Chinese case. 
The major goal of this research is to investigate issues, methods and policy implications regarding the interactions between trade and the environment in general and to focus on the case study of China in particular. More specifically, this research is intended to:

1. review the issues concerning economic interactions between environment and trade;

2. review the methods for analyzing interactions between environment and trade;

3. identify the causal relations among the variables linking trade and the environment that are relevant for policy purposes;

4. statistically investigate the interactions between the trade and environmental variables for the Chinese case; and

5. explore policy implications that are derived from the empirical Chinese case study and provide guidance for policy makers in areas of trade regimes and environmental policy formation and enforcement.

These objectives are accomplished through analyses of the interrelationship between trade, economic growth and the environment. These analyses include the development of a simultaneous equations trade and environment model (TEM), computation of the impacts between trade and environmental variables using the results of the model, and recommendation of appropriate policy responses to mitigate the adverse impacts. The TEM model is specified, estimated and evaluated based on a Chinese provincial panel data set. 


\subsection{Background}

It has been widely accepted that economic globalization is here and that international commerce plays an increasingly important role in determining relative economic growth among countries. International trade has grown considerably in recent decades. For example, over the period 1979 to 1991, world real export growth averaged 4.4 percent per year, while real output expansion averaged only 2.9 percent per year (Markusen et al. 1995). Since 1990, the average growth of international trade has exceeded 6 per cent while world merchandise output growth has averaged only 3 per cent, confirming that globalization is continuing at a rapid pace (WTO 1996). World integration is thus being accelerated through international trade in goods, services, resources and capital. Not only can trade help to optimize the utilization of global resources but it can benefit all participating countries. This realization has caused the General Agreement on the Tariffs and Trade (GATT) to evolve into the World Trade Organization (WTO). In addition, free trade zones have been expanding. More European countries now belong to the European Union (EU); and the United States, Canada, and Mexico have created the North American Free Trade Area (NAFTA).

Growth in trade has influenced the quality of the environment principally in exporting but also in importing countries. The notion that free trade among countries leads to welfare maximization becomes questionable when environmental degradation lowers that welfare. While comparative advantage implies that a country might specialize in the production of a pollution intensive commodity, such pollution would cause the environmental quality of the country to deteriorate. In this case there is a trade-off between gains from trade and environmental deterioration in this country compared to a 
country producing non-polluting goods, since income will increase only if gains from trade overcompensate welfare losses from environmental damage. Stricter environmental policies in the first country would thus affect its comparative advantage and consequently its economic growth.

Such interactions between trade and the environment have produced an increasingly greater need for a careful and balanced assessment of the issues involved and the challenges they pose to policy makers. Investigation of the interactions between trade and the environment can be traced back to the early 1970s and was stimulated by the first United Nations Conference on the Human Environment in 1972. Some earlier studies tracing this history include Baumol (1971), Blackhurst (1977), GATT (1971), Pethig (1976), Siebert (1973), Markusen (1975), and Walter (1975, 1976). Since the 1980s, concerns about increasing world economic development, trade liberalization, and environmental stabilization have become globally important. This reflects the growing recognition of the global impact of industrial development and related problems of environmental deterioration on sustainable development. Worldwide attention to these issues can be found in works of Anderson and Blackhurst (1992), Beghin et al. (1994), Bhagwati (1993), Dean (1992, 1999), Low (1992), Muzondo et al. (1990), Siebert et al. (1980), Jaffe et al. (1995), and Antweiler et al. (1998) among others.

In addition to a comprehensive literature survey of the issues concerning the relationship between trade and the environment and a review of the various methodologies or quantitative approaches that have been applied to evaluate those issues, this research examines the interactions between trade and the environment in one particular case of China's development. This development perspective is interesting for a 
number of reasons. Since the inception of economic reform in 1978, China has achieved remarkable economic progress at a highly sustained growth rate. Promotion of trade and attraction of foreign direct investment (FDI) have been central to the country's efforts to modernize its economy. The contribution of foreign trade to China's economy has also grown at an extraordinary pace. Since 1997, China has become one of the top ten exporters in the world, and since 1993, the largest recipient of foreign direct investment after the United States. While export-led economic growth has brought many benefits to China, the environment has suffered. As the World Bank (1997a) reports, "Moreover, the large scale and rapid growth of China's economy have exposed a growing population to serious air and water pollution".

Unfortunately, though some interesting attempts have been made to analyze this problem (Dean 1999, and $\mathrm{Wu} 2000$ ), the environmental implications of the surge in foreign trade and investment are complex, very largely contested, and not fully illuminated by existing empirical data and analysis. At the same time, China's environmental protection agencies, aware of its pollution problems, have responded by enforcing regulatory standards for wastewater and air pollutant discharges. It is worth noting that an extensive water and air pollution levy system has been in place in China since 1983 (Wang and Wheeler 1996). How the enforcement of environmental policy in China affects its trade and foreign direct investment is also an interesting topic of research and, to the best of my knowledge, has received no prior empirical investigation. 


\subsection{Methodology}

In order to achieve the stated objectives, this research uses econometric, simulation and comparative static methods to estimate, analyze and evaluate the Dean model investigating the interrelationship between trade, environmental and other economic variables. Specifically, the following procedures are applied:

1. A simultaneous equations system is extended to model the interactions between trade and the environment. This system consists of six equations, that is, a production function including emissions and trade; equations explaining emissions demand and supply; an equation for the share of pollution intensive goods in total output; an equation for international trade; and an equation for foreign direct investment (FDI) inflows.

2. Based on the trade and environment model (TEM), flowgraph analysis and comparative statics are employed to identify the causal effects among the variables relating trade and the environment that are relevant for policy purposes.

3. The structural model is adapted and specified according to Chinese provincial-level economic interactions and a descriptive panel data set.

4. The specified TEM system is estimated using two stage least squares (2SLS). Since a provincial panel data set is used, three estimation approaches are applied and compared in order to exploit the advantage of panel data. First, the system is estimated simply by pooling the data with no fixed or random effect specifications. Second, provincial and time period fixed effects are included in the estimation. And third, the system is estimated with a two-way error components 2SLS (EC2SLS) method. 
5. Finally, the impacts of trade and FDI variables on environmental variables and vice versa are evaluated with computer simulation and comparative static methods. The stability and consistence of the TEM model is also examined by performing deterministic and stochastic simulation.

\subsection{Contribution}

Given the above-stated objectives, methodological approaches employed and the nature of problems investigated, this research is expected to contribute to the trade and environment literature in the follow aspects.

From a subject-matter perspective, this research contributes with an extensive review of issues concerning and methods used to analyze the interactions between trade and the environment. Because of the diversity and complexity of these issues and methods, they traditionally have been only in separate areas of concentration. Consequently few major surveys have covered all of them in a comprehensive manner. Though there exist several valuable surveys (Dean 1992, de Boer 1994, Ulph 1994, van Beers and van den Bergh 1996 and Xing and Kolstad 1996), they tend to emphasize particular aspects of the total area and do not reflect recent advances in the literature. This research provides a more comprehensive survey of this area and helps to fill this literature gap.

This study also contributes to the literature by focusing on the interactions between trade and the environment within a single developing country. Most empirical studies have tended to analyze cross-country or panel data typically for a sample of both developing and developed countries. Relatively few quantitative analyses have been 
published on the trade and environmental interrelationship of a dynamic developing country such as China. This research enriches the trade and environment literature by providing a specific case study which analyzes how trade growth in China has affected different pollutant emissions and how China's pollution levy system has affected its trade values and FDI inflows.

In addition, this research contributes to the existing environmental Kuznets-curve literature in two aspects. First, it shows for the first time that an inverted-U relationship may also exist between pollution and economic scales both in absolute terms. The existing environmental Kuznets-curve literature usually measures pollution and economic scales in relative terms such as pollution intensity and GDP per capita. Second, it explicitly associates the existence of an inverted-U relationship with the effectiveness of environmental policies. In conventional environmental Kuznets-curve literature, since the effectiveness of environmental policies is usually approximated by relative economic scale variables themselves such as income or GDP per capita, the importance of environmental policies in this inverted-U relationship can not be separately identified.

Methodologically, one of the contributions of this study is the use of an expanded simultaneous equations trade and environment model. Most previous studies are based on single equation models and hence only a one-directional relationship between trade and the environment is examined, i.e., either how trade would affect environmental quality or how environmental policies would influence international trade flows. In reality, trade and the environment are interrelated and interact with each other. Moving a step forward, this study models the interrelationship employing a simultaneous system that enables one 
to investigate both the environmental impact of trade and the trade impact of an environmental policy.

Another methodological contribution is a non-linear specification of the relationship between pollution and economic scales. The existing environmental Kuznets curve literature suggests that there may exist an inverted-U relationship between pollution and economic scales. To test this hypothesis, a squared output term is incorporated into the emissions demand equation and the trade and environment system is thus made non-linear.

Finally, this research methodologically contributes to the literature through the incorporation of panel data. Due to the lack of long environmental and economic time series for China as a whole, a provincial-level panel data approach is not only necessary but also important for effective econometric estimation. Moreover, due to computational complexity, a non-linear simultaneous equations model plus a panel data set is relatively new and has found few applications to economic and social problems; this is particularly true for modeling the interactions between trade and the environment.

\subsection{Outline for the Study}

The remainder of this study consists of five chapters.

Chapter 2 provides a review of the literature divided into the major topic or policy issues surrounding interactions between trade and the environment. These topics and issues have been organized to include: (1) the nature of macroeconomic impacts, (2) patterns of trade and comparative advantage, (3) terms of trade, (4) patterns of production and consumption, (5) linkages between trade, environment and the economy, (6) 
pollution redeployment to developing countries, (7) environmental degradation, and (8) factor rewards.

Chapter 3 contains a review of the various methodologies or quantitative approaches that have been applied to analyze the issues concerning trade and environment interactions. These include: (1) computable general equilibrium models, (2) international trade models, (3) input-output models, (4) welfare analysis models, (5) game theoretic models, (6) optimization models, (7) spatial GIS models, and (8) econometric models.

Chapter 4 describes the trade and environment model expanded for the case study of China. Specifically, this chapter is divided into four sections: (1) model theory and equations; (2) interactions between trade and the environment; (3) model application; and (4) model specification.

Chapter 5 deals with model estimation and application. This chapter includes six sections: (1) data sources; (2) model identification; (3) model estimation; (4) model validation; (5) empirical relationship between trade and the environment; and (6) model simulation.

Chapter 6 concludes the study focusing on major findings, policy implications and concluding remarks.

The appendices feature the detailed analytical and empirical results of analyses involved in this research. Specifically, Appendix A provides the derivation of the causal relationships between trade and the environment from flowgraph analysis and comparative statics; Appendix B consists of the EViews codes written for the estimation of the TEM; and various estimation results are reported in Appendix C to G. 


\section{Chapter 2}

\section{ISSUES CONCERNING ECONOMIC INTERACTIONS BETWEEN ENVIRONMENT AND TRADE}

\subsection{Introduction}

Economic interactions between environmental and trade polices concern the effects that these policies have on resource allocation, income distribution, and environmental consequences, both among and within trading countries. Economic analysis of these interactions treats environmental and trade policies as having both positive and negative consequences depending on the economic mechanisms involved. Our survey of these many different topics or areas that studies have analyzed suggests that the following questions are most frequently addressed: (1) What are the macroeconomic impacts of environmental trade policies? (2) How do these policies determine the patterns of trade and comparative advantage? (3) How do environmental policies affect terms of trade? (4) What are the implications of these policies for patterns of production and consumption? (5) What is the relationship between trade, environment, and the economy? (6) Are environmental policies a determinant of industrial redeployment? (7) Does trade result in environmental degradation? And (8) How environmental trade policies affect returns to factors? The issues germane to these questions are further outlined in tables 2.1. This chapter evaluates previous research aiming to answer these questions, focusing on the economic theories that provide insights and possibilities for making policy recommendations. 
Table 2.1 Issues Concerning Economic Interactions between Environment and Trade

1 Macroeconomic Impacts Impacts on National Income Impacts on Employment Impacts on Other Economic Variables Impacts on Balance of Trade and Payments Impacts on Sustainable Development

2 Patterns of Trade and Comparative Advantage

Patterns of World Trade in Environmentally Sensitive Goods

Comparative Advantage

3 Terms of Trade

Impacts of Emission Standards in One Country

Impacts of Pollution Taxes in One Country

Transnational Pollution case

4 Patterns of Production and Consumption

Structural Change of Production Sectors

Impacts on Production-Supply Side

Impacts on Consumption-Demand Side

5 Linkages between Trade, Environment, and the Economy

Conflicts between Trade Policy and Environmental Policy

Transnational Pollution and Trade

Natural Resources and Trade

Hazardous Substances and Trade

Global Warming and Trade

6 Pollution Redeployment to Developing Countries

National Environmental Policy and Capital Mobility

Environmentally-Induced Industrial Relocation

7 Environmental Degradation

Trade and the Global Environment

Trade Induced Environmental Degradation

8 Factor Rewards

Capital and Labor Rewards

Resource Rewards 


\subsection{Macroeconomic Impacts}

\subsubsection{Impacts on national income}

The impacts of domestic environmental control policies on national income were first assessed by D'Arge (1971). For example, if environmental policies in the form of effluent charges are imposed on individual firms, the impact on comparative advantage will usually arise from two sources. First, substitution of relatively cheaper imports for domestic commodities will decrease the level of domestic production and, thus, domestic income. Second, these initial shifts in domestic demand and income through multiplier effects will result in further adjustments in domestic income and imports. Using the trade model, D'Arge estimated such domestic income effects resulting from changes in export prices due to the imposition of domestic environmental policies. He found that the impact on domestic income stemming from international feedback effects was negative and came primarily through impact multipliers.

Using general equilibrium models that include trade between countries, Siebert et al. (1980) also analyze the effects of domestic environmental policies on national income. They consider two cases: one is that the home country is small, which implies a given relative price for the home country; and the other is the two-country case, in which the home country is assumed to be no longer a small country but it affects the relative prices in the world market. Assuming non-inferior commodities and using a two-sector economy model, they conclude that environmental policy will reduce resources used in an emission-intensively producing sector and in production activities in both sectors. Resource use in abatement will increase. This holds for both the small- and the twocountry case. For a given relative commodity price, national income will decline. If the 
relative price is variable, national income will decline when either the emission intensity of a sector is relatively high or when it has a high price elasticity of demand.

Many other studies also reveal the negative effects of environmental policies on national income, e.g. Manne and Richels (1991a), (1991b), and (1992); Manne (1992); Dervis et al. (1982); Rose et al. (1994); Yao et al. (1994); and Zhang (1998). The economic theory implied in those studies is that pollution abatement policies reduce production and thus decrease national income. However, when we talk about the negative impacts of environmental policy on national income, we should also keep in mind that this does not mean a definite decrease in welfare. Due to the implementation of environmental policies, the supply of environmental goods increases; however, to a large extent, such impacts are not considered in national income account evaluations. In addition the production of pollution abatement equipment can offset losses in industrial production due to more stringent environmental standards.

\subsubsection{Impacts on Employment}

There has been substantial debate and confusion about whether environmental policies do or do not influence domestic employment (Hopkins 1992). So far it is difficult to come to any precise conclusions, though at least in the short run, negative effects caused by a cutback in production will lead to a considerable decline in employment (Zhang 1998). However, in the long run, environmental policies will result in investment in pollution control equipment and thus create more employment opportunities. According to the OECD (1985), with few exceptions employment levels rise with pollution-control expenditure, particularly under some variants in the United States, 
France, and Norway. Jobs are created by the production, installation, and maintenance of pollution control plants and equipment. However, this additional labor input does not generate additional measured output and capital stock is diluted with the portion of capital required to control pollution. The implication of this result is an implicit worsening of productivity growth. This occurs because national income growth rates are either somewhat lower, or only slightly higher, than they otherwise would have been, while labor inputs increase because of environmental measures.

\subsubsection{Impacts on Other Economic Variables}

Denison (1979) and Crandall (1981) show that environmental regulations adopted in the 1970s had a negative effect on U.S. productivity growth. Investigations on five OECD countries reveal that productivity levels are usually lower than they would have been without environmental programs (OECD 1982). However, the validity of these results is weakened by the underlying assumption that environmental policies increase production costs since capital and labor invested to comply with environmental policies do not contribute to measurable output, nor do the efforts required for paperwork and legal formalities of compliance. Many empirical studies show that, in general, the impact of environmental polices on industrial production costs is very small because pollution abatement costs constitute a very small portion of industrial costs on average, e.g. see Tobey (1990), OECD (1985), Smith and Ulph (1982), and Jaffe et al.(1995). Moreover, in some industries the implementation of environmental policies is accompanied by positive productivity effects. For instance, pollution reduction with energy saving and material recovery may lower the unit cost of production and increase product sales 
because in some cases recovered materials can be profitable by-products. Recent wisdom is that environmental policies induce "more cost-effective processes that both reduce emissions and the overall cost of doing business......"(U.S. Environmental Protection Agency 1992). Porter and Linde (1995) further point out that, from a dynamic view, environmental regulations provide incentives for technical innovation and hence in some industries productivity will rise in response to "properly crafted environmental regulations".

The impact of environmental protection costs on product prices also has received attention, e.g., Pasurka (1984), Mutti and Richardson (1977), Walter (1973), and Robinson (1988). Most studies of this kind utilize an input-output framework and assume that all costs pass through into prices. The price changes caused by environmental policies can be derived simply by multiplying the abatement cost vector by the standard total requirements matrix. Robinson (1988) argues that the assumption of full-cost passthrough into prices is reasonable in the long run. He also points out that greater than fullcost pass-through is possible in oligopolistic industries, while in highly competitive industries, price increases smaller than cost increases might occur. Moreover, the use of the full-cost pass-through assumption helps ensure that the estimates of the price changes are, in fact, upper bounds.

\subsubsection{Impacts on Balance of Trade and Payments}

Among the contributions to the impact of environmental policies on the balance of trade and payments, works by Baumol and Oates (1975) and Robinson (1988) are important. Based on a two-final-good model, Baumol and Oates (1975) analyze the trade 
impacts of industrial pollution abatement costs and derive the balance of trade conditions for a two-good, two-country world. In doing so, one good has pollution associated with its production, while the other does not. According to this model, only direct abatement costs have an impact on prices and thus on the balance of trade and payments. Robinson (1988) extends Baumol and Oates's (1975) two-good model to a seventy-eight sector model with all interindustry effects considered. Using this extended model, Robinson applies an ex-post partial-equilibrium method to measure the impact of marginal changes in industrial pollution abatement costs on the U. S. balance of trade in general, and on the balance of trade with Canada in particular. Robinson's work shows that environmental policy has a significant negative effect on the balance of trade if environmental costs are fully reflected in commodity prices.

\subsubsection{Impacts on Sustainable Development}

As is well known, free trade policy is designed to allow markets to allocate resources according to their most efficient uses, while environmental policy seeks to manage and maintain the earth's resources efficiently. Though conflicts may arise where the same resources are subject to both trade and environmental purposes, "on the most fundamental level, trade and environmental policy must meet in the concept of sustainable development. Both trade policy and environmental policy must serve that concept as their ultimate goal.” (EPA Trade and Environment Committee 1991).

Hudson (1993) provides a useful starting point from which to examine the issues related to trade, environmental policy, and sustainable development. He begins with a philosophical approach to trade and environment. He argues that an environmental 
perspective on trade should not be construed as anti-trade, since trade can be an important instrument with which to achieve development that is economically and environmentally sustainable. He points out that in the long run environmental policy will not be successful if it ignores the development needs of the world's poor; and on the other hand, the benefits of a more liberalizing trading system cannot be sustained over the long-term if environmental and natural resources considerations are not taken into account.

The impacts of trade liberalization and globalization on sustainable development have been examined by recent empirical case studies, i.e., Dragun and Tisdell (1999) and Jha, Markandya, and Vossenaar (1999). Though trade liberalization and world economic globalization portend an international "win-win" situation, those studies find that there is substantial evidence to suggest that trade liberalization and globalization appear to have a negative impact on agricultural sustainability in developing countries. The reconciliation of trade and the environment is the key to achieve sustainable development,. Moreover, special attention needs to be paid to local issues in poor countries in the face of trade liberalization and globalization.

\subsection{Patterns of Trade and Comparative Advantage}

\subsubsection{Patterns of World Trade in Environmentally Sensitive Goods}

Economic analysis would suggest that environmental policies raise production costs and hence encourage reduced specialization in the production of polluting outputs in countries with more stringent environmental regulations, e.g. Pethig (1976), Siebert (1977), McGuire (1982). That is, countries with less stringent environmental policies could increase their comparative advantage in the production of environmentally 
sensitive goods. However, this standard trade theory is challenged by a more recent revisionist view. Porter and van der Linde (1995) argue that tight environmental policies are actually positive forces driving private firms and the economy as a whole to become more competitive in world markets by spurring innovation in environmental technologies. These conflicting views have since then led to a heated debate (see Stewart 1993 for an overview).

Tobey $(1990,1993)$ approaches this problem empirically by examining environmental policy and patterns of world trade. Following earlier studies on shifting patterns of international trade by Leamer (1984) and Bowen (1983), Tobey employs a cross-section Heckscher-Ohlin-Vanek (HOV) model to test the hypothesis that the stringency of environmental policies is directly related to the exports of pollutionintensive commodities. Pollution-intensive commodities are defined by Tobey as the products of those industries whose abatement costs in the United States are equal to or greater than 1.85 percent of total costs. According to this criterion, among the 64 agricultural and manufacturing commodities under investigation, 24 are labeled as pollution-intensive commodities. Using econometric methods, Tobey aggregates the 24 commodities into five groups and regresses the net exports from each group on US endowments of 11 resources and a dummy variable which indicates the stringency of a country's environmental policies. The statistical results indicate that there is no significant linear relationship between the stringency of environmental policy and the net exports of the pollution-intensive commodities. That is, environmental policy has no significant impact on patterns of world trade. Tobey also tests the impact of environmental policy on trade patterns by investigating the bias in the regression 
residuals when the variables representing countries' environmental endowments are not included in the HOV model. If environmental policy does have an impact on net exports, then countries with stringent policy should have a negative expected sign in the error term, while the residuals of the countries with lenient policy should be positive. By examining the residuals, however, Tobey finds no assumed distribution of the error terms and thus concludes that the impact of environmental policy on world trade patterns is not significant.

\subsubsection{Comparative Advantage}

According to classical trade theory, a country's comparative advantage stems from differences in technologies and in factor endowments (as compared with the respective conditions of its trading partner). That is, a country may have a comparative advantage if a country has technology by which it can produce a product with relatively low cost, or it is rich in certain resources. Since the 1970 s, numerous theoretical studies have tried to examine the impact of environmental policy on comparative advantage, e.g. see Siebert (1977), Siebert et al. (1980), Pethig (1976), McGuire (1982), Baumol and Oates (1988), Krutilla (1991), Carraro and Siniscalo (1992), Brander and Taylor (1997), and Markusen (1997).

Siebert and his co-authors (1980) have employed a two-commodity-two-country model to investigate possible different technologies as determinants of comparative advantage. Their major result confirms the intuitively expected result that a country's technological comparative advantage to produce less pollution-intensive goods is strengthened by environmental policy. In addition, if one country has a technological 
comparative advantage for pollution intensive goods before trade, it can negate this advantage by adopting a sufficiently stringent environmental policy. That is, if a country exports and specializes in a pollution intensive good and if it has appropriate technologies, it generally can switch its trade flows by enforcing a sufficiently stringent environmental policy. This group also investigates comparative advantage stemming from differences in relative factor abundance, which include divergences in the quality of resource endowments and in demand conditions. The most interesting feature of their analysis was the treatment of a country's emission standards as a factor endowment. With this interpretation, they apply the traditional Heckscher-Ohlin-Samuelson theory of pure trade to the case of two countries, both of which implement an environmental price and standards system. They then point out that, given certain qualifications, even the FactorPrice-Equalization theorem applies to the emissions taxes. That is, the two countries' relative emission taxes also equalize in a trading equilibrium, even though both countries pursue stringent environmental policies in different ways.

Baumol and Oates (1988) also confirm conventional views on this issue. In their model, both countries produce an identical traded good and its production generates pollution in both countries. Using partial equilibrium analysis, Baumol and Oates demonstrate that if a country does not impose environmental policy when the other country does, then the first country will increase its comparative advantage or decrease its comparative disadvantage in the pollution-intensive industry. This change in comparative advantage will lead the first country to specialize in that industry at the cost of environmental degradation. 
Brander and Taylor (1997) more recently examined the question of whether countries with 'low standard' (LS) resource management policies might have a comparative advantage over countries with 'high standard' (HS) resource management policies. They construct a trade model between an LS country (countries possessing weak resource management) and an HS country (countries possessing rational resource management). Both countries are endowed with an identical renewable natural resource and both countries are identical except for their resource management policies. Using general equilibrium analysis, Brander and Taylor (1997) demonstrate that with no trade (autarky) there are two steady-state harvesting rates for the LS country: mild overuse and severe overuse. With the introduction of trade between the two countries, in the mild overuse case the LS country has a comparative advantage and thus is a net exporter of the resource good in steady state. This result confirms the received view on the relationship between environmental policy and comparative advantage. However, in the case of 'severe overuse' in autarky, the LS country becomes a steady state importer of the resource good after trade opens. The result in this case contradicts the received view.

As mentioned before, Porter and van der Linder (1995) challenge the received view relating environmental policy and comparative advantage by arguing that comparative advantage does not depend on static efficiency or on optimizing within fixed constraints; rather it is a function of the capacity of a firm to initiate innovation and improvements in order to shift those constraints. Moreover, tight environmental policy can, at times, act as an incentive to domestic firms with a strong home base to create a first mover-type of comparative advantage. Since such contradicting views result from applying theory alone, empirical studies can play a role in settling such disputes by 
measuring both the magnitude and sign of the impact of environmental policy on comparative advantage. However, so far the empirical results have been ambiguous, i.e. Ugelow (1982), Tobey (1990), and Jaffe et al. (1995).

\subsection{Terms of Trade}

\subsubsection{Impacts of Emission Standards in One Country}

According to trade theory, a change in terms of trade may increase or lower the social cost of attaining a given target of environmental quality from what it would have been if the terms of trade had remained constant. Therefore, it is worthwhile to examine whether a country will be able to share its costs of the imposition of environmental policies with the rest of the world via a terms-of-trade improvement. Siebert and his coauthors (1980) investigate the analytical links between alternative levels of the emissions standards in a country and any possible resulting changes in terms of trade.

Siebert and his co-authors use the well-known two-country model of trade as their framework of analysis. They assume that the home country undertakes an emissions standard policy while the rest of the world employs no environmental policies and that environmental policy affects comparative costs in the case of a binding emissions standard. Using comparative statics, they show that under their assumptions free trade with direct pollution control in the form of an emissions standard enables the acting country to improve its terms of trade if the production of the exportable good is relatively emissions intensive. They argue that the initiation of a pollution control policy of the home country decreases the relative abundance of the good affected by the policy and, in order to equalize world demand and output, the relative price of the good has to increase. 
The home country's terms of trade improve because its total output is smaller, while that of the foreign country remains unchanged. They interpret this result as signifying that trade enables a country which undertakes an environmental policy to transfer a share of its real costs of pollution control generated entirely within its own borders to the rest of the world. In the opposite case where the import is relatively emissions intensive, they obtain a deterioration effect of the terms of trade, which implies an additional component of social cost to achieve the policy goal. In reality, however, just as the authors themselves point out, the trading partner would likely also undertake a control policy so that the outcome on terms of trade must be different. A formal analysis of this case would be much more complicated.

\subsubsection{Impacts of Pollution Taxes in One Country}

Magee and Ford (1972) provide a fruitful analysis of the implications of alternative pollution abatement taxes for the terms of trade in the United States. The authors divide the U.S. economy into an import sector and an export sector and then set up a simple four-equation model of the demand for imports into the United States and the supply of imports from abroad. Throughout, the authors use partial equilibrium analysis, i. e., import and export price changes are assumed to be independent.

According to Bhagwati (1971), a production tax is the most efficient solution to controlling production pollution, while a consumption tax is the optimal response to consumption pollution. Using this principle, Magee and Ford (1972) first examine the consequences of government taxation to combat either production or consumption pollution in the import sector. They demonstrate that if pollution occurs at the production 
level, a production tax on U.S. import-competing production will unambiguously result in an increase in the quantity, the price and in the value of U.S. imports. This leads to deterioration in the U.S. terms of trade. In the case of pollution derived from goods consumed in the import sector, if U.S. imports are complementary to domestic nonimport-competing production, then the consumption tax increases the price, the quantity and hence the value of the import. Again, the U.S. terms of trade deteriorates. If, on the other hand, U.S. imports are substitutes with domestic non-import-competing production, then the consumption tax reduces the quantity, the price and the value of U.S. imports; this means that the consumption tax improves the U.S. terms of trade.

Magee and Ford then turn to a similar analysis of the case where pollution occurs in the export sector. Their results show that if a production tax is imposed on the export sector, export prices and the price of domestic goods will increase and hence the tax improves the U.S. terms of trade. If a tax is levied on domestic consumption of the exportable product in the United Stated, the authors illustrate that the U.S. terms of trade will deteriorate (improve), if exporter marginal costs are increasing (decreasing). The results are less clear in this case since it is difficult to empirically decide whether costs are increasing or decreasing for the U.S. exporters.

There appear to be no studies explaining how pollution taxes influence the terms of trade of the developing countries.

\subsubsection{Transnational Pollution Case}

Due to the spatial characteristics of environmental issues, transnational pollution issues (e.g., acid rain and the pollution of the Great Lakes or industrial pollution and the 
Rhine river) have inevitably become a serious problem for governments throughout the world. The solution to this problem usually requires that the countries involved adopt some abatement strategies appropriate to control transborder pollution.

To examine the impact of these strategies on terms of trade, Merrifield (1988) constructs a two-country general equilibrium (GE) trade model with pollution and introduces two abatement strategies, production taxes and the abatement equipment standard. Merrifield's model represents an advance over previous work (e.g. McGuire 1982), in that pollutants, goods, and capital are assumed to be internationally mobile, and prices of factors, goods and terms of trade are determined endogenously. The key to this analysis is the impact of abatement strategies on prices and, hence, on the movement of goods and productive resources between the trading countries. By means of comparative static analysis, Merrifield finds that, in general with internationally mobile goods, capital, and pollutants, the comparative static results are ambiguous except that the abatement equipment standard strategy has an unambiguous impact on pollution flows. He thus employs the model to analyze the impact of abatement strategies in the context of the acid rain deposition problem between the U.S. and Canada.

Merrifield illustrates that if the two countries jointly and simultaneously levy a production tax, production in both countries will not be altered and, consequently, the terms of trade will not change. Similarly, if both countries agree to raise their abatement equipment standards, there will be no change in the terms of trade if the elasticity of substitution of capital for labor is similar in the two countries. He also demonstrates that if Canada adopts a stricter abatement standard, the terms of trade will be shifted in Canada's favor. However, since much attention is paid to the analysis of the effect of 
abatement strategies on transnational pollution, many related questions, such as how a country's production tax influences the terms of trade or whether a country with a stricter abatement standard can improve its terms of trade, are not fully explored.

\subsection{Patterns of Production and Consumption}

\subsubsection{Adjustments in Production Sectors}

Environmental protection policies may lead to sectoral structure distortion in the conservationist country. This distortion is reflected by changes in product prices and in sectoral production. In general, with the imposition of environmental protection costs in one sector, the product price of that sector will increase and the rise in product price tends to be spread over the whole economy. Similarly, a reduction in emissions of certain pollutants may cause a change in sectoral production.

Utilizing a partial equilibrium input-output framework, Pasurka (1984) analyzed the magnitude of the impact of environmental protection costs on U.S. product prices in 1977. The advantage of the input-output framework is that the effects of the abatement costs that are passed along in the form of higher prices of intermediate goods can be observed. In his analysis, Pasurka divides the US economy into 79 production sectors. Pasurka's study reveals that the total percentage increase in product prices ranges from 0.12 percent for real estate and rental to 6.58 percent for electric, gas, water and sanitary services. The average weighted price increase is found to be 0.97 percent. This result shows that for most U.S. industry sectors, environmental protection costs do not result in significant price increases. However, the accuracy of the result is discounted by several of the assumptions made in order to conduct the input-output analysis. In particular, the 
assumption of fixed input-output coefficients, when there are changes in relative prices due to environmental protection costs, leads to imprecise results.

By means of a CGE model, Zhang (1998) empirically investigates the impact of $\mathrm{CO}_{2}$ emission limits on China's sectoral production. According to Zhang, aggregate gross production tends to contract at an increasing rate as carbon dioxide emission targets become more stringent. However, changes in sectoral gross production differ significantly among sectors in both absolute and relative terms. For example, under alternative scenarios that China's $\mathrm{CO}_{2}$ emissions in 2010 will be cut by 20 and 30 percent, the coal sector is affected most severely; its gross production falls by as much as 26 and 38 percent, respectively. The gross production of the agricultural sector is the least affected; it falls by only 0.49 and 0.28 percent respectively. In contrast to these negatively affected sectors, gross production increases are observed for the service sector. Moreover, its expansions rise at an increasing rate as $\mathrm{CO}_{2}$ emissions reduction become greater (1.71 and 5.53 percent in the two scenarios respectively). The results indicate that, given reductions in $\mathrm{CO}_{2}$ emission, an economy will restructure toward labor-intensive sectors.

\subsubsection{Impacts on Production}

The literature on environmental supply impacts has been inconclusive. According to Leontief's (1970) input-output study, in a closed economy assuming that the elimination of pollution can be achieved by use of intermediate products from sectors other than anti-pollution and that final deliveries to households remain constant, the output of all the productive sectors clearly will increase. Moreover, the more complete 
the elimination, the greater the magnitude of the increase. Siebert, Eichberger, Gronych and Pethig (1980) have studied the impacts of an emission standard on the supply side of a closed economy using a two-sector-two factor model. When a given commodity price ratio is assumed, the authors conclude that the restriction of the emissions standard reduces the output of the relatively emissions intensive sector and increases the output of the other sector. The authors further examine changes in relative commodity supply and show that the restriction of an emissions standard brings about a rise in the output of the capital intensive (labor intensive) sector, if it is much more difficult to substitute capital (labor) in both sectors with emissions relative to the other factor. The impact of the restriction on the total production of the economy is not discussed.

The OECD (1985) investigated the effects of various environmental programs on the levels of GDP in selected OECD countries. Its findings show that a period of initial GDP growth (0.1 and 0.2 percent in the Netherlands and the United States, respectively) is followed by a decline during the final program year and beyond (up to -0.7 and -1.1 percent). The GDP trend indicates that production is affected by environmental programs via two forces. The first force is generated by additional demands for goods and services. The installation of pollution controls increases capital investment and the services required to operate it. The second force is created by the multiplier and accelerator effects of these additions to demand. Both forces interact to promote production expansion in the early years of the programs. Over time, however, the expansion places pressure on the utilization of productive capacity and hence on costs and prices. Rising costs and prices begin to offset the favorable impact on production. And, when the programs are over, 
only negative price effects remain, and production levels fall below those without environmental programs.

\subsubsection{Impacts on Consumption}

There are also few studies that analyze how environmental policy influences consumption. Using macro econometric models, the OECD (1985) examined the impact of environmental protection programs on the aggregate demand components of some of its member countries. They found that four out of five case studies showed that in the final year of a pollution control program, total private consumption decreased only slightly, from 0.1 per cent in France to about 1.0 percent in the Netherlands and the United States, compared to consumption without the program. This decrease is caused by factors such as the impact of additional costs on consumer prices, and the rapid reduction of favorable multiplier effects on disposable income induced by taxation in some programs. Only in Norway does private consumption rise (by 0.3 per cent after the first few years and 0.7 per cent in the final year) as a result of environmental programs. Usually, the impact of abatement costs on prices has an unfavorable effect on real consumer spending. In the Norwegian case, however, this is more than offset by a higher overall level of activity leading to favorable multiplier effects on employment and household income. In addition all studies they reviewed report a slight decline in exports of goods and services (by 1 percentage point or less in the final year of a program) due to the adoption of environmental programs. Finally, the effects on private non-residential investment differ widely from study to study. While a negative effect is observed in the Netherlands, in the Finnish, French, and the U.S. studies, environmental programs lead to 
an increase in private non-residential investment. However, what causes this difference among these studies is not explored.

\subsection{Linkages between Trade, Environment and the Economy}

\subsubsection{Conflicts between Trade Policy and Environmental Policy}

The basic objective of trade policy is to liberalize international trade and to attain the benefits of comparative advantage. Taking this advantage leads a country to specialize in the production of goods and services that it can produce more efficiently. Accompanying the process of specialization, however, environmental problems may arise due to the externalities of specialization. In order to solve those problems, governments often have to provide certain kinds of environmental regulations or incentives that can either clash with trade policies or can alter them significantly. The conflicting relationship between trade and environmental policies has received both an economic and a political focus since the 1990s, e.g. see Housman and Zealke (1992), Jackson (1992), and Saunders (1994).

Audley (1997) points out that the conflicts between trade and environmental policy often involve the competitive differences between national and international environmental policies. Business leaders from multinational firms worry that competition with manufacturers operating in countries where they are not required to internalize similar environmental costs may enjoy price advantages created by such policy. On the other hand, developing countries argue that trade policies that require imports to meet domestic environmental standards effectively restrict access to larger markets, e.g. Snape (1995), Pearson (1993), and McAlpine and Le Donne (1993). The rise in non-tariff 
barriers reported by the WTO sparked concern that environmental policy would become a new form of non-tariff protection (Runge 1990, 1993). Under the guise of environmental policies, foreign products might be prohibited from access to markets where domestic products are more expensive (Snape 1995, and Stokes 1992). Policy standards such as auto emissions, agricultural regulations controlling pesticide residues, and product component quality, have been criticized by trading countries that believe these policies are designed to restrict market access for foreign products under the guise of insuring food safety or promoting cleaner air. The focus adopted by environmentalists, however, varies from that described above. In effect, in the name of trade liberalization, competitive pressures present adverse impacts on efforts to set higher environmental standards. Therefore, environmentalists have to pressure their governments to set standards and to impose those standards on their trading partners as part of their effort to set international standards for environmental protection. Due to the absence of an effective international enforcement mechanism, some countries have to resort to unilateral actions. Under most circumstances, unilateral actions are a violation of existing WTO jurisprudence (Bhagwati and Patrick 1990, and Durbin 1995).

Housman and Zaelke (1992) discuss some options for reducing or eliminating the conflict between trade agreements and environmental policy. The main points of those options are to incorporate environmental considerations into trade agreements. For example, the former GATT did not view a party's application of lower domestic environmental standards that allow the party's industries to externalize their environmental costs as a subsidy (or dumping when the product is exported) that could be countervailed by another party whose industries are harmed by the subsidy (or dumping). 
Some options suggest modifying or interpreting GATT Articles VI and XVI and the Subsidies Code to permit the imposition of countervailing duties or antidumping duties to counter such practices. However, Housman and Zaelke argue that quantifying the effect of differing environmental standards could pose additional administrative problems beyond those already associated with countervailing and antidumping statutes. Unfortunately, not much progress has resulted from research in this area.

\subsubsection{Transnational Pollution and Trade}

The recent interest in transnational pollution and trade is concentrated on two issues. First, does free trade increase transnational pollution? Second, is "green" trade policy an efficient way to regulate transnational pollution?

Copeland and Taylor (1995b) examine the first issue using an approach different from earlier studies such as Merrifield (1988) and Rauscher (1991b). They develop a multi-good, many-country trade model in a general equilibrium setting. Assuming that global environmental quality is a pure public good whose supply responds endogenously to trade-induced changes in relative prices and incomes and by dividing the countries into North and South groups, the authors use the model to explore how welfare and pollution levels are affected by free trade in goods and pollution permits, by international income transfers, and by international agreements limiting or reducing pollution emissions, respectively. They also demonstrate that, in a factor price equalized trade equilibrium, trade raises the level of pollution generated by each Southern country, lowers the pollution level generated by each Northern country, and leaves world pollution unaffected. They also show that if trade does not equalize factor prices, then free trade 
increases global pollution in a equilibrium under specialization and the supply response to the factor-price movements created by trade leads to reduced pollution in the North and increased pollution in the South. The authors further investigate the effect of income on trade and world pollution and find that the pre-trade world income distribution determines how trade will affect the environment. If the world distribution of income is highly skewed, then free trade increases world pollution; but if countries have relatively similar incomes, then free trade has no adverse effect on pollution.

There is also an extensive literature on the second issue concerning the efficiency of green trade policy. Baumol (1971), Markusen (1975b), and Rauscher (1991b) have shown that it may be in one country's interest to use trade policy in order to reduce transnational pollution from abroad. Recently, Maestad (1998) goes further by arguing that the use of green trade policy may be desirable from a global point of view as well because such measures may promote global economic efficiency. He assumes: firstly, that the trade provisions are implemented jointly with full Pigouvian taxes on domestic sources of environmental degradation; and secondly, that the trade provisions do not have any direct effect on the environmental policy pursued by a foreign government. Based on the analysis of a two-country partial equilibrium model, the author concludes that when some countries are reluctant to internalize environmental costs, efficiency in the global economy may be enhanced by regulating the trade with these countries; note that Baumol and Oates (1988) also obtain the same result. Efficient green trade policy may take the form of trade restrictions or trade promotions, depending on the type of environmental problem and on whether the domestic net import of the relevant commodity is positive or negative. The policy implication of this study is that international trade agreements such 
as those formed under the WTO should be revised in order to accommodate the demand for discriminating green trade measures to some extent. This study also shows that the usefulness of green trade policy is not restricted to the transnational pollution case; trade provisions may promote global economic efficiency when some countries take unilateral steps towards solving local environmental problems as well.

\subsubsection{Natural Resources and Trade}

There are many studies that evaluate the relations between natural resources and trade, e.g. see Withagen (1985), Puttock and Sabourin (1992), and Park and Labys (1999). In fact, the theoretical linkages between natural resources and international trade are many and varied. Research attempting to integrate natural resources and international trade usually captures one or both of the two essential features of the asset nature of natural resources. These include the rate of change of the resource stock over time and /or the long-run equilibrium condition on the rate of return from holding the resource (Dasgupta et al. 1978). There are two general approaches to this integration. The first places trade possibilities into the standard closed-economy model of resource use to determine whether the results obtained from the closed economy carry-over to the open economy. In the second approach, natural resources are added to a standard trade model to determine how they affect trade and whether standard trade theory carries over to economies that have natural resources.

In surveying these linkages, Segerson (1988) summarizes that, intertemporally, the existence of an externality associated with resource use implies a divergence between private and social comparative advantage. As a result, market-determined production and 
trade patterns are no longer Pareto optimal. The same is true if intertemporal externalities associated with user costs are not fully internalized. She further concludes that even if an intertemporal externality is fully internalized, the dynamic aspects of natural resource use can still affect international trade. In particular, it can: (1) cause resource production and trade decisions to be closely linked to capital markets and thus create an additional link between capital markets and trade, (2) force small countries that are dependent on imports of essential exhaustible resources to export more and more of their agricultural commodities to cover the increasing cost of resource inputs, (3) direct resource-rich countries to increase the degree of processing of natural resources prior to export to avoid rent extraction by resource-poor importers, and (4) increase the possibility of complete specialization due to relative resource endowments or differing rates of time preference.

\subsubsection{Hazardous Substances and Trade}

Hazardous substances usually refer to those which have a direct or indirect negative impact on environmental quality (pesticide, chemicals, and hazardous wastes for example). Since the 1980s, there is an increasing evidence of potential or actual damage due to exports of hazardous substances. Scherr (1987) and Azevedo (1982) survey the

evolution of U.S. regulations of such trade. The main issues in the U.S. involve the listing of ingredients or chemical components of exports and imports, explicit bans on drugs which are domestically prohibited, and procedures for altering importing countries of the export of hazardous substances.

Oates and Schwab (1988) propose four necessary conditions to achieve optimal trade in wastes: (1) the exporting country should inform the receiving country of the 
content of the wastes and their potential risks, (2) the reservation price must include not only the opportunity cost of the land but also the full social cost caused by the disposal of the waste, (3) transportation costs must incorporate the full social cost of shipping the wastes from the generating site to the destination, and (4) developing countries must effectively enforce environmental regulations to reduce the illegal dumping that creates substantial social costs. Xing and Kolstad (1996) point out that patterns of waste trade include two routes. One route is from a high-income country to a low-income country. The other route is between industrialized countries where the waste flows are from a country with abundant assimilative capacity to the one that has scarce assimilative capacity.

\subsubsection{Global Warming and Trade}

In the past two decades, academic and policy concerns over the risks of global warming have led to numerous publications addressing this issue. However, there is no discussion about the role of trade in the global warming process. On the contrary, there are many studies on the trade effects of greenhouse gas (GHG) abatement and the use of trade measures to limit GHG emissions in order to slow down the global warming process.

Whalley and Wigle (1991) quantitatively investigate the effect of GHG abatement on the terms of trade between fuels and final goods. They illustrate that the terms of trade between fuels and final goods are potentially sensitive to GHG abatement. Abatement is bound to lower the supply price of carboniferous fuels relative to business-as-usual, but it will also raise the demand price of such fuels, directly if it is pursued by taxes or tradable 
carbon permits or indirectly by raising shadow prices if it is pursued by regulation. Burniaux et al. (1991a, b) and Symons et al. (1990) have conducted similar research. These studies also show that the terms of trade between fuels and other goods will be altered no matter how abatement is achieved, but the direction of change depends on whether the (explicit or implicit) carbon tax is collected and kept by consumers or by producers.

The issue of how GHG abatement influences changes in international competitiveness has also received some consideration, e.g. see Glomsrod et al. (1992) and Blitzer et al. (1990). Competitive issues arise if abatement falls unevenly across countries. Unfortunately, the greater the abatement, the higher are industrial costs and the less competitive the economy.

In recent years, various forms of international GHG emissions trading systems have been studied, e.g. see Manne and Richels (1996), and Edmonds et al. (1997). It is believed that emissions trading can bring about substantial potential abatement cost savings compared with abatement measures such as international GHG taxation and quotas. However, one challenge in achieving such benefits in practice is that emissions trading requires an international allocation of emissions rights. International negotiation on this issue would be very difficult. Implementation and enforcement of such an emissions trading system are also a problem in an international setting. 


\subsection{Pollution Redeployment to Developing Countries}

\subsubsection{National Environmental Policy and Capital Mobility}

The relationship between national environmental policy and capital mobility has been studied extensively since the 1970s, e.g. see Cumberland (1978) and (1981), McGuire (1982), Oates and Schwab (1988), Sinn (1994), Wellisch (1995), and Schneider and Wellisch (1997). It is generally believed that in an open economy, the strictness of a country's environmental policy may influence the country's competitiveness for mobile capital. An earlier investigation into the issue was conducted by McGuire (1982). In order to analyze the movement of capital across frontiers caused by environmental regulation, McGuire incorporates an environmental factor, in the form of effluent output, as an input of the polluting industry into a two-factor-and-two-country Heckscher-Ohlin model. The environmental regulation is represented by the marginal product of the effluent, which is a variable determined by the public. In the absence of regulation the marginal product of effluent is equal to zero. Thus, the effect of the environmental regulation on the polluting industry is equivalent to negative neutral technical progress. That is, for the same bundle of labor and capital inputs, the polluting industry will produce less if an environmental regulation is applied. Therefore, if capital is freely mobile across boundaries, the least differential regulation between countries will entirely drive out the regulated industry from the more to the less regulated economy.

A recent interesting discussion on environmental policy and capital mobility is presented by Schneider and Wellisch (1997). In their analysis, an economy consists of a traded-good and a non-traded-good sector. Furthermore, free capital mobility is allowed between countries. According to the study, given that production technologies are the 
same in both sectors and the elasticity of substitution between capital and labor is positive, it is unambiguously the case that, in order to keep the outflow of the factor rewards to emissions low, the non-traded-good sector receives relatively more emissions permits. This counter-intuitive result is due to the fact that prices can be adjusted for nontraded but not for traded goods. Suppose that emissions allowances are increased in the traded sector at the expense of the non-traded-good sector, holding the overall emissions level constant. The traded-good sector experiences a capital inflow while the non-traded a capital outflow and fewer non-tradables will be produced. This drives up the price for non-tradables. Thus, due to the flexible output price for non-tradables, capital inflows into the traded-good sector are not fully offset by capital outflows of the non-traded sector. Restricting the outflow of emissions rents implies a limiting of the inflow of capital, since the implicit factor reward on emissions is part of the interest payments flowing out of the country. Hence the authors conclude that restricting the outflow of emissions rents results in relative generous pollution allowances in the non-traded-good sector.

\subsubsection{Environmentally-Induced Industrial Relocation}

The "industry flight hypothesis" suggests that since the developed countries impose tougher environmental policies than do the developing countries, polluting industries shift operations from the developed to the developing countries; developing countries thus become "pollution havens." According to Xing and Kolstad (1996), this hypothesis is based on three arguments. First, environmental policies will increase the production costs of the polluting industries. Second, tough environmental policies 
discourage new investment away from the polluting industries. Third, since some policies directly confine the range of products or the inputs of production, producers have to relocate their production in other areas.

However, neither theoretical nor empirical studies in most cases support the industry flight hypothesis, i.e. for overviews, see Dean (1992), Xing and Kolstad (1996), and Ulph and Valentini (1997). Ulph and Valentini (1997) probe the issue using a model of two countries, two industries, an upstream and a downstream sector, and two firms in each industry. The authors carry out their analysis through a three-stage game: in the first stage the two countries set their environmental policies; in the second stage the firms in both industries choose how many plants and where to locate; and in the third stage firms choose their output levels, with the demand for the upstream firms being determined endogenously by the production decisions of the downstream firms. Based on their analysis, the authors come up with some surprising results. The effect of environmental policy imposed in one industry can sometimes be positive: i.e., a country imposing a small emissions tax can attract firms from other industries to locate in that country. In addition, environmental policy may have important hysteresis effects: once a country's emission tax is high enough to drive firms out of the country, the country is unlikely to attract the firms back by lowering its emission tax. The authors attribute these results to the multiple-equilibrium feature of the models and to incentives for agglomeration.

Leonard and Duerksen (1980), Walter (1982), Pearson (1987), Leonard (1988), Lucas, Wheeler and Hettige (1992), and Low and Yeates (1992) empirically investigate the industry flight hypothesis. Leonard and Duerksen (1980) analyze trade and investment data to find whether the differences in environmental control costs have led to 
industrial flight toward developing countries. Their study shows that, instead of developing countries, the receivers of most foreign investment in polluting industries such as paper, chemicals, metals and petroleum refining are other industrial countries. Moreover, the percent of U.S. foreign direct investment in polluting industries in developing countries compared to developed countries did not show a significant increase over time. Hence they conclude that there is no evidence of the flight of U.S. industries to developing countries. Based on his study on the trend in foreign direct investment by firms from Western Europe, Japan, and the United States in the 1970s, Walter (1982) reaches the same conclusion. Although there exists a large amount of overseas production in polluting industries, there is little evidence that it has been caused by differing pollution abatement costs and that foreign direct investment is fleeing to countries with less stringent environmental policies. Pearson's (1987) survey also supports the conclusion that there is little evidence of industrial flight to developing countries.

According to Leonard (1988), the industrial flight and pollution haven hypotheses are not convincing because they are based on too static and too narrow a definition of comparative advantage. Therefore, in his case studies of foreign direct investment in Ireland, Spain, Mexico, and Romania, Leonard includes in his analysis factors such as the product cycle, industrial location decisions by firms, bargaining processes between multinationals and host countries, and development strategies. Again, the author finds no supportive evidence for the industrial flight and the pollution haven hypotheses. The four investigated countries seemed to react in accordance with the pollution haven hypothesis in the 1970s. However, gains obtained from lenient environmental policies were not great enough to change the locational preferences of multinationals since other considerations 
such as labor supply, infrastructure and political stability appeared much more important in location selections.

Lucas, Wheeler, and Hettige (1992) econometrically test the hypothesis that environmental policies drive polluting industries from the OECD countries to developing countries. In their study two regression models are employed. The first model regresses the toxic emissions density on GDP per capita and a time trend variable. The second regression is the growth rate of toxic emissions density on the growth rate of GDP per capita and an economic structure variable, the ratio of domestic prices to world prices, which is usually considered a measure of the openness of an economy. Though the two regressions reveal that the poorest countries have the highest growth rate of toxic emissions density, the results are insufficient to draw the conclusion that environmental policies lead to a flight of polluting industries to developing countries. The estimates show that economic growth has a significantly smaller effect on toxic emissions in open economies than in closed economies. If the industrial flight hypothesis held, then developing countries with open economies would have experienced a rapid growth of toxic emissions density. Their investigation finds no support for this.

Low and Yeates (1992) support the industrial flight hypothesis. The authors examine the worldwide redistribution of polluting industries with two indicators: the share of polluting industries' exports in total world exports and the revealed comparative advantage of an industry, which is defined as the ratio of the industry's share in the country's exports to the industry's share in total manufacturing exports. A country is said to have an advantage in an industry if the industry's revealed comparative advantage indicator is greater than one. According to this study, the world's polluting industries' 
share of exports in total world exports shrank from 18.9 to 15.7 percent between 1965 and 1988. For all developed countries, this share also declined from 20.4 to 15.9 percent during the same period. From 1966 to 1968, only 11 percent of the 109 countries sampled had a revealed comparative advantage indicator greater than one in their polluting industry. From 1986 to 1988, however, 22 percent of these countries had an indicator greater than one and most of the increase in the percentage was from developing countries. In contrast to the decreasing share of polluting industries (especially in developed countries), the authors conclude that stringent environmental policies in developed countries probably lead to the shift of polluting industries from developed to developing countries.

\subsection{Environmental Degradation}

\subsubsection{Trade and the Global Environment}

The close linkages between trade and the global environment hava been widely recognized yet remain heavily disputable, e.g. see Baumol (1971), Grossman and Krueger (1993), World Bank (1992), French (1993), Bhagwati (1993), Daly (1993), Chichilnisky (1994), Copelead and Taylor (1994, 1997, 1999), Perroni and Wigle Taylor (1994), Lopez (1994), and Selden and Song (1994). In cases such as the shipment of lowcost tropical timber from Malaysia to Japan and the U.S. exportation of lead car batteries to a plant near Sao Paulo, one could infer that trade affects the global environment negatively. However, in many other cases, world trade has demonstrated positive environmental effects as well. For example, fuel-efficient Japanese cars not only reduce air emissions in the United States but also force U.S. manufacturers to develop more fuel- 
efficient models. French (1993) summarizes that, for better or for worse, trade and tradeinduced integration of the world economy are shaping global environmental trends in at least three ways. First, trade intensifies the environmental impacts of domestic production by expanding international markets. Second, trade makes it possible for countries to obtain from other countries the desired products that are domestically either unavailable or protected by strict laws and hence effectively pass the environmental effects of consumption to someone else. Third, since national environmental policies and even some international environmental treaties are often attacked as "nontariff barriers to trade", efforts to restore environmental quality within countries and to protect the global commons, such as the atmosphere and the oceans, are erroneously misjudged.

In the debate over the environmental consequences of free trade, Bhagwati (1993) argues with Daly (1993) that environmentalists are wrong to fear the effects of free trade because both trade and environmental protection can be advanced by imaginative solutions. In responding to the widespread fear among environmentalists that free trade accelerates economic growth and that growth harms the environment, Bhagwati points out that the fear is misplaced since growth enables governments to tax and to raise resources for objectives such as pollution abatement and the general protection of the environment. For instance, rich countries today show greater concern about the environment than do poor countries. In addition, an empirical study by Grossman and Krueger (1993) also shows that some environmental quality indicators improve as income increases. Therefore, in Bhagwati's opinion, international trade should generally help protect the environment rather than harm it. 
On the other side of the debate, Daly (1993) contends that the free traders seek to maximize profits and production without taking into consideration social and environmental costs. He further argues that by separating the costs and benefits of environmental exploitation, international trade makes the comparison between them more difficult and hence may mislead economies beyond their optimal scale. In this case environmental costs would rise faster than would any production benefits and the economy would enter an anti-economic phase that impoverished rather than enriched itself. What's worse, Daly points out, since evidence shows that we have already passed that point, the faster we run the farther we fall behind.

Chichilnisky (1994) addresses the trade and the global environment issue in a different way. She thinks that the problem reflects a North-South dimension. Developing countries in the South tend to over-produce and export environmentally intensive goods even if they are not well endowed with them. Developed countries in the North, on the other hand, tend to over-consume, even if trade equalizes all traded goods and all factor prices worldwide. According to Chichilnisky, the patterns of North-South trade in the global economy can be explained by differences in property rights, a factor previously neglected in the literature on trade and environmental issues. Her analysis proves that, if the South has ill-defined while the North has well-defined property rights, this property right difference can create the above-mentioned patterns of trade between the North and the South, even if the two region were identical in technologies, resource endowments, and preferences. She also examines some environmental policies and shows that taxing the use of environmental resources in the South is not always reliable since it can lead to more over-extraction if the resources are exploited using labor from a subsistence sector. 
The author suggests that property-rights policies may be more effective for improving environmental and trade linkages.

\subsubsection{Trade-Induced Environmental Degradation}

As discussed in the previous section, in response to Bhagwati's (1993a) argument that trade promotes economic growth and that growth improves environmental quality, Daly (1993a) proposes that trade can induce environmental degradation and that degradation can lead to income losses and these income losses can result in further environmental degradation. Copeland and Taylor $(1997,1999)$ refer to Daly's conjecture as the "trade-induced degradation hypothesis" and work out a theoretic framework for this hypothesis. The authors examine the environmental consequences of trade by studying the role that trade plays in industries that are not only spatially separated but also functionally incompatible. They base their analysis on a simple two-industry dynamic model. Two incompatible industries are assumed to be a polluting manufacturing industry compared to an environmentally sensitive industry. If there is no trade, the productivity of the environmentally sensitive industry will be harmed by the production of the polluting manufacturing industry. Once trade exists, the two incompatible industries can move away from each other. Hence, trade can help to reduce cross-industry production externalities and to improve global productivity gains. However, all countries do not always benefit from any increase in global productivity, since changes in productivity can cause changes in terms of trade. The authors show that, if the share of world income spent on polluting goods is high, the environmental effects of trade will be positive in case of two identical, unregulated countries. When that share 
is low, trade may worsen environmental degradation and result in a real income loss for the polluting goods exporting country.

Lopez (1994) investigates the economic growth, trade, and environmental degradation relationship in a different setting in which unilateral trade liberalization in a small open developing economy is focused on. The study employs a neoclassical model with assumptions that have been widely applied to conventional general equilibrium and growth analyses (such as the existence of an aggregate function of capital, labor and technology, and constant return to scale of the production technology). In the macro production function environmental resources are incorporated as input factors represented by the level of pollution. The results of the analysis show that the stock effects of environmental resources on production and whether producers internalize such effects are closely related to the impacts of economic growth and trade liberalization on the environment. If and only if individual producers internalize the stock feedback effects on production, will economic growth and trade decrease environmental degradation. If environmental factors do not have stock effects on production, economic growth can harm the environment when preferences are homothetic. In the non-homothetic case, the level of the elasticity of substitution in production between conventional and environmental factors and the relative degree of curvature of utility in income inversely affect the relationship between economic growth and environmental degradation. That is, the lower are the former, the worse the degradation that growth brings about.

Empirical studies on this growth, trade, and environmental degradation issue are few and most draw similar conclusions. The World Bank (1992) concludes that international trade as such cannot be regarded as a cause of environmental degradation, 
but what causes this degradation is the absence of appropriate environmental protection policies. And indeed, trade could improve the allocative efficiency of environmental goods among and within countries and hence reverse environmental degradation, if environmental costs are adequately internalized by removing domestic and international distortions. Lucus, Wheeler and Hettige (1992) focus their empirical study on air pollution and economic growth using data from both developing and developed countries over 1960-1988. The authors find that air pollution, in general, does not decline with economic growth. Specifically, the income effect on pollution intensity tends to be negative in more open countries while it is positive in closed economies. However, total emissions increase with income even in the most open countries, though in these countries pollution intensity declines. Since the openness of an economy directly reflects its extent of trade liberalization, this study implies that even though trade may not improve the environment, it at least does no harm to the environment.

Perroni and Wigle (1994) have developed a numerical general equilibrium model of the world economy with local and global environmental externalities to examine the effect of trade on environment degradation. The authors group countries into North America (U.S. and Canada), other developed countries, and low and middle income countries. Population, trade, demand, and value-added data used in model calibration stem from 1986. Perfect competition and capital immobility are assumed in the analysis. In addition, three trade-policy scenarios--benchmark trade barriers, free trade, and trade wars, are designed for simulation. The numerical results of the study clearly show that compared to environmental policies, trade policies have little impact on environment quality. Though free trade may more or less deteriorate the environment, its relative 
contribution to environmental degradation is quite small. The study also suggests that it would be very costly to use trade measure for environmental purposes.

\subsection{Factor Rewards}

\subsubsection{Capital and Labor Rewards}

The costs incurred by environmental policies can be passed forward to the consumers of the polluting products, and/or backward to their factors of production. It seems, however, that the issue of how environmental policies affect factor rewards has not yet received much attention in the literature. Moreover, studies on the issue have been theoretical and general equilibrium in nature, e.g. see Yohe (1979), Siebert et al (1980), McGuire (1982), and Merrifield (1988). Another common feature of these studies is the use of a two-commodity and two-sector framework in which one sector is polluting and the other nonpolluting. Siebert et al. (1980) is an exception, and assumes that both sectors generate homogenous pollution. More often, pollution or environmental factors are incorporated in these studies as a production input into the polluting sector.

Yohe (1979) takes such an approach in his closed economy analysis. At first, he examines the incidence of stricter pollution standards on labor and capital rewards, given the assumption of fixed output prices in both sectors. With prices fixed, Yohe concludes that real returns to capital and labor move in opposite directions and that the shadow price of pollution increases when environmental policies become more restrictive. Especially, if the non-polluting sector is labor (capital) intensive, the transfer of production factors from the polluting to the non-polluting sector leads to a higher capitallabor ratio and an increase (decrease) in labor reward, and at the same time a decrease 
(increase) in capital reward. Further, the author re-examines the issue by setting output prices flexible and derives the same qualitatively identical result as with the presumption of fixed output price, but the magnitude of the effect of more restrictive pollution control on capital and labor rewards varies with the relative and weighted price elasticities of demand in both sectors.

Based upon almost the same framework as Yohe (1979), Siebert et al. (1980) investigate the case where both sectors produce homogenous emissions. Their study shows that if one sector is strongly pollution intensive while the other is strongly capital (labor) intensive, then a tighter pollution standard results in a rise (decline) in the capital reward and a decline (rise) in the labor reward. If neither of the sectors is relatively pollution intensive, a tighter standard reduces the rewards of both factors.

McGuire (1982) also develops an approach similar to Yohe's (1979) concerning the environmental regulation and factor reward issue. However, he also introduces international trade and emissions damages and assumes a fixed marginal social cost of pollution. Prior to the incorporation of international trade, McGuire analyzes the effect of regulation on factor rewards in an autarchic equilibrium. It is not surprising that the author comes to conclusions close to those of Yohe (1979) and Siebert et al. (1980): environmental regulation results in movements of capital and labor rewards in opposite directions and the rewards of capital and labor depend on the elasticity of demand for the polluting good and on the relative capital/labor intensity of the polluting good in comparison with the non-polluting good. After introducing international trade, the author separately analyzes the regulation effect on factor rewards in a coordination and an uncoordition case. When the two countries coordinate, a uniform shadow piece is levied 
on emissions in the production of the polluting sector. The analysis demonstrates that the coordinated control does not change the outcome of factor price equalization obtained in the autarchy case. In the uncoordination case, however, factor price equalization no longer exists; it is destroyed by non-uniform regulations between the two countries. The author concludes that, for a small country with no influence over world commodity prices, pollution control regulation definitely decreases the reward of the factor used intensively in the production of the polluting sector and unambiguously raises the reward of the other factor. For a large country, its uncoordinated regulation will increase the world price of the regulated commodity, and the reward of the factor used intensively in the production of the regulated commodity will unambiguously enjoy a worldwide increase.

Merrifield's (1988) research follows up and advances the above studies. The model used by Merrifield is basically the same as that of Yohe (1979) and McGuire (1982). However, the author additionally allows pollution, commodities, and capital to be internationally mobile and output prices and factor rewards to be endogenous. The author also improves the model by including more restrictive emissions control equipment standards. In a general case, the analysis reveals that a production tax will cause changes in factor rewards. Specifically, if a country's exporting commodity is taxed, the consumer's price rises and the producer's price falls, and both capital and labor rewards decrease in that country. If a restrictive abatement equipment standard is adopted in either country, the relative scarcity of products in the adoptive country may increase. The scarcity will be reduced if the country can absorb the excess capital supply released from the reduction in pollution. Therefore, if the production of pollution control equipment is 
sufficiently capital-intensive, the excess capital supply will lower the rewards for capital and raise the rewards for labor in both countries. If the non-acting country's share of total income is large and there is easier substitution of capital for labor in the acting country, labor rewards may decrease. The author also applies his analytical framework to the North American acid deposition issue in order to illustrate his theoretical results and finds that if Canada levies a production tax on its output, the pollution abatement effort reduces both capital and labor rewards. Similar results are derived if the U.S. acts alone. In case that two countries act jointly, the price of capital and wages in both countries fall.

\subsubsection{Resource Rewards}

According to the Heckscher-Ohlin theory, resource endowment is the key factor leading to trade. However, the conventional Heckscher-Ohlin model usually includes only two resource factors of production, namely labor and capital. Some economists now recognize that other resources such as the environment, as well as other productive resources such as land and other natural resources, should be taken into consideration for more realistic models and theories, i.e. see Abbott and Haley (1988), Lopez (1994), McGuire (1982), Merrifield (1988), and Yohe (1979).

Environment as a resource has been incorporated into the Heckscher-Ohlin model as a factor of production by Yohe (1979), McGuire (1982), and Merrifield (1988). Lopez (1994) uses a different neoclassical general equilibrium set up but the treatment of the environmental resource is about the same. The environmental factor is usually measured in those analyses in physical quantity of emissions to the environment as a result of production. The relationship between environmental policies and the prices of this factor 
revealed in those studies is rather straightforward. In the case of no environmental policy, firms can discharge whatever amount of effluent generated in production into the environment without any costs. Thus, the price of the environmental factor is virtually zero. With an environmental policy, firms will use the environmental factor to the point where the value of its marginal product is equal to its price, which is determined by the marginal costs of pollution abatement. In general, the stricter an environmental policy, the higher the marginal abatement costs and hence the higher the price of the environmental factor. Obviously, those studies underestimate the price of the environmental resource because they neglect the marginal social costs of pollution. A reasonable determination of the environmental resource price should include not only the marginal costs of abatement but also the marginal social costs of pollution.

There is little evidence on how environmental policies affect the rewards to land and other natural resources such as energy and materials when treated as factors of production. Lopez (1994) does model land and forest as two productive factors in his analysis. However, the author's interest is mainly on the stock feedback effect of those resources on economic growth and trade liberalization. The rent of land and the rewards of forest remain unconsidered.

\section{10 Conclusions}

Though approaches taken in the above studies are sufficiently varied to make comparisons among them difficult, together they constitute a body of knowledge that enables us to better understand how and to what extent environmental policies influence world trade and the degree to which interactions occur between trade and the 
environment. To this end, it has been found that environmental policies can have an impact on a country's domestic income and balance of trade and payments. However their impacts on employment are less clear. What's more, their impacts on production costs and prices are still in dispute; theoretically, the enacting of environmental policies increases commodity prices and production costs, but this has not been fully supported by empirical studies. Second, according to conventional trade theory, environmental policies should affect patterns of world trade in environmentally sensitive goods and this would result in loss of comparative advantage. However, this conventional view has been challenged by recent theoretical and empirical studies. Third, the above studies show that impacts of environmental policies on the terms of trade depend on the type of policy and economic conditions under which a policy applies. In some cases, an environmental policy can improve the terms of trade, but in other cases, it may deteriorate the terms of trade.

The message these studies have sent to policy-makers is not unreasonable: there is no convincing evidence from empirical studies to support the hypothesis about the negative impact of environmental policy on international trade. Therefore, environmental policies which are usually designed to serve social objectives, at least, shouldn't seriously cause adverse trade effects. However, since the quantitative models employed for studying trade and environmental issues are always the result of abstractions and simplifications, it is difficult to directly apply the conclusions obtained from any theoretical or empirical study to other kinds of policy situations. Instead, one should evaluate results from several different studies, each shedding a specific light on the policy 
issue of interest, in order to better understand what policy alternatives we have and how they are related to each other. 


\section{Chapter 3}

\section{METHODS OF ANALYZING INTERACTIONS BETWEEN ENVIRONMENT AND TRADE}

\subsection{Problems of Measuring Trade and Environmental Interactions}

Among the various environment and trade issues reviewed in the previous chapter, attempts to analyze them have lacked robustness, e.g. Smith and Espinosa (1995), Copeland and Taylor (1995), and Perroni and Wigle (1994). This has led more recently to studies focused on developing and applying more effective quantitative approaches. Such efforts, however, have encountered a number of difficulties. First, any attempt to model trade and environmental interactions requires an interdisciplinary approach and hence knowledge of subjects such as economics, environmental science, international relations, and scientific law. Second, not much theoretical research has been quantified sufficiently to provide functional relations suitable for hypothesis testing. Third, little empirical evidence exists globally concerning the degree to which economic activities such as trade affect the natural environment and how individuals value environmental quality. Fourth, it is very difficult to link economic to physical dimensions, that is, to define and to estimate unambiguous indicators for environmental effects, specific environmental factors, strictness of environmental policies, or even of trade strategies. This problem includes the suitability and availability of comparable environmental data and indexes at the global level. And fifth, where it is possible to test qualitative relations, the nonlinear and other confounding effects make it difficult to apply conventional parametric or nonparametric test statistics. 
Nonetheless, researchers have attempted to evaluate important environment and trade issues. The methods they have employed, as shown in Table 3.1, appear to concentrate on the following modeling approaches: (1) computable general equilibrium (CGE) models, (2) international trade models, (3) input-output models, (4) welfare models, (5) game theory models, (6) optimization models, (7) spatial GIS models, and (8) econometric models. Below we review each of these methods and discuss their applications in an environment and trade context. The results concerning possible policy implications also are discussed.

\subsection{Computable General Equilibrium Models}

\subsubsection{Market CGE Models}

Computable General Equilibrium (CGE) models have been frequently used in studies of this kind, e.g., see Lee and Roland-Holst (1994), Perroni and Wigle (1994), Dessus and Bussolo (1998), Davies et al. (1998), Felder and Rutherford (1993), and Beghin et al (1997). CGE models have evolved from linear programming-based planning models. These models describe Walrasian equilibrium with many goods and factors. Typical market models use production structures based on profit-maximizing producers and demand structures derived from utility-maximizing consumers. The general equilibrium theory employed is the same as in trade theory, where open economies are modeled. A prominent advantage of CGE models lies in the possibility of combining detailed and consistent real-world databases with a theoretically sound framework.

Perroni and Wigle (1994) have constructed a CGE model of the world economy with local and global externalities to investigate the impacts of international trade on 
1 Computable General Equilibrium Models

CGE Models

Non-Market CGE Models

2 International Trade Models

The Heckscher-Ohlin Model

Empirical Trade Models

3 Input-output Models

I-O Models, Multipliers and linkages

Trade and I-O Models

Environmental I-O Models

4 Welfare Models

Welfare Analysis and Impact Measurement

Welfare Analysis of Gains from Trade

Welfare Analysis of Environmental Policy

Impact of Environmental Policy on the Net Benefits from Trade

5 Game theoretic Models

Cooperative game Theoretic Models

Noncooperative Game Theoretic Models

6 Optimization Models

Searching for Optimal Trade and Environmental Policies

Lack of Applications

7 Spatial GIS Models

Spatial Analysis

GIS Model Theory

GIS Model Applications

8 Econometric Models

Trade and Environment Linkages over Time

Potential Applications 
environmental quality. Their results show that, though free trade may have a negative impact on environmental quality, its relative contribution to environmental degradation is very small. The authors also find that the magnitude of the welfare effects of environmental policies is not significantly affected by changes in trade policies. What's more, the size and distribution of gains from trade liberalization appear to be little affected by change in environmental policies.

Dessus and Bussolo (1998) have employed a CGE model to examine whether there is a trade-off between trade liberalization and pollution abatement in Costa Rica. Unlike previous analyses, their model embodies a high level of disaggregation for pollutants, products, sectors, and types of households. They also explicitly include dynamic features in the model to reveal the temporal interdependencies of environmental and trade policies by comparing the trends of outputs and emissions obtained from different scenarios. Furthermore, their model allows for substitution between nonpolluting and polluting factors which other similar studies usually fail to include, e.g., see Lee and Roland-Holst (1994). Using this model, the authors show that further integration of Costa Rica into the world economy presents a great risk of environmental degradation if not accompanied by voluntary environmental reforms. These reforms could achieve significant pollution abatement without hampering economic growth or international competitiveness through targeted fiscal policies related to the utilization of polluting goods. Moreover, free trade combined with appropriate effluent taxes enhances factor reallocation towards competitive industries, and hence growth, while significantly abating emissions. 
It should be noted that CGE models examining the relationship between environment and trade have mainly concentrated on energy and carbon dioxide emissions, largely because these allow significant economy-wide effects to be found, as the required policy interventions are quite severe. A disadvantage of CGE market models is their complexity in computation and difficulty of validation.

\subsubsection{Non-Market CGE Models}

In general, past efforts to incorporate non-market environmental resources into CGE models have encountered a number of problems. The first arises from being able to specify only a limited role for environmental resources to be included in the behavioral relationships of a typical aggregate economic model. For example, some models introduce environmental resources as providing a separable contribution to individual well-being (Perroni and Wigle 1994, Ballard and Medema 1993). However, this separable specification assures that commodity demand, and hence relative prices, will not be affected by preference-related substitutions between marketed goods due to changes in environmental resources. The second problem is that most of those models have no spatial dimension that would distinguish the differential environmental impacts of production activities occurring at different locations. These studies would suggest that none of the available CGE trade models are capable of consistently linking the value of environmental resources to consumer preferences.

Responding to this challenge, Espinosa and Smith (1995) developed a composite non-market and CGE model (NM/CGE) for the European Union, the United States, Japan, and a single region for the rest of the would. This NM/CGE model advanced the 
Harrison, Rutherford, Wooton model (HRW1--Harrison, Rutherford, and Wooton 1991) by incorporating the morbidity and mortality effects of three air pollutants: sulphur oxides $\left(\mathrm{SO}_{\mathrm{x}}\right)$ as a transboundary externality and particulate matter $(\mathrm{PM})$ and nitrogen oxides $\left(\mathrm{NO}_{\mathrm{x}}\right)$ as sources of local externalities. Other important modifications made to HRW1 include: (1) replacing the Cobb-Douglas with Stone-Geary utility functions for aggregate consumers in each region, (2) introducing nine air pollution-induced morbidity effects as translating effects on each household's subsistence parameter for services, and (3) introducing an explicit set of pollution generation and dispersion models for each of the three air pollutants. Each of these modifications has been introduced so that the model's initial calibration is maintained.

This NM/CGE model distinguishes itself from market CGE models by allowing existing non-market valuation estimates to include a specification for consumer preferences that allows changes in atmospheric emissions to diffuse in different amounts in each region and to exert feedback effects on market demands. Specifically, the authors examine the importance of both sets of impacts, market and non-market, on Hicksian welfare measures by comparing the results of model specifications with and without environmental feedback effects to evaluate scenarios that combine trade liberalization with environmental degradation. Two scenarios are used in their analysis: (1) a pure trade scenario which considers a 50 percent reduction in nontariff barriers for all trade between UK and the other EU regions and (2) a composite scenario which combines this reduction in nontariff barriers with an increase of 25 percent in the emission rates for all three pollutants for the durable manufacturing sector in the UK. Their simulation results indicate that the impact of environmental effects on the economic variables examined, 
such as GDP and prices, are not great when the policy scenario focuses on parameters linked to market transactions. When the mortality effects of pollution are combined with those of morbidity, the impact of removing trade barriers produces greater change in GDP (19.8 vs 18.9 percent). In the composite scenario, the analysis clearly shows the same response. That is, in the absence of a model that accounts for emission changes, the reduced trade barriers would be counted as welfare-enhancing. However, when taking into account the environment, including both morbidity and mortality effects, that judgment changes. The authors further point out that even if we limit our attention to the morbidity effects of the increased pollution, the environmental feedback effects from the joint change of trade barriers and emission rates are important.

The NM/CGE model provides a novel and useful framework for analyzing trade and environment interactions. However, the uncertainty and complexity of non-market valuation hampers it from having wide-scale applications.

\subsection{International Trade Models}

\subsubsection{The Heckscher-Ohlin Model}

The Heckscher-Ohlin (H-O) trade model, based on neoclassical supply-side theories, leads itself to environmental applications. The equilibrium formulation of the model includes two commodities, two factors of production(labor and capital), and two countries. Factors are assumed to be perfectly mobile within a country but immobile between countries. In addition, identical technologies and identical demands between countries are also assumed. The main tenet of the model is that a country will export the particular commodity that most intensively uses its relatively abundantly-endowed factor. 
Comparative advantage and trade, therefore, are determined by differences in factor endowments among countries. From this model, three additional theorems are derived: the factor-price-equalization theorem, the Stolper-Samuelson theorem and the Rybczynski theorem (Markusen et al. 1995). These theorems form the core of modern trade theory and have been widely used in international trade analysis.

Many theoretical and empirical studies on trade and environment issues are based on modifications of the H-O model, e.g. Walter (1975), Grubel (1976), Yohe (1979), McGuire (1982), Merrifield (1988), Siebert (1992), and Diao and Roe (1997), among others. One modification is to treat environmental damage avoidance as a third good in the model, the output of which competes with the production of other two conventional goods. Walter (1975) demonstrates that that general equilibrium exists in such a threegood H-O model and increased pollution abatement reduces the output of the conventional goods but raises social welfare. However, actual application of this approach to examine the terms of trade, the volume of trade flows and the efficiency of environmental policy has been limited.

Another modification following Grubel (1976) assumes that environmental pollution is associated with either the production of one of the two goods or with the consumption of a good. Hence, environmental pollution results in either a shrinkage in a country's production possibility frontier or a reduction of the consumption level of the polluting good due to the implementation of proper environmental protection measures. Based on this approach and using general equilibrium analysis, Grubel obtains many useful results about the impact of environmental policy on international trade and welfare. Diao and Roe (1997) have followed the same approach, but unlike Grubel 
(1976), they assume non-homothetic utility to explain changes in the demand for the nonpolluting good when income increases. Both studies conclude that countries have incentives to adopt environmental policies and, in the large-country case, a country adopting environmental policies may benefit from an improvement in its terms of trade.

And still another modification introduces environmental elements as input factors of production, e.g., Yohe (1979), McGuire (1982), Merrifield (1988), and Siebert (1992). McGuire (1982), in his study of the impact of environmental regulation on factor rewards, for instance, assumes that one good is production-polluting and thus environmental usage or depletion represents a productive factor of that good. Efficient environmental regulations should make the value of marginal product of the environmental factor equal to its shadow price. A similar treatment is also employed by Siebert (1992) where environmental scarcity is interpreted as a factor of production in the H-O model. If both trading countries' environmental policies find the correct shadow price of their environmental factor, the environmentally rich country will have a comparative advantage to produce and to export the pollution-intensive good, while the country with limited environmental resources will export the less polluting good. Merrifield (1988) models the environmental factor in a more detailed way. Both emissions and pollution abatement equipment appear as inputs in the commodity production functions of both economies. This approach is thus able to capture the economic effects of tighter abatement standards. 


\subsubsection{Empirical Trade Models}

Among the empirical applications of the $\mathrm{H}-\mathrm{O}$ model to environmental issues, the cross-sectional Heckscher-Ohlin-Vanek alternative (H-O-V) has proven popular, e.g., see Bowen (1983), Leamer (1984), Brecher and Choudhri (1988), Murrell (1990), Trefler (1994), and Leamer and Levinsohn (1995). The H-O-V model is a multi-factor and multicommodity extension of the H-O model (Vanek 1968; Melvin 1968; Leamer 1980). According to the $\mathrm{H}-\mathrm{O}-\mathrm{V}$ theorem, in reasonably generalized cases, differences in relative factor endowments still determine comparative advantage. Unlike the $\mathrm{H}-\mathrm{O}$ theorem, comparative advantage in the generalized case refers to the patterns of trade in factor contents rather than in commodities. The practical significance of the $\mathrm{H}-\mathrm{O}-\mathrm{V}$ theorem is in the establishment of the relationship between the net exports of commodities and the endowments of factors. Therefore, it is unsurprising that an empirical H-O-V model usually consists of a set of linear equations explicitiy expressing this net-export and endowment relationship.

An econometric application of the $\mathrm{H}-\mathrm{O}-\mathrm{V}$ model to trade and environmental issues made by Tobey (1990) extends the conventional H-O-V model by introducing a qualitative variable into the net-export and endowment equation to represent the environmental endowment measured by the stringency of environment policy. Other resource endowments include capital, different types of labor and land uses, coal, minerals, and oil. Five aggregate pollution-intensive commodity groups are examined: paper, mining, iron and steel, nonferrous metals, and chemicals. Econometric estimation of the resultant equations is based on observations from 23 countries (13 developed and 10 developing countries). In addition, the author also investigates the trade effects of 
environmental policy by examining the signs of the estimated error terms when the variable of the environmental endowment of a country is excluded in the H-O-V system. The most important finding of this study is that the strict environmental policies adopted by developed countries in the late 1960s and early 1970s do not have measurable impacts on patterns of world trade.

Another empirical model successfully applied to international trade is the gravity model, e.g., see Tinbergen (1962), Hamilton and Winters (1992), van Beers and van den Bergh (1997), and Wall (1999). The gravity model of trade explains trade flows between two countries based on income, population, and measures of economic and geographic proximity. In a common specification of the gravity model, bilateral trade flows are a loglinear function of the two trading partners' incomes, the geographic distance, and any other factors either promoting or resisting trade between them. Despite its consistent empirical success in explaining trade flows, the gravity model has often been criticized because of its lack of a rigorous theoretical foundation. However, Anderson (1979) and Bergstrand (1985) show that the gravity model can be derived from trade models under certain assumptions, and Deardorff (1998) proves the gravity model to be consistent with some variants of Ricardian and H-O models.

Extending the basic gravity model to include variables describing the stringency of domestic environmental policies, van Beers and van den Bergh (1997) empirically investigate the impact of environmental measures on particular trade flows. In the study, two types of environmental indicators are used: a narrow one, directly relating to economic costs of the environmental policy imposed on producers, and a broad one, made up of environmental indicators, some of which do not result in an increase in 
producers' economic costs. The authors repeat the empirical test of Tobey (1990) by applying the gravity model with the same environmental policy stringency measure and the same cross-section observations. The authors conclude, similar to Tobey, that stringent environmental policies have an insignificant impact on trade flows of pollutionintensive industries. The authors also estimate the gravity model with total bilateral trade flows as the independent variable and find that the impact of broad policy indicators that do not directly reveal environmental costs reflected in producer prices on bilateral trade flows is not significant, while more narrow policy indictors that are more directly in line with the "polluter pays principle" do have a significant negative impact on exports.

\subsection{Input-output Models}

\subsubsection{Basic I-O Models}

Input-Output (I-O) models have been widely applied to the analysis of economic growth, trade and environmental issues, e.g., see Brody and Carter (1972), BulmerThomas (1982), Leontief (1986), Pasurka (1984), Ozaki et al (1995), Gale and Lewis (1995), Miller er al. (1989), van Ierland (1993) and Frechtling and Horvath (1999). Inputoutput models describe and explain the production and consumption of each sector of a given economy in terms of its relationships to the corresponding activities in all the other sectors. Conventional I-O models (Leontief 1966, 1970) are presented by a set of liner equations which express balances between the total input and the aggregate output of each commodity and service, produced and used during a certain period of time. In addition to static general equilibrium models (Davar 1994), other developments include dynamic models (Leontief 1986 and Duchin 1989), optimization models (Nijkamp and 
Reggiani 1989 and Kohno 1996), stochastic models (West 1986 and Ten Raa 1995), and extended models (Bulmer-Thomas 1982, Batey 1985, and Batey and Weeks 1989).

Multiplier analysis constitutes an important aspect of I-O model application. Multipliers measure the impacts of exogenous economic changes or policies on endogenous variables such as the total output, employment, and income. One can incorporate only direct effects (intersectoral linkages) into the calculation of total effects, or one can take into account both the direct and induced effects (linkages between the spending of income payments and intersectoral demands). Linkage analysis, also considered an important application of multiplier analysis, consists of two forms. Backward linkages reflect the extent that other primary, intermediate and capital goods are consumed by a given sector and measure the potential stimulus to other activities from an output increase in a given sector. Forward linkages show how the output of a sector is used by other sectors and measure the induced incentive of an output increase in a sector to the output expansion of other sectors. Linkage analysis is often used to explain interindustry investment effects and their impact on income (Hirschman 1958, and Prasad and Swaminathan 1992). However, Stewart et al. (1972) and Bulmer-Thomas (1982) point out that this could be misleading since both forms of linkages are not reflected in market prices and, therefore, indicate the existence of externalities, which could cause the social benefits of an investment to diverge from private benefits.

\subsubsection{Trade and I-O Models}

There are at least two approaches to incorporate trade into an I-O model, i.e. see Barker (1972) for a useful overview. The first approach omits prices; early studies by 
Leontief (1951) and Stone (1962) fall into this category. Exports are usually exogenously introduced into the model and imports are determined according to domestic levels of output and balance of payments constraints. Though prices appear in the balance of payments constraints, they are assumed to be constant. Such models can ascertain the sources of comparative advantage and the production structures for international trade. The second approach introduces a price mechanism along with exports and imports, e.g., Aukrust (1970), Cambridge (1970) and Waelbroeck et al. (1970). That is, relationships between imports and domestic output are determined by relative prices instead of constant price coefficients. Exports are also made responsive to relative prices. In addition, relative prices per se are allowed to change with other economic variables such as exchange rates. The balance of payments constraints hence can be more effectively described.

Since the 1970s, the use of the international I-O model permits one to explain relationships between one country's imports and another's exports and the reciprocating effects of trade via both quantity flows and price levels, e.g., see Petri (1976), Torii et al. (1989), and van der Linden et al. (1995). Moreover, the feedback effects of various international trade policies such as tariff reductions and trade liberalization can be conveniently simulated and analyzed, e.g., see Torii et al (1989) and Almon et al. (1991). There are two types of international I-O trade models. Consistency models are composed of balance equations for each sector in each country (Petri 1976, and Almon et al 1991 amongst others). Optimization models usually consist of a member countries' total income maximizing objective function and a set of I-O relationship-based constraints, e.g. see Panchamukhi (1976) and Torii et al. (1989). In addition to trade policy impact 
assessment, the latter can also serve as a useful tool for analyzing optimal production and trade.

Bulmer-Thomas (1982) demonstrates that I-O models can also contribute to the investigation of comparative advantage and patterns of international trade in an economic development context. The examination of comparative advantage usually requires that domestic and foreign costs be measured in terms of shadow prices and prefers optimization algorithms. The rationality of patterns of trade are examined using the relative factor content of exports and imports (the ratio of capital to labor content of exports and imports). For a recent application of international I-O models to trade patterns, see Ozaki et al. (1995).

Gale and Lewis (1995) also extend I-O applications to include trade liberalization and environmental pollution issues. The authors have developed a detailed I-O model of production and trade in the Mexican economy where $\mathrm{CO}_{2}$ emissions are measured by fuel use in production and trade consumption, while free trade-induced change in production and trade is expressed by a change in total emissions. Based on this model, the authors first determine the changes in production and trade that result from the implementation of NAFTA. These results are then used to estimate the change in in the quantity of $\mathrm{CO}_{2}$ emissions for each industry. The results suggest that free trade within North America increases Mexico's total $\mathrm{CO}_{2}$ emissions but it also shifts resources away from more polluting to less polluting sectors. 


\subsubsection{Environment and I-O Models}

Extending I-O models to include interactions between the environment and the economy began in the late 1960s, e.g., see Ayres and Kneese (1969), Leontief (1970, 1973) and Leontief and Ford (1972); see Forsund (1985) and Forssell and Polenske (1998) for reviews. The early environmental I-O models are notable for augmenting the technical coefficient matrix with additional rows and columns to describe pollution generation and abatement activities. Typically, each pollutant appears as a row in the matrix and pollution produced in each sector is assumed to be a function of its output. Specific anti-pollution sectors are included in the matrix as columns. These abatement sectors obtain inputs from all economic sectors and at the same time also produce various pollutants. Clearly, the concept of materials balance is essential. That is, materials not embodied in final products must be embodied in emissions of pollutants. Therefore, these models are often used to trace environment-economy interactions and to investigate how environmental policy influences the two-way flow process.

Since the 1970s, as a result of increasing concerns over global warming and other transboundary pollution problems such acid deposition, environmental I-O models have evolved to give special emphasis on energy production and consumption (Leontief et al. 1977, and van Ierland 1993, among others). As a response to the challenge of Limits to Growth (Meadows et al. 1972), Leontief and his co-authors (1977) modeled energy and environmental policy within a detailed global I-O framework. The world economy is divided into fifteen regions. A fixed coefficient I-O model with 45 sectors and including resource requirements, in particular, energy requirements, and emission abatement activities is built for each region. All separate regional I-O models are linked through 
international trade. An important conclusion of the study is that the availability of energy as well as other resources and requirements for environmental protection are not an insurmountable obstacle to the economic growth of developing countries.

Van Ierland (1993) employs a non-linear dynamic I-O model to analyze economic, energy, and environmental policy in an open economy. The empirical setting of the model is the economy of the Netherlands from 1950 to 2010 (1950-1988 for parameter estimation and 1990-2010 for policy scenarios). Since the impacts of environmental policy differ substantially among branches of industries due to the fact that the intensities of energy, labor, capital, and pollution and that the import and export coefficients are not the same for any of the branches, the economy is further disaggregated into separate sectors such that the environmental and energy characteristics of the branches show up clearly. In addition, the model not only includes the most important economic variables for the various branches of industries, it also computes the demand for energy in physical units for different fuel types and for the branches of industries, transportation, households and government. Furthermore, the emissions of carbon dioxide can be directly calculated. This model provides a useful tool for both the "hypothetical" policy makers and the "actual" policy makers to obtain an overview of the impact of different sets of policy measures such as an increase in volume of international trade and a reduction in the level of household taxation, and the impact of the changes in external circumstances such as environmental strategies adopted in foreign countries. Clearly, the model can also be used as a framework for trade and environment interaction analysis. 
It should be noted that many applied and computable general equilibrium (AGE, CGE) models used to study economic, trade and environmental analysis actually can be considered as extensions of I-O models by explicitly incorporating a supply and demand system. In those CGE or AGE models, parameters of the behavioral and structural equations are either calibrated to data of a certain single year or estimated econometrically, e.g. Jorgenson and Wilcoxen (1993, 1990), Hazilla and Kopp (1990), and Whalley (1991).

\subsection{Welfare Models}

\subsubsection{Welfare Analysis and Impact Measurement}

Welfare analysis is one of the most important tools for policy assessment and, in particular, plays a critical role in measurement of the impact of trade and environmental policies. To begin with, the existence of externalities makes non-market evaluation crucial for policy impact measurement; welfare analysis provides a vehicle to achieve such measurement, e.g., for overviews, see Freeman (1993) and Cropper and Oates (1992). In addition, trade and environmental policies may result in a reallocation of both benefits and costs among nations and among different interest agents; welfare analysis again provides a useful framework to examine the policy-induced benefit distribution, e.g., see Anderson (1992a, b), Kohn (1991), and Eldor and Levin (1990). Finally, policy impacts can also be measured using the surplus components of welfare, e.g., see Thurman (1991), Just and Rausser (1992), and Haley and Dixit (1988). A policy that leads to an increase in the sum of producers' and consumers' surplus can be considered at least Pareto efficient. The most widely used framework for welfare analysis of policy impact 
measurement involves both partial and general equilibrium models. See Van Beers and Van den Bergh (1996) for a methodological overview; see Eldor and Levin (1990) for a partial equilibrium example and Thurman (1991) for a general equilibrium example. Extensions to three-sector analysis can be found in Anderson (1992a, b), and Haley and Dixit (1988), among others.

\subsubsection{Welfare Analysis of Gains from Trade}

Gains from trade are one of the most fundamental issues of international economics. Since being initially examined by Ricardo in the early nineteenth century, it has been widely recognized that a country almost always improves its overall welfare by engaging in international trade. For important contributions to the issue see Samuelson (1939, 1962). In general, gains from trade are considered to derive from two distinct sources (Markusen et al. 1995). The first source is gains from exchange which relate to the fact that countries differ from each other in endowments of goods or in preferences and they can mutually benefit from trading with each other. The second source is gains from specialization that refer to the fact that countries can raise their total production and gain from this production increase by specializing in the goods in which they have a comparative advantage.

While in most cases countries can gain from international trade, welfare analysis reveals that not all agents within countries will necessarily benefit from trade; in fact, some sectors may suffer a welfare loss (Dixit and Norman 1980, and Jones 1956). That is, the distribution effect of trade on welfare can be very uneven. For example, trade makes worse off the owners of resources that are specific to the production of goods that 
compete with imports (Krugman and Obstfeld 1997). Welfare analysis of the distribution effect of trade has long been a subject of international trade research.

\subsubsection{Welfare Analysis of Environmental Policy}

Economic welfare analysis of environmental policy serves at least two purposes. In the first place, welfare analysis can provide useful guidance for environmental policy design. Usually, maximizing social welfare and influencing its distribution are considered appropriate objectives of environmental policies, e.g., see Baumol and Oates (1988) and Hennipman (1995). On the other hand, welfare analysis of environmental policy is often used in policy comparison and selection. Cost-benefit analysis is a widely employed tool for this purpose, but it has to be accompanied by measures of externalities, e.g. see Thomas (1983) and Torries (1998). Since environmental policy is closely related to the correction of market distortion induced by externalities, willingness to pay hence turns out to be an important concept in the measurement of welfare costs and welfare benefits (Freeman 1993 and Field 1994). For other applications of welfare analysis of environmental policy, see discussions in Section 3.5.1 and 3.5.4.

\subsubsection{Welfare Model Applications}

In section 3.5.2, it was mentioned that in most cases countries gain from trade. A key assumption in this regard is that the production possibility set must be convex in order to guarantee that production is maximized at world trade prices (Markusen et al. 1995). However, as long as environmental pollution is concerned, this assumption can be inappropriate since non-convexity may exist in the production possibility set when there 
are cross-sectoral production externalities (Baumol and Bradford 1972). Intuitively, if a country exports a pollution-intensive good, the environmental quality of that country is likely to deteriorate. The social welfare loss induced by environmental deterioration will reduce, and perhaps even outweigh the conventional gains from trade.

The welfare analysis of gains from trade when taking into account environmental degradation and the impact of environmental policy has been a focus of several studies. Adding an environmental variable to the social welfare function and using a comparative static approach, Siebert (1977) and Siebert et al. (1980) examine the gains from trade when no environmental regulations exist. They conclude that if a country exports relatively less pollution-intensive goods, the improvement in environmental quality will lead to welfare gains from trade that are higher than the traditional measure in which environmental quality is excluded. In contrast, if a country exports a pollution-intensive good, welfare gains from trade are lower than the traditional measure and may even be negative due to the welfare loss resulting from environmental degradation. Using partial equilibrium and comparative-static analysis, Anderson (1992a) investigates the same case in a small-country setting and arrives at the same conclusion. Further, Anderson (1992a) places the problem in a large-country setting: namely, a country that is now large enough to influence world market prices and production abroad. The author shows that if the large country imports a polluting good, welfare gains from trade are unambiguous but smaller than can be achieved in a small country because of a rise in the import price (the terms-of-trade effect). If the large country exports the polluting good, welfare gains from trade are ambiguous because two opposite effects are interwined: a negative welfare 
effect of the export price decrease and increased domestic pollution and a positive welfare effect of decreased transboundary pollution from foreign production.

Now consider the presence of environmental regulations. Siebert (1977) and Siebert et al. (1980) demonstrate that, in a small-country case, if a country exports a production polluting good, welfare gains from trade increase with the introduction of environmental regulations if in the initial situation the marginal social costs of the polluting good production are higher than the export price. This welfare improvement comes from two possible sources: a positive effect of prevented environmental damage and an improvement in the terms of trade. Anderson (1992a) also shows that there are unambiguous welfare gains from trade in the same case provided an optimal environmental policy is adopted. In addition, Anderson extends the analysis to trade in a good whose consumption is polluting. With the introduction of an optimal environmental policy, welfare gains from trade increase no matter whether the country is an exporter or an importer of the consumption-pollutive good. In the large-country case, so long as the optimal environmental policy is in place, welfare gains from trade will always be positive.

In a separate paper, Anderson (1992b) investigates the impact of liberalizing international trade in coal and food on the environment and welfare with a partialequilibrium-welfare-analysis framework. In the coal-trade-liberalizing case, the world coal market consists of three groups of countries: (1) the protected industrial market economies where the coal producer price is subsidized to be above the coal consumer price which, due to import restrictions, is above the international price, (2) the reforming centrally planned economies where the coal price is set well below international levels, 
and (3) other market economies where the average domestic coal price level is assumed to be equal to that in the world market. In the case of liberalizing food trade, similar to the previous case, the world market is assumed to be made up of three country groups: (1) a group of almost autarkic centrally planned economies, (2) a set of rich countries whose agricultural market is protected by their governments, and (3) the rest of the world where the price of agricultural products is relatively lower than other tradeables. By means of diagrammatic partial equilibrium welfare analysis, Anderson shows that with appropriate environmental policies, in both cases, liberalizing international trade is beneficial to the environment and to overall welfare.

\subsection{Game-theoretic Models}

\subsubsection{Cooperative Game Theoretic Models}

Game theory and game theoretic models have been applied to the study of various trade and environment issues; for overviews, see Ulph (1994) and Blackhurst and Subraminian (1992); for recent examples, see Ulph (1996), Ulph and Valentini (1997), Barrett (1997), Abrego et al. (1997), and Alemdar and Ozyildirim (1998). Multilateral negotiation and cooperation play an important role in the formation of efficient domestic trade and environmental policies as well as international agreements on trade and environmental issues. The 1997 Kyoto agreement is a good example of such negotiation and cooperation. Cooperative game models, which can provide useful theoretical support for those negotiation processes, distinguish themselves from noncooperative game theoretic models in assuming that binding agreements are indeed possible (Friedman 1986). They also assume that each agent has a clear idea about the outcome that 
cooperation will bring to them. Other features shared are the existence of leadship and reliance on side-payments and side-sanctions. Moreover, leaders are willing to take cooperative action to maximize their joint net benefit, and hence cooperative equilibrium solutions of the models are sometimes heralded as fair outcomes or Pareto optimal outcomes. It is not surprising that many studies conclude that cooperative outcomes are more efficient than noncooperative ones, e.g. Dockner and Long (1993), Barrett (1997), and Alemdar and Ozyildirim (1998), among others.

Specifications of cooperative game theory models as applied to trade and environmental issues differ in many respects. For example, Dockner and Long (1993) analyze international pollution control strategies with a dynamic two-player game. The players are the governments of two neighboring countries. A dynamic framework helps attenuate the free-rider problem and the prisoners' dilemma type of situation because the punishment of any observed noncooperative behavior can be reflected in this intertemporal dimension. The cooperative game is modeled with a joint welfare maximizing presentation. Quite naturally, Pontryagin's maximum principle can be employed to obtain a solution. Barrett (1997) develops a two-stage, multi-player game to examine the capability of trade measures in the enforcement of international environmental agreements. The players include $\mathrm{N}$ symmetric countries (governments) and $\mathrm{N}$ symmetric firms (one firm per country). In the first stage, governments set abatement standards which the firms must comply with. In the second stage, firms simultaneously choose their segmented outputs in response. Here international cooperation can be incorporated in the first stage; the abatement standards in each country are chosen so as to maximize the $\mathrm{N}$ countries' joint benefits. Alemdar and 
Ozyildirim (1998) compose a dynamic two-player North-South trade game model to investigate the positive impact of the North-South trade on the Southern environment and its policy implications due to the presence of transboundary knowledge spillovers brought about through trade. North and South are the two players and the joint potential gains from cooperation are characterized with a weighted sum of the two players' lifetime utilities. Weights are regarded as the distributive parameter of the cooperation benefits and their values can be bargained between the two players in the process of negotiation and finalized in a cooperative agreement. The study also features a generalpurpose genetic algorithm to solve an open-loop differential game of infinite duration. The optimal regional trade policies are obtained from the numerical solution.

\subsubsection{Non-cooperative Game Theoretic Models}

Putting the trade and environment issues within a game setting, players often behave non-cooperatively in order to maximize their individual benefits. For instance, in the absence of supra-national authority to enforce the cooperative solution, multilateral cooperation in international trade and global environmental issues is likely to be sabotaged by free-riding and the Prisoners' Dilemma problem (Barrett 1994a,b and Carraro and Siniscalao 1993). Sometimes, differences in agents' ultimate self-interests can be a source of non-cooperation. Governmental policies are aimed to enhance the social welfare while firms' strategies usually pursue profit maximization. In addition, there are also cases in which players are unable to make legally binding agreements with one another (for example, antitrust provisions prevent firms from colluding). For these and other reasons, non-cooperative game theoretic models have been the more popular in 
the application to trade and environmental issues. For overviews, see Ulph (1994) and Kreps (1990); and for particular studies, see Hoel (1991), Martin et al. (1993), Dockner and Long (1993), Ulph (1996), Ulph and Valentini (1997), Barrett (1994b, 1997), Abreg et al. (1997), and Alemdar and Ozyildirim (1998).

There are various formations of non-cooperative game theoretic models (see the corresponding discussion in cooperative game theoretic models since each of those studies includes, by contrast, a same structural non-cooperative game). The prisoners' dilemma is the most fundamental presentation (Snidal 1985), while Nash equilibrium is the most important criterion of strategies (Myerson 1999 and Mailath 1998). That is, in non-cooperative game theoretic models, each player is maximizing his own private benefit given the supposed actions of the others, and a solution is obtained only when a Pareto optimal strategy exists (i.e., no player has an incentive to deviate from the solution) (Kreps 1990).

In addition to the above applications, non-cooperative game theoretic models have also been used in many other trade and environment issue related analyses. For example, Hauptmann (1982) applies a two-player nonzero-sum non-cooperative dynamic game to the oil embargo problem between OPEC and the oil importing countries; Martin and his co-authors (1993) investigate the implication of different environmental policy options in a transboundary pollution setting with an N-asymmetric-player, nonzero-sum dynamic game model; Ulph (1996) uses a three-stage game model to analyze the relationship between environmental policy and international trade when governments and the producers act non-cooperatively; and Ulph and Valentini (1997) examine the effect of environmental policy on plant location based on a three-stage non-cooperative model 
with two countries, two industries (one upstream and one downstream), and two firms in each industry. Since various kinds of players such as international organizations, countries, governments and firms are involved, the best strategies for different players derived from those studies can provide useful insights for policy design at different levels.

\subsection{Optimization Models}

\subsubsection{The Search for Optimal Trade and Environmental Policies}

Although the relationship between trade and the environment is not uniquely defined, e.g., see Daly (1993a, 1993b), and Bhagwati (1993a, 1993b), there is a wide consensus that "on the most fundamental level, trade and environmental policy must meet in the concept of sustainable development. Both trade policy and environmental policy must serve that concept as their ultimate goal" (EPA Trade and Environment Committee 1991). Trade policy helps enhance world economic welfare on the one hand while environmental policy aims to manage and maintain natural resources efficiently on the other; together they constitute the most important aspects of sustainable development. How should trade and environmental policies be combined to achieve the goal of sustainable development? In other words, within a sustainable development setting, what are optimal trade and environmental policies? Quite naturally, optimization models can provide a solution to resolving such issues. Potential models must share at least two key features. First, the concept of sustainable development must be concretely or mathematically expressed rather than vaguely stated. Second, the spatio-temporal nature of the trade and environment issue must be captured. 


\subsubsection{Lack of Applications}

Since the fundamental problem in economics is how to make the best use of limited resources, optimization methods are among the most important tools in economic analysis. Indeed, various different kind of optimization models have been used in a wide range of economic research fields, e.g., for overviews, see Wilson et al. (1981), Feichtinger (1982), Mills (1984), and Schellnhuber and Wenzel (1988). Optimization models can be generally divided into calculus optimization models, programming models, optimal control theory models, and differential game theoretic models. Luptacik and Schubert (1982) build an optimization model for optimal environmental investment decisions. The focus of their study is on how to allocate output between consumption and investment in productive capacity and pollution abatement so as to maximize social welfare. The concept of sustainable development and the implication of trade in a growing economy are untouched. In Schellnhuber and Wenzel (1998), optimization models are created to analyze the co-evolution of human civilization (the anthroposphere) and its ecological support system (the ecosphere), in particular the analysis of global change, sustainable development (defined as co-evolution of the anthroposphere and the ecosphere in the long run), and international equity and governance. However, the role of trade and environmental policies is not discussed. Due to the complexity of the problem, no optimization models aiming to search for optimal trade and environmental policies have been built thus far. 


\subsection{Spatial Analysis and GIS Models}

\subsubsection{Spatial Analysis}

The spatial nature of economic activities and variables was first examined in the early 1950s and spatial equilibrium analysis gained attention of the ecomonic literature of that time (Enke 1951 and Samuelson 1952). Since the 1960s, spatial analysis in economics has greatly expanded its range of study, varying from spatial equilibrium models for trade, transportation and labor markets, to various kinds of more general models for environmental, energy, and geographical and regional economic analyses, e.g., see Labys et al. (1989), Labys and Yang (1991), van den Bergh et al. (1996), Nijkamp (1986), and Bockstael (1996).

Spatial equilibrium and price models (SPE) have evolved from the basic neoclassical model and most of them have a programming presentation. Samuelson (1952) was the first to give the SPE a linear programming specification. Takayama and Judge (1964) and Takayama and Woodland (1970) further extended this approach to include simultaneous price determination in a temporal as well as spatial framework (STPE). In these models, markets and transportation are spatially separated from an equilibrium perspective and therefore spatial quantities equilibrate only when demand prices equal the sum of supply costs and transportation costs. Given transportation cost, and domestic demand and supply functions in spatial markets, a spatial equilibrium consists of the market-clearing prices in all spatial markets, demands and supplies of all locations, and all exports and imports. For SPE applications see Labys et al. (1989) and van den Bergh et al. (1996). 
Spatial models also serve as a useful framework for environment-energyeconomy analysis. They are usually an integration of models of the environmental system, energy system and national or regional economy. These models, in general, consist of the following common components: a macroeconomic model; production and consumption functions; equations revealing the relationships between the energy sector, the rest of the economy and environmental quality; a reference energy supply system describing energy demand as well as energy production and consumption technologies; and a setup reflecting spatially separated regions, e.g. see Lakahmanan and Bolton (1986).

\subsubsection{GIS Model Theory}

Since the 1980s, geographic information systems (GIS) have found wide applications in resource management and environmental modeling, i.e., for historical reviews, see Goodchild et al. (1993) and Maguire et al. (1991); for more recent work, see Fischer et al. (1996), Hallam et al. (1996), and Goodchild et al. (1996).

Model applications in this area comprise two categories. The first or major category can be considered coupling models that link conventional environmental models to a GIS model, where GIS is used as a preprocessing and postprocessing tool, e.g., see Darwin et al. (1995), Neganban et al. (1996), Lee and Pielke (1996), and Chomitz et al. (1999). The second category, which is still developing and not yet broadly recognized, uses GIS as the principal tool or language for more sophisticated spatial and temporal environmental modeling. For an introductory review see Maidment (1996); examples are provided in Frysinger et al. (1996), and Keller and Strapp (1996). 
Models of the first category seem to be not only much more realistic but also more successful. The advantage of these models is obvious; they utilize the power of environmental and spatial modeling software to model environmental processes and other spatial-natured problems; and they use the power of GIS to fulfill input, output, and other data representation and management tasks such as data sampling and data transformation. A shortcoming of the models is the absence of common data models, structures, and interfaces. Model builders thus frequently have to write programs to create workable linkages. Models of the second category, which attempt to incorporate environmental modeling and spatial analysis techniques fully within a GIS setting, rest in an early, experimental stage.

\subsubsection{GIS Model Applications}

Since the beginning of the 1990s, spatial GIS models have found some applications in describing the relationships between the environment and agricultural production, e.g., see Carter et al. (1991), Eswaran and Van den Berg (1992), Leemans and Solomon (1993), and Darwin et al. (1995). The focus of those studies is mainly on the direct effects of climate change on crop production. Carter et al. (1991) examined with a GIS the shifts in production of grain maize, sunflower, and soybeans in Europe. Eswaran and Van den Berg (1992) used a GIS derived index of agricultural production based on growing season lengths to investigate the impact of climate change on grain production and grazing in India, Pakistan, and Afghanistan. With similar methodology, Leemans and Solomon (1993) extended their study to match crop production with global climate conditions. Darwin et al. (1995) distinguished their research from those the above 
by combining a GIS with a CGE economic model. The research divided the world into eight geographical regions and used the GIS to link climate with production possibilities of agricultural products in the eight regions. The CGE model was used to determine the effects of changes in production possibilities on production, trade, and consumption of thirteen major agricultural and non-agricultural commodities.

More recently, Chomitz et al. (1999) employed a GIS-based spatial price equilibrium model to study the impact of trade and tax policies on deforestation in the Sahel. Specifically, based on GIS data, spatially disaggregate woodfuel supply was modeled at each one-square-kilometer-gridded landscape cell, which had an associated transport cost for supplying the market. GIS methods were used to compute the economically shortest path to the market, allowing for relative differences in travel cost on and off roads. Market equilibrium was determined annually through aggregate demand and supply equations. A simultaneous equation solution was written in GAUSS to integrate supply, demand, regrowth, and accounting procedures and use a grid search to solve for the market-clearing woodfuel prices.

There are also applications of non-GIS-based spatial analysis to trade issues and to environmental policy issues, e.g., see Van den Bergh et al. (1996). Applications of GIS to environmental modeling, resource management, and sustainable development planning include Goodchild et al. (1993, 1996), Hallam et al. (1996), Despotakis (1991), and Despotakis et al. (1993). 


\subsection{Econometric Time Series Models}

\subsubsection{Trade and Environment Linkages over Time}

The interaction between trade and the environment is not an instant process, particularly since the quality of resources deteriorates overtime. This deterioration is recoverable for non-depletable resources but otherwise exhaustion takes place. International trade also is intertwined with the intertemporal processes of economic growth and development. Both development and trade have led to unprecedented natural resource extraction and environmental pollution. For instance, in the past 200 years, the use of land, water, minerals and other natural resources has increased more than ten times (Rotmans 1998). However, the detrimental effects of economic growth, especially of international trade, are usually not immediately appreciated because of environmental assimilative capacity, i.e. see Park and Labys (1999). It is often the case that only after these effects become apparent that public concern leads to the enactment of environmental regulations. Econometric time-series models have been successfully used to investigate the relationship between $\mathrm{CO}_{2}$ emissions and the use of fossil fuels and to analyze the temporal decomposition and cyclicality of global $\mathrm{CO}_{2}$ concentrations and emissions, e.g., see Nordhaus and Yohe (1983), and Cohen et al. (2001), repectively. No doubt, econometric methods based on data recorded periodically or over time can also provide a useful tool to analyze temporal relationships between trade and the environment. 


\subsubsection{Potential Model Applications}

Econometric time series models have a long tradition in analyzing temporal interactions, e.g., for modeling possibilities, see Mills (1990), Granger and Terasvirta (1994), and Harvey (1994), among others. The basic or univariate models attempt to explain the behavior of an economic variable based only on its temporal history. Typically, models of this kind include autoregressive-moving average (ARMA), autoregressive-integrated-moving average (ARIMA) processes, and autoregressive conditional heteroscedastic $(\mathrm{ARCH})$ models. In multivariate models the joint behavior of two or more variables is explained. These models can capture the interactions, which are considered a distinguishing feature, among economic time series. Commonly used multivariate models are causal models, cointegration models, vector autoregressive (VAR) models, bivariate ARCH, and dynamic simultaneous equation models. Nonlinear time series models refer to models which have a nonlinear presentation (for example, exponential autoregressive models), or in which the conditional variance of the process under analysis is allowed to vary over time (for instance, autoregressive conditional heteroskedastic or ARCH models). These models can be used to describe the non-linear feature of economic time series. Curiously, although time series data provide bases for empirical trade and environmental studies, there are no specific time series applications, e.g., see Robison (1988). However, such applications are not difficult to conceive. For example, with time series data, one can test whether trade causes environmental degradation or not. Or one can also examine the effects of growth cycles on trade and environmental interactions. 


\subsection{Conclusions}

The objective of this chapter has been to provide ovderview of various methodological approaches to modeling the multi-dimensional interactions between trade and the environment. The implications this overview has for research and model building are quite clear. Each approach has proven useful but it can generate only a limited and partial insight into those issues due to restrictive assumptions or analytical complexities. One implication is a need for both more general theoretical models and their quantitative implementation. For example, major approaches to the problem such as CGE models, GIS methods and econometric methods have been applied less often than one would expect and hence need further attention. Moreover, the spatial nature of environmental and trade problems should be addressed more adequately and greater attention should be paid to spatial data needs. 


\section{Chapter 4}

\section{MODELING TRADE AND THE ENVIRONMENT}

\subsection{Introduction}

Empirical attempts to model trade and environment relationships have pursued impact measurement rather obliquely, as reflected in Chapters 2 and 3. One view examines the impact of environmental regulation and pollution abatement costs on international trade flows. Examples include Tobey (1990), Grossman and Krueger (1993), Jaffe et al. (1995) and Antweiler (1996). The other view highlights how international trade, including a country's openness, may affect economic growth and the environment. Examples are Grossman and Krueger (1993, 1995), Shafik (1994), Seldon and Song (1994), Gale and Mendez (1996), Antweiler, et al. (1998), and Dean (1999). Overall, the results from these studies show little evidence that freer trade would bring about significant changes in environmental quality. Also, there is little evidence that differences in the strictness of environmental policy represent a significant determinant of trade patterns and flows. In addition, the inverted-U shaped environment-income relationship (the environmental Kuznets curve) is still in dispute and the role that trade plays in this relationship is far from clear (Asafu-Adjaye 1999 and Suri and Chapman 1998).

The ambiguousness among these empirical results can be ascribed to at least two major methodological pitfalls. First, most studies have tended to analyze cross-country or panel data typically for a sample of both developing and developed countries. Since different countries may have comparative advantage in the production of different goods, 
the environmental effect of trade may differ from one country to another, not only in magnitude but also in sign. In a cross-country setting, positive and negative effects would probably cancel each other. Therefore, it is not surprising that cross-country studies often conclude that trade has no significant impact on the environment.

The same criticism is also true in analyzing trade effects of environmental policy since the mixed effects that environmental policies have on trade may tend to weaken the statistical investigation of this effect. What's more, the environmental Kuznets curve that emerges in cross-section analysis can be a spurious one, because it may simply reflect the juxtaposition of a positive relationship between pollution and income in developing countries, compared to a fundamentally different one in developed countries (Vincent 1997). A single-country approach, therefore, has been suggested in several recent studies (Vincent 1997, Carson et al. 1997, and Dean 1999).

Secondly, most studies, both cross- and single-country, are based on single equation models. These models enable economists to estimate the impact of trade and income on quality of the environment or vice versa. However, they reveal only a onedirectional relationship among trade, income and the environment, i.e., either how trade or income affects environmental quality or how environmental policies influence trade flows and income. In reality, trade, income and the environment are interrelated and interact with each other. For instance, the environment is a major factor of production in many developing countries that heavily rely on natural resources as a source of output. Environmental degradation in these countries could well reduce their capacity to produce and hence to export and to grow. 
According to Grossman and Kruger (1993), Antweiler, et al. (1998), and Dean (1999), an empirical investigation of these various interactions should be able to decompose the change in emissions in three ways: a scale effect, a composition effect, and a technique effect. A scale effect occurs when the scale of economic activity expands. If the nature of that activity is unchanged but the scale is growing, then more pollution will be generated alone with output. A composition effect occurs when national output composition is altered. If the share of pollution-intensive goods in output increases, then this change in output composition will exacerbate existing environmental problems. A technique effect arises from increases in income that call for cleaner production methods. In addition, a technique effect may also exist as a result of increases in income if newly affluent individuals would demand a leaner environment.

Empirical investigation should be able to isolate the effects of trade on the environment among these three effects. It should also be able to identify how emissions and environmental policies have affected trade flows through their impacts on economic scale and composition. As far as these interactions appear to be endogenously interrelated, a simultaneous equations model can better capture the interrelationships between trade, growth, and the environment. So far only Dean (1999) has attempted to model the relationship between trade and the environment with a simultaneous system. The system consists of four equations:

$$
\begin{aligned}
& Y=A(t) h(L, K, E) \\
& E=f(r, Y, S) \\
& r=g(E, Y) \\
& S=z(t, Y)
\end{aligned}
$$


The first equation shows total output (real income, Y) as a function of the level of trade restrictions ( $\mathrm{t}$ ), the stock of conventional factors of production $(\mathrm{L}, \mathrm{K})$ and the level of emissions (E). Increased openness is assumed to lead to higher total factor productivity $\left(A^{\prime}<0\right)$. Since emissions are treated as an input, the total output $\mathrm{Y}$ is positively related to the equilibrium level of emissions $\mathrm{E}$ at any point of time. The second equation shows that demand for $\mathrm{E}$ is a function of the emissions charge (r), $\mathrm{Y}$, and the share of pollutionintensive goods in total output (S). The third equation is the inverse supple curve for E which is derived from the individuals' utility function. The second and third equations simultaneously determine the equilibrium level of emissions and the equilibrium emissions charge. The fourth equation describes that the composition of output, $\mathrm{S}$, is a function of real income and the restrictiveness of the trade regime $(t)$.

For a country with a comparative advantage in pollution intensive goods, an increase in trade restrictiveness moves resources toward production of relatively cleaner goods and hence leads to a lowered share of pollution-intensive goods in total output. Clearly, this system provides a useful framework for the investigation how trade liberalization can affect the environment in different ways. Since the trade variable is exogenous, the relationship between trade and the environment modeled in the system is one-directional, and the impact of environmental policies on trade is neglected.

Given the potential of the simultaneous interaction approach, this chapter applies this model to the particular case of China's development. This development perspective is interesting for a number of reasons. Since the inception of economic reform in 1978, China has achieved remarkable economic progress at a highly sustained growth rate. Promotion of trade and attraction of foreign direct investment (FDI) have been central to 
the country's efforts to modernize its economy. The contribution of foreign trade to China's economy has also grown at an extraordinary pace. Since 1997, China has become one of the top ten exporters in the world, and since 1993, the largest recipient of foreign direct investment after the United States. While export-led economic growth has brought many benefits to China, the environment has suffered. "Moreover, the large scale and rapid growth of China's economy have exposed a growing population to serious air and water pollution" (World Bank 1997).

Unfortunately, though some interesting attempts have been made to analyze this problem (Dean 1999, and Wu 2000), the environmental implications of the surge in foreign trade and investment are complex, very largely contested, and not fully illuminated by existing empirical data and analysis. At the same time, China's environmental protection agencies, aware of its pollution problems, have responded by enforcing regulatory standards for waste water and air pollutant discharges. It is worth noting that an extensive water and air pollution levy system has been in place in China since 1983 (Wang and Wheeler 1996). How the enforcement of environmental policy in China affects its trade and foreign direct investment is also an interesting topic of research and, to the best of my knowledge, has received no empirical investigation.

The remainder of the chapter is organized as follows. Section 2 presents a theoretical framework suitable for analyzing the relationship between these variables. Section 3 examines the model-implied causal effects between the trade and environmental variables. Section 4 details China's trade, foreign direct investment, and environmental status. Section 5 discusses model specification and Section 6 provides a summarization. 


\subsection{Model Theory and Equations}

The following model structure resembles Dean (1999), with the following enhancement: trade and foreign direct investment are included as endogenous variables. The endogenous treatment of trade highlights the trade effects of domestic environmental policy. Another significant improvement over the previous model is the introduction of foreign direct investment (FDI), an important determinant of trade in the China's case. What's more, the inclusion of FDI allows one to test whether differences in environmental regulations affect location. Instead of testing the "pollution haven" and "industrial flight" hypotheses due to data limitations, the present test evaluates whether more stringent environmental regulations have an economic impact on a region's absorption of FDI.

\subsubsection{The Production Function Including Emissions and Trade}

Physically, pollution is an unwanted by-product or output of production. From another perspective, however, the environment can be regarded as a factor of production because it is "used up" in the productive process. Also, pollution abatement requires the input of valuable production factors such as labor and capital, and higher permissible emissions hence can save the use of conventional production factors. It has been suggested that emissions, labor and capital can be substitutes in a sense. Therefore, it is not surprising that treating emissions as a production factor in addition to labor and capital has become the standard approach in the trade and environment literature (McGuire 1982, Merrifield 1988, Siebert 1992, and Dean 1999). 
Including trade in a production function seems to be difficult because it may be inappropriate to simply treat exports, imports or the total trade values as an output or as a productive factor. For example, in a trade balance situation, while part of production output is exported, the same amount of goods is usually imported, leaving total output level unchanged. According to Heckscher and Ohlin (1991), however, difference in the relative scarcity of production factors between regions implies an uneconomic pattern of production, and the tendency of trade to equalize factor prices reflects production efficiency. In one region, a scarce factor might be used in a very economical way, and every measure is taken to substitute other less scarce resources for it; while in another region it may be the opposite case that these substitute resources are more scarce and must be used sparingly. That is, what is available in abundance in one region and used accordingly is scarce in another region, and conversely. Trade tends to lessen, if not completely eliminate, factor scarcity among trading regions by encouraging regions to specialize in the production of goods that intensively use resources with relative abundance. A relatively equalized supply of production factors would obviously increase the efficiency of production, and according to Ohlin (Heckscher and Ohlin 1991, pp 104), "it is this that benefits the trading partners". Therefore, it is reasonable to model trade as a component leading to a shift in the production function, as trade flows increase with the input bundle held constant.

This suggests the following relationship between output, inputs, emissions, and trade:

$$
\mathrm{Y}=\mathrm{A}(\mathrm{T}) \mathrm{h}(\mathrm{L}, \mathrm{K}, \mathrm{E})
$$

where, $\mathrm{Y}=$ output;

$$
\mathrm{L}=\text { labor input; }
$$


$\mathrm{K}=$ capital input;

$\mathrm{E}=$ emissions released to the environment in the course of production;

$\mathrm{T}=$ trade, i.e. exports plus imports ;

Here $h_{L}>0, h_{K}>0$, and $h_{E}>0$ ( where the subscript refers to the derivative of the function with respect to $\mathrm{L}, \mathrm{K}$, and $\mathrm{E}$, respectively). In addition, assume $\mathrm{A}^{\prime}>0$, that is, the more an economy is engaged in trade, the higher the total factor productivity.

\subsubsection{Emissions Demand and Supply}

Factor theory suggests that emissions are released until their marginal product equals their price, which in the presence of a pollution levy system is the effective levy rate. However, it is difficult to directly measure this marginal product since emissions are a joint output rather than a direct input of production. Emissions are typically reduced through abatement activities. The opportunity costs of a reduced level of emissions thus consist of the resources forgone in production. This implies that pollution abatement could result in a loss of output. Hence, from the polluter's perspective, the optimal level of emissions discharged will be the point at which the marginal cost of abatement and the levy rate are equal.

According to Dean (1999), the derived demand for emissions can be expressed as a function of the levy rate, $r$; output, $\mathrm{Y}$; and the share of pollution-intensive goods in output, S:

$$
E=f(r, Y, S)
$$

where, $f_{r}<0$ and $f_{S}>0\left(f_{r}, f_{Y}\right.$ and $f_{S}$ are derivatives of function $f$ with respect to $r, Y$, and $\mathrm{S}$ respectively). Assuming an inverted-U relationship exists between per capita emissions and per capita outputs as reported in studies by Seldon and Song (1994) and Shafik and 
Bandyopadhyay (1992), the relationship between emissions and output would also have an inverted-U shape (see Figure 4.1). We may then expect that $f_{Y}>0$, given a position on the left side of the inverted $\mathrm{U}$, and $\mathrm{f}_{\mathrm{Y}}<0$ on the right side of the inverted $\mathrm{U}$.

While emissions demand reflects the economics of cost-minimizing abatement by industry, emissions supply, which specifies the pollution price imposed by the community as damage increases, reflects marginal social damage (MSD). In practice, emissions supply can be an interplay of limited information, perceived self-interest and a different ability or willingness to enforce community standards (Wang and Wheeler 1996). In Dean (1999) the supply of emissions is interpreted as the community's willingness to tolerate environmental damage. Let utility be a positive function of goods and clean environment, $\mathrm{E}_{\mathrm{o}}$, then $\mathrm{E}=\overline{\mathrm{E}}-\mathrm{E}_{\mathrm{o}}$, where $\overline{\mathrm{E}}$ is the total stock of environment as a good. Analogous to modeling the labor/leisure tradeoff, Dean notes that utility maximization yields the community's demand for $\mathrm{E}_{o}$, and their willingness, therefore, to supply (tolerate) E. The inverse supply curve for E can be represented as

$$
\mathrm{r}=\mathrm{g}(\mathrm{E}, \mathrm{Y})
$$

The community will allow higher levels of emissions only if polluters pay a higher charge $\left(\mathrm{g}_{\mathrm{E}}>0\right)$. Assuming clean environment is a normal good and higher output, $\mathrm{Y}$, means higher income, an increase in output raises income and hence the demand for clean environment, and thus reduces the supply of emissions $\left(\mathrm{g}_{\mathrm{Y}}>0\right)$.

It should be pointed out that the effective levy rate and the level of emissions are simultaneously determined by the emissions demand and supply functions in each economy and at each time period. But the equilibrium emissions level (at the intersection 
of emissions demand and supply curves) may not be optimal because the emissions supply function may not fully reflect the marginal social damage of pollution discharges.

Following Dean (1999), the share of pollution intensive goods in total output can be simply written as:

$$
\mathrm{S}=\mathrm{Z}(\mathrm{T}, \mathrm{Y})
$$

Again, assume that an increase in output raises income and clean goods are relatively income elastic, then $\mathrm{S}$ will decrease as $\mathrm{Y}$ increases and $\mathrm{Z}_{\mathrm{Y}}<0$. For economies that possess a comparative advantage in pollution intensive goods, an increase in trade will lead to a rise in $\mathrm{S}$ and hence $\mathrm{Z}_{\mathrm{T}}>0$; while for economies with a comparative advantage in relative clean goods, one expects $\mathrm{Z}_{\mathrm{T}}<0$.

\subsubsection{Trade and Foreign Direct Investment (FDI)}

Trade may arise from a variety of causes. For example, trade can be caused by differences in technology and/or by differences in endowment between trading partners. Though they may not be ranked with factor endowments as a cause of trade, government policies such as trade policies and environment policies and regulations can also have a profound impact on trade (Markusen et al. 1995). In addition, FDI can be trade promoting rather than trade destroying (Kojima 1976 and Reuber 1973). Both Kojima and Reuber

argue that FDI is likely to occur when a country's comparative advantage in some product in eroded or when comparative disadvantage exists. FDI moves factors (technology, management skills, and movable capital) to foreign locations, where total production costs are lowest for any given product. Hence, FDI can generate exports and imports for the host country. 
Emissions intensity

(Emissions per capita)

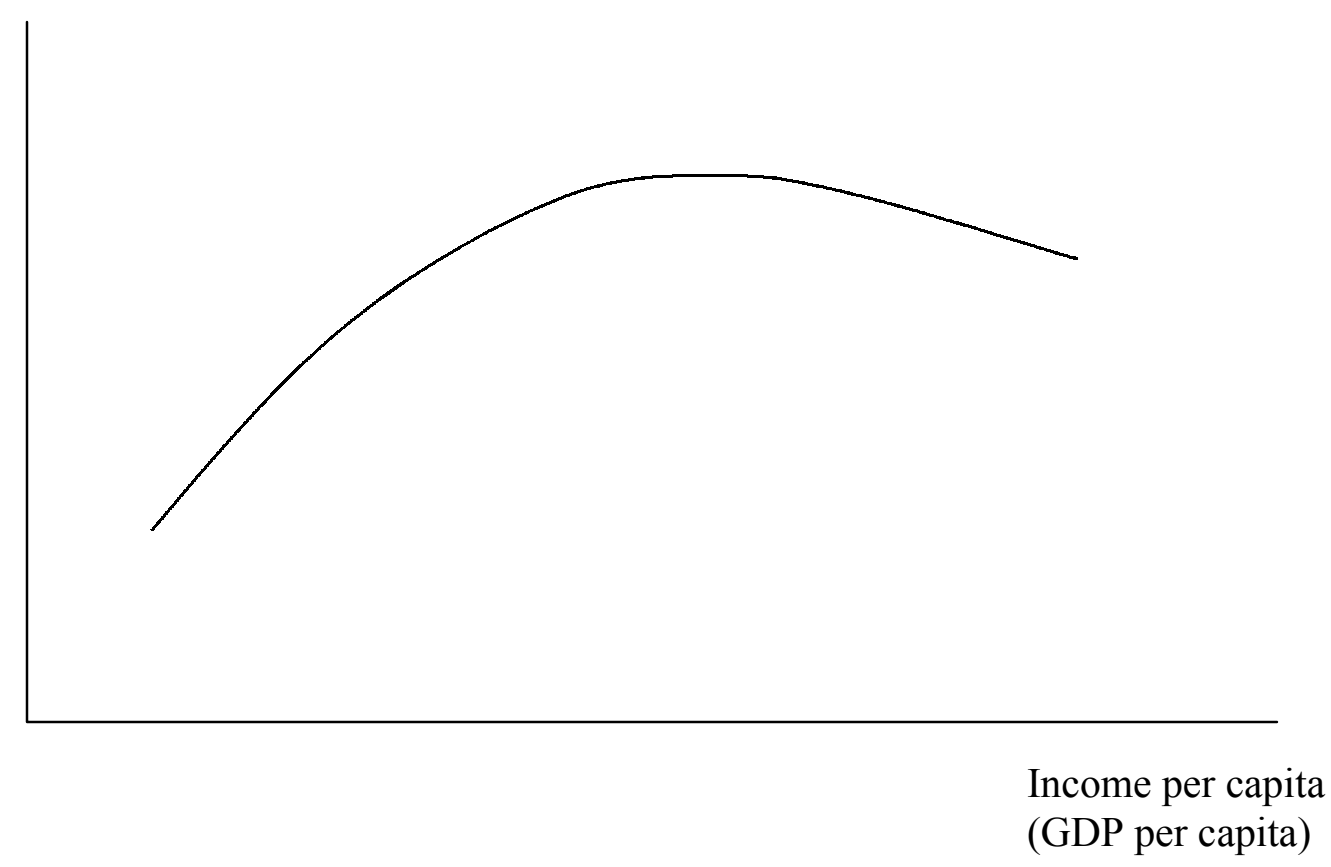

Figure 4.1 The Environmental Kuznets Curve 
In general, the size of an economy, the economy's proximity to its trading partners and the economy's trade regime are important determinants of its production and trade patterns (Leamer and Stern 1970, Markusen et al. 1995, and Frankel and Romer 1999). Trade flows (exports plus imports), T, thus reflect output, Y (the size of the economy), FDI, geographic remoteness, $\mathrm{R}$, and a trade policy indicator, $\mathrm{t}$ :

$$
\mathrm{T}=\mathrm{W}(\mathrm{Y}, \mathrm{FDI}, \mathrm{R}, \mathrm{t})
$$

where $\mathrm{W}_{\mathrm{Y}}>0, \mathrm{~W}_{\mathrm{FDI}}>0, \mathrm{~W}_{\mathrm{R}}<0$, and $\mathrm{W}_{\mathrm{t}}>0$ if a trade policy is designed to promote trade. Otherwise, $\mathrm{W}_{\mathrm{t}}<0$.

There are many explanations of FDI motives and patterns (see Leamer and Stern 1970 and Ni 1998 for an overview of the theory of international capital movements). From the Heckscher-Ohlin-Samuelson theory, decisions on the location of FDI's are predominantly made on the basis of traditional sources of comparative advantage such as relative wages, market sizes, and transportation costs (Vernon 1966, Aliber 1970, and Hirsch 1976). In addition, impediments to international trade such as tariffs and non-tariff barriers may also influence location (Clegg 1992). From a geographic perspective, agglomeration economies, that is, the advantages of co-locating different economic units, also play an important role in location (Wheeler and Mody 1992). The attractiveness of an area can be enhanced by factors such as the quality of infrastructure, the availability of specialized service supplies and of skilled labor, location related reputation effects, and the development of so-called industrial clusters (Porter 1990).

Once location advantages have been achieved, they tend to be self-reinforcing (Head and Ries 1996 and Ni 1998). An existing economic base of a region will increase its attractiveness to subsequent FDI. The empirical evidence available suggests that both 
conventional comparative advantage factors, market size and market growth (Kravis and Lipsey 1982, Culem 1988, Veugelers 1991,), and agglomeration factors such as infrastructure quality and the level of previous FDI (Wheeler and Mody 1992, Head and Ries 1996, and ZI 1998), are important determinants of a country's FDI inflows. Moreover, though a higher wage rate means higher production costs, some empirical studies also reveal a positive relationship between FDI and wage rates because higher wage rates are usually related to higher productivity (Kravis and Lipsey 1982, Erickson and Kuruvilla 1994, and Chen 1997). These various interactions can be represented as follows:

$$
\mathrm{FDI}=\mathrm{V}\left(\mathrm{Y}, \mathrm{CFDI}_{-1}, \mathrm{w}, \mathrm{I}, \mathrm{P}, \mathrm{r}\right)
$$

where, FDI and $\mathrm{CFDI}_{-1}=$ FDI inflows and cumulative FDI inflows in the previous year;

$\mathrm{Y}=$ output, a measure of market size;

$\mathrm{W}=$ wage rates;

$\mathrm{I}=$ infrastructure quality indicator;

$\mathrm{P}=$ policy indicators;

$\mathrm{r}=$ levy rate, which is separated from other policy indicators in order to test whether stricter environmental policies affect FDI inflows .

Typically, $\mathrm{V}_{\mathrm{Y}}>0, \mathrm{~V}_{\mathrm{FDI}-1}>0, \mathrm{~V}_{\mathrm{I}}>0, \mathrm{~V}_{\mathrm{P}}>0, \mathrm{~V}_{\mathrm{r}}<0$, and $\mathrm{V}_{\mathrm{w}}<>0$.

\subsection{Interactions between Trade and the Environment}

Equation (4-1) to (4-6) reveal how trade and environmental variables are interrelated. Their interpretation depends on totally differentiating equations (4-1) to (46):

$$
\begin{aligned}
& d \mathrm{Y}=\mathrm{hA}^{\prime} d \mathrm{~T}+\mathrm{Ah}_{1} d \mathrm{~L}+\mathrm{Ah}_{\mathrm{K}} d \mathrm{~K}+\mathrm{Ah}_{\mathrm{E}} d \mathrm{E} \\
& d \mathrm{E}=\mathrm{f}_{\mathrm{r}} d \mathrm{r}+\mathrm{f}_{\mathrm{Y}} d \mathrm{Y}+\mathrm{f}_{\mathrm{S}} d \mathrm{~S} \\
& d \mathrm{r}=\mathrm{g}_{\mathrm{E}} d \mathrm{E}+\mathrm{g}_{\mathrm{Y}} d \mathrm{Y}
\end{aligned}
$$




$$
\begin{aligned}
& d \mathrm{~S}=\mathrm{Z}_{\mathrm{T}} d \mathrm{~T}+\mathrm{Z}_{\mathrm{Y}} d \mathrm{Y} \\
& d \mathrm{~T}=\mathrm{W}_{\mathrm{Y}} d \mathrm{Y}+\mathrm{W}_{\mathrm{F}} d \mathrm{~F}+\mathrm{W}_{\mathrm{R}} d \mathrm{R}+\mathrm{W}_{\mathrm{T}} d \mathrm{~T} \\
& d \mathrm{FDI}=\mathrm{V}_{\mathrm{Y}} d \mathrm{Y}+\mathrm{V}_{\mathrm{r}} d \mathrm{r}+\mathrm{V}_{\mathrm{F}-1} d \mathrm{CF}_{-1}+\mathrm{V}_{\mathrm{I}} d \mathrm{I}+\mathrm{V}_{\mathrm{P}} d \mathrm{P}+\mathrm{V}_{\mathrm{w}} d \mathrm{~W}
\end{aligned}
$$

Diagrammatically, the implied mechanism of the system in (4-7) - (4-12) is shown in Figure 4.2.

Rearranging equations (4-7) - (4-12), the proposed trade and environment model (TEM) can be written in matrices notation form as follows:

$$
\left[\begin{array}{cccccc}
1 & -A h_{E} & 0 & 0 & -h A^{\prime} & 0 \\
-f_{Y} & 1 & -f_{r}-f_{S} & 0 & 0 \\
-g_{Y} & -g_{E} & 1 & 0 & 0 & 0 \\
-Z_{Y} & 0 & 0 & 1 & -Z_{T} & 0 \\
-W_{Y} & 0 & 0 & 0 & 1 & -W_{F} \\
-V_{Y} & 0 & -V_{r} & 0 & 0 & 1
\end{array}\right]\left[\begin{array}{c}
d Y \\
d E \\
d r \\
d S \\
d T \\
d F D I
\end{array}\right]=\left[\begin{array}{c}
A h_{L} d L+A h_{K} d K \\
0 \\
0 \\
0 \\
V_{C F-1} d C F_{-1}+V_{I} d I+V_{P} d P+V_{w} d w
\end{array}\right]
$$

The static causal effects among the variables relating trade and the environment that are relevant for policy purposes can be interpreted as follows: (1) how a change in trade policy or in trade values would affect the level of emissions and the emissions charge (effects of a trade policy on emissions and effects of a trade policy on emissions charges); and (2) how a change in an emissions charge or in emissions level would influence FDI inflows and trade flows (effects of an emissions charge on FDI and effects of an emissions charge on trade). These relationships involve not only effects between exogenous and endogenous variables, but also effects between endogenous variables that are simultaneously related. The latter are usually not dealt with in the existing literature. Appendix A shows that these effects can be solved either by flowgraph analysis or by conventional mathematics. 


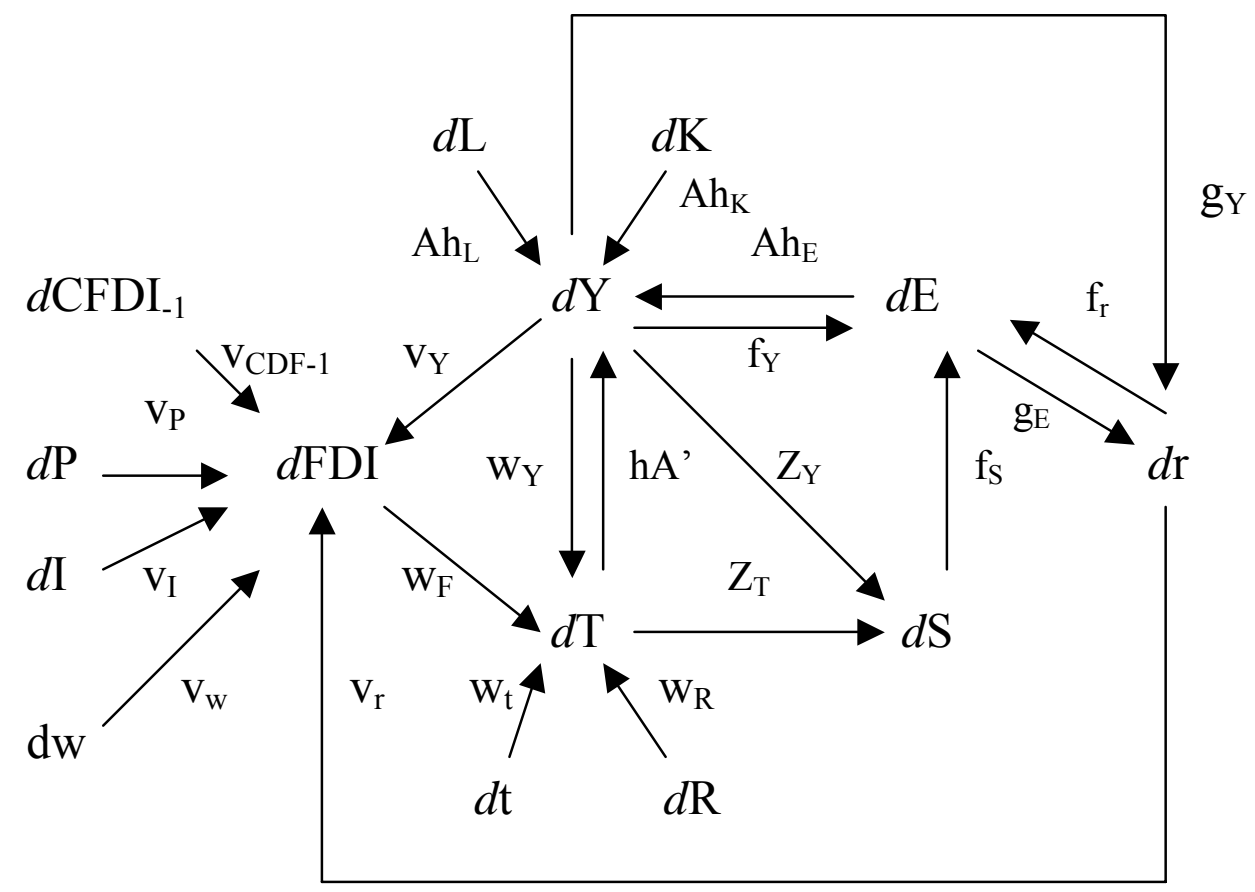

Figure 4.2 Interactions between Trade and the Environment 


\section{The effects of a trade policy on emissions}

Changes in emissions as suggested above would be given by

$$
\frac{d E}{d t}=|\Delta|^{-1} W_{t}\left[f_{S} Z_{T}+h A^{\prime}\left(f_{r} g_{Y}+f_{Y}+f_{S} Z_{Y}\right)\right]
$$

where $|\Delta|$ is the determinant of the system:

$$
|\Delta|=\left[\begin{array}{cccccc}
1 & -A h_{E} & 0 & 0 & -h A^{\prime} & 0 \\
-f_{Y} & 1 & -f_{r} & -f_{S} & 0 & 0 \\
-g_{Y} & -g_{E} & 1 & 0 & 0 & 0 \\
-Z_{Y} & 0 & 0 & 1 & -Z_{T} & 0 \\
-W_{Y} & 0 & 0 & 0 & 1 & -W_{F} \\
-V_{Y} & 0 & -V_{r} & 0 & 0 & 1
\end{array}\right]
$$

Assuming at present that a theoretically correct system should not change the sign of the direct impact of an exogenous variable on an endogenous variable, then $|\Delta|>0$.

The first term $f_{s} Z_{T}$ in the square brackets of (4-14) demonstrates the effect of a trade policy on the demand for emissions as an input due to a change in the composition of output. If an economy has a comparative advantage in pollution-intensive goods and its trade policy is designed to promote trade, then $Z_{T}>0$ and $f_{S} Z_{T}>0$. That is, increased trade could induce increased emissions. The second term in the square brackets captures the income effect of trade. The terms in parentheses reflect, respectively, the technique $\left(f_{r} g_{Y}\right)$, scale $\left(f_{Y}\right)$ and composition effects $\left(f_{s} Z_{Y}\right)$ of an increase in income caused by the trade promoting policy. If an economy is in a state of development where increased income growth reduces emissions, i.e., on the right side of an inverted $\mathrm{U}$, the sum of the term in parentheses would be negative. In addition, even if an economy is on the left side of an inverted $\mathrm{U}$, the sum in parentheses could still be negative, once the technique and composition effects outweigh the scale effect. Though an economy may have a 
comparative advantage in pollution-intensive goods, a trade-promoting policy can lead to lower emissions, if the income effect of trade prevails.

Similarly, the effects of trade flows on emissions would be given by

$$
\frac{d E}{d T}=|\Delta|^{-1}\left[f_{S} Z_{T}+h A^{\prime}\left(f_{r} g_{Y}+f_{Y}+f_{S} Z_{Y}\right)\right]
$$

\section{The effects of a trade policy on FDI}

Changes in foreign direct investment derive from

$$
\begin{aligned}
\frac{d F}{d t}= & |\Delta|^{-1} W_{t}\left[\mathrm{hA}^{\prime}\left(\mathrm{f}_{\mathrm{S}} \mathrm{g}_{\mathrm{E}} \mathrm{V}_{\mathrm{r}} \mathrm{Z}_{\mathrm{Y}}+\mathrm{f}_{\mathrm{S}} \mathrm{g}_{\mathrm{E}} \mathrm{V}_{\mathrm{r}}+\mathrm{V}_{\mathrm{Y}}+\mathrm{g}_{\mathrm{Y}} \mathrm{V}_{\mathrm{r}}-\mathrm{f}_{\mathrm{r}} \mathrm{g}_{\mathrm{E}} \mathrm{V}_{\mathrm{Y}}\right)\right. \\
& +\mathrm{Z}_{\mathrm{T}}\left(\mathrm{Ah}_{\mathrm{E}}\left(\mathrm{f}_{\mathrm{S}} \mathrm{V}_{\mathrm{Y}}+\mathrm{Ah}_{\mathrm{E}} \mathrm{f}_{\mathrm{S}} \mathrm{g}_{\mathrm{Y}} \mathrm{V}_{\mathrm{r}}+\mathrm{f}_{\mathrm{S}} \mathrm{g}_{\mathrm{E}} \mathrm{V}_{\mathrm{r}}\right)\right]
\end{aligned}
$$

The first term in the square brackets summarizes the effects of an increase in income on FDI due to the imposition of a given trade policy. The second term in brackets captures the trade-induced composition effects on FDI. Both the income and the composition effects are mixed in signs. If the impact of environmental policy on FDI is very small $\left(\mathrm{V}_{\mathrm{r}} \rightarrow 0\right)$, i.e., the strictness of environmental policies is not significant factor for foreign firms to choose places to invest, then the first term would be positive but the second term would only be positive as long as the economy has a comparative advantage in pollutionintensive goods. In this case, trade liberalization stimulates foreign investment. For an economy with a comparative advantage in environmentally safe goods (ESG), the second term could be negative due to the negative impact of a relatively reduced share of pollution-intensive goods on emissions and hence on economic scales. In the case that the trade-induced income effects dominate, trade promotion would lead to more FDI inflows. 


\section{The effects of a trade policy on emissions charges}

The emissions charge impact is defined by

$$
\frac{d r}{d t}=|\Delta|^{-1} W_{t}\left[Z_{\mathrm{T}}\left(\mathrm{f}_{\mathrm{S}} \mathrm{g}_{\mathrm{E}}+\mathrm{Ah}_{\mathrm{E}} \mathrm{f}_{\mathrm{S}} \mathrm{g}_{\mathrm{Y}}\right)+\mathrm{hA}^{\prime}\left(\mathrm{f}_{\mathrm{S}} \mathrm{g}_{\mathrm{E}} \mathrm{Z}_{\mathrm{Y}}+\mathrm{f}_{\mathrm{Y}} \mathrm{g}_{\mathrm{E}}+\mathrm{g}_{\mathrm{Y}}\right)\right]
$$

The first term in square brackets shows the effect of trade on the price of the environment due to the trade-induced change in output composition. With a comparative advantage in pollution-intensive goods, the emissions charge can be raised in two ways. On the demand side, increased trade implies an increased demand for environment and hence higher environmental prices (captured by $\mathrm{f}_{\mathrm{S}} \mathrm{g}_{\mathrm{E}}$ ). On the supply side, this increased demand for environment as an input would also imply a higher lever of output and income, which would lead to reduced supply of the environmental factor and hence to a higher emissions charge (captured by $\mathrm{Ah}_{\mathrm{E}} \mathrm{f}_{\mathrm{S}} \mathrm{g}_{\mathrm{Y}}$ ). On the other hand, with a comparative advantage in clean goods, increased trade would result in a decrease in demand for and an increase in supply of emissions; the first term would thus be negative and trade would lower emissions charges.

The second term in square brackets reveals the income effect of a trade policy on the emissions charge. Similar to the decomposition of effects that trade has on emissions, the components of the term can be interpreted as respectively the composition, scale, and technique effects of income, on emissions demand and supply. The composition effect of income, $f_{\mathrm{S}} \mathrm{g}_{\mathrm{E}} Z_{\mathrm{Y}}$, states that higher income reduces the demand for emissions provided that clean goods are relatively income elastic, leading to a lower emissions charge. The scale effect of income, $f_{Y} g_{E}$, would increase (decrease) the demand for emissions if an economy is on the left (right) side of the inverted $U$ and hence would cause the emissions charge to rise (decline). The technique effect of income, $g_{\mathrm{Y}}$, implying that a rise in 
income would enhance an economy's ability and willingness to pay a higher price for a cleaner environment and would thus reduce the supply of emissions and raise the emissions charge.

Generally, if an economy specializes in pollution-intensive goods and the technique affect of income dominates the overall effect of trade on the emissions charge would be positive, that is, trade could lead to stricter environmental policies and enforcement.

Similar to Equation (4-17), the emissions charge impact of trade flows can be defined by:

$$
\frac{d r}{d T}=|\Delta|^{-1}\left[Z_{T}\left(f_{S} g_{E}+A h_{E} f_{S} g_{Y}\right)+h A^{\prime}\left(f_{S} g_{E} Z_{Y}+f_{Y} g_{E}+g_{Y}\right)\right]
$$

\section{The effects of the emissions charge on FDI}

Another foreign direct investment effect can be measured by

$$
\frac{d F}{d r}=|\Delta|^{-1}\left\{\mathrm{~V}_{\mathrm{r}}\left[1-\mathrm{hA} \mathrm{A}^{\prime} \mathrm{W}_{\mathrm{Y}}-\mathrm{Ah}_{\mathrm{E}}\left(\mathrm{f}_{\mathrm{S}} \mathrm{W}_{\mathrm{Y}} \mathrm{Z}_{\mathrm{T}}+\mathrm{f}_{\mathrm{Y}}+\mathrm{f}_{\mathrm{S}} \mathrm{Z}_{\mathrm{Y}}\right)\right]+\mathrm{Ah}_{\mathrm{E}} \mathrm{f}_{\mathrm{r}} \mathrm{V}_{\mathrm{Y}}\right\}
$$

The first term in braces consists of both the positive and the negative effects of a change in the emissions charge on FDI. The negative effects include the direct impact (Vr) of the emissions charge, and the indirect impact $\left(\mathrm{Ah}_{\mathrm{E}} \mathrm{f}_{\mathrm{S}} \mathrm{Z}_{\mathrm{Y}}\right)$ of decreased economic scale caused by income-induced change in output composition. The positive effect comes from the increased output scale due to positive interactions between trade and output $\left(\mathrm{hA}^{\prime} \mathrm{W}_{\mathrm{Y}}\right)$. The other two components of this term could be either positive or negative. If an economy has a comparative advantage in pollution-intensive goods, the trade-induced increasing demand for environment as an input would raise the output and hence make 
the economy more attractive to FDIs (captured by $\mathrm{Ah}_{\mathrm{E}} \mathrm{f}_{\mathrm{S}} \mathrm{W}_{\mathrm{Y}} \mathrm{Z}_{\mathrm{T}}$ ). Otherwise this effect would be negative. When an economy is on the left (right) side of the inverted $U$, increased (decreased) output due to positive (negative) inter-influence between output and emissions (captured by $\mathrm{Ah}_{\mathrm{E}} \mathrm{f}_{\mathrm{Y}}$ ) could lead to more (less) FDIs. Finally, the last term in braces $\left(A h_{E} f_{r} V_{Y}\right)$ suggests that the negative impact of a strict environmental policy such as a higher emissions charge on output would lead to lower FDIs, and this effect would dominate as long as the direct effect $\mathrm{V}_{\mathrm{r}}$ approaches to zero.

\section{The effects of the emissions charge on trade}

Finally, trade impacts of an emissions charge can be measured by

$$
\frac{d T}{d r}=|\Delta|^{-1}\left[\mathrm{~V}_{\mathrm{r}} \mathrm{W}_{\mathrm{F}}\left(1-\mathrm{Ah}_{\mathrm{E}} \mathrm{f}_{\mathrm{Y}}-\mathrm{Ah}_{\mathrm{E}} \mathrm{f}_{\mathrm{S}} \mathrm{Z}_{\mathrm{Y}}\right)+\mathrm{Ah}_{\mathrm{E}}\left(\mathrm{f}_{\mathrm{r}} \mathrm{W}_{\mathrm{Y}}+\mathrm{f}_{\mathrm{r}} \mathrm{V}_{\mathrm{Y}} \mathrm{W}_{\mathrm{F}}\right)\right]
$$

Though the proposed model does not explicitly measure the impact of environmental policies on trade, equation (4-19) can evaluate all the indirect effects from an increase in the emissions charge to trade, most likely negative. The only likely source of a positive effect, $\mathrm{Ah}_{\mathrm{E}} \mathrm{f}_{\mathrm{Y}}$, is derived from the positive interaction between output and emissions when the economy is on the left side of the inverted U. In this case, the negative effect of an emissions charge on trade via FDI, $\mathrm{V}_{\mathrm{r}} \mathrm{W}_{\mathrm{F}}$, would be mitigated. Otherwise, just like the term $A h_{E} f_{S} Z_{Y}$ relating the composition effect of an increase in output, $A h_{E} f_{Y}$ would aggravate the negative effect of the emissions charge on trade. A plausible explanation could be that, given emissions as an important input, any reductions in emissions would first lower the output scale and then the trade volume, given the direct impact of output on trade. For similar reasons, the second term in square brackets is negative because an increase in an emissions charge would reduce the demand for environment as an input, 
leading to a lower level of output and hence reduced trade (captured by $\mathrm{Ah}_{\mathrm{E}} \mathrm{f}_{\mathrm{r}} \mathrm{W}_{\mathrm{Y}}$ ). In addition, lowered output would make the economy less appealing to FDIs, and reduced FDIs would result in reduced exports and imports (captured by $\mathrm{Ah}_{\mathrm{E}} \mathrm{f}_{\mathrm{r}} \mathrm{V}_{\mathrm{Y}} \mathrm{W}_{\mathrm{F}}$ ).

Conventional trade and environment theory suggests that environment policies would raise production costs, lower the competitiveness of the economy, and hence lead to reduced trade (Siebert et al. 1980, McGuire 1982, and Baumol and Oates 1988). Though production costs and price are excluded, the analytical results of the theoretical framework on the trade effects of environmental policies are consistent with the conventional view, but stem from a different perspective.

\subsection{Model Application}

\subsubsection{China as an Appropriate Case Study}

Since the post-1978 reform, China has experienced the longest and most rapid period of economic growth in its modern history. Over the past two decades, the average rate of GDP growth has been around 9 percent per annum and the economy has quadrupled in size. Equally impressive is the extent to which China has integrated into the world economy. Indeed, enhanced trade performance and increased trade flows and foreign direct investment (FDI) have been key to the high growth rate of the Chinese economy. Table 4.1 provides basic statistics and information of China's economic growth, trade volumes and FDI inflows over the past twenty years.

Over the same time period, there also has been a significant change in the composition of China's exports and imports. Before the reform process began, about 54 percent of China's exports were typically primary products such as crude petroleum and 
non-staple foods, while imports were strongly biased toward manufactured goods (Lardy 1992). By 1998, while imports were still dominated by manufactured goods ( 83.6 percent), the exports of manufactured goods increased significantly and accounted for 88.8 percent of total exports. Table 4.2 and 4.3 show the totals of China's exports and imports, respectively, by main commodity groups from 1980-1998. It is believed that China's accession to the World Trade Organization (WTO) in 2001 may significantly impact the country's economic and trade growth.

An important feature of China's trade has been the role of foreign direct investment. Evidence shows that by 1994, nearly 30 percent of China's exports were from foreign funded enterprises (Lardy 1995). Moreover, most of these exports consisted of products assembled from imported goods and accounted for nearly one-half of the values of manufactured exports.

\subsubsection{The Present Environmental Status and Regulations}

China's environmental problems have been aggravated by its rapidly developing economy (Wu 2000, and World Bank 1997). Rapid economic growth has instigated enormous volumes of air emissions, wastewater, and toxic hazards and resulted in widespread depletion of natural resources. These factors, in turn, have adversely affected human health, increased natural disasters, dampened gains from trade, and resulted in social instability and conflicts.

Water pollution is the first major environmental concern. Briefly, according to the 1996 annual governmental report (NEPA 1997), 78 percent of China's river sections cannot be used for drinking purpose and 50 percent of urban groundwater has been contaminated. Lakes, reservoirs, and coastal regions are polluted by various degrees. 
Table 4.1 Major Economic Indicators in China, 1980-1998

\begin{tabular}{|l|r|c|c|c|c|c|c|c|c|}
\hline Year & $\begin{array}{c}\text { Real } \\
\text { GDP } \\
\text { Growth } \\
(\%)\end{array}$ & $\begin{array}{c}\text { Popula- } \\
\text { tion } \\
\text { (M) }\end{array}$ & $\begin{array}{c}\text { Exchange } \\
\text { Rate } \\
(100 \text { US\$) }\end{array}$ & $\begin{array}{c}\text { Exports } \\
(100 \mathrm{M} \\
\text { US \$ })\end{array}$ & $\begin{array}{c}\text { Imports } \\
(100 \mathrm{M} \\
\text { US \$ })\end{array}$ & $\begin{array}{c}\text { Total } \\
\text { Trade } \\
(100 \mathrm{M} \\
\text { US } \$\end{array}$ & $\begin{array}{c}\text { Trade to } \\
\text { GDP } \\
\text { Ratio }\end{array}$ & $\begin{array}{c}\text { FDI } \\
(100 \mathrm{M} \\
\text { US \$) }\end{array}$ & $\begin{array}{c}\text { GDP } \\
\text { from } \\
\text { Industry } \\
(\%)\end{array}$ \\
\hline 1980 & 7.8 & 987.05 & - & 181.2 & 200.2 & 381.4 & 12.6 & - & 44.2 \\
1981 & 5.2 & 1000.72 & - & 220.1 & 220.2 & 440.3 & 15.1 & - & 42.1 \\
1982 & 9.1 & 1016.54 & - & 223.2 & 192.9 & 416.1 & 14.6 & - & 40.8 \\
1983 & 10.9 & 1030.08 & - & 222.3 & 213.9 & 436.2 & 14.5 & 6.36 & 40.0 \\
1984 & 15.2 & 1043.57 & - & 261.4 & 274.1 & 535.5 & 16.7 & 12.58 & 38.9 \\
1985 & 13.5 & 1058.51 & 293.67 & 273.5 & 422.5 & 696.0 & 23.1 & 16.61 & 38.5 \\
1986 & 8.8 & 1075.07 & 345.28 & 309.4 & 429.1 & 738.5 & 25.3 & 18.74 & 38.9 \\
1987 & 11.6 & 1093.00 & 372.21 & 394.4 & 432.1 & 826.5 & 25.8 & 23.14 & 38.3 \\
1988 & 11.3 & 1110.26 & 372.21 & 475.2 & 552.7 & 1027.9 & 25.6 & 31.94 & 38.7 \\
1989 & 4.1 & 1127.04 & 376.59 & 525.4 & 591.4 & 1116.8 & 24.6 & 33.92 & 38.3 \\
1990 & 3.8 & 1143.33 & 478.38 & 620.9 & 533.5 & 1154.4 & 30.0 & 34.87 & 37.0 \\
1991 & 9.2 & 1158.23 & 532.27 & 718.4 & 637.9 & 1356.3 & 33.4 & 43.66 & 37.4 \\
1992 & 14.2 & 1171.71 & 551.49 & 849.4 & 805.9 & 1655.3 & 34.2 & 110.07 & 38.6 \\
1993 & 13.5 & 1185.17 & 576.19 & 917.4 & 1039.6 & 1957.0 & 32.5 & 275.15 & 40.8 \\
1994 & 12.6 & 1198.50 & 861.87 & 1210.1 & 1156.1 & 2366.2 & 43.6 & 337.67 & 41.4 \\
1995 & 10.5 & 1211.21 & 835.07 & 1487.8 & 1320.8 & 2808.6 & 40.2 & 375.21 & 42.3 \\
1996 & 9.6 & 1223.89 & 831.42 & 1510.5 & 1388.3 & 2898.8 & 35.6 & 417.25 & 42.8 \\
1997 & 8.8 & 1236.26 & 828.98 & 1827.9 & 1423.7 & 3251.6 & 36.1 & 452.57 & 42.5 \\
1998 & 7.8 & 1248.10 & 827.91 & 1837.6 & 1401.7 & 3239.3 & 33.8 & 454.63 & 42.2 \\
\hline
\end{tabular}

Source: China Statistical Abstract 1999, Beijing: China Statistical Press. 
Table 4.2 China's total exports by main commodity categories, 1980-1998 (US\$ 100 million)

\begin{tabular}{|c|c|c|c|c|c|c|c|c|c|c|c|}
\hline \multirow[b]{2}{*}{ Year } & \multirow[b]{2}{*}{ Total } & \multicolumn{5}{|c|}{ Primary } & \multicolumn{5}{|c|}{ Manufactured } \\
\hline & & Total & $\begin{array}{l}\text { Primary } \\
\text { Share \% }\end{array}$ & $\begin{array}{l}\text { Food } \\
\text { and } \\
\text { Agri. }\end{array}$ & $\begin{array}{l}\text { Non- } \\
\text { Edible } \\
\text { Raws } \\
\end{array}$ & $\begin{array}{l}\text { Fuels } \\
\text { and } \\
\text { Ores }\end{array}$ & Total & $\begin{array}{l}\text { Manuf. } \\
\text { Share \% }\end{array}$ & $\begin{array}{l}\text { Che- } \\
\text { micals }\end{array}$ & $\begin{array}{l}\text { Mach. } \\
\text { and } \\
\text { Equip. }\end{array}$ & $\begin{array}{l}\text { Tex- } \\
\text { tiles }\end{array}$ \\
\hline 1980 & 181.19 & 91.14 & 50.30 & 29.85 & 17.11 & 42.80 & 90.05 & 49.70 & 11.20 & 8.43 & 39.99 \\
\hline 1981 & 220.07 & 102.48 & 46.57 & 29.24 & 19.48 & 52.28 & 117.59 & 53.43 & 13.42 & 10.87 & 47.06 \\
\hline 1982 & 223.21 & 100.50 & 45.02 & 29.08 & 16.53 & 53.14 & 122.71 & 54.98 & 11.96 & 12.63 & 43.02 \\
\hline 1983 & 222.26 & 96.20 & 43.28 & 28.53 & 18.92 & 46.66 & 126.06 & 56.72 & 12.51 & 12.21 & 43.65 \\
\hline 1984 & 261.39 & 119.34 & 45.66 & 32.32 & 24.21 & 60.27 & 142.05 & 54.34 & 13.64 & 14.93 & 50.54 \\
\hline 1985 & 273.50 & 138.28 & 50.56 & 38.03 & 26.53 & 71.32 & 135.22 & 49.44 & 13.58 & 7.72 & 44.93 \\
\hline 1986 & 309.42 & 112.72 & 36.43 & 44.48 & 29.08 & 36.83 & 196.70 & 63.57 & 17.33 & 10.94 & 58.86 \\
\hline 1987 & 394.37 & 132.31 & 33.55 & 47.81 & 36.50 & 45.44 & 262.06 & 66.45 & 22.35 & 17.41 & 85.70 \\
\hline 1988 & 475.16 & 144.06 & 30.32 & 58.90 & 42.57 & 39.50 & 331.10 & 69.68 & 28.97 & 27.69 & 104.89 \\
\hline 1989 & 525.38 & 150.78 & 28.70 & 61.45 & 42.12 & 43.21 & 374.60 & 71.30 & 32.01 & 38.74 & 108.97 \\
\hline 1990 & 620.91 & 158.86 & 25.59 & 66.09 & 35.37 & 52.37 & 462.05 & 74.41 & 37.30 & 55.88 & 125.76 \\
\hline 1991 & 718.43 & 161.45 & 22.47 & 72.26 & 34.86 & 47.54 & 556.98 & 77.53 & 38.18 & 71.49 & 144.56 \\
\hline 1992 & 849.40 & 170.04 & 20.02 & 83.09 & 31.43 & 46.93 & 679.36 & 79.98 & 43.48 & 132.19 & 161.35 \\
\hline 1993 & 917.44 & 166.66 & 18.17 & 83.99 & 30.52 & 41.09 & 750.78 & 81.83 & 46.23 & 152.82 & 163.92 \\
\hline 1994 & 1210.06 & 197.08 & 16.29 & 100.1 & 41.27 & 40.69 & 1012.98 & 83.71 & 62.36 & 218.95 & 232.18 \\
\hline 1995 & 1487.80 & 214.85 & 14.44 & 99.54 & 43.75 & 53.32 & 1272.95 & 85.56 & 90.94 & 314.07 & 322.40 \\
\hline 1996 & 1510.48 & 219.25 & 14.52 & 102.3 & 40.45 & 59.31 & 1291.23 & 85.48 & 88.77 & 353.12 & 284.98 \\
\hline 1997 & 1827.68 & 239.30 & 13.09 & 110.5 & 41.93 & 69.87 & 1588.38 & 86.91 & 102.27 & 437.08 & 344.32 \\
\hline 1998 & 1837.57 & 206.00 & 11.21 & 106.1 & 35.17 & 51.81 & 1631.57 & 88.79 & 103.16 & 502.33 & 323.83 \\
\hline
\end{tabular}

Source: Department of Comprehensive Statistics of National Bureau of Statistics (1999), Comprehensive Statistical Data and Materials on 50 Years of New China, Beijing: China Statistical Press, pp: 61. 
Table 4.3 China's total imports by main commodity categories, 1980-1998 (US\$ 100 million)

\begin{tabular}{|c|c|c|c|c|c|c|c|c|c|c|c|}
\hline \multirow[b]{2}{*}{ Year } & \multirow[b]{2}{*}{ Total } & \multicolumn{5}{|c|}{ Primary } & \multicolumn{5}{|c|}{ Manufactured } \\
\hline & & Total & $\begin{array}{l}\text { Primary } \\
\text { Share \% }\end{array}$ & $\begin{array}{l}\text { Food } \\
\text { and } \\
\text { Agri. }\end{array}$ & $\begin{array}{l}\text { Non- } \\
\text { Edible } \\
\text { Raws } \\
\end{array}$ & $\begin{array}{l}\text { Fuels } \\
\text { and } \\
\text { Ores }\end{array}$ & Total & $\begin{array}{l}\text { Manuf. } \\
\text { Share \% }\end{array}$ & $\begin{array}{l}\text { Che- } \\
\text { micals }\end{array}$ & $\begin{array}{l}\text { Mach. } \\
\text { and } \\
\text { Equip. }\end{array}$ & $\begin{array}{l}\text { Tex- } \\
\text { tiles }\end{array}$ \\
\hline 1980 & 200.17 & 69.59 & 34.77 & 29.27 & 35.54 & 2.03 & 130.58 & 65.23 & 29.09 & 51.19 & 41.54 \\
\hline 1981 & 220.15 & 80.44 & 36.54 & 36.22 & 40.27 & 0.83 & 139.71 & 63.46 & 26.06 & 58.66 & 40.35 \\
\hline 1982 & 192.85 & 76.34 & 39.59 & 42.01 & 30.12 & 1.83 & 116.51 & 60.41 & 29.36 & 32.04 & 39.06 \\
\hline 1983 & 213.90 & 58.08 & 27.15 & 31.22 & 24.59 & 1.11 & 155.82 & 72.85 & 31.83 & 39.88 & 62.89 \\
\hline 1984 & 274.10 & 52.08 & 19.00 & 23.31 & 25.42 & 1.39 & 222.02 & 81.00 & 42.37 & 72.45 & 73.18 \\
\hline 1985 & 422.52 & 52.89 & 12.52 & 15.53 & 32.36 & 1.72 & 369.63 & 87.48 & 44.69 & 162.39 & 118.98 \\
\hline 1986 & 429.04 & 56.49 & 13.17 & 16.25 & 31.43 & 5.04 & 372.55 & 86.83 & 37.71 & 167.81 & 111.92 \\
\hline 1987 & 432.16 & 69.15 & 16.00 & 24.43 & 33.21 & 5.39 & 363.01 & 84.00 & 50.08 & 146.07 & 97.30 \\
\hline 1988 & 552.75 & 100.6 & 18.21 & 34.76 & 50.90 & 7.87 & 452.07 & 81.79 & 91.39 & 166.97 & 104.10 \\
\hline 1989 & 591.40 & 117.5 & 19.87 & 41.92 & 48.35 & 16.50 & 473.86 & 80.13 & 75.56 & 182.07 & 123.35 \\
\hline 1990 & 533.45 & 98.53 & 18.47 & 33.35 & 41.07 & 12.72 & 434.92 & 81.53 & 66.48 & 168.45 & 89.06 \\
\hline 1991 & 637.90 & 108.3 & 16.98 & 27.99 & 50.03 & 21.13 & 529.57 & 83.02 & 92.77 & 196.01 & 104.93 \\
\hline 1992 & 805.85 & 132.5 & 16.45 & 31.46 & 57.75 & 35.70 & 673.30 & 83.55 & 111.57 & 131.12 & 192.73 \\
\hline 1993 & 1039.59 & 142.1 & 13.67 & 22.06 & 54.38 & 58.19 & 897.49 & 86.33 & 97.04 & 450.23 & 285.27 \\
\hline 1994 & 1156.14 & 164.8 & 14.26 & 31.37 & 74.37 & 40.35 & 991.28 & 85.74 & 121.30 & 514.67 & 280.84 \\
\hline 1995 & 1320.84 & 244.1 & 18.49 & 61.32 & 101.59 & 51.27 & 1076.67 & 81.51 & 172.99 & 526.42 & 287.72 \\
\hline 1996 & 1388.33 & 254.4 & 18.32 & 56.72 & 106.98 & 68.77 & 1133.92 & 81.68 & 181.06 & 547.63 & 313.91 \\
\hline 1997 & 1423.70 & 286.2 & 20.10 & 43.04 & 120.06 & 103.06 & 1137.50 & 79.90 & 192.97 & 527.74 & 322.20 \\
\hline 1998 & 1401.66 & 229.5 & 16.37 & 37.93 & 107.16 & 67.73 & 1171.24 & 83.56 & 201.66 & 567.68 & 310.71 \\
\hline
\end{tabular}

Source: Department of Comprehensive Statistics of National Bureau of Statistics (1999), Comprehensive Statistical Data and Materials on 50 Years of New China, Beijing: China Statistical Press, pp: 62. 
While there has been progress in water pollution control, it has been largely offset by increased pollution. Besides water pollution, water scarcity has become an increasingly serious problem in Northern China, which, in turn, has led to ambitious schemes to divert water from the Yangtze River in the South to ease water shortages in the North.

Similarly, despite considerable efforts to control air pollution, China's industrial sulfur dioxide $\left(\mathrm{SO}_{2}\right)$ emissions doubled between 1982 and 1997 and most major city centres have $\mathrm{SO}_{2}$ concentrations substantially above legal limits. A study by the World Resources Institute concludes that nine of the ten worst air polluted cities in the world appear in China (Fox 1999). This problem is closely related to the fact that coal accounts for more than 70 percent of China's total energy consumption (with little adoption of clean coal technologies) (see Table 4.4). Rapid growth in coal-based energy consumption and in motorized urban transportation is also responsible for the large increases in greenhouse gas emissions such as carbon dioxide $\left(\mathrm{CO}_{2}\right)$ in China.

Another major environmental concern in China has been the growth in industrial solid wastes. In 1996, 660 million tons of solid wastes were produced, 20 million tons more than the amount produced in the previous year and 75 percent higher than in 1991. Of the total solid wastes generated, 10 million tons are considered hazardous. In addition, nearly 70 million tons of household garbage are produced nationwide each year. Due to lack of sufficient handling facilities, solid wastes are stockpiled in suburbs and rural areas and waste accumulations surround many cities. What makes the situation even worse is that China imports wastes from other countries to supplement its need for materials to sustain industrial production. Due to the lack of adequate regulations and strict 
Table 4.4 Energy Consumption in China, 1980-1995

\begin{tabular}{lccc}
\hline & 1980 & 1990 & 1995 \\
\hline Total consumption (million tonnes) & 602.7 & 987.0 & 1290.0 \\
(Shares in percentages) & & & \\
Coal & 72.2 & 76.2 & 75.0 \\
Oil & 20.7 & 16.6 & 17.3 \\
Natural gas & 3.1 & 2.1 & 1.8 \\
Hydropower & 4.0 & 5.1 & 5.9 \\
Nuclear power & 0 & N/A & $<0.1$ \\
Non-biomass renewable energy & N/A & N/A & $<0.1$ \\
\hline
\end{tabular}

Source: Zhongguo Tongji Nianjian 1996 (China Statistical Yearbook 1996). Beijing: China Statistical Press, 1997, p p: 203 
environmental enforcement, China receives millions of tons of toxic wastes that pollute its domestic environment and constitute a serious health hazard.

As a result, the Chinese government has begun to treat environmental protection as an important national policy. It has been widely accepted in China that the pace of environmental protection must be commensurate with economic growth in order for China to achieve sustainable development. China has promulgated and enforced its Environmental Protection Law, first implemented in 1979 and later amended in 1989. Efforts have been made to gradually promote an integrated environmental system of unified management, with an increased emphasis for coordination between different sectors and the agencies of environmental protection at varying levels. Many other laws also exist for marine protection and for air, water and noise pollution prevention. In addition, stringent measures have been established with the aim of adhering to three basic principles: intensive management, prevention first, and the polluter-pays principle. It is worth noting that China has the most extensive pollution charge system in the developing countries. From its inception in the early 1980s to 1996, about 30 billion RMB yuan (3.66 billion US dollars) have been collected from more than 500,000 major polluters. In 1996 alone, the system collected about 4 billion RMB yuan ( 0.49 billion US dollars). Charges are levied for effluents of wastewater, air pollutants, and solid waste discharge; the majority comes from levies on wastewater. According to the China Environmental Yearbook 1997 (NEPA 1998), about 63 percent of total environmental levies in 1996 were derived from water pollution sources. 


\subsubsection{Interface between Trade and the Environment}

Historically, China's trade policy regime has aimed to stimulate export growth to generate foreign exchange without regarding its costs, while its import policy has been hampered with controls to reduce import growth. Such an approach has neglected any relationships between trade and the environment. According to Jha et al. (1999), unchecked production from export-oriented rural small and medium-sized enterprises has led to the deterioration of China's environment. Since the 1980s, market growth has gradually become the dominant force in decisions concerning exports. Environmental policies have not generally affected investment and trade decisions significantly. Other factors such as production costs, market access and resource availability dominate. Though not the intention of the central government, exporters have so far encountered few domestic environmental regulations due to provincial regional protectionism $(\mathrm{Wu}$ 2000 and Jha et al. 1999).

The impact of FDI on the environment has been mixed and controversial. In China's case, Jha et al. (1999) note that FDI enterprises have a higher investment share in pollution abatement (2.27 percent) than that of their local counterparts ( 0.94 percent). Moreover, the former tend to use more efficient technology and equipment that also reduce pollution. In the case of wastewater recycling, it was found that the rate of recycling was about 29 percent for domestic firms, while it was over 68 percent for FDI enterprises. However, under pressures of the rising costs of pollution abatement in their parent country or in other developed countries, some foreign firms have diverted their pollution intensive industries to China. In 1991, for example, over 36 percent of all FDI was invested in highly polluting industries, including printing, dyeing and electroplating 
industries (Xia 1995). It has been found that technologies used in some foreign-funded enterprises are often out of date and result in heavy pollution. A survey of foreign firms in the special economic zone of Guangdong reveals that only 28.4 percent of these enterprises have equipment that can control dust and toxic substances (Xia 1995). Hence, some parts of China may indeed be "pollution havens" for some foreign investors.

\subsection{Model Specification}

The empirical framework employed for model specifications reflects the lack of long environmental and economic time series for China as a whole. As a consequence, more attention is given to model disaggregation with concentration on the Chinese provinces. A provincial-level panel data set not only expands the sample size for econometric estimation and improves the efficiency of estimates, but it also permits one to better deal with the effects of missing or unobserved variables (Hsiao 1986). Below, equations (4-1) to (4-6) that form the core of the model have been modified to permit estimation according to the 1987-1995 provincial-level panel data set.

\section{The Production Function}

Given the Cobb-Douglas production function form matched by the trade-induced productivity term $A(T)=a_{0} T^{a l}$, Equation (4-1) can be rewritten as:

$$
Y_{i t}=a_{0}{ }^{\prime} T_{i t}{ }^{a 1} L_{i t}{ }^{a 2} K_{i t}{ }^{a 3} E_{i t}{ }^{a 4} e^{u l i t}
$$

Taking logs of (20) and setting $\mathrm{a}_{0}=\log \mathrm{a}_{0}$, , one obtains an equation suitable for employing with the provincial panel data set

$$
\log Y_{i t}=a_{0}+a_{1} \log T_{i t}+a_{2} \log L_{i t}+a_{3} \log K_{i t}+a_{4} \log E_{i t}+u_{1 i t}
$$


where $Y_{\text {it }}=$ output, measured as GDP;

$\mathrm{T}_{\mathrm{it}}=$ trade, measured as exports plus imports;

$\mathrm{L}_{\mathrm{it}}=$ labor input, measured as the number of total employed persons;

$\mathrm{K}_{\mathrm{it}}=$ capital input, measured as cumulative total investments in fixed assets;

$\mathrm{E}_{\mathrm{it}}=$ emissions generated in production;

$\mathrm{u}_{1 \mathrm{it}}=$ disturbance term;

$\mathrm{i}, \mathrm{t}=$ subscripts denoting provinces and time periods respectively.

Here, $a_{0}, a_{1}, a_{2}, a_{3}$ and $a_{4}$ are parameters to be estimated. One expects $a_{1}>0, a_{2}>0, a_{3}>$ 0 and $\mathrm{a}_{4}>0$. For information regarding the definitions, units, and coefficient assumptions of the variables, see Table 4.5.

\section{Emissions Demand}

As noted earlier, there may exist an inverted-U relationship between demand for emissions and output. Therefore, the inclusion of a quadratic output term would be appropriate in specifying the emissions demand function. In addition to the three determinants of emissions demand included in Equation (4-2), it is hypothesized that state ownership may also be important. According to Wang and Wheeler (1996), stateowned firms may be more pollution intensive than those of other ownership types for several reasons. First, state-owned firms may generate more emissions per unit of output because they are less efficient. Second, state-owned firms may be less sensitive to emissions charges due to soft budget constraints. Third, evidence from other Asian countries suggests that state-owned firms resist environment regulations more successfully than privately owned ones (Pargal and Wheeler 1996 and Hartman et al. 1996). Therefore, the industrial output share of state-owned firms is added to control for this ownership factor. The specification of Equation (4-2) thus becomes: 
Table 4.5 Variable Definition and Coefficient Assumption

\begin{tabular}{|c|c|c|}
\hline Variable Name & Definition & Coefficient Assumption \\
\hline \multicolumn{3}{|l|}{ Endogenous Variable } \\
\hline $\mathrm{Y}_{\text {it }}$ & $\begin{array}{l}\text { Gross Domestic Product (GDP), in } 100 \\
\text { million RMB yuan at } 1990 \text { constant prices. }\end{array}$ & $\mathrm{b}_{2}>0, \mathrm{c}_{2}>0, \mathrm{~d}_{2}<0, \mathrm{e}_{1}>0, \mathrm{f}_{1}>0$ \\
\hline $\mathrm{E}_{\mathrm{it}}$ & $\begin{array}{l}\text { Industrial wastewater discharges, in million } \\
\text { tons ; industrial waste gas emissions, in } \\
\text { billion } \mathrm{m}^{3} \text {; industrial } \mathrm{SO}_{2} \text { emissions, in } \\
\text { tons ; } \mathrm{CO}_{2} \text { emissions, in million tons; } \\
\text { industrial particle emissions, in tons ; and } \\
\text { industrial dust discharges, in tons. }\end{array}$ & $a_{4}>0, c_{1}>0$ \\
\hline$r_{i t}$ & $\begin{array}{l}\text { The levy rate, at } 1990 \text { constant prices, } \\
\text { computed as total levy collected on } \\
\text { industrial wastewater (gas) discharge } \\
\text { divided by total amount of wastewater (gas) } \\
\text { discharge, in cents per ton (cents per } \\
\text { thousand } \mathrm{m}^{3} \text { ). }\end{array}$ & $\mathrm{b}_{1}<0, \mathrm{f}_{2}<0$. \\
\hline $\mathrm{S}_{\mathrm{it}}$ & Share of industrial GDP in total GDP, $\%$. & $\mathrm{b}_{4}>0$ \\
\hline $\mathrm{T}_{\text {it }}$ & $\begin{array}{l}\text { Total trade flows (exports plus imports), in } \\
10,000 \text { US } \$ \text { at } 1990 \text { constant prices. }\end{array}$ & $\mathrm{a}_{1}>0, \mathrm{~d}_{1}<>0$ \\
\hline $\mathrm{FDI}_{\mathrm{it}}$ & $\begin{array}{l}\text { Foreign direct investment inflows, in } 10,000 \\
\text { US\$ at } 1990 \text { constant prices. }\end{array}$ & $\mathrm{e}_{2}>0$ \\
\hline \multicolumn{3}{|l|}{ Exogenous Variables } \\
\hline Lit & $\begin{array}{l}\text { Number of total employed persons, in } \\
10,000 \text {. }\end{array}$ & $a_{2}>0$. \\
\hline $\mathrm{K}_{\mathrm{it}}$ & $\begin{array}{l}\text { Cumulative total investment in fixed assets, } \\
\text { in } 100 \text { million RMB yuan at } 1990 \text { constant } \\
\text { prices. }\end{array}$ & $a_{3}>0$ \\
\hline $\mathrm{SOE}_{\text {it }}$ & $\begin{array}{l}\text { Share of state-owned firms in industrial } \\
\text { GDP, } \% \text {. }\end{array}$ & $\mathrm{b}_{5}>0$ \\
\hline $\mathrm{N}_{\mathrm{it}}$ & Population, in 10,000 & $\mathrm{c}_{2}^{\prime}>0$ \\
\hline $\mathrm{C}_{\mathrm{it}}$ & $\begin{array}{l}\text { Number of pollution complaints per million } \\
\text { population. }\end{array}$ & $\mathrm{c}_{3}<>0$ \\
\hline $\mathrm{ed}_{\mathrm{it}}$ & Illiteracy and semi-illiteracy rate, $\%$. & $\mathrm{c}_{4}<0$. \\
\hline $\mathrm{PD}_{\mathrm{it}}$ & $\begin{array}{l}\text { Population density, in number of inhabitants } \\
\text { per } \mathrm{km}^{2} \text {. }\end{array}$ & $\mathrm{c}_{5}<>0$ \\
\hline
\end{tabular}


(Table 4.5 continued)

\begin{tabular}{|c|c|c|}
\hline Variable Name & Definition & Coefficient Assumptions \\
\hline \multicolumn{3}{|l|}{ Exogenous Variable } \\
\hline $\mathrm{V}_{\text {it }}$ & $\begin{array}{l}\text { Investment in fixed assets, in } 100 \text { million } \\
\text { RMB yuan at } 1990 \text { constant prices. }\end{array}$ & $\mathrm{d}_{4}<>0$ \\
\hline $\mathrm{R}_{\mathrm{it}}$ & $\begin{array}{l}\text { Remoteness, computed as the nearest } \\
\text { distance between a province's capital and } \\
\text { the capitals of China's } 15 \text { biggest trading } \\
\text { partners, in kilometers. }\end{array}$ & $\mathrm{e}_{3}<0$ \\
\hline $\mathrm{ER}_{\mathrm{t}}$ & Exchange rate, in RMB yuan per 100 US\$. & $\mathrm{e}_{4}<>0$ \\
\hline $\mathrm{TN}_{\mathrm{t}}$ & $\begin{array}{l}\text { National total tariff revenues divided by } \\
\text { national total imports, } \% \text {. }\end{array}$ & $\mathrm{e}_{5}<0$ \\
\hline $\mathrm{TP}_{\mathrm{i}}$ & 1996 provincial ad valorem tariff rates, $\%$. & $\mathrm{e}_{5}<0$ \\
\hline $\mathrm{CFDI}_{\mathrm{I}(\mathrm{t}-1)}$ & $\begin{array}{l}\text { Lagged cumulative FDI inflows, in } 10,000 \\
\text { US\$ at } 1990 \text { constant prices. }\end{array}$ & $\mathrm{f}_{3}>0$ \\
\hline $\mathrm{TI}_{\mathrm{it}}$ & $\begin{array}{l}\text { Highway intensity, kilometers per } 100 \\
\text { square kilometers. }\end{array}$ & $\mathrm{f}_{4}>0$. \\
\hline $\mathrm{TAX}_{\mathrm{it}}$ & $\begin{array}{l}\text { Overall tax rate, tax revenue divided by } \\
\text { GDP, } \% \text {. }\end{array}$ & $\mathrm{f}_{5}<0$. \\
\hline $\operatorname{PGDP}_{\mathrm{i}(\mathrm{t}-1)}$ & $\begin{array}{l}\text { Lagged per capita GDP, in RMB yuan per } \\
\text { capita. }\end{array}$ & $\mathrm{f}_{6}>0$ \\
\hline $\mathrm{D}_{\mathrm{i}}$ & $\begin{array}{l}\text { Regional geographic and policy dummy } \\
\text { variable, } 1 \text { for coastal provinces and Beijing, } \\
\text { and } 0 \text { for other provinces. }\end{array}$ & $\mathrm{d}_{5}<>0, \mathrm{e}_{6}>0, \mathrm{f}_{7}>0$ \\
\hline $\mathrm{DT}_{\mathrm{t}}$ & $\begin{array}{l}\text { Time dummy variable, } 1 \text { for } 1989,1990 \text { and } \\
\text { 1991, and } 0 \text { for other years. }\end{array}$ & $\mathrm{e}_{7}<0, \mathrm{f}_{8}<0$ \\
\hline
\end{tabular}


$\log E_{i t}=b_{0}+b_{1} \log r_{i t}+b_{2} \log Y_{i t}+b_{3}\left(\log Y_{i t}\right)^{2}+b_{4} \log S_{i t}+b_{5} \log S O E_{i t}+u_{2 i t}$

where $\mathrm{E}_{\mathrm{it}}=$ emissions, measured as industrial wastewater, waste gas, $\mathrm{CO} 2, \mathrm{SO} 2$, particle, and dust discharges, respectively;

$\mathrm{r}_{\mathrm{it}}=$ the emissions charge, measured as pollution levy rates;

$\mathrm{Y}_{\mathrm{it}}=$ output, measured as GDP;

$\mathrm{S}_{\mathrm{it}}=$ pollution-intensive goods in output, measured as the industrial output share in GDP;

$\mathrm{SOE}_{\mathrm{it}}=$ the industrial output share of state-owned enterprises in total industrial GDP;

$\mathrm{u}_{2 \mathrm{it}}=$ disturbance term.

Here, $b_{0}, b_{1}, J, b_{5}$ are parameters to be estimated. one expects $b_{1}<0, b_{2}>0, b_{3}<0, b_{4}>0$, and $b_{5}>0$. See Table 4.5 for variable definitions and coefficient assumptions.

\section{$\underline{\text { Emissions Supply }}$}

As income increases, ceteris paribus, emissions supply will decrease because the demand for clean environment, which is a normal good, will increase. Income is not only directly related to a community's willingness to tolerate emissions but also the key variable that the Chinese provincial regulators use to establish emissions charge standards (Wang and Wheeler 1996). Therefore, given the importance of income in emissions supply, instead of approximating it with output as is in Equation (4-3), income per capita is explicitly introduced.

Other factors that may affect emissions supply or a province's decision on emissions charges are environmental complaints from citizens, average education levels, and population density. Citizen environmental complaints can be considered both an indication of weak enforcement of environmental standards and regulations and an 
indication of pressure that communities place on regulators for lower emissions supply. If the primary role of complaints is an indication of weak enforcement dominates, the relation between complaints and emissions charges will be negative, i.e., lower emissions charges incur more complaints. This relation will be positive if the effect of pressure on emissions supply is to increase the price or levy. Education levels may have an impact on emissions supply because they would affect local perceptions of environmental problems and a community's ability to organize and bring pressure on regulators to enforce desired levels of compliance (Wang and Wheeler 1996).

Population density may be a factor in emissions supply as well for two reasons. On one hand, the increasing pressure of population growth often forces developing countries such as China to assign a high priority to economic development. In this case, environmental quality is sacrificed for higher growth rates. Hence higher population density could mean more lenient environmental enforcement, higher emissions supply, and lower pollution charges. On the other hand, according to the Samuelson condition for the provision of public goods, the optimized emissions charge should be the sum of marginal damages across all individuals (Antweiler et al. 1998). Therefore, high population density would call for high emissions charges and low emissions supply.

Given the above considerations, the inverse emissions supply equation becomes:

$\log r_{i t}=c_{0}+c_{1} \log E_{i t}+c_{2} \log I N_{i t}+c_{3} \log C_{i t}+c_{4} \log e d_{i t}+c_{5} \log P D_{i t}+u_{3 i t}$

where $r_{i t}=$ the emissions charge, measured as pollution levy rates;

$\mathrm{E}_{\mathrm{it}}=$ emissions, measured as different types of industrial pollution discharges;

$\mathrm{IN}_{\mathrm{it}}=$ per capita income, approximated as per capita GDP;

$\mathrm{C}_{\mathrm{it}}=$ citizen environmental complaints, measured as complaint letters and visits that authorities receive per 10,000 population; $\mathrm{ed}_{\mathrm{it}}=$ education levels, measured as illiteracy and semi-illiteracy rate; 
$\mathrm{PD}_{\mathrm{it}}=$ population density, in number of inhabitants per $\mathrm{km}^{2}$;

$\mathrm{u}_{3 \mathrm{it}}=$ disturbance term.

Here, $\mathrm{c}_{0}, \mathrm{c}_{1}, \mathrm{~J}, \mathrm{c}_{5}$ are estimating parameters, and $\mathrm{c}_{1}>0, \mathrm{c}_{2}>0, \mathrm{c}_{3}<>0, \mathrm{c}_{4}<0$, and $\mathrm{c}_{5}<$ $>0$.

Since $I N_{i t}=Y_{i t} / N_{i t}$, where $N_{i t}=$ population, Equation (4-23) can be rewritten as:

$\log r_{i t}=c_{0}+c_{1} \log E_{i t}+c_{2} \log Y_{i t}-c_{2}^{\prime} \log N_{i t}+c_{3} \log C_{i t}+c_{4} \log e d_{i t}+c_{5} \log P D_{i t}$

where $c_{2}=c_{2}$, a restriction imposed on these two parameters. Detailed variable definitions and coefficient assumptions are shown in Table 4.5.

\section{The Share of Pollution- Intensive Goods in Output}

In this study, the industrial output share in GDP is used to approximate the share of pollution-intensive goods in output. In China, industrial sector includes mining, manufacturing, construction, and the production and supply of tap water, power, steam, hot water, and gas (CSP 1999). According to Park and Labys (1999), industry is a very important source of environmental pollution in an economy since it generates huge emissions on both input and output sides from its productive activities. Industry is a major consumer of energy, and power generation is the major source of airborne pollutants such as $\mathrm{CO}_{2}, \mathrm{SO}_{2}$ and particles. Also, many industrial processes rely heavily on the use of water and this directly leads to millions of tons of wastewater discharge each year. In addition, there are many types of solid waste due to industrial production, particularly in China. China's National Environmental Protection Agency (NEPA) estimates that industrial pollution accounts for over 70 percent of the national total, including 70 percent of wastewater pollution, 72 percent of $\mathrm{SO}_{2}$ emissions, 75 percent of flue dust, and 87 percent of solid wastes (Dasgupta, Wang and Wheeler 1997). 
The determination of industrial output share in GDP has to be an empirical one due to the absence of a readily applicable economic theory. Inclusion of trade in the specification can be justified by the fact that the share of manufactured goods in China's total exports and imports has averaged around 80 percent since the 1980s. Evidence that an unusually large fraction of the population have been absorbed in the tertiary of the "services" sector suggests that the industrial share in GDP may shrink as the economy grows. In China's case, the tertiary sector has developed faster in the coastal provinces than in the inland areas due to demographical and policy differences. Historically, the Chinese central government intentionally placed industrial bases in the inland provinces as part of national security policy. Hence, a dummy variable is needed to control for the effect of these demographical and policy differences.

Investment in fixed assets is also specified because industry is more capital intensive than the agricultural and services sectors, and the direction of this investment may have an important impact on the industrial output share of GDP. What's more, since industrial production relies heavily on capital input, its capacity determined output is relatively fixed in the short term and time lags are needed to adjust capacity and output (Labys 2000). In order to capture this time lag effect, the industrial share in the previous time period is therefore added in the equation.

The equation describing the share of pollution-intensive goods in output can be written as follows:

$\log S_{i t}=d_{0}+d_{1} \log T_{i t}+d_{2} \log Y_{i t}+d_{3} \log S_{i(t-1)}+d_{4} \log V_{i t}+d_{5} D_{i}+u_{4 i t}$

where $S_{i t}=$ pollution-intensive goods in output, measured as the industrial output share in GDP;

$\mathrm{T}_{\mathrm{it}}=$ trade, measured as exports plus imports; 
$\mathrm{Y}_{\mathrm{it}}=$ output, measured as GDP;

$\mathrm{S}_{\mathrm{i}(\mathrm{t}-1)}=$ industrial output share in the previous time period;

$\mathrm{V}_{\mathrm{it}}=$ investment in fixed assets;

$\mathrm{D}_{\mathrm{i}}=$ regional dummy variable, one for the coastal provinces and Beijing, and zero for other provinces;

$\mathrm{u}_{4 i t}=$ disturbance term.

Here, $\mathrm{d}_{0}, \mathrm{~d}_{1}, \mathrm{~J}, \mathrm{~d}_{5}$ are parameters, and one expects $\mathrm{d}_{1}<>0, \mathrm{~d}_{2}<0, \mathrm{~d}_{3}>0, \mathrm{~d}_{4}<>0$, and $\mathrm{d}_{5}<>0$. A summary of variable definitions and coefficient assumptions is provided in Table 4.5.

\section{The Trade Equation}

From the standard gravity model of international trade, a log-linear functional relation can be derived to describe China's provincial aggregate trade flows with the rest of the world (Chen 1997). A province's proximity to the rest of the world is measured as the geographic distance between the province's capital and the nearest capital city of China's fifteen largest trading partners. Hence, it is conceivable that a province's proximity index can be time varying, because China's top fifteen trading partners may change from time to time. The impact of this variable on trade would be negative taking into account trading costs such as transportation and information costs associated with the distance. Other trade-related policy variables considered include foreign exchange rates and tariffs. Since the 1980s, China has adjusted its exchange rates in order to stimulate its exports (see Table 1). At the same time, however, these devaluations may have lessened China's ability to import from other countries. The exchange rate variable could thus provide an interesting test for the overall effect of the exchange rate policy on trade. 
In the past twenty years, as one of its many efforts for accession to the WTO, China has gradually but significantly reduced its tariffs on imports. Though tariffs are uniformly set in China, provincial weighted-average of ad valorem tariffs vary considerably across provinces due to different import preferences (World Bank 1997, Annex Table A.1). Unfortunately, only the 1996 provincial tariff data are available. We thus assume that a province's import preferences were relatively stable during the period of study. However, in order to capture the change in tariffs across provinces and over time, a product term of the national average and the provincial average tariffs is introduced in the specification. Again, a regional geographical and policy dummy variable is used to control for the effect of the resulting differences between the coastal and the inland areas.

In addition, a time dummy is introduced to control for the impact of the wellknown 1989 Tiananmen Square Incident (or the 1989 Tiananmen Square Massacre). The Chinese communist government's use of military force to suppress student demonstrators led to economic sanctions by Western countries. The trade equation becomes:

$$
\begin{aligned}
\log T_{i t}= & e_{0}+e_{1} \log Y_{i t}+e_{2} \log F D I_{i t}+e_{3} \log R_{i t}+e_{4} \log E R_{1 t} \\
& +e_{5}\left(\log T N_{t}\right) *\left(\log T P_{i}\right)+e_{6} D_{i}+e_{7} D T_{t}+u_{5 i t}
\end{aligned}
$$

where $T_{i t}=$ trade flows, measured as exports plus imports;

$\mathrm{Y}_{\mathrm{it}}=$ output, measured as GDP;

$\mathrm{FDI}_{\mathrm{it}}=$ foreign direct investments;

$\mathrm{R}_{\mathrm{it}}=$ proximity index, measured as the geographic distance between a province's capital and the nearest capital of China's top 15 trading partners;

$\mathrm{ER}_{\mathrm{t}}=$ the exchange rate, measured as the amount of RMB yuan (Renmibi yuan, name of the official Chinese currency) that can be bought with one US dollar; 
$\mathrm{TN}_{\mathrm{t}}=$ average tariffs at national level;

$\mathrm{TP}_{\mathrm{i}}=$ the 1996 provincial average tariffs;

$\mathrm{D}_{\mathrm{i}}=$ regional dummy variable, one for the coastal provinces and Beijing, and zero for other provinces;

$\mathrm{DT}_{\mathrm{t}}=$ time dummy variable, one for the years 1989, 1990 and 1991, and zero for other years;

$\mathrm{u}_{5 \mathrm{it}}=$ disturbance term.

Here, $\mathrm{e}_{0}, \mathrm{e}_{1}, \mathrm{~J}, \mathrm{e}_{7}$ are parameters, and one expects $\mathrm{e}_{1}>0, \mathrm{e}_{2}>0, \mathrm{e}_{3}<0, \mathrm{e}_{4}<>0, \mathrm{e}_{5}<0, \mathrm{e}_{6}$ $>0$, and $\mathrm{e}_{7}<0$. See Table 4.5 for a list of variable definitions nd coefficient assumptions.

\section{The FDI Equation}

The specification of the FDI equation is relatively straightforward, following the structure of equation (4-6). In addition to the geographical and policy-related regional dummy variable discussed earlier, a provincial average tax rate variable is also introduced to represent a province's general policy environment for FDIs. The infrastructure proxy used in this study is the length of highways per unit area, because of the unique importance of transportation in infrastructure and to the economy as well. Rail way also plays an important role in China's tranportation but not included in this study because it is relatively more evenly distributed for national security considerations. The proxy for wage rates is lagged per capita GDP. In fact, per capita GDP is not only a good proxy for real wages but also a good indicator of economic development, which reflects a province's overall investment environment (Chen 1997). For the reason discussed in the specification of the trade equation, the same time dummy variable is included to capture the impact of the 1989 Tiananmen Square incident. Thus, Equation (4-6) is specified as: 


$$
\begin{aligned}
\log F D I_{i t}= & f_{0}+f_{1} \log Y_{i t}+f_{2} \log r_{i t}+f_{3} \log C F D I_{i(t-1)}+f_{4} \log T I_{i t} \\
& +f_{5} \log T A X_{i t}+f_{6} \log P G D P_{i(t-1)}+f_{7} D_{i}+f_{8} D T_{t}+u_{6 i t}
\end{aligned}
$$

where $\mathrm{FDI}_{\mathrm{it}}=$ Foreign direct investment inflows;

$\mathrm{Y}_{\mathrm{it}}=$ output, measured as GDP;

$r_{i t}=$ the emissions change, measured as pollution levy rates;

$\mathrm{CFDI}_{\mathrm{i}(\mathrm{t}-1)}=$ lagged cumulative FDI inflows;

$\mathrm{TI}_{\mathrm{it}}=$ infrastructure indicator, measured as the length of highways per unit area;

$\mathrm{TAX}_{\mathrm{it}}=$ average tax rates, a proxy for the policy environment of investment and measured as a province's total tax revenue divided by its GDP;

PGDP $_{\mathrm{i}(\mathrm{t}-1)}=$ lagged per capita GDP, a proxy for real wage and economic development;

$\mathrm{D}_{\mathrm{i}}$ and $\mathrm{DT}_{\mathrm{t}}=$ dummy variables as defined in the specification of the trade Equation;

$\mathrm{u}_{6 \mathrm{it}}=$ disturbance term.

Here, $\mathrm{f}_{0}, \mathrm{f}_{1}, \mathrm{~J}, \mathrm{f}_{8}$ are parameters, and one expects $\mathrm{f}_{1}>0, \mathrm{f}_{2}<0, \mathrm{f}_{3}>0, \mathrm{f}_{4}>0, \mathrm{f}_{5}<0, \mathrm{f}_{6}>0$, $\mathrm{f}_{7}>0$, and $\mathrm{f}_{8}<0$. Variable definitions and coefficient assumptions are summarized in Table 4.5.

\subsection{Conclusions}

China is a country that is experiencing both rapid economic growth, trade expansion and severe environmental degradation. In addtion, it appears that a tradeoff between high growth rates in the economy and environmental protection has taken place. A case study of China could provide important information as to how trade and the environment affect each other in a developing world and hence help to deepen our understanding of the nexus between trade and the environment in any country. 
Existing empirical investigations of the interactions between trade and the environment are usually based on single equation models which focus on a onedirectional static impact between trade and environemntal variables. This chapter presents a simultaneous model of trade and environment by adding to Dean's framework an international trade and an FDI inflow equation. This model can be used not only to examine the interactions between trade and environmental variables but also to disaggregate such impacts into three different effects: a scale effect, a composition effect, and a technique effect. This model makes an inverted-U relationship between emissions and economic scales explicit and thus allows for testing the existence of an environmental Kuznets curve in the Chinese case. 


\section{Chapter 5}

\section{MODEL ESTIMATION AND APPLICATION}

\subsection{Introduction}

Chapter 4 has presented a simultaneous trade and environment model (TEM) and derived some useful analytical results regarding the interactions between trade and the environment. These results, however, reveal only qualitative theoretical relationships between trade and environmental variables. Questions as to how these variables impact on each other and how they relate to China's development remain unansweared. Econometric estimation and application of the TEM model is required to analyze these questions. This chapter is dedicated to this purpose. The organization of this chapter is as follows. Section 2 provides information about data sources. Section 3 focuses on model indentification. Section 4 discusses model estimation and presents the estimated results in detail. Section 5 reports on model validation. Section 6 examines the model results concerning the relationship between trade and the environment. Section 7 presents results of model simulation, while Section 8 concludes the chapter.

\subsection{Data Sources}

Most provincial emissions data were obtained from a province-level panel database constructed by the World Bank. This data set is limited to the industrial sector for the 1987-1995 period. The only exception is the $\mathrm{CO}_{2}$ emissions data, which are based on the national total $\mathrm{CO}_{2}$ emissions provided by Zhang (1999); these data have been disaggregated to the provincial level according to the industrial coal consumption share 
of a province in the national total, reflecting the dominant role of coal in China's energy use. Other provincial social and economic data are from various China Statistical Yearbooks (1987-1999) and the provincial Statistical Yearbooks (1987-1999). Detailed data sources and variable definitions are reported in Table 5.1.

All nominal variables such as GDP, investments, trade flows, and FDIs are measured either in 1990 constant RMB yuan or in 1990 constant US dollars. Nominal variables measured in RMB yuan were converted either by Chinese GDP price indexes, by price indexes for investment in fixed assets, or by general consumer price indexes (obtained from various China Statistical Yearbooks) while variables in US dollars were by implicit price deflators for US GDP published in Survey of Current Business (BEA 2000).

As shown in Figure 5.1, China now consists of 34 provinces, autonomous regions, municipalities directly under the central government, and special administration regions (all referred to as provinces in this study). The number of provinces that are included in this analysis is 28 . Tibet and Hainan are excluded due to data insufficiency. Chongqing was part of Sichuan before 1997. Taiwan is also excluded for evident reasons, and Hong Kong and Macao were not yet returned to China in the study period. Instead, these three regions were China's major trading partners and FDI sources. Summary statistics of the variables are reported in Table 5.2.

Explanation with regard to the measurement of some variables is required. China initiated its nationwide pollution discharge levy system in 1982. Levies were initially applied when pollutant discharges exceeded the required standards. In order to provide incentive for enterprises to further abate water pollution, a volume-based industrial 
wastewater discharge fee was introduced in 1993. Since the data available are total levies separately collected on excess industrial wastewater discharges and on excess industrial waste gas emissions, the levy rate is approximated as the total levy on wastewater (gas) divided by the total discharge of the pollutant. Though this is a rough measure as a price indicator for environmental demand and supply, it does reflect the differentials in strictness of environmental enforcement across provinces. Another variable whose measurement requires explanations is the national level tariffs. These tariffs are simply calculated as the national total tariff revenues divided by national total imports. It is noticeable that our calculated tariffs are much lower than those reported by other sources such as the World Bank (1999). Nevertheless, they are used in this analysis because they capture the decreasing trend of the variable during the study period and there is no available single source that releases China's tariff series.

\subsection{Model Identification}

The final model specification that has been selected for estimation is summarized in Table 4.7. Before proceeding to model estimation, it is important to check the model's identification. If a model is unidentified, structural estimation may not be computed or it may be computed but it is not consistent. Rearranging equations (4-21)- (4-26) reported in Table 5.3, we have: 
Table 5.1 List of Variables and Data Sources

\begin{tabular}{|c|c|c|}
\hline Variable Name & Definition & Source \\
\hline \multicolumn{3}{|c|}{ Endogenous Variable } \\
\hline $\mathrm{Y}_{\mathrm{it}}$ & $\begin{array}{l}\text { Gross Domestic Product (GDP), in } 100 \\
\text { million RMB yuan at } 1990 \text { constant prices. }\end{array}$ & $\begin{array}{l}\text { Various issues of China } \\
\text { Statistical Yearbook. }\end{array}$ \\
\hline $\mathrm{E}_{\mathrm{it}}$ & $\begin{array}{l}\text { Industrial wastewater discharges, industrial } \\
\text { waste gas emissions, industrial } \mathrm{SO} 2 \\
\text { emissions, } \mathrm{CO} 2 \text { emissions, industrial particle } \\
\text { emissions, and industrial dust discharges. }\end{array}$ & $\begin{array}{l}\text { China's provincial environmental } \\
\text { data set compiled by the World } \\
\text { Bank, various issues of China } \\
\text { Environmental Year Book, and } \\
\text { Zhang (1999). }\end{array}$ \\
\hline$r_{i t}$ & $\begin{array}{l}\text { The levy rate, at } 1990 \text { constant prices, } \\
\text { computed as total levy collected on } \\
\text { industrial wastewater (gas) discharge } \\
\text { divided by total amount of wastewater (gas) } \\
\text { discharge. }\end{array}$ & $\begin{array}{l}\text { China's provincial environmental } \\
\text { data set compiled by the World } \\
\text { Bank, various issues of China } \\
\text { Environmental Yearbook. }\end{array}$ \\
\hline $\mathrm{S}_{\mathrm{it}}$ & Share of industrial GDP in total GDP. & China Statistical Yearbooks. \\
\hline $\mathrm{T}_{\mathrm{it}}$ & $\begin{array}{l}\text { Total trade flows (exports plus imports), in } \\
10,000 \text { US } \$ \text { at } 1990 \text { constant prices. }\end{array}$ & China Statistical Yearbooks. \\
\hline $\mathrm{FDI}_{\mathrm{it}}$ & $\begin{array}{l}\text { Foreign direct investment inflows, in } 10,000 \\
\text { US\$ at } 1990 \text { constant prices. }\end{array}$ & China Statistical Yearbooks. \\
\hline \multicolumn{3}{|c|}{ Exogenous Variables } \\
\hline Lit & $\begin{array}{l}\text { Number of total employed persons, in } \\
10,000 .\end{array}$ & China Statistical Yearbooks. \\
\hline $\mathrm{K}_{\mathrm{it}}$ & $\begin{array}{l}\text { Cumulative total investment in fixed assets, } \\
\text { in } 100 \text { million RMB yuan at } 1990 \text { constant } \\
\text { prices. }\end{array}$ & China Statistical Yearbooks. \\
\hline $\mathrm{SOE}_{\mathrm{it}}$ & $\begin{array}{l}\text { Share of state-owned firms in industrial } \\
\text { GDP }\end{array}$ & China Statistical Yearbooks. \\
\hline $\mathrm{N}_{\mathrm{it}}$ & Population, in 10,000 & China Statistical Yearbooks. \\
\hline $\mathrm{C}_{\mathrm{it}}$ & $\begin{array}{l}\text { Number of pollution complaints per million } \\
\text { population. }\end{array}$ & $\begin{array}{l}\text { China's provincial environmental } \\
\text { data set compiled by the World } \\
\text { Bank, various issues of China } \\
\text { Environmental Yearbook. }\end{array}$ \\
\hline $\mathrm{ed}_{\mathrm{it}}$ & Illiteracy and semi-illiteracy rate. & China Statistical Yearbooks. \\
\hline $\mathrm{PD}_{\text {it }}$ & $\begin{array}{l}\text { Population density, in number of inhabitants } \\
\text { per } \mathrm{km}^{2} \text {. }\end{array}$ & China Statistical Yearbooks. \\
\hline
\end{tabular}




\section{( Table 5.1 continued)}

\begin{tabular}{|c|c|c|}
\hline Variable Name & Definition & Source \\
\hline \multicolumn{3}{|l|}{ Exogenous Variable } \\
\hline $\mathrm{V}_{\text {it }}$ & $\begin{array}{l}\text { Investment in fixed assets, in } 100 \text { million } \\
\text { RMB yuan at } 1990 \text { constant prices. }\end{array}$ & China Statistical Yearbooks. \\
\hline $\mathrm{R}_{\mathrm{it}}$ & $\begin{array}{l}\text { Remoteness, computed as the nearest } \\
\text { distance between a province's capital and } \\
\text { the capitals of China's } 15 \text { biggest trading } \\
\text { partners, in kilometers. }\end{array}$ & Author's calculation. \\
\hline $\mathrm{ER}_{\mathrm{t}}$ & Exchange rate, ratio of RMB yuan to US\$. & China Statistical Yearbooks. \\
\hline $\mathrm{TN}_{\mathrm{t}}$ & $\begin{array}{l}\text { National total tariff revenues divided by } \\
\text { national total imports. }\end{array}$ & China Statistical Yearbooks. \\
\hline $\mathrm{TP}_{\mathrm{i}}$ & 1996 provincial ad valorem tariffs. & World Bank (1997). \\
\hline $\mathrm{CFDI}_{\mathrm{I(t-1)}}$ & Lagged cumulative FDI inflows. & China Statistical Yearbooks. \\
\hline $\mathrm{TI}_{\mathrm{it}}$ & $\begin{array}{l}\text { Highway intensity, kilometers per } 100 \\
\text { square kilometers. }\end{array}$ & China Statistical Yearbooks. \\
\hline $\mathrm{TAX}_{\mathrm{it}}$ & $\begin{array}{l}\text { Overall tax rate, tax revenue divided by } \\
\text { GDP. }\end{array}$ & China Statistical Yearbooks. \\
\hline PGDP $_{\mathrm{i}(\mathrm{t}-1)}$ & $\begin{array}{l}\text { Lagged per capita GDP, in RMB yuan per } \\
\text { capita. }\end{array}$ & China Statistical Yearbooks. \\
\hline $\mathrm{D}_{\mathrm{i}}$ & $\begin{array}{l}\text { Regional geographic and policy dummy } \\
\text { variable, } 1 \text { for coastal provinces and Beijing, } \\
\text { and } 0 \text { for other provinces. }\end{array}$ & \\
\hline $\mathrm{DT}_{\mathrm{t}}$ & $\begin{array}{l}\text { Time dummy variable, } 1 \text { for } 1989,1990 \text { and } \\
\text { 1991, and } 0 \text { for other years. }\end{array}$ & \\
\hline
\end{tabular}




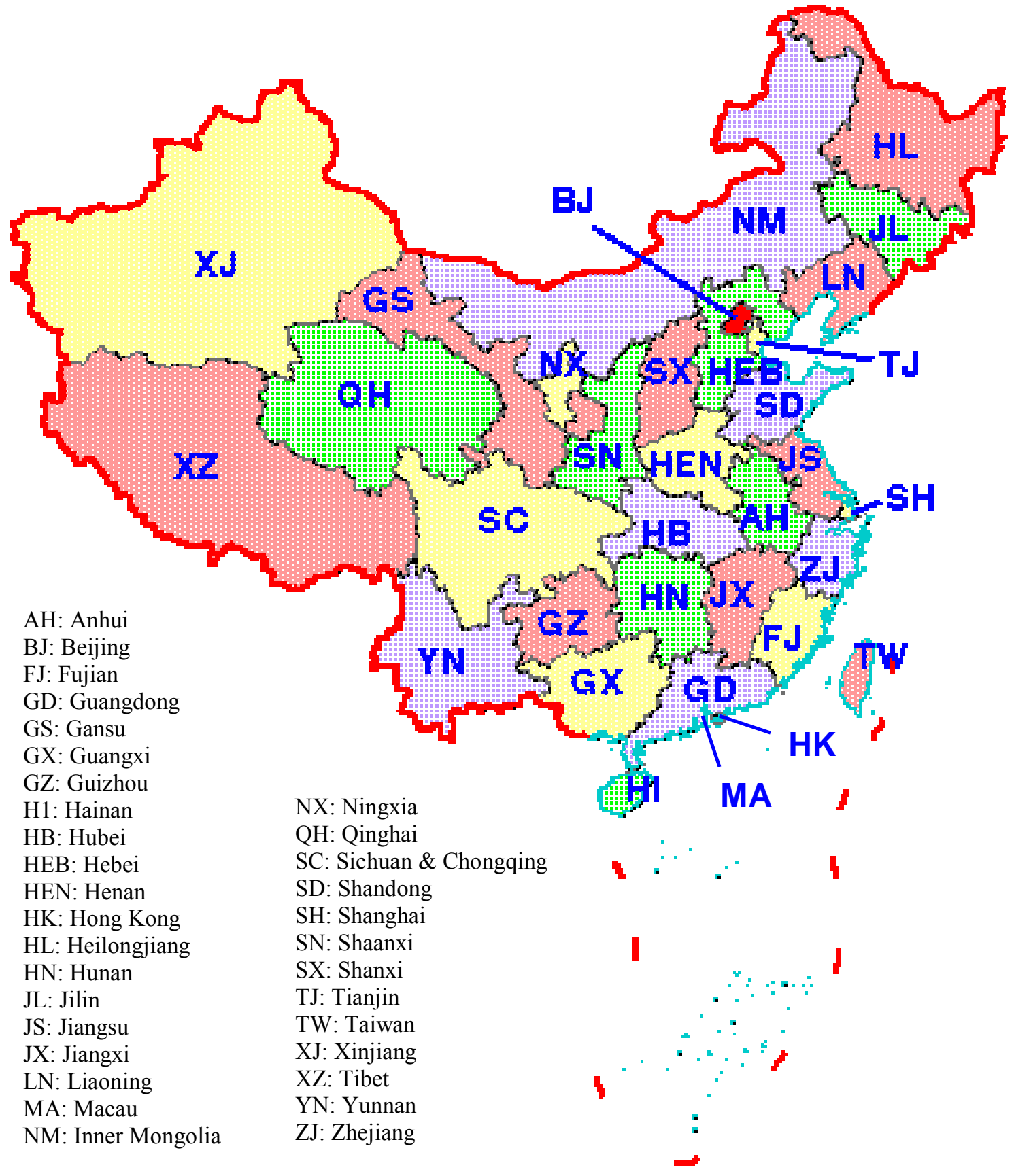

Figure 5.1 Map of China 
Table 5.2 Summary Statistics of Variables (1987-1995)

\begin{tabular}{|c|c|c|c|c|c|}
\hline Variable & $\begin{array}{l}\text { Number } \\
\text { of Obs. }\end{array}$ & $\begin{array}{l}\text { Sample } \\
\text { Mean }\end{array}$ & $\begin{array}{l}\text { Standard } \\
\text { Deviation }\end{array}$ & Minimum & Maximum \\
\hline \multicolumn{6}{|l|}{ Endogenous Variable } \\
\hline Yit: GDP & 252 & 809.23 & 624.44 & 51.79 & 3749.77 \\
\hline $\mathrm{E}_{\mathrm{it}}$ : Wastewater & 252 & 853.99 & 596.28 & 50.29 & 2471.64 \\
\hline Waste gases & 252 & 332.87 & 323.92 & 31.00 & 4479.00 \\
\hline $\mathrm{SO}_{2}$ & 252 & 588529.4 & 460628.7 & 20000.0 & 2319157.0 \\
\hline $\mathrm{CO}_{2}$ & 252 & 22.55 & 13.73 & 2.00 & 59.40 \\
\hline Particles & 252 & 501177.5 & 354842.1 & 55515.0 & 1788377.0 \\
\hline Dust & 252 & 266926.8 & 207402.8 & 10000.0 & 2070000.0 \\
\hline$r_{i t}:$ Levy rate on wastewater & 252 & 4.12 & 1.73 & 1.06 & 10.35 \\
\hline Levy rate on waste gases & 252 & 5.17 & 1.86 & 0.54 & 10.63 \\
\hline $\mathrm{S}_{\mathrm{it}}$ : Industrial GDP share & 252 & 43.35 & 8.81 & 26.38 & 68.73 \\
\hline $\mathrm{T}_{\mathrm{it}}$ : Trade & 252 & 436587.4 & 1119777 & 5732.8 & 9177245 \\
\hline $\mathrm{FDI}_{\mathrm{it}}$ & 252 & 61879.1 & 297739.7 & 0.0 & 4432341 \\
\hline \multicolumn{6}{|l|}{ Exogenous Variables } \\
\hline $\mathrm{L}_{\mathrm{it}}$ & 252 & 2057.15 & 1371.05 & 190.90 & 6335.30 \\
\hline $\mathrm{K}_{\mathrm{it}}$ & 252 & 1091.69 & 1026.38 & 46.39 & 6714.08 \\
\hline $\mathrm{SOE}_{\mathrm{it}}$ & 252 & 58.04 & 17.56 & 13.86 & 84.48 \\
\hline $\mathrm{N}_{\mathrm{it}}$ & 252 & 4020.27 & 2573.60 & 417.50 & 11162.90 \\
\hline $\mathrm{C}_{\mathrm{it}}$ & 252 & 135.31 & 93.55 & 2.40 & 550.70 \\
\hline $\mathrm{ed}_{\mathrm{it}}$ & 252 & 21.88 & 8.76 & 8.84 & 47.09 \\
\hline $\mathrm{PD}_{\mathrm{it}}$ & 252 & 329.58 & 365.72 & 5.84 & 1947.91 \\
\hline $\mathrm{V}_{\mathrm{it}}$ & 252 & 218.86 & 188.35 & 18.92 & 1146.77 \\
\hline $\mathrm{R}_{\mathrm{it}}$ & 252 & 1025.60 & 580.22 & 124.50 & 2143.00 \\
\hline $\mathrm{ER}_{\mathrm{t}}$ & 9 & 550.70 & 176.08 & 372.21 & 861.87 \\
\hline $\mathrm{TN}_{\mathrm{t}}$ & 9 & 5.64 & 2.13 & 2.65 & 8.85 \\
\hline $\mathrm{TP}_{\mathrm{i}}$ & 28 & 22.70 & 6.63 & 9.20 & 41.30 \\
\hline $\mathrm{CFDI}_{\mathrm{i}(\mathrm{t}-1)}$ & 252 & 192201.4 & 713954.5 & 5.7 & 4514707.0 \\
\hline $\mathrm{TI}_{\mathrm{it}}$ & 252 & 22.57 & 13.17 & 1.53 & 71.02 \\
\hline $\mathrm{TAX}_{\mathrm{it}}$ & 252 & 9.70 & 3.70 & 2.84 & 20.90 \\
\hline PGDP $_{\mathrm{i}(\mathrm{t}-1)}$ & 252 & 2065.25 & 1360.86 & 659.42 & 9404.50 \\
\hline
\end{tabular}




\section{Table 5.3 TEM Specification}

\section{Equations}

Gross Domestic Product (GDP)

$$
\log Y_{i t}=a_{0}+a_{1} \log T_{i t}+a_{2} \log L_{i t}+a_{3} \log K_{i t}+a_{4} \log E_{i t}+u_{1 i t}
$$

Emissions Demand

$$
\log E_{i t}=b_{0}+b_{1} \log r_{i t}+b_{2} \log Y_{i t}+b_{3}\left(\log Y_{i t}\right)^{2}+b_{4} \log S_{i t}+b_{5} \log S O E_{i t}+u_{2 i t}
$$

Emissions Supply (Inverted)

$$
\log r_{i t}=c_{0}+c_{1} \log E_{i t}+c_{2} \log I N_{i t}+c_{3} \log C_{i t}+c_{4} \log e d_{i t}+c_{5} \log P_{i t}+u_{3 i t}
$$

Industrial Output Share in GDP

$$
\log S_{i t}=d_{0}+d_{1} \log T_{i t}+d_{2} \log Y_{i t}+d_{3} \log S_{i(t-1)}+d_{4} \log V_{i t}+d_{5} D_{i}+u_{4 i t}
$$

Trade Values (Exports plus Imports)

$$
\begin{aligned}
\log T_{i t}= & e_{0}+e_{1} \log Y_{i t}+e_{2} \log F D I_{i t}+e_{3} \log R_{i t}+e_{4} \log E R_{1 t} \\
& +e_{5}\left(\log T N_{t}\right) *\left(\log T P_{i}\right)+e_{6} D_{i}+e_{7} D T_{t}+u_{5 i t}
\end{aligned}
$$

Foreign Direct Investment (FDI) Inflows

$$
\begin{aligned}
\log F D I_{i t}= & f_{0}+f_{1} \log Y_{i t}+f_{2} \log r_{i t}+f_{3} \log C F D I_{i(t-1)}+f_{4} \log T I_{i t} \\
& +f_{5} \log T A X_{i t}+f_{6} \log P G D P_{i(t-1)}+f_{7} D_{i}+f_{8} D T_{t}+u_{6 i t}
\end{aligned}
$$


$\log Y_{i t}-a_{4} \log E_{i t}-a_{1} \log T_{i t}-a_{2} \log L_{i t}-a_{3} \log K_{i t}-a_{0}=u_{1 i t}$

$-b_{2} \log Y_{i t}+\log E_{i t}-b_{1} \log r_{i t}-b_{3}\left(\log Y_{i t}\right)^{2}-b_{4} \log S_{i t}-b_{5} \log S O E_{i t}-b_{0}=u_{2 i t}$

$-c_{2} \log Y_{i t}-c_{1} \log E_{i t}+\log r_{i t}+c_{2}{ }^{\prime} \log P_{i t}-c_{3} \log C_{i t}-c_{4} \log e d_{i t}-c_{5} \log P D i t-c_{0}=u_{3 i t}$

$-d_{2} \log Y_{i t}+\log S_{i t}-d_{1} \log T_{i t}-d_{3} \log S_{i(t-1)}-d_{4} \log V_{i t}-d_{5} D_{i}-d_{0}=u_{4 i t}$

$-e_{1} \log Y_{i t}+\log T_{i t}-e_{2} \log F D I_{i t}-e_{3} \log R_{i t}-e_{4} \log E R_{t}-e_{5} \log T N_{t} * \log T P_{i}$

$-e_{6} D_{i}-e_{7} D T_{t}-e_{0}=u_{5 i t}$

$-f_{1} \log Y_{i t}-f_{2} \log r_{i t}+\log F D I_{i t}-f_{3} \log C F D I_{i(t-1)}-f_{4} \log T I_{i t}-f_{5} \log T A X_{i t}$

$-f_{6} \log P G D P P_{i(t-1)}-f_{7} D_{i}-f_{8} D T_{t}-f_{0}=u_{6 i t}$

where $c_{2}=c_{2}$ '.

In matrix terms, the system can be written

$$
\left(\begin{array}{ccccccc}
1 & -a_{4} & 0 & 0 & -a_{1} & 0 & 0 \\
-b_{2} & 1 & -b_{1} & -b_{4} & 0 & 0 & -b_{3} \\
-c_{2} & -c_{1} & 1 & 0 & 0 & 0 & 0 \\
-d_{2} & 0 & 0 & 1 & -d_{1} & 0 & 0 \\
-e_{1} & 0 & 0 & 0 & 1 & -e_{2} & 0 \\
-f_{1} & 0 & -f_{2} & 0 & 0 & 1 & 0
\end{array}\right)\left(\begin{array}{c}
\log Y_{i t} \\
\log E_{i t} \\
\log r_{i t} \\
\log S_{i t} \\
\log T_{i t} \\
\log F D I_{i t} \\
\left(\log Y_{i t}\right)^{2}
\end{array}\right)+
$$

$\left(\begin{array}{ccccccccccccccccccc}-a_{2}-a_{3} & 0 & 0 & 0 & 0 & 0 & 0 & 0 & 0 & 0 & 0 & 0 & 0 & 0 & 0 & 0 & 0 & -a_{0} \\ 0 & 0 & -b_{5} & 0 & 0 & 0 & 0 & 0 & 0 & 0 & 0 & 0 & 0 & 0 & 0 & 0 & 0 & 0 & -b_{0} \\ 0 & 0 & 0 & c_{2}{ }^{\prime}-c_{3} & -c_{4} & -c_{5} & 0 & 0 & 0 & 0 & 0 & 0 & 0 & 0 & 0 & 0 & 0 & -c_{0} \\ 0 & 0 & 0 & 0 & 0 & 0 & 0 & -d_{3}-d_{4} & 0 & 0 & 0 & 0 & 0 & 0 & 0 & -d_{5} & 0 & -d_{0} \\ 0 & 0 & 0 & 0 & 0 & 0 & 0 & 0 & 0 & -e_{3}-e_{4}-e_{5} & 0 & 0 & 0 & 0 & -e_{6}-e_{7}-e_{0} \\ 0 & 0 & 0 & 0 & 0 & 0 & 0 & 0 & 0 & 0 & 0 & 0 & -f_{3} & -f_{4}-f_{5}-f_{6}-f_{7}-f_{8}-f_{0}\end{array}\right) *$ 


$$
\left(\begin{array}{c}
\log L_{i t} \\
\log K_{i t} \\
\log S O E_{i t} \\
\log P_{i t} \\
\log C_{i t} \\
\log e d_{i t} \\
\log P D_{i t} \\
\log S_{i(t-1)} \\
\log V_{i t} \\
\log R_{i t} \\
\log E R_{t} \\
\log T N_{t} \times \log T P_{i} \\
\log C F D I_{i(t-1)} \\
\log T I_{i t} \\
\log T A X_{i t} \\
\log P G D P_{i(t-1)} \\
D_{i} \\
D T_{t} \\
1
\end{array}\right)=\left(\begin{array}{l}
u_{1 i t} \\
u_{2 i t} \\
u_{3 i t} \\
u_{4 i t} \\
u_{5 i t} \\
u_{6 i t}
\end{array}\right)
$$

Again, $c_{2}=c_{2}$.

It can be noticed that this system is linear in parameters but nonlinear in variables. In particular with the term $\left(\log \mathrm{Y}_{\mathrm{it}}\right)^{2}$, nonlinearity in the endogenous variables arises, and this makes the identification problem even more complicated (Fisher 1976, Brown 1983, and McConnell and Phipps 1987). Fortunately, there exists a useful result for the common case, such as Equation (5-2), in which the endogenous variables and nonlinear functions of them each involve a single variable (Fisher 1976, Goldfeld and Quandt 1972, and Greene 1997). Let $A$ be the structure coefficients matrix with one row for each equation and one column for each variable, $\Phi_{j}$ be the restrictions matrix on the parameters of the $j$ th equation, in which one column stands for each restriction and one 
row for each parameter in the equation, and $M$ be the number of the endogenous variables; then the necessary and sufficient rank condition for the $j$ th equation to be identifiable is:

$$
\operatorname{rank}\left[A \Phi_{j}\right]=M-1
$$

This system can be extended simply by adding the nonlinear functions to the system as additional endogenous variables and maintaining the same number of equations (as shown in Equation (5-2)), while the necessary order condition is that

$$
\operatorname{rank}\left[\Phi_{j}\right] \geq M-1
$$

Based on the above identification criteria, it is not difficult to find that all of the six equations in the model are over-identified; therefore, the corresponding system is thus also identified.

\subsection{Model Estimation}

To properly estimate the above model, two tasks must be resolved. First, we need to deal with the difficulties of computation and statistical inference that usually arise in the estimation of a nonlinear simultaneous equations system (Amemiya 1985, and Goldfeld and Quandt 1972). For instance, because of the nonlinearity, it may not be possible to solve for the reduced-form equations, and hence the application of two stage least squares (2SLS) becomes difficult (Greene 1997). In the present case, because of the presence of the squared output term in the second equation of (5-2), the reduced form equations of the system consist of functions of the square root of linear relations among the exogenous variables. Kelejian (1971), Parke (1982), and Amemiya (1985), however, demonstrate that equivalent systems linear in parameters but nonlinear in endogenous 
variables can still be consistently estimated with 2SLS based on a Taylor expansion approximation for the reduced-form equations, using a polynomial function of the exogenous variables.

Second, though more precise parameter estimates may be obtained by exploiting the variation in data both across individuals and within individuals over time, the exploitation in a nonlinear simultaneous equation setting is obviously a challenge, particularly when error components are considered. Hsiao (1986) and Baltagi (1995), nonetheless, provide a general treatment of panel data in a linear simultaneous equations framework. There also are a number of ways of dealing with simultaneous equations with unobservable error components (Baltagi 1981 and 1984, Magnus 1982, Prucha 1985, and Kinal and Lahiri 1990 and 1993). Despite the success of the methodological research, few applications of these techniques have been followed in empirical studies (Maddala 1987, and Kinal and Lahiri 1993).

This study attempts to extend such applications by employing 2SLS and approximating the reduced-form equations with second-degree polynomials. Specifically, fitted values for 2SLS are obtained by regressing all of the endogenous variables, including $\log ^{2} Y$ and $\log (Y / p)$ on a constant, the exogenous variables and their squares, and all distinct cross products. This process includes three estimation strategies. (1) System (5-2) can be estimated simply by pooling the data with no fixed or random effect specifications. (2) Provincial and time period fixed effects can be included in the estimation. And (3) a two-way error components 2SLS(EC2SLS) method is tried for overall system estimation. The coding and estimating of the model then follows employing Eviews (version 4.0 or 3.1 ). The Eviews codes written for estimating the 
model are attached in Appendix B. Three different sets of results are presented here: the first with no fixed or random effects, the second with fixed effects, and the third with random effects.

\subsubsection{SLS Estimation Results}

The 2SLS estimates of the six structural equations shown in Table 5.4-5.9 assumes that given exogenous variables $X_{i t}, E\left[u_{j i t} \mid X_{i t}\right]=0, E\left[u_{j i t}{ }^{2} \mid X_{i t}\right]=\sigma_{j}^{2}$, and $E\left[u_{j i t}\right.$ $\left.\mathrm{u}_{\mathrm{jks}}\right]=0$, for all $\mathrm{i} \neq \mathrm{k}$ and $\mathrm{t} \neq \mathrm{s}$, i.e., no fixed or random effects are controlled for in this estimator. Since both the economic and the environmental data differ significantly in magnitude over provinces, heteroskedasticity problems may arise. The 2SLS provide consistent parameter estimates in the presence of heteroskedasticity, but the 2SLS standard errors will be incorrect and should not be used for inference. Therefore, the White heteroskedasticity consistent covariance matrix estimator is applied to derive the correct estimates of coefficient covariances in the presence of heteroskedasticity of unknown form (see Eviews User's Guide 1997).

\section{Industrial wastewater discharges as the emissions variable}

Table 5.4 summarizes the results in the case that industrial wastewater discharges and the levy rate on industrial wastewater discharges are included as key environmental variables in the system. Most of the coefficients of the variables bear the expected signs and are significantly different from zero. The first equation shows, as expected, that increases in industrial wastewater discharges, trade, labor input, and capital input will 
Table 5.4 2SLS Estimates When Industrial Wastewater (IWW) Included

\begin{tabular}{|c|c|c|c|c|c|c|}
\hline \multirow[b]{2}{*}{$\begin{array}{l}\text { ( } t \text {-statistics } \\
\text { are shown in } \\
\text { parentheses) }\end{array}$} & \multicolumn{3}{|c|}{ Dependent } & \multicolumn{3}{|c|}{ Variable } \\
\hline & $\begin{array}{c}\text { GDP } \\
(\log Y) \\
(1)\end{array}$ & $\begin{array}{l}\text { IWW } \\
(\log E) \\
(2)\end{array}$ & $\begin{array}{c}\text { Levy rate } \\
\text { on IWW } \\
(\log r) \\
(3)\end{array}$ & $(\log S)$ & $(\log T)$ & $\begin{array}{c}\text { FDI } \\
(\log \text { FDI }) \\
(6)\end{array}$ \\
\hline Constant & $\begin{array}{c}-1.238 \\
(-10.903) \\
\end{array}$ & $\begin{array}{c}-5.327 \\
(-4.003)\end{array}$ & $\begin{array}{c}4.443 \\
(7.721) \\
\end{array}$ & $\begin{array}{c}0.223 \\
(3.295) \\
\end{array}$ & $\begin{array}{l}10.619 \\
(4.382)\end{array}$ & $\begin{array}{c}-2.212 \\
(-1.694) \\
\end{array}$ \\
\hline $\begin{array}{l}\text { GDP } \\
(\log Y) \\
\end{array}$ & & $\begin{array}{c}2.406 \\
(6.426) \\
\end{array}$ & & $\begin{array}{c}-0.011 \\
(-1.021) \\
\end{array}$ & $\begin{array}{c}0.715 \\
(11.689) \\
\end{array}$ & $\begin{array}{c}1.010 \\
(6.332) \\
\end{array}$ \\
\hline $\begin{array}{l}\text { GDP Square } \\
\left(\log ^{2} Y\right)\end{array}$ & & $\begin{array}{c}-0.103 \\
(-3.413)\end{array}$ & & & & \\
\hline $\begin{array}{l}\text { Income } \\
(\log (Y / P))\end{array}$ & & & $\begin{array}{c}0.264 \\
(3.609)\end{array}$ & & & \\
\hline $\begin{array}{l}\text { Emissions } \\
(\mathrm{IWW})(\log \mathrm{E})\end{array}$ & $\begin{array}{c}0.137 \\
(6.466) \\
\end{array}$ & & $\begin{array}{c}-0.055 \\
(-1.833) \\
\end{array}$ & & & \\
\hline $\begin{array}{l}\text { Levy Rate on } \\
\text { IWW }(\log r)\end{array}$ & & $\begin{array}{c}-0.509 \\
(-6.741)\end{array}$ & & & & $\begin{array}{c}0.252 \\
(0.962)\end{array}$ \\
\hline $\begin{array}{l}\text { Industrial output } \\
\text { share }(\log S)\end{array}$ & & $\begin{array}{c}-0.108 \\
(-0.671)\end{array}$ & & & & \\
\hline $\begin{array}{l}\text { Trade } \\
(\log T) \\
\end{array}$ & $\begin{array}{c}0.157 \\
(10.072) \\
\end{array}$ & & & $\begin{array}{c}0.006 \\
(1.273) \\
\end{array}$ & & \\
\hline $\begin{array}{l}\text { FDI } \\
(\log F D I)\end{array}$ & & & & & $\begin{array}{c}0.127 \\
(4.032)\end{array}$ & \\
\hline $\begin{array}{l}\text { Labor } \\
(\log \mathrm{L})\end{array}$ & $\begin{array}{c}0.345 \\
(16.746)\end{array}$ & & & & & \\
\hline $\begin{array}{l}\text { Capital } \\
(\log K)\end{array}$ & $\begin{array}{c}0.357 \\
(17.890) \\
\end{array}$ & & & & & \\
\hline $\begin{array}{l}\text { State-owned } \\
\text { Enterprises } \\
(\log \text { SOE) }\end{array}$ & & $\begin{array}{c}0.430 \\
(4.946)\end{array}$ & & & & \\
\hline $\begin{array}{l}\text { Citizen } \\
\text { Complaints } \\
(\log C)\end{array}$ & & & $\begin{array}{c}-0.163 \\
(-2.800)\end{array}$ & & & \\
\hline $\begin{array}{l}\text { Education } \\
(\log \text { ed) }\end{array}$ & & & $\begin{array}{c}-0.362 \\
(-4.138)\end{array}$ & & & \\
\hline $\begin{array}{l}\text { Population } \\
\text { Density } \\
(\log P D)\end{array}$ & & & $\begin{array}{c}0.119 \\
(3.877)\end{array}$ & & & \\
\hline $\begin{array}{l}\text { Industrial } \\
\text { Share }_{-1} \\
\left(\log S_{-1}\right)\end{array}$ & & & & $\begin{array}{c}0.915 \\
(61.326)\end{array}$ & & \\
\hline $\begin{array}{l}\text { Investments } \\
(\log \mathrm{V})\end{array}$ & & & & $\begin{array}{c}0.023 \\
(1.877) \\
\end{array}$ & & \\
\hline $\begin{array}{l}\text { Remoteness } \\
(\log \mathrm{R})\end{array}$ & & & & & $\begin{array}{c}-0.478 \\
(-5.312)\end{array}$ & \\
\hline $\begin{array}{l}\text { Exchange rate } \\
(\log \text { E R) }\end{array}$ & & & & & $\begin{array}{c}-0.198 \\
(-0.648)\end{array}$ & \\
\hline $\begin{array}{l}\text { Tariffs } \\
(\operatorname{LogTN} * \log \mathrm{TP})\end{array}$ & & & & & $\begin{array}{c}-0.035 \\
(-0.560)\end{array}$ & \\
\hline $\begin{array}{l}\text { Cumulative FDI } \\
\left(\log \text { CFDI }_{-1}\right)\end{array}$ & & & & & & $\begin{array}{c}0.358 \\
(3.910) \\
\end{array}$ \\
\hline $\begin{array}{l}\text { Road intensity } \\
(\log T I)\end{array}$ & & & & & & $\begin{array}{c}0.648 \\
(3.270)\end{array}$ \\
\hline $\begin{array}{l}\text { Tax rate } \\
(\log \text { Tax })\end{array}$ & & & & & & $\begin{array}{c}-0.197 \\
(-1.146) \\
\end{array}$ \\
\hline $\begin{array}{l}\text { GDP per capita }_{-1} \\
\left(\log \text { PGDP }_{-1}\right)\end{array}$ & & & & & & $\begin{array}{c}0.389 \\
(1.628) \\
\end{array}$ \\
\hline $\begin{array}{l}\text { Regional } \\
\text { Dummy D }\end{array}$ & & & & $\begin{array}{c}-0.010 \\
(-1.400)\end{array}$ & $\begin{array}{c}0.542 \\
(5.095)\end{array}$ & $\begin{array}{c}0.395 \\
(2.016)\end{array}$ \\
\hline $\begin{array}{l}\text { Time Dummy } \\
\text { DT }\end{array}$ & & & & & $\begin{array}{c}0.033 \\
(0.450)\end{array}$ & $\begin{array}{c}-0.827 \\
(-4.651)\end{array}$ \\
\hline Adjusted $\mathrm{R}^{2}$ & 0.982 & 0.810 & 0.369 & 0.968 & 0.895 & 0.802 \\
\hline Observations & 252 & 252 & 252 & 252 & 252 & 252 \\
\hline
\end{tabular}


lead to GDP growth. The output elasticities of these factors are explicitly indicated by the estimated coefficients.

Most of the results from the second equation are also as expected. They confirm statistically that there exists an inverted-U relationship between industrial wastewater discharges and GDP. Given all other things equal, industrial wastewater discharges are likely to rise as GDP increases, but will reach their peak when provincial level of GDP reaches 11813.8 billion RMB yuan (about 1440.7 billion US\$), which is about 146 times as much as the mean over the 1987-1995 period. In terms of per capita GDP measure, this result implies that industrial wastewater discharge will begin to decrease when GDP per capita reaches 293,854 RMB yuan (about 35,836 US\$), which is well above a realistic level. This inverted-U relationship is further tested by an auxiliary regression of industrial wastewater discharges on a constant and GDP featuring only the provincial crosssectional data. The results of this regression show that the coefficient estimate of GDP is 1.639 for 1987 and monotonically decreases to 0.448 for 1995 . That is, though wastewater discharges increase as GDP grows, the rate of this pollution increase decreases from year to year, suggesting that industrial wastewater pollution is concave in GDP levels over time.

The results of the second also clearly suggest that China's pollution levy system is an effective instrument for industrial wastewater pollution control since, as the direct impact suggests, a one percent increase in the levy rate could lead to about a 0.5 percent decrease in industrial wastewater discharges. Some studies assert that China's pollution levy rates are too low to have significant impacts on industrial emissions (Qu 1991, NEPA 1992 and 1994, and Shibli and Markandya 1995). Our findings agree with those of 
Wang and Wheeler (1996) that, regarding the control for industrial wastewater pollution, China's levy system has proven reasonably effective. The value of the estimated coefficient of the state ownership variable confirms that the state-owned enterprises pollute more than firms of other types of ownership. It is surprising, however, that the coefficient of the industrial output share fails to carry the expected sign and is not statistically different from zero, suggesting that provinces with a higher industrial output share might be more environmentally efficient in wastewater pollution control.

The third equation indicates a positive relationship between levy rate and per capita GDP. That is, as per capita GDP increases, people would pay a higher price for a clean environment. Since this equation explains environment supply, we expect that there also exists a positive relationship between the levy rate and wastewater discharges, because, theoretically, individuals would tolerate more pollution if the polluter pays a higher price. But, in the third equation, the coefficient of wastewater discharges is negative and not significant. This might suggest a zero or a negative price elasticity for environmental supply. That is, even if a higher levy rate is in place, individuals still do not have the willingness to tolerate more pollution.

As noted earlier, China's pollution levy rates have been argued to be too low to have significant effects on pollution control. Our point is that, from the perspective of the environmental supply side, these levy rates are indeed too low for individuals to tolerate pollution discharges at the existing level. This point is supported by the significant negative coefficient of citizen environmental complaints, because a negative sign indicates citizens' unsatisfaction with the environmental situation and environmental 
enforcement. Moreover, as expected, population density has a significant positive effect, and the illiteracy and semi-illiteracy rate has a significant negative effect on the levy rate.

In the fourth equation, trade might have a positive effect on industrial output share but the effect is not significantly different from zero. Different results have been obtained in studies on whether China has a comparative advantage in pollution-intensive goods (Dasgupta et al. 1997 and Dean 1999). Our results suggest that trade does not have a significant impact on industrial output share, and, therefore, China may not have a comparative advantage in relatively pollution-intensive industrial goods. The result is consistent with the fact that the shares of manufactured goods in China's total exports and imports are very close for most of the 1987-1995 period (See Table 4.2 and Table 4.3). The coefficients of GDP and the regional policy dummy variable both have the expected negative signs but are not significant. As is the case of many developing countries, industrialization still provides a key to China's economic development (Syrquin (1989) offers a discussion on structural change in development). Therefore, it is not surprising that GDP does not have a significant negative effect on the industrial output share. In addition, the coefficient of the investment variable shows that China's investments in fixed assets tend to slightly increase the industrial output share, indicating a strengthened trend of industrialization. The results also confirm that the share of industrial output heavily depends on its previous level.

In the fifth equation, variables derived from the gravity model, i.e. GDP and remoteness, both bear the expected signs and are statistically significant. Also as expected, both FDI and regional geographical and policy dummy variable have significant positive effects on trade. The coefficient of the exchange rate suggests that a 
one percent increase in the exchange rate might lead to more trade, though the coefficient is negative (since trade is measured in US dollars, any change in the exchange rate should change trade by the same magnitude but in opposite direction given the real trade flow constant). Unfortunately, this coefficient is not statistically significant. Similarly, the coefficient of tariffs might suggest that lower tariffs would stimulate trade, but it is not statistically significant either.

In addition, we expect that the 1989 Tiananmen Square Incident may have had a negative effect on trade because of the economic sanctions that Western countries imposed on China in those years. The results, however, show that this impact is not significant and, if it were, the impact would probably be positive. This is not difficult to understand. Though in those years China's trade with its major Western trading partners such as the United States and Japan was negatively affected, this negative impact might have been overcompensated by China's efforts to expand its trade with its other trading partners.

Finally, in the sixth equation, except for the levy rate coefficient all results have the expected effects though the coefficient of taxes fails the $t$ test. Provinces with higher GDP, cumulative FDIs, GDP per capita, and road intensity receive more FDIs. Also, coastal provinces are more attractive to multinational firms. Higher taxes may have a negative effect on FDI inflows, but this effect is not significant. Though no negative trade effect has been associated with the 1989 Tiananmen Square Incident in the fifth equation, the coefficient of the time dummy clearly indicates that the 1989 Incident had a significant negative impact on FDI inflows (the same result is obtained in Ni 1998). It is interesting to note that the levy rate variable does not have a negative effect on FDIs. 
Indeed this result is not surprising. So far no study has found hard evidence that environmental policies are crucial in the location choice of multinationals.

\section{Industrial waste gas discharges as the emissions variable}

Table 5.5 presents the results when industrial waste gas emissions and the levy rate on these emissions are used as endogenous environmental variables. The first equation does not change much. All estimates have the expected signs and are statistically significant. In the second equation, the coefficient of the levy rate suggests that China's levy system is not significantly effective in controlling industrial waste gas emissions. Also unlike wastewater pollution, an inverted-U relationship between waste gas emissions and GDP is not identified. Instead, a positive linear relationship is suggested. Another difference is that the share of industrial output has a significant positive effect on waste gas discharges. If, as suggested by the estimation in Table 5.4, provinces with a higher industrial share may be more efficient in wastewater pollution control, then the same is not true for the waste gas pollution case. As before, state-owned factories show a lower efficiency in waste gas control.

There are also some important changes in the third equation. The coefficient of GDP per capita is negative and significant, implying that higher GDP per capita does not lead to stricter enforcement of waste gas emissions control. Combining results from the second and the third equation may explain why many air-polluted cities can be found in China. Besides, population density does not show a statistically significant effect on the levy rate on waste gas discharges. Moreover, citizens' environmental complaints might 
Table 5.5 2SLS Results When Industrial Waste Gas Emissions (IGE) Included

\begin{tabular}{|c|c|c|c|c|c|c|}
\hline \multirow[b]{2}{*}{$\begin{array}{l}\text { ( } t \text {-statistics } \\
\text { are shown in } \\
\text { parentheses) }\end{array}$} & \multicolumn{3}{|c|}{ Dependent } & \multicolumn{3}{|c|}{ Variable } \\
\hline & $\begin{array}{c}\text { GDP } \\
(\log Y) \\
(1)\end{array}$ & $\begin{array}{c}\mathrm{IGE} \\
(\log \mathrm{E}) \\
(2)\end{array}$ & $\begin{array}{c}\text { Levy rate } \\
\text { on IGE } \\
(\log r) \\
(3)\end{array}$ & $\begin{array}{c}(\log S) \\
(4) \\
\end{array}$ & $\begin{array}{l}\text { Trade } \\
(\log \mathrm{T}) \\
(5)\end{array}$ & $\begin{array}{c}\text { FDI } \\
(\log \text { FDI }) \\
(6) \\
\end{array}$ \\
\hline Constant & $\begin{array}{c}-1.541 \\
(-15.611) \\
\end{array}$ & $\begin{array}{c}-4.616 \\
(-5.205) \\
\end{array}$ & $\begin{array}{c}1.672 \\
(2.011) \\
\end{array}$ & $\begin{array}{c}0.223 \\
(3.295) \\
\end{array}$ & $\begin{array}{l}10.619 \\
(4.382) \\
\end{array}$ & $\begin{array}{c}-2.093 \\
(-1.657) \\
\end{array}$ \\
\hline $\begin{array}{l}\text { GDP } \\
(\log Y)\end{array}$ & & $\begin{array}{c}0.835 \\
(2.690) \\
\end{array}$ & & $\begin{array}{c}-0.011 \\
(-1.001) \\
\end{array}$ & $\begin{array}{c}0.715 \\
(11.689) \\
\end{array}$ & $\begin{array}{c}1.064 \\
(5.867) \\
\end{array}$ \\
\hline $\begin{array}{l}\text { GDP Square } \\
\left(\log ^{2} Y\right)\end{array}$ & & $\begin{array}{c}0.002 \\
(0.063) \\
\end{array}$ & & & & \\
\hline $\begin{array}{l}\text { Income } \\
(\log (Y / P)\end{array}$ & & & $\begin{array}{c}-0.431 \\
(-5.151)\end{array}$ & & & \\
\hline $\begin{array}{l}\text { Emissions } \\
(\mathrm{IGE})(\log \mathrm{E})\end{array}$ & $\begin{array}{c}0.133 \\
(5.391) \\
\end{array}$ & & $\begin{array}{c}-0.041 \\
(-0.521) \\
\end{array}$ & & & \\
\hline $\begin{array}{l}\text { Levy Rate on } \\
\text { IGE }(\log r)\end{array}$ & & $\begin{array}{c}-0.145 \\
(-1.164) \\
\end{array}$ & & & & $\begin{array}{c}-0.057 \\
(-0.339) \\
\end{array}$ \\
\hline $\begin{array}{l}\text { Industrial output } \\
\text { share }(\log S)\end{array}$ & & $\begin{array}{c}0.632 \\
(5.366) \\
\end{array}$ & & & & \\
\hline $\begin{array}{l}\text { Trade } \\
(\log T) \\
\end{array}$ & $\begin{array}{c}0.194 \\
(14.114) \\
\end{array}$ & & & $\begin{array}{c}0.006 \\
(1.272) \\
\end{array}$ & & \\
\hline $\begin{array}{l}\text { FDI } \\
(\log F D I)\end{array}$ & & & & & $\begin{array}{c}0.127 \\
(4.032)\end{array}$ & \\
\hline $\begin{array}{l}\text { Labor } \\
(\log L)\end{array}$ & $\begin{array}{c}0.410 \\
(28.641) \\
\end{array}$ & & & & & \\
\hline $\begin{array}{l}\text { Capital } \\
(\log K) \\
\end{array}$ & $\begin{array}{c}0.285 \\
(15.561) \\
\end{array}$ & & & & & \\
\hline $\begin{array}{l}\text { State-owned } \\
\text { Enterprises } \\
(\log \mathrm{SOE}) \\
\end{array}$ & & $\begin{array}{c}0.656 \\
(6.524)\end{array}$ & & & & \\
\hline $\begin{array}{l}\text { Citizen } \\
\text { Complaints } \\
(\log C)\end{array}$ & & & $\begin{array}{c}0.057 \\
(0.956)\end{array}$ & & & \\
\hline $\begin{array}{l}\text { Education } \\
(\log \text { ed })\end{array}$ & & & $\begin{array}{c}-0.279 \\
(-2.292) \\
\end{array}$ & & & \\
\hline $\begin{array}{l}\text { Population } \\
\text { Density } \\
(\log P D)\end{array}$ & & & $\begin{array}{c}0.004 \\
(0.112)\end{array}$ & & & \\
\hline $\begin{array}{l}\text { Industrial } \\
\text { Share }_{-1} \\
\left(\log S_{-1}\right)\end{array}$ & & & & $\begin{array}{c}0.915 \\
(61.327)\end{array}$ & & \\
\hline $\begin{array}{l}\text { Investments } \\
(\log \mathrm{V})\end{array}$ & & & & $\begin{array}{c}0.023 \\
(1.877) \\
\end{array}$ & & \\
\hline $\begin{array}{l}\text { Remoteness } \\
(\log R)\end{array}$ & & & & & $\begin{array}{c}-0.478 \\
(-5.312) \\
\end{array}$ & \\
\hline $\begin{array}{l}\text { Exchange rate } \\
(\log \text { E R) }\end{array}$ & & & & & $\begin{array}{c}-0.198 \\
(-0.648) \\
\end{array}$ & \\
\hline $\begin{array}{l}\text { Tariffs } \\
(\log \mathrm{TN} * \log \mathrm{TP})\end{array}$ & & & & & $\begin{array}{c}-0.035 \\
(-0.559) \\
\end{array}$ & \\
\hline $\begin{array}{l}\text { Cumulative FDI } \\
\left(\log \text { CFDI }_{-1}\right)\end{array}$ & & & & & & $\begin{array}{c}0.355 \\
(3.881) \\
\end{array}$ \\
\hline $\begin{array}{l}\text { Road intensity } \\
(\log T I)\end{array}$ & & & & & & $\begin{array}{c}0.631 \\
(3.223) \\
\end{array}$ \\
\hline $\begin{array}{l}\text { Tax rate } \\
(\log \text { Tax })\end{array}$ & & & & & & $\begin{array}{c}-0.152 \\
(-0.873) \\
\end{array}$ \\
\hline $\begin{array}{l}\text { GDP per capita } \\
\left(\log \text { PGDP }_{-1}\right)\end{array}$ & & & & & & $\begin{array}{c}0.435 \\
(1.866) \\
\end{array}$ \\
\hline $\begin{array}{l}\text { Regional } \\
\text { Dummy D }\end{array}$ & & & & $\begin{array}{c}-0.010 \\
(-1.400)\end{array}$ & $\begin{array}{c}0.542 \\
(5.095)\end{array}$ & $\begin{array}{c}0.444 \\
(2.449)\end{array}$ \\
\hline $\begin{array}{l}\text { Time Dummy } \\
\text { DT }\end{array}$ & & & & & $\begin{array}{c}0.033 \\
(0.450) \\
\end{array}$ & $\begin{array}{c}-0.839 \\
(-4.684) \\
\end{array}$ \\
\hline $\begin{array}{l}\text { Adjusted } \mathrm{R}^{2} \\
\text { Observations }\end{array}$ & $\begin{array}{c}0.982 \\
252\end{array}$ & $\begin{array}{c}0.771 \\
252\end{array}$ & $\begin{array}{c}0.140 \\
252\end{array}$ & $\begin{array}{c}0.968 \\
252\end{array}$ & $\begin{array}{c}0.895 \\
252\end{array}$ & $\begin{array}{c}0.802 \\
252\end{array}$ \\
\hline
\end{tabular}


have a positive effect on the levy rate but this effect is not statistically different from zero. Similar to the wastewater case, the environmental supply side is not statistically sensitive to the levy rate and a higher illiteracy rate implies a lower environmental enforcement. The fourth and the fifth equations remain unchanged since they exclude the emissions discharge and the levy rate variables. The sixth equation shows that the levy on waste gas might have a small negative effect on FDIs, but again, the effect is not statistically significant.

\section{$\underline{\mathrm{SO}_{2}} \underline{\text { discharges as the emissions variable }}$}

The results of the $\mathrm{SO}_{2}$ emissions case are provided in Table 5.6. These emissions are very harmful industrial waste gases and hence regulated under the levy system. As expected and similar to the results obtained by Dasgupta, Wang and Wheeler (1997), the levy rate on waste gases is a significantly effective means of $\mathrm{SO}_{2}$ emissions control. The results also suggest that there might exist an inverted-U relationship between $\mathrm{SO}_{2}$ emissions and GDP levels, but this relationship is not statistically significant. It is worth noting that, according to the coefficient of industrial output share, provinces with higher industrial GDP shares are significantly more efficient in $\mathrm{SO}_{2}$ emissions removal (in the wastewater case, a similar result is suggested but lacks statistical significance). State-

owned enterprises once again are less environmentally friendly because they emit more $\mathrm{SO}_{2}$ than firms under other types of ownership. Other results in this table are, as expected, same as the corresponding results in Table 5.5. 
Table 5.6 2SLS Results When Industrial $\mathrm{SO}_{2}$ Emissions Included

\begin{tabular}{|c|c|c|c|c|c|c|}
\hline \multirow[b]{2}{*}{$\begin{array}{l}\text { ( } t \text {-statistics } \\
\text { are shown in } \\
\text { parentheses) }\end{array}$} & \multicolumn{3}{|c|}{ Dependent } & \multicolumn{3}{|c|}{ Variable } \\
\hline & $\begin{array}{c}\text { GDP } \\
(\log Y) \\
(1)\end{array}$ & $\begin{array}{c}\mathrm{SO}_{2} \\
(\log \mathrm{E}) \\
(2)\end{array}$ & $\begin{array}{c}\text { Levy rate } \\
\text { on } \mathrm{IGE} \\
(\log r) \\
(3)\end{array}$ & $\begin{array}{l}\text { Industrial share } \\
(\log S) \\
(4)\end{array}$ & $\begin{array}{l}\text { Trade } \\
(\log \mathrm{T}) \\
(5)\end{array}$ & $\begin{array}{c}\text { FDI } \\
\left(\log _{(6)} \text { FDI }\right)\end{array}$ \\
\hline Constant & $\begin{array}{c}-1.836 \\
(-17.695\end{array}$ & $\begin{array}{c}6.332 \\
(3.364)\end{array}$ & $\begin{array}{c}2.280 \\
(2.484)\end{array}$ & $\begin{array}{c}0.223 \\
(3.295)\end{array}$ & $\begin{array}{l}10.619 \\
(4.382)\end{array}$ & $\begin{array}{c}-2.093 \\
(-1.657)\end{array}$ \\
\hline $\begin{array}{l}\text { GDP } \\
(\log Y)\end{array}$ & & $\begin{array}{c}0.991 \\
(1.734)\end{array}$ & & $\begin{array}{c}-0.011 \\
(-1.001)\end{array}$ & $\begin{array}{c}0.715 \\
(11.689)\end{array}$ & $\begin{array}{c}1.064 \\
(5.867)\end{array}$ \\
\hline $\begin{array}{l}\text { GDP Square } \\
\left(\log ^{2} Y\right)\end{array}$ & & $\begin{array}{l}-0.005 \\
(-0.117)\end{array}$ & & & & \\
\hline $\begin{array}{l}\text { Income } \\
(\log (\mathrm{Y} / \mathrm{P}))\end{array}$ & & & $\begin{array}{c}-0.459 \\
(-5.359)\end{array}$ & & & \\
\hline $\begin{array}{l}\text { Emissions } \\
\left(\mathrm{SO}_{2}\right)(\log \mathrm{E})\end{array}$ & $\begin{array}{c}0.045 \\
(3.250)\end{array}$ & & $\begin{array}{c}-0.058 \\
(-1.411)\end{array}$ & & & \\
\hline $\begin{array}{l}\text { Levy Rate on } \\
\text { IGE }(\log r)\end{array}$ & & $\begin{array}{c}-0.223 \\
(-2.288)\end{array}$ & & & & $\begin{array}{c}-0.057 \\
(-0.339)\end{array}$ \\
\hline $\begin{array}{l}\text { Industrial output } \\
\text { share }(\log S)\end{array}$ & & $\begin{array}{c}-0.404 \\
(-2.191)\end{array}$ & & & & \\
\hline $\begin{array}{l}\text { Trade } \\
(\log T)\end{array}$ & $\begin{array}{c}0.205 \\
(14.278)\end{array}$ & & & $\begin{array}{c}0.006 \\
(1.272)\end{array}$ & & \\
\hline $\begin{array}{l}\text { FDI } \\
(\log \text { FDI })\end{array}$ & & & & & $\begin{array}{c}0.127 \\
(4.032)\end{array}$ & \\
\hline $\begin{array}{l}\text { Labor } \\
(\log \mathrm{L})\end{array}$ & $\begin{array}{c}0.430 \\
(27.572)\end{array}$ & & & & & \\
\hline $\begin{array}{l}\text { Capital } \\
(\log K)\end{array}$ & $\begin{array}{c}0.311 \\
(15.438)\end{array}$ & & & & & \\
\hline $\begin{array}{l}\text { State-owned } \\
\text { Enterprises } \\
(\log \mathrm{SOE})\end{array}$ & & $\begin{array}{c}0.603 \\
(4.065)\end{array}$ & & & & \\
\hline $\begin{array}{l}\text { Citizen } \\
\text { Complaints } \\
(\log C)\end{array}$ & & & $\begin{array}{c}0.050 \\
(0.811)\end{array}$ & & & \\
\hline $\begin{array}{l}\text { Education } \\
(\log \text { ed) }\end{array}$ & & & $\begin{array}{c}-0.294 \\
(-2.259)\end{array}$ & & & \\
\hline $\begin{array}{l}\text { Population } \\
\text { Density } \\
(\log P D)\end{array}$ & & & $\begin{array}{c}0.016 \\
(0.483)\end{array}$ & & & \\
\hline $\begin{array}{l}\text { Industrial } \\
\text { Share }_{-1} \\
\left(\log \mathrm{S}_{-1}\right)\end{array}$ & & & & $\begin{array}{c}0.915 \\
(61.327)\end{array}$ & & \\
\hline $\begin{array}{l}\text { Investments } \\
(\log \mathrm{V})\end{array}$ & & & & $\begin{array}{c}0.023 \\
(1.877)\end{array}$ & & \\
\hline $\begin{array}{l}\text { Remoteness } \\
(\log R)\end{array}$ & & & & & $\begin{array}{c}-0.478 \\
(-5.312)\end{array}$ & \\
\hline $\begin{array}{l}\text { Exchange rate } \\
\text { (log E R) }\end{array}$ & & & & & $\begin{array}{c}-0.198 \\
(-0.648)\end{array}$ & \\
\hline $\begin{array}{l}\text { Tariffs } \\
(\operatorname{LogTN} * \log \mathrm{TP})\end{array}$ & & & & & $\begin{array}{c}-0.035 \\
(-0.559)\end{array}$ & \\
\hline $\begin{array}{l}\text { Cumulative FDI } \\
\left(\log _{\left.\mathrm{CFDI}_{-1}\right)}\right.\end{array}$ & & & & & & $\begin{array}{c}0.355 \\
(3.881)\end{array}$ \\
\hline $\begin{array}{l}\text { Road intensity } \\
(\log T I)\end{array}$ & & & & & & $\begin{array}{c}0.631 \\
(3.223)\end{array}$ \\
\hline $\begin{array}{l}\text { Tax rate } \\
(\log \text { Tax })\end{array}$ & & & & & & $\begin{array}{c}-0.152 \\
(-0.873)\end{array}$ \\
\hline $\begin{array}{l}\text { GDP per capita } \\
\left.\left(\log _{\text {PGDP }}\right)_{-1}\right)\end{array}$ & & & & & & $\begin{array}{c}0.435 \\
(1.866)\end{array}$ \\
\hline $\begin{array}{l}\text { Regional } \\
\text { Dummy D }\end{array}$ & & & & $\begin{array}{c}-0.010 \\
(-1.400)\end{array}$ & $\begin{array}{c}0.542 \\
(5.095)\end{array}$ & $\begin{array}{c}0.444 \\
(2.449)\end{array}$ \\
\hline $\begin{array}{l}\text { Time Dummy } \\
\text { DT }\end{array}$ & & & & & $\begin{array}{c}0.033 \\
(0.450)\end{array}$ & $\begin{array}{c}-0.839 \\
(-4.684)\end{array}$ \\
\hline $\begin{array}{l}\text { Adjusted } \mathrm{R}^{2} \\
\text { Observations }\end{array}$ & $\begin{array}{c}0.979 \\
252\end{array}$ & $\begin{array}{c}0.553 \\
252\end{array}$ & $\begin{array}{c}0.143 \\
252\end{array}$ & $\begin{array}{c}0.968 \\
252\end{array}$ & $\begin{array}{c}0.895 \\
252\end{array}$ & $\begin{array}{c}0.802 \\
252\end{array}$ \\
\hline
\end{tabular}




\section{$\mathrm{CO}_{2}$ discharges as the emissions variable}

Table 5.7 reports the results in the case that $\mathrm{CO}_{2}$ emissions are used as the endogenous emissions variable. The levy rate on industrial gas emissions is applied to the case as a proxy for $\mathrm{CO}_{2}$ emissions' price because China does not impose separate charges on $\mathrm{CO}_{2}$ emissions. Also, some $\mathrm{CO}_{2}$ emissions may have been counted as part of industrial waste gas discharges, but keep in mind, our $\mathrm{CO}_{2}$ emissions data are from a different data source and emissions are not limited to industrial pollution sources. The only significant difference between the results of Table 5.6 and those of Table 5.5 is that the coefficient of the levy rate on $\mathrm{CO}_{2}$ emissions, though negative in sign, is not statistically different from zero. This result is reasonable since this levy rate is not purposed to control $\mathrm{CO}_{2}$ emissions. The result also provides indirect proof that China's industrial wastewater and $\mathrm{SO}_{2}$ emissions control levy system, which has been identified in the results shown in Table 5.4 and 5.6, actually works.

\section{Particle and dust discharges as emissions variables}

The particle and dust emissions endogenous variables are also regressed separately, though detailed examination of the data does not clearly indicate whether these two pollutants are included in China's industrial waste gas statistics or not. The results of these two regressions are reported in Table 5.8 and Table 5.9 respectively. In Table 5.8 the levy rate on industrial waste gases shows no statistically justifiable effect on particle emissions and all other estimates show little deviations from those of the industrial gas emissions case. However, in the dust emissions case (see Table 5.9), some results are significantly different from those of the previous cases. The role of dust 
emissions as a production factor is still manifested in the first equation, but any association between GDP and dust emissions in the second equation is statistically weak and insignificant. This suggests that dust emissions do not increase as the economy grows. The other result that contradicts our previous finding is the significant positive relationship between the levy rate and dust emissions. This statistically significant and positive relationship is also present in the third equation. Since the second equation is no longer an equation describing environmental demand due to the fact that the levy rate is not directly related to the price that the polluter pays for dust emissions, together with the results of the third equation, this positive relationship suggests that more dust emissions may lead to higher levy rates, i.e., stricter environmental policy enforcement.

\subsubsection{SLS Estimation Results with Fixed Effects}

The following general form of structured equations $\mathrm{j}(\mathrm{j}=1,2, \ldots, 6)$ is used to obtain the 2SLS estimation, now including a fixed effect:

$$
\mathrm{y}_{\mathrm{j}}=\mathrm{Y}_{\mathrm{j}} *_{\mathrm{j}}+\mathrm{X}_{\mathrm{j}} \exists_{\mathrm{j}}+\forall_{\mathrm{j}}+\mathrm{c}_{\mathrm{j}}+\gamma_{\mathrm{j}}
$$

where $y_{j}$ is an $N T \times 1$ vector of observations of the dependent variable, $Y_{j}$ the data matrix of included endogenous variables, $\mathrm{X}_{\mathrm{j}}$ the data matrix of included exogenous variables, $*_{\mathrm{j}}$ and $\exists_{\mathrm{j}}$ are parameter vectors to be estimated, and $\forall_{\mathrm{j}}$ and ${ }_{\mathrm{j}}$ are respectively the matrices of the provincial individual and time period effects:

$$
\forall_{\mathrm{j}}=\operatorname{diag}\left(\forall_{\mathrm{j} 1}, \ldots, \forall_{\mathrm{jN}}\right) \otimes \mathrm{e}_{\mathrm{T}}
$$

and $\quad\left({ }_{\mathrm{j}}=\mathrm{e}_{\mathrm{N}} \otimes \operatorname{diag}\left(\left(_{\mathrm{j} 1}, \ldots,{ }_{\mathrm{jT}}\right)\right.\right.$

where $\mathrm{e}_{\mathrm{T}}$ is a $\mathrm{T} \times 1$ vector of ones, $\mathrm{e}_{\mathrm{N}}$ an $\mathrm{N} \times 1$ vector of ones, and diag denotes a diagonal matrix. The disturbance terms $\gamma_{j}$ represent an $\mathrm{NT} \times 1$ vector assuming conventional 
Table 5.7 2SLS Results When $\mathrm{CO}_{2}$ Emissions Included

\begin{tabular}{|c|c|c|c|c|c|c|}
\hline \multirow[b]{2}{*}{$\begin{array}{l}\text { ( } t \text {-statistics } \\
\text { are shown in } \\
\text { parentheses) }\end{array}$} & \multicolumn{3}{|c|}{ Dependent } & \multicolumn{3}{|c|}{ Variable } \\
\hline & $\begin{array}{c}\text { GDP } \\
(\log Y) \\
(1)\end{array}$ & $\begin{array}{c}\mathrm{CO}_{2} \\
(\log \mathrm{E}) \\
(2)\end{array}$ & $\begin{array}{l}\text { Levy rate } \\
\text { on IGE } \\
(\log r) \\
\text { (3) }\end{array}$ & $\begin{array}{l}\text { Industrial share } \\
(\log S) \\
(4)\end{array}$ & $\begin{array}{l}\text { Trade } \\
(\log \mathrm{T}) \\
(5)\end{array}$ & $\begin{array}{c}\text { FDI } \\
(\log \text { FDI }) \\
(6)\end{array}$ \\
\hline Constant & $\begin{array}{c}-1.204 \\
(-10.267)\end{array}$ & $\begin{array}{c}-7.653 \\
(-7.135)\end{array}$ & $\begin{array}{c}1.431 \\
(2.019)\end{array}$ & $\begin{array}{c}0.223 \\
(3.295)\end{array}$ & $\begin{array}{l}10.619 \\
(4.382)\end{array}$ & $\begin{array}{c}-2.093 \\
(-1.657)\end{array}$ \\
\hline $\begin{array}{l}\text { GDP } \\
(\log Y)\end{array}$ & & $\begin{array}{c}0.849 \\
(2.955) \\
\end{array}$ & & $\begin{array}{c}-0.011 \\
(-1.001)\end{array}$ & $\begin{array}{c}0.715 \\
(11.689) \\
\end{array}$ & $\begin{array}{c}1.064 \\
(5.867) \\
\end{array}$ \\
\hline $\begin{array}{l}\text { GDP Square } \\
\left(\log ^{2} Y\right)\end{array}$ & & $\begin{array}{c}0.003 \\
(0.108)\end{array}$ & & & & \\
\hline $\begin{array}{l}\text { Income } \\
(\log (\mathrm{Y} / \mathrm{P}))\end{array}$ & & & $\begin{array}{c}-0.429 \\
(-5.123)\end{array}$ & & & \\
\hline $\begin{array}{l}\text { Emissions } \\
\left(\mathrm{CO}_{2}\right)(\log \mathrm{E})\end{array}$ & $\begin{array}{c}0.140 \\
(7.939) \\
\end{array}$ & & $\begin{array}{c}-0.021 \\
(-0.455)\end{array}$ & & & \\
\hline $\begin{array}{l}\text { Levy Rate on } \\
\text { IGE }(\log r)\end{array}$ & & $\begin{array}{c}-0.087 \\
(-1.230)\end{array}$ & & & & $\begin{array}{c}-0.057 \\
(-0.339)\end{array}$ \\
\hline $\begin{array}{l}\text { Industrial output } \\
\text { share }(\log S)\end{array}$ & & $\begin{array}{c}0.559 \\
(4.035) \\
\end{array}$ & & & & \\
\hline $\begin{array}{l}\text { Trade } \\
(\log T)\end{array}$ & $\begin{array}{c}0.205 \\
(16.378)\end{array}$ & 1 & & $\begin{array}{c}0.006 \\
(1.272)\end{array}$ & & \\
\hline $\begin{array}{l}\text { FDI } \\
(\log F D I)\end{array}$ & & & & & $\begin{array}{c}0.127 \\
(4.032)\end{array}$ & \\
\hline $\begin{array}{l}\text { Labor } \\
(\log L)\end{array}$ & $\begin{array}{c}0.403 \\
(30.858) \\
\end{array}$ & & & & & \\
\hline $\begin{array}{l}\text { Capital } \\
(\log K)\end{array}$ & $\begin{array}{c}0.273 \\
(14.803)\end{array}$ & & & & & \\
\hline $\begin{array}{l}\text { State-owned } \\
\text { Enterprises } \\
(\log \mathrm{SOE})\end{array}$ & & $\begin{array}{c}0.764 \\
(9.371)\end{array}$ & & & & \\
\hline $\begin{array}{l}\text { Citizen } \\
\text { Complaints } \\
(\log C)\end{array}$ & & & $\begin{array}{c}0.059 \\
(0.955)\end{array}$ & & & \\
\hline $\begin{array}{l}\text { Education } \\
(\log \text { ed) }\end{array}$ & & & $\begin{array}{c}-0.263 \\
(-2.005) \\
\end{array}$ & & & \\
\hline $\begin{array}{l}\text { Population } \\
\text { Density } \\
(\log P D)\end{array}$ & & & $\begin{array}{c}-0.001 \\
(-0.039)\end{array}$ & & & \\
\hline $\begin{array}{l}\text { Industrial } \\
\text { Share }_{-1} \\
\left(\log S_{-1}\right)\end{array}$ & & & & $\begin{array}{c}0.915 \\
(61.327)\end{array}$ & & \\
\hline $\begin{array}{l}\text { Investments } \\
(\log V)\end{array}$ & & & & $\begin{array}{c}0.023 \\
(1.877)\end{array}$ & & \\
\hline $\begin{array}{l}\text { Remoteness } \\
(\log \mathrm{R})\end{array}$ & & & & & $\begin{array}{c}-0.478 \\
(-5.312) \\
\end{array}$ & \\
\hline $\begin{array}{l}\text { Exchange rate } \\
(\log E \mathrm{R})\end{array}$ & & & & & $\begin{array}{c}-0.198 \\
(-0.648)\end{array}$ & \\
\hline $\begin{array}{l}\text { Tariffs } \\
(\log \mathrm{TN} * \log \mathrm{TP})\end{array}$ & & & & & $\begin{array}{c}-0.035 \\
(-0.559)\end{array}$ & \\
\hline $\begin{array}{l}\text { Cumulative FDI } \\
\left(\log \mathrm{CFDI}_{-1}\right)\end{array}$ & & & & & & $\begin{array}{c}0.355 \\
(3.881)\end{array}$ \\
\hline $\begin{array}{l}\text { Road intensity } \\
(\log T I)\end{array}$ & & & & & & $\begin{array}{c}0.631 \\
(3.223)\end{array}$ \\
\hline $\begin{array}{l}\text { Tax rate } \\
(\log \text { Tax })\end{array}$ & & & & & & $\begin{array}{c}-0.152 \\
(-0.873)\end{array}$ \\
\hline $\begin{array}{l}\text { GDP per capita } \\
\left(\log \text { PGDP }_{-1}\right)\end{array}$ & & & & & & $\begin{array}{c}0.435 \\
(1.866) \\
\end{array}$ \\
\hline $\begin{array}{l}\text { Regional } \\
\text { Dummy D }\end{array}$ & & & & $\begin{array}{c}-0.010 \\
(-1.400)\end{array}$ & $\begin{array}{c}0.542 \\
(5.095)\end{array}$ & $\begin{array}{c}0.444 \\
(2.449)\end{array}$ \\
\hline $\begin{array}{l}\text { Time Dummy } \\
\text { DT }\end{array}$ & & & & & $\begin{array}{c}0.033 \\
(0.450)\end{array}$ & $\begin{array}{c}-0.839 \\
(-4.684)\end{array}$ \\
\hline $\mathrm{R}^{2}$ & 0.982 & 0.767 & 0.137 & 0.968 & 0.895 & 0.802 \\
\hline Observations & 252 & 252 & 252 & 252 & 252 & 252 \\
\hline
\end{tabular}


Table 5.8 2SLS Results When Industrial Particle Emissions Included

\begin{tabular}{|c|c|c|c|c|c|c|}
\hline \multirow{2}{*}{$\begin{array}{l}\text { ( } t \text {-statistics } \\
\text { are shown in } \\
\text { parentheses) }\end{array}$} & \multicolumn{3}{|c|}{ Dependent } & \multicolumn{3}{|c|}{ Variable } \\
\hline & $\begin{array}{c}\text { GDP } \\
(\log Y) \\
(1)\end{array}$ & $\begin{array}{l}\text { Particles } \\
(\log E) \\
(2)\end{array}$ & $\begin{array}{l}\text { Levy rate } \\
\text { on IGE } \\
(\log r) \\
(3)\end{array}$ & $\begin{array}{l}\text { Industrial share } \\
\qquad \begin{array}{c}(\log S) \\
(4)\end{array}\end{array}$ & $\begin{array}{l}\text { Trade } \\
(\log T) \\
(5)\end{array}$ & $\begin{array}{c}\text { FDI } \\
\left(\begin{array}{c}\log \text { FDI }) \\
(6)\end{array}\right.\end{array}$ \\
\hline Constant & $\begin{array}{c}-2.358 \\
(-8.427)\end{array}$ & $\begin{array}{c}1.763 \\
(1.121) \\
\end{array}$ & $\begin{array}{c}1.769 \\
(1.826)\end{array}$ & $\begin{array}{c}0.223 \\
(3.295) \\
\end{array}$ & $\begin{array}{l}10.619 \\
(4.382) \\
\end{array}$ & $\begin{array}{c}-2.093 \\
(-1.657)\end{array}$ \\
\hline $\begin{array}{l}\text { GDP } \\
(\log Y)\end{array}$ & & $\begin{array}{c}1.036 \\
(2.659) \\
\end{array}$ & & $\begin{array}{c}-0.011 \\
(-1.001) \\
\end{array}$ & $\begin{array}{c}0.715 \\
(11.689) \\
\end{array}$ & $\begin{array}{c}1.064 \\
(5.867) \\
\end{array}$ \\
\hline $\begin{array}{l}\text { GDP Square } \\
\left(\log ^{2} Y\right)\end{array}$ & & $\begin{array}{c}-0.013 \\
(-0.375)\end{array}$ & & & & \\
\hline $\begin{array}{l}\text { Income } \\
(\log (Y / P))\end{array}$ & & & $\begin{array}{c}-0.445 \\
(-5.197)\end{array}$ & & & \\
\hline $\begin{array}{l}\text { Emissions } \\
(\text { Smoke) }(\log E)\end{array}$ & $\begin{array}{c}0.096 \\
(7.652)\end{array}$ & & $\begin{array}{c}-0.029 \\
(-0.725)\end{array}$ & & & \\
\hline $\begin{array}{l}\text { Levy Rate on } \\
\text { IGE }(\log r)\end{array}$ & & $\begin{array}{c}-0.003 \\
(-0.028) \\
\end{array}$ & & & & $\begin{array}{c}-0.057 \\
(-0.339) \\
\end{array}$ \\
\hline $\begin{array}{l}\text { Industrial output } \\
\text { share }(\log S)\end{array}$ & & $\begin{array}{c}0.135 \\
(0.578) \\
\end{array}$ & & & & \\
\hline $\begin{array}{l}\text { Trade } \\
(\log T) \\
\end{array}$ & $\begin{array}{c}0.218 \\
(16.679) \\
\end{array}$ & & & $\begin{array}{c}0.006 \\
(1.272) \\
\end{array}$ & & \\
\hline $\begin{array}{l}\text { FDI } \\
(\log \text { FDI })\end{array}$ & & & & & $\begin{array}{c}0.127 \\
(4.032) \\
\end{array}$ & \\
\hline $\begin{array}{l}\text { Labor } \\
(\log L)\end{array}$ & $\begin{array}{c}0.407 \\
(33.394) \\
\end{array}$ & & & & & \\
\hline $\begin{array}{l}\text { Capital } \\
(\log K) \\
\end{array}$ & $\begin{array}{c}0.294 \\
(15.196) \\
\end{array}$ & & & & & \\
\hline $\begin{array}{l}\text { State-owned } \\
\text { Enterprises } \\
\text { (log SOE) }\end{array}$ & & $\begin{array}{l}1.125 \\
(7.676)\end{array}$ & & & & \\
\hline $\begin{array}{l}\text { Citizen } \\
\text { Complaints } \\
\text { (log C) }\end{array}$ & & & $\begin{array}{c}0.059 \\
(0.943)\end{array}$ & & & \\
\hline $\begin{array}{l}\text { Education } \\
\text { (log ed) }\end{array}$ & & & $\begin{array}{l}-0.280 \\
(-2.032)\end{array}$ & & & \\
\hline $\begin{array}{l}\text { Population } \\
\text { Density } \\
\text { (log PD) }\end{array}$ & & & $\begin{array}{c}-0.003 \\
(-0.102)\end{array}$ & & & \\
\hline $\begin{array}{l}\text { Industrial } \\
\text { Share }-1 \\
\left(\log S_{-1}\right)\end{array}$ & & & & $\begin{array}{c}0.915 \\
(61.327)\end{array}$ & & \\
\hline $\begin{array}{l}\text { Investments } \\
(\log V)\end{array}$ & & & & $\begin{array}{c}0.023 \\
(1.877) \\
\end{array}$ & & \\
\hline $\begin{array}{l}\text { Remoteness } \\
(\log R)\end{array}$ & & & & & $\begin{array}{c}-0.478 \\
(-5.312) \\
\end{array}$ & \\
\hline $\begin{array}{l}\text { Exchange rate } \\
(\log E R)\end{array}$ & & & & & $\begin{array}{c}-0.198 \\
(-0.648) \\
\end{array}$ & \\
\hline $\begin{array}{l}\text { Tariffs } \\
(\log T N * \log T P)\end{array}$ & & & & & $\begin{array}{c}-0.035 \\
(-0.559) \\
\end{array}$ & \\
\hline $\begin{array}{l}\text { Cumulative FDI } \\
\left(\log _{\text {CFDI }}\right)\end{array}$ & & & & & & $\begin{array}{c}0.355 \\
(3.881) \\
\end{array}$ \\
\hline $\begin{array}{l}\text { Road intensity } \\
(\log T I)\end{array}$ & & & & & & $\begin{array}{c}0.631 \\
(3.223) \\
\end{array}$ \\
\hline $\begin{array}{l}\text { Tax rate } \\
(\log \text { Tax })\end{array}$ & & & & & & $\begin{array}{c}-0.152 \\
(-0.873) \\
\end{array}$ \\
\hline $\begin{array}{l}\text { GDP per capita } \\
\left(\log _{\text {PGDP }}\right)\end{array}$ & & & & & & $\begin{array}{c}0.435 \\
(1.866)\end{array}$ \\
\hline $\begin{array}{l}\text { Regional } \\
\text { Dummy D }\end{array}$ & & & & $\begin{array}{c}-0.010 \\
(-1.400)\end{array}$ & $\begin{array}{c}0.542 \\
(5.095)\end{array}$ & $\begin{array}{c}0.444 \\
(2.449)\end{array}$ \\
\hline $\begin{array}{l}\text { Time Dummy } \\
\text { DT }\end{array}$ & & & & & $\begin{array}{c}0.033 \\
(0.450)\end{array}$ & $\begin{array}{c}-0.839 \\
(-4.684)\end{array}$ \\
\hline $\mathrm{R}^{2}$ & 0.982 & 0.810 & 0.138 & 0.968 & 0.895 & 0.802 \\
\hline Observations & 252 & 252 & 252 & 252 & 252 & 252 \\
\hline
\end{tabular}


Table 5.9 2SLS Results When Industrial Dust Emissions Included

\begin{tabular}{|c|c|c|c|c|c|c|}
\hline \multirow{2}{*}{$\begin{array}{l}\text { ( } t \text {-statistics } \\
\text { are shown in } \\
\text { parentheses) }\end{array}$} & \multicolumn{3}{|c|}{ Dependent } & \multicolumn{3}{|c|}{ Variable } \\
\hline & $\begin{array}{c}\text { GDP } \\
(\log Y) \\
(1)\end{array}$ & $\begin{array}{c}\text { Dust } \\
(\log E) \\
(2)\end{array}$ & $\begin{array}{c}\text { Levy rate } \\
\text { on IGE } \\
(\log r) \\
\text { (3) }\end{array}$ & $\begin{array}{c}\text { Industrial share } \\
\qquad(\log S) \\
(4)\end{array}$ & $\begin{array}{c}\text { Trade } \\
(\log \mathrm{T}) \\
(5)\end{array}$ & $\begin{array}{c}\text { FDI } \\
(\log \text { FDI }) \\
(6)\end{array}$ \\
\hline Constant & $\begin{array}{c}-1.957 \\
(-12.757)\end{array}$ & $\begin{array}{l}12.456 \\
(7.647)\end{array}$ & $\begin{array}{c}-0.724 \\
(-0.701)\end{array}$ & $\begin{array}{c}0.223 \\
(3.295)\end{array}$ & $\begin{array}{l}10.619 \\
(4.382)\end{array}$ & $\begin{array}{c}-2.093 \\
(-1.657)\end{array}$ \\
\hline $\begin{array}{l}\text { GDP } \\
(\log Y)\end{array}$ & & $\begin{array}{c}0.217 \\
(0.437)\end{array}$ & & $\begin{array}{c}-0.011 \\
(-1.001)\end{array}$ & $\begin{array}{c}0.715 \\
(11.689)\end{array}$ & $\begin{array}{c}1.064 \\
(5.867)\end{array}$ \\
\hline $\begin{array}{l}\text { GDP Square } \\
\left(\log ^{2} Y\right)\end{array}$ & & $\begin{array}{c}0.047 \\
(1.165) \\
\end{array}$ & & & & \\
\hline $\begin{array}{l}\text { Income } \\
(\log (\mathrm{Y} / \mathrm{P}))\end{array}$ & & & $\begin{array}{c}-0.257 \\
(-2.836) \\
\end{array}$ & & & \\
\hline $\begin{array}{l}\text { Emissions } \\
\text { (Dust) (log E) }\end{array}$ & $\begin{array}{c}0.072 \\
(3.721) \\
\end{array}$ & & $\begin{array}{c}0.144 \\
(2.947) \\
\end{array}$ & & & \\
\hline $\begin{array}{l}\text { Levy Rate on } \\
\text { IGE }(\log r)\end{array}$ & & $\begin{array}{c}0.342 \\
(3.540)\end{array}$ & & & & $\begin{array}{c}-0.057 \\
(-0.339)\end{array}$ \\
\hline $\begin{array}{l}\text { Industrial output } \\
\text { share }(\log S)\end{array}$ & & $\begin{array}{c}-1.500 \\
(-6.982) \\
\end{array}$ & & & & \\
\hline $\begin{array}{l}\text { Trade } \\
(\log T)\end{array}$ & $\begin{array}{c}0.193 \\
(12.201)\end{array}$ & & & $\begin{array}{c}0.006 \\
(1.272)\end{array}$ & & \\
\hline $\begin{array}{l}\text { FDI } \\
(\log \text { FDI })\end{array}$ & & & & & $\begin{array}{c}0.127 \\
(4.032)\end{array}$ & \\
\hline $\begin{array}{l}\text { Labor } \\
(\log L)\end{array}$ & $\begin{array}{c}0.388 \\
(17.661)\end{array}$ & & & & & \\
\hline $\begin{array}{l}\text { Capital } \\
(\log K) \\
\end{array}$ & $\begin{array}{c}0.352 \\
(15.775) \\
\end{array}$ & & & & & \\
\hline $\begin{array}{l}\text { State-owned } \\
\text { Enterprises } \\
\text { (log SOE) }\end{array}$ & & $\begin{array}{c}0.374 \\
(2.695)\end{array}$ & & & & \\
\hline $\begin{array}{l}\text { Citizen } \\
\text { Complaints } \\
(\log C)\end{array}$ & & & $\begin{array}{c}0.064 \\
(1.029)\end{array}$ & & & \\
\hline $\begin{array}{l}\begin{array}{l}\text { Education } \\
(\log \text { ed) }\end{array} \\
\end{array}$ & & & $\begin{array}{c}-0.123 \\
(-0.908) \\
\end{array}$ & & & \\
\hline $\begin{array}{l}\text { Population } \\
\text { Density } \\
\text { (log PD) }\end{array}$ & & & $\begin{array}{c}-0.044 \\
(-1.351)\end{array}$ & & & \\
\hline $\begin{array}{l}\text { Industrial } \\
\text { Share } \\
\left(\log S_{-1}\right)\end{array}$ & & & & $\begin{array}{c}0.915 \\
(61.327)\end{array}$ & & \\
\hline $\begin{array}{l}\text { Inverstments } \\
(\log V)\end{array}$ & & & & $\begin{array}{c}0.023 \\
(1.877) \\
\end{array}$ & & \\
\hline $\begin{array}{l}\text { Remoteness } \\
(\log R)\end{array}$ & & & & & $\begin{array}{c}-0.478 \\
(-5.312) \\
\end{array}$ & \\
\hline $\begin{array}{l}\text { Exchange rate } \\
(\log E \text { E) }\end{array}$ & & & & & $\begin{array}{c}-0.198 \\
(-0.648) \\
\end{array}$ & \\
\hline $\begin{array}{l}\text { Tariffs } \\
\left(\log T^{*} \log T P\right)\end{array}$ & & & & & $\begin{array}{c}-0.035 \\
(-0.559) \\
\end{array}$ & \\
\hline $\begin{array}{l}\text { Cumulative FDI } \\
\left(\log _{\text {CFDI }}\right)\end{array}$ & & & & & & $\begin{array}{c}0.355 \\
(3.881) \\
\end{array}$ \\
\hline $\begin{array}{l}\text { Road intensity } \\
(\log T I)\end{array}$ & & & & & & $\begin{array}{c}0.631 \\
(3.223)\end{array}$ \\
\hline $\begin{array}{l}\text { Tax rate } \\
(\log \text { Tax }) \\
\end{array}$ & & & & & & $\begin{array}{c}-0.152 \\
(-0.873) \\
\end{array}$ \\
\hline $\begin{array}{l}\text { GDP per capita } \\
\left(\log _{\text {PGDP }}\right)\end{array}$ & & & & & & $\begin{array}{c}0.435 \\
(1.866)\end{array}$ \\
\hline $\begin{array}{l}\text { Regional } \\
\text { Dummy D }\end{array}$ & & & & $\begin{array}{c}-0.010 \\
(-1.400)\end{array}$ & $\begin{array}{c}0.542 \\
(5.095)\end{array}$ & $\begin{array}{c}0.444 \\
(2.449)\end{array}$ \\
\hline $\begin{array}{l}\text { Time Dummy } \\
\text { DT }\end{array}$ & & & & & $\begin{array}{c}0.033 \\
(0.450) \\
\end{array}$ & $\begin{array}{c}-0.839 \\
(-4.684) \\
\end{array}$ \\
\hline $\mathrm{R}^{2}$ & 0.979 & 0.564 & 0.172 & 0.968 & 0.895 & 0.802 \\
\hline Observations & 252 & 252 & 252 & 252 & 252 & 252 \\
\hline
\end{tabular}


assumptions about these error terms. In estimating both the fixed time and the fixed individual effects, the first column of $(\mathrm{j}$ is dropped to avoid perfect collinearity.

Estimation proceeds in three steps. First, the fixed time and individual effects are both controlled for. Second, only the fixed individual effects are considered. And third, only the fixed time effects are included. The estimation results of the three approaches to the six different pollutants are reported in Appendix C. Only the estimates of the fixed time effect approach are close to those in Table 5.4-5.9. The fixed individual effect estimator produces the most significantly different results, many of which provide no readily apparent economic interpretation.

\subsubsection{SLS Estimation Results with Random Effects (EC2SLS)}

Similar to Equation (5-5), the general two-way error components form of structural equation $\mathrm{j}$ can be written as

$$
y_{j}=Y_{j} *_{j}+X_{j} \exists_{j}+v_{j}
$$

where $y_{j}, Y_{j}, X_{j}, *_{j}$ and $\exists_{j}$ are as defined in Equation (5-7). Here, $v_{j}$ is an NT $\times 1$ vector of error terms,

$$
\mathrm{v}_{\mathrm{j}}=\left(\mathrm{I}_{\mathrm{N}} \otimes \mathrm{e}_{\mathrm{T}}\right) 0_{\mathrm{j}}+\left(\mathrm{e}_{\mathrm{N}} \otimes \mathrm{I}_{\mathrm{T}}\right) 8_{\mathrm{j}}+\gamma_{\mathrm{j}}
$$

where $0_{\mathrm{j}}=\left(0_{\mathrm{j} 1}, \ldots, 0_{\mathrm{jN}}\right)^{\prime}, 8_{\mathrm{j}}=\left(8_{\mathrm{j} 1}, \ldots, 8_{\mathrm{jT}}\right)^{\prime}$, and $\gamma_{\mathrm{j}}=\left(\gamma_{\mathrm{j} 11}, \ldots, \gamma_{\mathrm{j} 1 \mathrm{~T}}, \gamma_{\mathrm{j} 21}, \ldots, \gamma_{\mathrm{jNT}}\right)^{\prime}$ are random vectors with 0 means and covariances given by

$$
\mathrm{E}\left(\begin{array}{l}
\eta_{j} \\
\lambda_{j} \\
\varepsilon_{j}
\end{array}\right)\left(\eta_{l}{ }^{\prime} \lambda_{l}{ }^{\prime} \varepsilon_{l}{ }^{\prime}\right)=\left[\begin{array}{ccc}
\sigma_{\eta_{j l}}^{2} I_{N} & 0 & 0 \\
0 & \sigma_{\lambda_{j l}}^{2} I_{T} & 0 \\
0 & 0 & \sigma_{\varepsilon_{j l}}^{2} I_{N T}
\end{array}\right]
$$

for $\mathrm{j}$ and $1=1,2, \mathrm{~J}, 6$. 
The system is estimated with the error component two-stage least squares (EC2SLS) method proposed by Baltagi (1981) and Hsiao (1986). The EC2SLS estimates are shown in Appendix D. It is noticeable that the EC2SLS estimates are obviously different from the results obtained from 2 SLS and 2SLS with fixed effects. Though most of the coefficients in the equations of production, emissions demand, emissions supply, and industrial share possess the expected signs and are economically interpretable, the poor performance of the estimator in trade and FDI equation reduces the credibility of the results. For example, in the sixth equation of Table D-1, only the levy rate on industrial wastewater has a statistically significant effect on FDI inflows and the coefficient of the levy rate variable on FDI is positive and large in magnitude (2.405). However, the same equation in Table D-2 shows that only cumulative FDI variable has a statistically significant effect on FDIs and this effect is negative. Indeed, the only difference between the two equations is that the former includes the levy rate on wastewater pollution while the latter uses the levy rate on waste gas emissions. It is difficult to reasonably explain why such a dramatic change in the results would happen. Also difficult is any attempt to interpret the above-mentioned results employing any existing economic theories.

\subsubsection{Which Estimation Method Works Best}

The results of the three different empirical estimation approaches, suggest that the results obtained with 2 SLS estimator appear to be the most reasonable. Therefore, our initial attempt to exploit the advantage of the panel data set in this specific case study of China has provided a paradox between theory and results. More methodological research as to why this exploitation has been unsuccessful and how improvement can be made 
would be interesting but outside the scope of this study. However, the following points may help to improve our understanding.

According to Greene (1997), the inclusion of the fixed effects is reasonable when differences between individuals can be viewed as parametric shifts of the regression model. The fixed effects approach might be viewed as applying only to the individuals in the study, not to the ones outside the sample. Therefore, this approach would be more appropriate when the number of individuals included in the study is close to the size of the population. On the other hand, if individual observations can be considered as sampled from a large population, it would be more appropriate to view the fixed effects as randomly distributed across individuals and hence the random effects approach would be reasonable. In China's case, the sample of 28 provinces is almost exhaustive. This might suggest that the random effects approach, EC2SLS, would be an inappropriate estimator for this study.

Can one conclude that the fixed effects approach is the most appropriate approach for estimating the Chinese model? Consider the underlying assumptions of this approach. The fixed effects approach takes either the individual effect to be constant over time or the time effect to be the same across individuals. Obviously, the assumptions could be too strong to be applied to the diverse provincial economies of China. Rapid economic growth and fundamental social change in China make it hard to imagine that the provincial individual effect can be constant over the study period. This belief is partially supported by the evidence that half of the six equations do not have statistically significant estimates for the fixed provincial effects. Also, it is hard to imagine that in a diverse and unevenly-developed country like China, the time effect can be the same 
across provinces. According to Jian, et al. (1996), economic development converges across provinces between 1978 and 1990 but diverges between 1990 and 1993. Similarly, the estimation results show that about one-half of the fixed time effects are not statistically significant either. Hence, it would be inappropriate to assume a common time effect over provinces. In addition, the fixed effects approach is costly in terms of degrees of freedom lost due to the use of the individual and time dummy variables.

Though the 2SLS approach may result in such misspecification problems, 2SLS estimators are shown to be more robust to various specification problems (Kennedy 1992, Ch. 10). Besides, the appropriateness of an estimator ultimately depends on whether it generates reasonable estimates. As already shown, the 2SLS method yields the most plausible results in this empirical study. Furthermore, the use of 2SLS does not mean a total omission of provincial differences and time shocks. Instead, the effects of these differences and shocks are nicely captured by the regional policy and geographic dummy variable and the time dummy variable. However, such regional and time effects have to be excluded in both the fixed and the random effects approaches due to multicollinearity problems. Therefore, in the following parts of the chapter, the analysis will proceed based on the 2SLS estimates.

Please note that the 3SLS estimator is not used in this study for several reasons. Though preferred to 2SLS for its efficiency advantage, it produces inconsistent estimates if an incorrect exclusionary restriction is placed on any of the system equations. The 2SLS approach may have the same problem, but the problem is limited to the misspecified equations only and will not be spread throughout the system. Computational complexity is another problem that discourages the use of the 3SLS estimator. Attempts 
to estimate the model using 3SLS were made for all the three types of models, but the presence of nearly singular matrices led to termination of computations before the final estimates were obtained. This suggests that different instruments for different equations may be required (Amemiya 1977 and Schmidt 1990).

\subsection{Model Validation}

Four considerations are necessary to evaluate the validity of simultaneous equations systems estimated with 2SLS. Firstly, the case in which the system is linearly specified by removing the squared endogenous variable from the second equation is examined. The purpose of doing this is to see how great a variation in the coefficient estimates would result if the system is differently specified. Secondly, we also evaluate whether the estimated system is robust according to the selected time period. Thirdly, the sensitivity of the estimates is again analyzed by deleting all observations from three municipalities (Beijing, Shanghai and Tianjin), which are obviously different from other provinces in terms of economic and social development. And lastly, the stability of the estimated system and the existence of equilibrium values for endogenous variables are examined by solving the estimated model for endogenous variables.

\subsubsection{Linear Specification}

From Table 5.4-5.9, except for the wastewater case, an inverted-U relationship between emissions and GDP is not significantly identified. Even in the wastewater case, since the turning point is well above the current GDP levels, it seems reasonable to remove the squared $\log G D P$ term from the second equation and thus make the system a 
linear one. Therefore, the conventional 2SLS approach can be applied to the linear system, i.e., the Taylor expansion is no longer required in the reduced form estimation. The estimation results of the linear system are reported in Appendix E. Compared with the results in Table 5.4-5.9, most results are theoretically consistent with those in Table 5.4-5.9, though some changes in estimates can be easily discerned. However, changes in coefficients are generally in magnitude only. Changes in sign do happen to a few coefficients, but in such cases the coefficients are usually not statistically significant in either the nonlinear or linear models. Therefore, the interpretation for Table 5.4-5.9 in general also applies here. Taking into account the change made in system specification and in econometric estimation method, these changes in estimates are then not surprising. In effect, the results show that the theoretical underpinning of the model is rather strong.

\subsubsection{Estimation Results from a Shorter Time Period}

The results shown in Table 5.4-5.9 are 2SLS estimates bases on the data set from 1987 to 1995 . The system is re-estimated with the same econometric approach but with data of a shorter time period 1987-1993 (see Appendix F for the results). This means a more then 22 percent reduction in sample size. Also, since 1993, a volume-based industrial wastewater discharge fee has been introduced into China's pollution levy system. This suggests that the levy rate data as well as the environmental demand and supply behavior after 1993 may not be consistent with those in the previous years. Hence, sampling data from 1987 to 1993 also helps to check whether the model is sensitive to this possible structural change. From Appendix F, most of the estimates show only a marginal deviation from those in Table 5.4-5.9. Therefore, it can be concluded that the 
estimates are not sensitive to the chosen time period and the change of the levy system has no significant impact on the model.

\subsubsection{Estimation Results with Exclusion of three municipalities}

Among the sampled twenty-eight provinces, three of them are municipalities directly under the central government: Beijing, Shanghai and Tianjin. The three cities are China's political, economic, and cultural centers. Compared with the other provinces, though small in size, these cities are densely populated and highly industrialized. Due to the significant difference between these three cities and other provinces, data from these cities may often tend to be "outliers". Although observations from the three cities account for less than 11 percent of the total, deleting these observations and re-estimating the model with the same approach, one would expect changes in certain parameters. A theoretically sound model and an appropriate estimator should able one to explain these changes in estimates. The estimation results with no data from the three cities are reported in Appendix G. As expected, the changes in estimates are obviously more dramatic than those from estimation with shorter time period data, though the reduction in sample size of the former is less than one-half of the latter. It is worth noting that in the wastewater case (see Table G-1), only a few of the estimates have a significant change in magnitude. However, in the air pollution case (Table G-2 to G-6), more dramatic changes in coefficient estimates are widely observed, and the results even suggest that the inverted-U relationship might also exist between some air pollutant emissions and GDP levels. The results also imply that municipalities and provinces are more similar to each other in wastewater pollution control than in air pollution control. 


\subsubsection{Dynamic Response and Characteristics}

In Model (28), three lagged endogenous variables (GDP, industrial output share, and FDI) are either explicitly or implicitly included. Therefore, the system is not only nonlinear but also more dynamic in nature, and its existence, stability and convergence conditions for the equilibrium values of endogenous variables should be examined. For a linear model, the examination of these conditions requires the characteristic roots (or their modulus) of the coefficient matrix corresponding to lagged endogenous variables in the reduced form to lie within the unit circle (Labys 1973 and Greene 1997). For a nonlinear model, however, this rule is not applicable due to the difficulty in obtaining the reduced form of such a model. One way of examining these conditions in this case is to solve the estimated system for the endogenous variables using a simulation procedure and this has been accomplished and appears in Section 5.7.

\subsection{Empirical Relationship between Trade and the Environment}

\subsubsection{Introduction}

So far the empirical interrelationships between trade and the environment in China's case have not been examined because they are not explicitly revealed in any of the equations of the system. However, the suggested theoretical interactions between trade and the environment shown in Equation (4-13)-(4-19) and the empirical results in Table 5.4-5.9, should permit such an analysis. Several considerations are first necessary. (1) Though the logarithms of variables are used in empirical estimation, the causal relations among variables identified in Equation (4-14)-(4-19) still hold. However, the effects are no longer viewed as marginal effects. Instead, they should be interpreted as 
elasticities. (2) In cases where the value of a variable is needed for computation, the sample mean of the variable is used and therefore the effects can be regarded as those applying to an "average province" in the sample. (3) The estimated values of the coefficients in Table 5.4-5.9 will be used for computation only if they are statistically significant at the 5 percent level. Otherwise, the coefficients will be assigned a value of zero because they are not significantly different from zero. In addition, to avoid misinterpretation, coefficient estimates will not be used in computation if they do not possess a theoretically defendable sign. Therefore, if an effect is zero, the correct interpretation should be that the effect can not be identified with the model and the data used, rather than concluding, "there is no impact".

In order to fully reflect the impact of one variable on another, the value of the determinant of the system is required (see Equation (4-15)), a property often neglected in empirical studies with simultaneous equations models. The determinant was assumed to be positive based on intuitive reasoning. As the parameters needed for this computation are now available, one can check whether this assumption is true or not. Using data in Table 5.4-5.9, the determinants of the system are calculated respectively for all the six different pollutant cases. In order to examine the robustness of the results, the computation of the determinants is conducted in two ways. First, the computation is based on the estimates that are significant at the 5 percent level. For those estimates that are not significant at this level, zeros are used to replace them in the computation. The second method of computation simply use the original coefficient estimates with no control for statistical significance. The results are reported in Table 5.10. The system 
determinates under different cases all are positive and have a value between 0.613 and 0.821 , indicating an amplifying effect of the system.

\subsubsection{Environmental impacts of Trade}

Two trade-policy exogenous variables, i.e., the exchange rate and the tariff rate, are introduced in the system. Though theoretically acceptable both in sign and in magnitude, the coefficient estimates of these two variables are not statistically significant. The focus of analysis in this subsection is therefore on the environmental effects of trade flows (total values of trade, i.e., exports plus imports).

According to Equation (4-14a), the impact of trade flows on emissions are computed and reported in Table 4.15. The results suggest that trade would lead to more discharges of wastewater, waste gases, $\mathrm{CO}_{2}$ and particles, because trade induces an increase in economic scale (captured by term $|\Delta|^{-1} h A^{\prime} f_{Y}$ ). However, trade can also lead to reduced wastewater discharges through its income effect (captured by term $\left|{ }_{\Delta}\right|^{-1} h A^{\prime} f_{r} g_{Y}$ ). But the total impact of trade on wastewater discharges is still positive. The result shows that a one percent increase in trade would increase wastewater discharges by 0.188 percent. Incidentally, the model can not identify the impact of trade on $\mathrm{SO}_{2}$ and dust emissions.

Since the results show that trade may positively lead to increased pollution discharges, can it be inferred that China has a comparative advantage in pollutionintensive goods? Indeed, the results provide no support for this hypothesis because no indication has been found that trade may change the composition of output and hence 
Table 5.10 System Determinant Results

\begin{tabular}{|l|c|c|}
\hline \multirow{2}{*}{ Models of different emissions } & \multicolumn{2}{|c|}{ Determinant $|\Delta|$} \\
\cline { 2 - 3 } & Significant at 5\% level & No control for significance \\
\hline Wastewater & 0.745 & 0.613 \\
\hline Waste gas & 0.725 & 0.709 \\
\hline SO2 & 0.821 & 0.766 \\
\hline CO2 & 0.709 & 0.697 \\
\hline Particles & 0.715 & 0.721 \\
\hline Dust & 0.801 & 0.765 \\
\hline
\end{tabular}

Source: the author's computation.

Table 5.11 Impacts of trade on emissions

\begin{tabular}{l|c|c|c|c|c|c}
\hline \multirow{2}{*}{ Impacts } & \multicolumn{6}{c}{ Emissions } \\
\cline { 2 - 7 } & Wastewater & Waste gas & SO2 & CO2 & Particles & Dust \\
\hline Composition by trade $^{\mathrm{a}}$ & 0 & 0 & 0 & 0 & 0 & 0 \\
Income $^{\mathrm{b}}$ & -0.028 & 0 & 0 & 0 & 0 & 0 \\
Scale $^{\mathrm{c}}$ & 0.216 & 0.223 & 0 & 0.246 & 0.316 & 0 \\
Composition by income $^{\mathrm{d}}$ & 0 & 0 & 0 & 0 & 0 & 0 \\
\hline \multicolumn{1}{c}{ Total } & 0.188 & 0.223 & 0 & 0.246 & 0.316 & 0 \\
\hline
\end{tabular}

Source: the author's computation.

a: trade induced composition effect, $|\Delta|^{-1} \mathrm{f}_{\mathrm{S}} \mathrm{Z}_{\mathrm{T}}$.

b: income effect, $|\Delta|^{-1} \mathrm{hA}^{\prime} \mathrm{f}_{\mathrm{r}} \mathrm{g}_{\mathrm{Y}}$.

c: scale effect, $|\Delta|^{-1} \mathrm{hA}^{\prime} \mathrm{f}_{\mathrm{Y}}$.

d: income induced composition effect, $|\Delta|^{-1} \mathrm{hA}^{\prime} \mathrm{f}_{\mathrm{S}} \mathrm{Z}_{\mathrm{Y}}$.

\section{Table 5.12 Impacts of an emissions charge on trade}

\begin{tabular}{c|c|c|c|c|c|c}
\hline \multirow{2}{*}{ Impacts } & \multicolumn{6}{|c}{ Model of different pollutant emissions } \\
\cline { 2 - 7 } & Wastewater & Waste gas & SO2 & CO2 & Particles & Dust \\
\hline Scale $^{\text {a }}$ & -0.067 & 0 & -0.009 & 0 & 0 & 0 \\
Scale via FDI $^{\mathrm{b}}$ & -0.012 & 0 & -0.002 & 0 & 0 & 0 \\
\hline \multicolumn{1}{c}{ Total } & -0.079 & 0 & -0.011 & 0 & 0 & 0 \\
\hline
\end{tabular}

Source: the author's computation.

a: scale effect, $|\Delta|^{-1} \mathrm{Ah}_{\mathrm{E}} \mathrm{f}_{\mathrm{r}} \mathrm{W}_{\mathrm{Y}}$.

b: scale effect via FDI, $|\Delta|^{-1} \mathrm{Ah}_{\mathrm{E}} \mathrm{f}_{\mathrm{r}} \mathrm{V}_{\mathrm{Y}} \mathrm{W}_{\mathrm{F}}$. 
generate more emissions (the term $f_{s} Z_{T}$ that captures this effect is straight zeros in Table 5.11).

\subsubsection{Trade impact of an emissions charge}

As already discussed, though the impact of an emissions charge on trade is not explicitly measured in the model, an emissions charge may affect trade by many indirect paths (see Figure 4.2 and Equation (4-19)). Since the direct impact (Vr) of an emissions charge on FDI is not significantly identified in any of the empirical cases, Equation (419 ) is then reduced to two terms, that is, $A h_{E} f_{r} W_{Y}$, a direct impact on trade from a reduced economic scale due to the presence of emissions charges; and $A h_{E} f_{r} V_{Y} W_{F}$, an indirect impact also from the reduced economic scale but via its impact on FDIs. These two trade effects are computed and are shown in Table 5.12. The negative impacts of an emissions charge on trade are identified in two pollution cases, but these impacts, as one might expect, are very small. What's more, if the results may suggest that the levy rate on industrial wastewater discharges would have some adverse effects on trade, then the levy rate on air pollutant emissions shows no obvious impact. This is reasonable. As pointed out earlier, China's levy system in general is more effective in wastewater pollution control than in air pollution control.

\subsubsection{Impacts of trade flows on emissions charges}

Since the empirical results suggest that the effect of trade on industrial GDP share is not statistically different from zero (i.e., $Z_{T}=0$ ), according to the model-defined relations in Equation (4-17a), trade may then have three possible impacts on the 
emissions charge: the composition effect of income $\left(h A^{\prime} f_{S} g_{E} Z_{Y}\right)$, the scale effect of income $\left(h A^{\prime} f_{Y} g_{E}\right)$, and the technique effect of income $\left(h A^{\prime} g_{Y}\right)$. These impacts are computed for each of the pollution cases and reported in Table 5.13. It is interesting to notice that trade shows a positive impact only in the wastewater pollution case, where trade increases the wastewater levy rate through a technique effect. In all the air pollution cases, trade seems to have negative impact on the waste gas levy rate. But this result could be substantially weakened because of the inconsistency of the air pollution data used and of the poor performance of the system in modeling environmental demand and supply.

\subsubsection{Impacts of an emissions charge on FDI}

Throughout the empirical estimation results, no statistically significant impact that an emissions charge may have on FDI has been found, even though this effect is explicitly defined in the sixth equation of the system. The result can be interpreted that differentials in emissions levy rates across provinces are not a significant factor for foreign firms to decide where to locate their production. However, one cannot conclude that emissions charges have no effect on FDI. In Equation (4-18) though the first term in braces disappears as $V_{r}$ is virtually equal to zero, the second term, $|\Delta|^{-1} A h_{E} f_{r} V_{Y}$, still exists, suggesting that emissions charges may affect FDI via the path of reduced emissions and lowered GDP levels. This effect is computed and presented in Table 5.14. The results show that China's relatively tight controls on wastewater pollution may have a negative impact on FDI, but that the impact of China's air pollution levy on FDI may not. 
Table 5.13 Impacts of trade on emissions charges

\begin{tabular}{l|c|c|c|c|c|c}
\hline \multirow{2}{*}{ Impacts } & \multicolumn{6}{c}{ Model of different pollutant emissions } \\
\cline { 2 - 7 } & Wastewater & Waste gas & SO2 & CO2 & Particles & Dust \\
\hline Composition $^{\text {a }}$ & 0 & 0 & 0 & 0 & 0 & 0 \\
Scale $^{\mathrm{b}}$ & 0 & 0 & 0 & -0.105 & -0.141 & 0 \\
Income $^{\mathrm{c}}$ & 0.056 & -0.115 & -0.115 & -0.124 & -0.136 & -0.062 \\
\hline \multicolumn{1}{c|}{ Total } & 0.056 & -0.115 & -0.115 & -0.229 & -0.277 & -0.062 \\
\hline
\end{tabular}

Source: the author's computation.

a: composition effect, $|\Delta|^{-1} \mathrm{hA}{ }^{\prime} \mathrm{f}_{\mathrm{S}} \mathrm{g}_{\mathrm{E}} Z_{\mathrm{Y}}$.

b: scale effect, $|\Delta|^{-1} \mathrm{~h} A^{\prime} f_{Y} g_{E}$.

c: income effect, $|\Delta|^{-1} \mathrm{hA}^{\prime} \mathrm{g}_{\mathrm{Y}}$.

Table 5.14 Impact of an emissions charge on FDI

\begin{tabular}{l|c|c|c|c|c|c}
\hline \multirow{2}{*}{ Impact } & \multicolumn{6}{|c}{ Model of different pollutant emissions } \\
\cline { 2 - 7 } & Wastewater & Waste gas & $\mathrm{SO} 2$ & $\mathrm{CO} 2$ & Particles & Dust \\
\hline Scale $^{\text {a }}$ & -0.095 & 0 & -0.013 & 0 & 0 & 0 \\
\hline
\end{tabular}

Source: the author's computation.

a: scale effect, $|\Delta|^{-1} \mathrm{Ah}_{\mathrm{E}} \mathrm{f}_{\mathrm{r}} \mathrm{V}_{\mathrm{Y}}$. 


\subsection{Model Simulation}

\subsubsection{Introduction}

Much information can also be obtained from the TEM model by examining its dynamic characteristics using computational simulation. Only in this way can one observe simultaneously and dynamically how the endogenous and exogenous variables are interrelated. This is particularly true when explicit analytical solutions for the reduced form of nonlinear simultaneous equations are difficult or impossible to obtain. Before the era of computable general equilibrium models, macroeconomic and market econometric models were typically enclosed in an equilibrium or disequilibrium framework that enabled computational solutions of models over time and over space.

This research began when computer methods permitted multi-equation models to be solved for simultaneous solution paths. Under controlled scenarios, these solutions were termed simulations. Simulations were conducted to explain dependent variables in a historical context, to examine how certain policy variables impacted on the dependent variables, and to forecast these variables.

Advances in computer simulation enabled economists to consider models as formal systems that could be dealt with in terms of response surfaces or statistical experiments. Some of the early work by Naylor $(1969,1971)$ established formal methods and procedures for manipulating econometric and related models. The concept of experimental design was expanded so that model inputs could be varied systematically or stochastically and the simulation outputs observed not only as model solutions, but statistical tests also could be employed to perform model validation. Experimental design was also extended into exploratory experiments, for example, involving full factorial 
designs, fractional factorial designs, rotatable designs, response surface and other designs.

The significant results obtained by computer simulation experiments is well known. One of the more important was the analysis and forecasting experiments conducted with macroeconometric models, e.g., the Wharton model. Evans and Klein (1969) showed how simulation experiments could be conducted with the model, and the algorithm employed was made available by Klein and Evans (1969). Later Klein and Young (1980) provided advice on validating and forecasting econometric models with computer simulation methods. Other simulation experiments dealt with primary commodity market models as explained by Labys $(1973,1975,1984,1989)$ and by Adams and Behrman (1976). Today there is a proliferation of econometric modeling studies involving computer simulation analysis. Examples of more recent simulation developments of interest can be found in Mariano, Schuermann and Weeks (2000) and in Marimon and Scott (2001).

This section descibes simulation analysis with the TEM model for the Chinese economy. Simulation here is defined as a numerical technique suitable for conducting experiments with mathematical and econometric models that describe the behavior of a complex system employing solution algorithms over time and space. The approach normally taken in conducting such simulations is to consider a model system as composed of endogenous and exogenous variables, parameters or coefficients, and error or residual terms. Whether it be for explanatory, forecasting or validation purposes, the response of the endogenous variables of the model (or the response surface) can be observed in relation to changes in the exogenous variables, changes in the coefficients of 
the model, or variations in error terms with different underlying generating processes. The changes induced can derive from deterministic selection, probabilistic testing, or stochastic generation.

Based on these guidelines, simulations have been conducted for the TEM model to learn more about the interactions between trade and the environment in the Chinese context and to further validate the model upon which the interactions are based. Three separate simulations are discussed:

1. Deterministic solutions are conducted to learn more about how trade and environment variables interact with each other in a policy context.

2. Stochastic solutions are performed by shocking the error structure of the model to determine the stability of the model and the impacts of uncertainty on model performance.

3. Stochastic solutions are performed both on random errors and on the estimated coefficients of the model to test its validity based on the robustness of the estimated values of those coefficients.

\subsubsection{Simulation Procedure}

The computer simulations in this analysis are performed with EViews 4 since this latest version of the software provides a powerful functionality for model simulation. In a deterministic simulation, all equations in the TEM model are solved so that they hold without error during the simulation period, and all coefficients are fixed at their point estimates. That is, the equations of the model are solved so that each of the equations is exactly satisfied. This results in a single path for the endogenous variables which can be evaluated by solving the model once. 
The computational algorithm is based on an iterative Gauss-Seidel method, which is useful for both linear and nonlinear models. The solution method is dynamic simulation, i.e., observed data are used for lagged endogenous variables if they are dated prior to the first period of the simulation, and thereafter it uses the values forecast by the model itself. The convergence criterion used is 0.00001 . Values for endogenous variables of the model are computed for each observation in the solution sample. Since the solution sample is set to cover all 28 provinces and 9 time periods, each endogenous variable thus has 252 simulated values.

In a stochastic simulation, the model is solved for a set of randomly drawn residuals and/or coefficients. That is, the model is solved so that the fitted residuals match randomly drawn errors, and/or the coefficients of the model are varied randomly. For each variable and observation of a stochastic simulation, a set of independent random numbers are drawn from the standard normal distribution, then these numbers are scaled to match the estimated variance-covariance matrix of the system calculated from the model equation residuals. Using the EViews 4 framework, simulation of the model generates a distribution of outcomes for the endogenous variables in every period. This distribution is approximated by repeatedly solving the model using different draws for the random components in the model and then calculating statistics, such as means and standard deviations, over different outcomes. In each repetition, as for the deterministic simulation, each endogenous variable has 252 simulated values. Therefore, though a stochastic simulation follows a similar procedure to that of a deterministic one, EViews 4 provides several variations. First, when binding the variables, a temporary series is created for every endogenous variable in the model. Additional series in the workfile are 
used to hold the statistics for the tracked endogenous variables. Second, the model is solved repeatedly for different draws of the stochastic components of the model. If coefficient uncertainty is included in simulation, then a new set of coefficients is drawn before each repetition. During the repetition, errors are generated for each observation in accordance with the residual uncertainty. At the end of each repetition, the statistics for the tracked endogenous variables are updated to reflect the additional results.

Since the panel observations of the variables in the workfile are stacked first by province and then by time period, in both deterministic and stochastic simulations lagged endogenous variables in the model were based on actual historical values of the endogenous variables. This treatment helps to reduce the inconsistency in simulation results due to data arrangement.

Because the TEM model analyzes interactions between trade and the environment, ten scenarios, as described in Table 5.15, are considered. Clearly, all of the scenarios involve initial changes in the included endogenous variables. In order to investigate the effect of these changes on other endogenous variables, the model is solved by excluding the endogenous variables that initiate a change for the entire solution sample. That is, the excluded endogenous variables are treated as exogenous variables for purpose of simulation. To evaluate the net effect of each scenario, the results of a scenario obtained from a deterministic or a stochastic simulation are compared with its corresponding deterministic or stochastic baseline solutions. This comparison is measured by percentage changes of the mean average of an endogenous variable relative to that of its baseline solution. In a deterministic simulation, this represents an average of 
Table 5.15 List of Simulation Scenarios

\begin{tabular}{|c|c|c|c|}
\hline \multirow{2}{*}{ Scenario } & \multicolumn{3}{|c|}{ Increase in Endogenous Variables } \\
\cline { 2 - 4 } & Trade & FDI & Levy Rate \\
\hline Scenario 1 & $10 \%$ & & \\
\hline Scenario 2 & $20 \%$ & $10 \%$ & \\
\hline Scenario 3 & & $20 \%$ & \\
\hline Scenario 4 & & & $10 \%$ \\
\hline Scenario 5 & & & $20 \%$ \\
\hline Scenario 6 & & & $10 \%$ \\
\hline Scenario 7 & $10 \%$ & $10 \%$ & $20 \%$ \\
\hline Scenario 8 & $20 \%$ & $20 \%$ & $10 \%$ \\
\hline Scenario 9 & & & $20 \%$ \\
\hline Scenario 10 & & & \\
\hline
\end{tabular}


252 simulated values. In a stochastic simulation, however, this average becomes the mean of 252,000 simulated values for each of the scenarios analyzed is simulated with one thousand repetitions. Since stochastic simulations are very time consuming, all of the simulations are focused only on the industrial wastewater pollution and the industrial waste gas emissions cases; the levy rate and emissions data used in estimating the TEM system are most consistent in these two pollution cases.

The simulations were conducted by first performing a set of deterministic simulations. The presentation of the results of these simulations in Tables 5.15-5.24 follows the equation structure of the estimated model (as presented in Tables 5.4 and 5.5). The stochastic simulations were conducted as outlined. The several simulation procedures employed involve applying shocks to the baseline solution and then to the various scenarios. The means and deviations of various baseline solutions for the wastewater pollution and for the waste gas emissions case are summarized in Table 5.16 and 5.17, respectively. The impact of the introduction of error shocks and coefficient shocks on the deterministic baseline solutions for these two cases are accordingly reported in Table 5.18 and 5.19.

\subsubsection{Deterministic Solution}

According to Howrey and Kelejian (1971), the application of deterministic simulation procedures to econometric models that contain nonlinearities in the endogenous variables can yield results diverging systematically from the corresponding historical values even if the econometric model is properly specified. This result helps to 
Table 5.16 Means and Deviations of Baseline Solutions In Industrial Wastewater Pollution (IWW) Case

\begin{tabular}{|c|c|c|c|c|c|c|}
\hline \multirow[b]{2}{*}{ Baseline } & \multicolumn{6}{|c|}{ Means and Deviations (in parentheses) } \\
\hline & $\begin{array}{l}\text { GDP } \\
\text { (eq1) }\end{array}$ & $\begin{array}{l}\text { IWW } \\
\text { (eq2) }\end{array}$ & $\begin{array}{l}\text { Levy Rate } \\
\text { (eq3) }\end{array}$ & $\begin{array}{c}\text { Industrial } \\
\text { Share } \\
\text { (eq4) }\end{array}$ & $\begin{array}{l}\text { Trade } \\
\text { (eq5) }\end{array}$ & $\begin{array}{l}\text { FDI } \\
(\mathrm{eq} 6)\end{array}$ \\
\hline $\begin{array}{l}\text { Actual Sample Mean } \\
\text { (Deviation) }\end{array}$ & $\begin{array}{c}809.23 \\
(624.44)\end{array}$ & $\begin{array}{c}853.99 \\
(596.28) \\
\end{array}$ & $\begin{array}{c}4.12 \\
(1.73)\end{array}$ & $\begin{array}{l}43.35 \\
(8.81) \\
\end{array}$ & $\begin{array}{r}436587.4 \\
(1119777)\end{array}$ & $\begin{array}{c}61879.1 \\
(297739.7)\end{array}$ \\
\hline Trade Det. Solution & 809.09 & 796.69 & 3.91 & 43.33 & 436587.4 & 44934.5 \\
\hline $\begin{array}{l}\text { Excluding trade with } \\
\text { error shocks only }\end{array}$ & $\begin{array}{c}815.62 \\
(108.31)\end{array}$ & $\begin{array}{c}896.71 \\
(469.22)\end{array}$ & $\begin{array}{c}4.16 \\
(1.50)\end{array}$ & $\begin{array}{l}43.36 \\
(1.57)\end{array}$ & $\begin{array}{c}436587.4 \\
(0.0)\end{array}$ & $\begin{array}{c}89028.4 \\
(149588.7)\end{array}$ \\
\hline $\begin{array}{l}\text { Excluding trade with } \\
\text { error \& coef. shocks }\end{array}$ & $\begin{array}{c}816.65 \\
(111.02) \\
\end{array}$ & $\begin{array}{c}899.99 \\
(478.57) \\
\end{array}$ & $\begin{array}{c}4.16 \\
(1.54) \\
\end{array}$ & $\begin{array}{l}43.37 \\
(1.58) \\
\end{array}$ & $\begin{array}{c}436587.4 \\
(0.0) \\
\end{array}$ & $\begin{array}{c}90458.3 \\
(158860.0) \\
\end{array}$ \\
\hline FDI Det Solution & 807.31 & 800.49 & 3.90 & 43.32 & 316719.0 & 61879.1 \\
\hline $\begin{array}{l}\text { Excluding FDI with } \\
\text { error shocks only }\end{array}$ & $\begin{array}{c}818.20 \\
(139.46) \\
\end{array}$ & $\begin{array}{c}902.99 \\
(475.44) \\
\end{array}$ & $\begin{array}{c}4.15 \\
(1.51) \\
\end{array}$ & $\begin{array}{l}43.35 \\
(1.55) \\
\end{array}$ & $\begin{array}{c}362892.1 \\
(202833.8) \\
\end{array}$ & $\begin{array}{c}61879.1 \\
(0.0) \\
\end{array}$ \\
\hline $\begin{array}{l}\text { Excluding FDI with } \\
\text { error \& coef. shocks }\end{array}$ & $\begin{array}{c}819.48 \\
(143.29)\end{array}$ & $\begin{array}{c}908.79 \\
(492.60)\end{array}$ & $\begin{array}{c}4.16 \\
(1.54)\end{array}$ & $\begin{array}{l}43.35 \\
(1.58)\end{array}$ & $\begin{array}{c}366493.5 \\
(212256.0)\end{array}$ & $\begin{array}{c}61879.1 \\
(0.0)\end{array}$ \\
\hline $\begin{array}{c}\text { Levy Rate Det } \\
\text { Solution }\end{array}$ & 806.49 & 809.75 & 4.11 & 43.32 & 312118.3 & 43031.7 \\
\hline $\begin{array}{l}\text { Excluding levy rates } \\
\text { with error shocks } \\
\text { only }\end{array}$ & $\begin{array}{c}818.46 \\
(146.09)\end{array}$ & $\begin{array}{c}902.00 \\
(451.86)\end{array}$ & $\begin{array}{c}4.11 \\
(0.00)\end{array}$ & $\begin{array}{l}43.35 \\
(1.55)\end{array}$ & $\begin{array}{c}358904.5 \\
(204440.2)\end{array}$ & $\begin{array}{c}87797.9 \\
(167416.6)\end{array}$ \\
\hline $\begin{array}{c}\text { Excluding levy rates } \\
\text { with error \& coef. } \\
\text { shocks }\end{array}$ & $\begin{array}{c}818.83 \\
(149.72)\end{array}$ & $\begin{array}{c}907.37 \\
(464.63)\end{array}$ & $\begin{array}{c}4.11 \\
(0.00)\end{array}$ & $\begin{array}{l}43.35 \\
(1.58)\end{array}$ & $\begin{array}{c}361261.3 \\
(213816.1)\end{array}$ & $\begin{array}{c}88650.6 \\
(148457.5)\end{array}$ \\
\hline $\begin{array}{l}\text { Levy rate \& Trade } \\
\text { Det. Solution }\end{array}$ & 807.56 & 803.35 & 4.11 & 43.33 & 436587.4 & 45463.3 \\
\hline $\begin{array}{l}\text { Excluding levy rates } \\
\& \text { trade with error } \\
\text { shocks only }\end{array}$ & $\begin{array}{c}815.24 \\
(113.24)\end{array}$ & $\begin{array}{c}892.94 \\
(433.73)\end{array}$ & $\begin{array}{c}4.11 \\
(0.00)\end{array}$ & $\begin{array}{l}43.36 \\
(1.56)\end{array}$ & $\begin{array}{c}436587.4 \\
(0.0)\end{array}$ & $\begin{array}{c}86805.7 \\
(137525.1)\end{array}$ \\
\hline $\begin{array}{l}\text { Excluding levy rates } \\
\& \text { trade with error \& } \\
\text { coef. shocks }\end{array}$ & $\begin{array}{c}816.02 \\
(115.74)\end{array}$ & $\begin{array}{c}897.03 \\
(443.39)\end{array}$ & $\begin{array}{c}4.11 \\
(0.00)\end{array}$ & $\begin{array}{l}43.37 \\
(1.58)\end{array}$ & $\begin{array}{c}436587.4 \\
(0.0)\end{array}$ & $\begin{array}{c}90267.8 \\
(156330.0)\end{array}$ \\
\hline $\begin{array}{l}\text { Levy rate \& FDI } \\
\text { Det. Solution }\end{array}$ & 805.79 & 809.69 & 4.11 & 43.32 & 315500.3 & 61879.1 \\
\hline $\begin{array}{l}\text { Excluding levy rates } \\
\text { \& FDI with error } \\
\text { shocks only }\end{array}$ & $\begin{array}{c}817.81 \\
(146.39)\end{array}$ & $\begin{array}{c}905.39 \\
(457.67)\end{array}$ & $\begin{array}{c}4.11 \\
(0.00)\end{array}$ & $\begin{array}{l}43.35 \\
(1.55)\end{array}$ & $\begin{array}{c}361563.0 \\
(205943.2)\end{array}$ & $\begin{array}{c}61879.1 \\
(0.0)\end{array}$ \\
\hline $\begin{array}{l}\text { Excluding levy rates } \\
\& \text { FDI with error \& } \\
\text { coef. shocks }\end{array}$ & $\begin{array}{c}818.99 \\
(149.63)\end{array}$ & $\begin{array}{c}906.36 \\
(463.63)\end{array}$ & $\begin{array}{c}4.11 \\
(0.00)\end{array}$ & $\begin{array}{l}43.36 \\
(1.58)\end{array}$ & $\begin{array}{c}365519.4 \\
(213555.2)\end{array}$ & $\begin{array}{c}61879.1 \\
(0.0)\end{array}$ \\
\hline
\end{tabular}


Table 5.17 Means and Deviations of Baseline Solutions In Industrial Waste Gas Emissions (IGE) Case

\begin{tabular}{|c|c|c|c|c|c|c|}
\hline \multirow[b]{2}{*}{ Baseline } & \multicolumn{6}{|c|}{ Means and Deviations (in parentheses) } \\
\hline & $\begin{array}{l}\text { GDP } \\
\text { (eq1) }\end{array}$ & $\begin{array}{l}\text { IGE } \\
\text { (eq2) }\end{array}$ & $\begin{array}{c}\text { Levy Rate } \\
\text { (eq3) }\end{array}$ & $\begin{array}{c}\text { Industrial } \\
\text { Share } \\
\text { (eq4) }\end{array}$ & $\begin{array}{l}\text { Trade } \\
\text { (eq5) }\end{array}$ & $\begin{array}{l}\text { FDI } \\
\text { (eq6) }\end{array}$ \\
\hline $\begin{array}{c}\text { Actual Sample Mean } \\
\text { (Deviation) }\end{array}$ & $\begin{array}{r}809.23 \\
(624.44) \\
\end{array}$ & $\begin{array}{c}332.87 \\
(323.92) \\
\end{array}$ & $\begin{array}{c}5.17 \\
(1.86) \\
\end{array}$ & $\begin{array}{l}43.35 \\
(8.81) \\
\end{array}$ & $\begin{array}{l}436587.4 \\
(1119777) \\
\end{array}$ & $\begin{array}{c}61879.1 \\
(297739.7) \\
\end{array}$ \\
\hline Trade Det. Solution & 810.16 & 309.04 & 4.84 & 43.33 & 436587.4 & 46864.9 \\
\hline $\begin{array}{l}\text { Excluding trade with } \\
\text { error shocks only }\end{array}$ & $\begin{array}{c}816.32 \\
(102.88)\end{array}$ & $\begin{array}{c}333.94 \\
(135.89)\end{array}$ & $\begin{array}{c}5.23 \\
(2.32)\end{array}$ & $\begin{array}{l}43.36 \\
(1.56)\end{array}$ & $\begin{array}{c}436587.4 \\
(0.0)\end{array}$ & $\begin{array}{c}92350.8 \\
(148390.3)\end{array}$ \\
\hline $\begin{array}{l}\text { Excluding trade with } \\
\text { error \& coef. shocks }\end{array}$ & $\begin{array}{c}817.21 \\
(105.95)\end{array}$ & $\begin{array}{c}335.60 \\
(141.92)\end{array}$ & $\begin{array}{c}5.31 \\
(2.38)\end{array}$ & $\begin{array}{l}43.36 \\
(1.58)\end{array}$ & $\begin{array}{c}436587.4 \\
(0.0)\end{array}$ & $\begin{array}{c}93644.7 \\
(155063.9)\end{array}$ \\
\hline FDI Det Solution & 806.50 & 306.45 & 4.83 & 43.32 & 318432.2 & 61879.1 \\
\hline $\begin{array}{l}\text { Excluding FDI with } \\
\text { error shocks only }\end{array}$ & $\begin{array}{c}818.57 \\
(140.27)\end{array}$ & $\begin{array}{c}331.36 \\
(136.78)\end{array}$ & $\begin{array}{c}5.28 \\
(2.32)\end{array}$ & $\begin{array}{l}43.35 \\
(1.55)\end{array}$ & $\begin{array}{c}367601.6 \\
(209674.5)\end{array}$ & $\begin{array}{c}61879.1 \\
(0.0)\end{array}$ \\
\hline $\begin{array}{l}\text { Excluding FDI with } \\
\text { error \& coef. shocks }\end{array}$ & $\begin{array}{c}819.33 \\
(144.63)\end{array}$ & $\begin{array}{c}332.95 \\
(143.01)\end{array}$ & $\begin{array}{c}5.30 \\
(2.39)\end{array}$ & $\begin{array}{l}43.35 \\
(1.58)\end{array}$ & $\begin{array}{c}370582.2 \\
(218485.1)\end{array}$ & $\begin{array}{c}61879.1 \\
(0.0)\end{array}$ \\
\hline $\begin{array}{c}\text { Levy Rate Det } \\
\text { Solution }\end{array}$ & 806.28 & 305.92 & 5.17 & 43.32 & 314583.0 & 42806.9 \\
\hline $\begin{array}{c}\text { Excluding levy rates } \\
\text { with error shocks } \\
\text { only }\end{array}$ & $\begin{array}{c}818.24 \\
(139.62)\end{array}$ & $\begin{array}{c}329.11 \\
(128.69)\end{array}$ & $\begin{array}{c}5.17 \\
(0.00)\end{array}$ & $\begin{array}{l}43.35 \\
(1.55)\end{array}$ & $\begin{array}{c}363359.3 \\
(212463.7)\end{array}$ & $\begin{array}{c}86187.5 \\
(143743.3)\end{array}$ \\
\hline $\begin{array}{l}\text { Excluding levy rates } \\
\text { with error \& coef. } \\
\text { shocks }\end{array}$ & $\begin{array}{c}819.37 \\
(143.99)\end{array}$ & $\begin{array}{c}330.75 \\
(133.45)\end{array}$ & $\begin{array}{c}5.17 \\
(0.00)\end{array}$ & $\begin{array}{l}43.35 \\
(1.58)\end{array}$ & $\begin{array}{c}368197.5 \\
(222105.0)\end{array}$ & $\begin{array}{c}89061.6 \\
(157362.1)\end{array}$ \\
\hline $\begin{array}{c}\text { Levy rate \& Trade } \\
\text { Det. Solution }\end{array}$ & 808.94 & 308.22 & 5.17 & 43.33 & 436587.4 & 46165.7 \\
\hline $\begin{array}{l}\text { Excluding levy rates } \\
\& \text { trade with error } \\
\text { shocks only }\end{array}$ & $\begin{array}{c}815.61 \\
(102.41)\end{array}$ & $\begin{array}{c}330.94 \\
(128.27)\end{array}$ & $\begin{array}{c}5.17 \\
(0.00)\end{array}$ & $\begin{array}{l}43.36 \\
(1.56)\end{array}$ & $\begin{array}{c}436587.4 \\
(0.0)\end{array}$ & $\begin{array}{c}91569.9 \\
(149735.8)\end{array}$ \\
\hline $\begin{array}{l}\text { Excluding levy rates } \\
\& \text { trade with error \& } \\
\text { coef. shocks }\end{array}$ & $\begin{array}{c}815.37 \\
(105.14)\end{array}$ & $\begin{array}{c}331.63 \\
(131.96)\end{array}$ & $\begin{array}{c}5.17 \\
(0.00)\end{array}$ & $\begin{array}{l}43.36 \\
(1.58)\end{array}$ & $\begin{array}{c}436587.4 \\
(0.0)\end{array}$ & $\begin{array}{c}93140.6 \\
(156040.8)\end{array}$ \\
\hline $\begin{array}{c}\text { Levy rate \& FDI } \\
\text { Det. Solution }\end{array}$ & 805.18 & 305.74 & 5.17 & 43.32 & 317532.6 & 61879.1 \\
\hline $\begin{array}{l}\text { Excluding levy rates } \\
\& \text { FDI with error } \\
\text { shocks only }\end{array}$ & $\begin{array}{c}816.78 \\
(138.98)\end{array}$ & $\begin{array}{c}328.32 \\
(129.54)\end{array}$ & $\begin{array}{c}5.17 \\
(0.00)\end{array}$ & $\begin{array}{l}43.35 \\
(1.55)\end{array}$ & $\begin{array}{c}366320.4 \\
(208766.8)\end{array}$ & $\begin{array}{c}61879.1 \\
(0.0)\end{array}$ \\
\hline $\begin{array}{l}\text { Excluding levy rates } \\
\& \text { FDI with error \& } \\
\text { coef. shocks }\end{array}$ & $\begin{array}{c}817.61 \\
(143.85)\end{array}$ & $\begin{array}{c}330.11 \\
(134.55)\end{array}$ & $\begin{array}{c}5.17 \\
(0.00)\end{array}$ & $\begin{array}{l}43.36 \\
(1.58)\end{array}$ & $\begin{array}{c}368885.1 \\
(216847.1)\end{array}$ & $\begin{array}{c}61879.1 \\
(0.0)\end{array}$ \\
\hline
\end{tabular}


Table 5.18 Deterministic Baseline Solution (DBS) vs. Stochastic Baseline Solution (SBS) In Industrial Wastewater Pollution (IWW) Case

\begin{tabular}{|c|c|c|c|c|c|c|}
\hline \multirow[b]{2}{*}{ Stochastic Baseline } & \multicolumn{6}{|c|}{ Changes in Endogenous Variables Compared with DBS (\%) } \\
\hline & $\begin{array}{l}\text { GDP } \\
\text { (eq1) }\end{array}$ & $\begin{array}{l}\text { IWW } \\
\text { (eq2) }\end{array}$ & $\begin{array}{c}\text { Levy Rate } \\
\text { (eq3) }\end{array}$ & $\begin{array}{c}\text { Industrial } \\
\text { Share } \\
\text { (eq4) }\end{array}$ & $\begin{array}{l}\text { Trade } \\
\text { (eq5) }\end{array}$ & $\begin{array}{l}\text { FDI } \\
\text { (eq6) }\end{array}$ \\
\hline $\begin{array}{l}\text { 1. Excluding trade } \\
\text { with error shocks } \\
\text { only }\end{array}$ & 0.81 & 12.55 & 6.34 & 0.07 & 0.00 & 98.13 \\
\hline $\begin{array}{l}\text { 2. Excluding trade } \\
\text { with error \& coef. } \\
\text { shocks }\end{array}$ & 0.82 & 12.86 & 6.40 & 0.07 & 0.00 & 99.82 \\
\hline $\begin{array}{l}\text { 3. Excluding FDI } \\
\text { with error shocks } \\
\text { only }\end{array}$ & 1.35 & 12.80 & 6.32 & 0.06 & 14.58 & 0.00 \\
\hline $\begin{array}{l}\text { 4. Excluding FDI } \\
\text { with error \& coef. } \\
\text { shocks }\end{array}$ & 1.51 & 13.53 & 6.62 & 0.05 & 15.72 & 0.00 \\
\hline $\begin{array}{l}\text { 5. Excluding levy } \\
\text { rates with error } \\
\text { shocks only }\end{array}$ & 1.48 & 11.39 & 0.00 & 0.07 & 14.99 & 104.03 \\
\hline $\begin{array}{l}\text { 6. Excluding levy } \\
\text { rates with error \& } \\
\text { coef. shocks }\end{array}$ & 1.53 & 12.06 & 0.00 & 0.07 & 15.74 & 106.01 \\
\hline $\begin{array}{l}\text { 7. Excluding levy } \\
\text { rates \& trade with } \\
\text { error shocks only }\end{array}$ & 0.95 & 11.15 & 0.00 & 0.06 & 0.00 & 90.94 \\
\hline $\begin{array}{l}8 . \text { Excluding levy } \\
\text { rates \& trade with } \\
\text { error \& coef. shocks }\end{array}$ & 1.05 & 11.66 & 0.00 & 0.08 & 0.00 & 98.55 \\
\hline $\begin{array}{l}\text { 9. Excluding levy } \\
\text { rates \& FDI with } \\
\text { error shocks only }\end{array}$ & 1.49 & 11.82 & 0.00 & 0.07 & 14.60 & 0.00 \\
\hline $\begin{array}{l}\text { 10. Excluding levy } \\
\text { rates \& FDI with } \\
\text { error \& coef. shocks }\end{array}$ & 1.64 & 11.94 & 0.00 & 0.08 & 15.85 & 0.00 \\
\hline
\end{tabular}


Table 5.19 Deterministic Baseline Solution (DBS) vs. Stochastic Baseline Solution (SBS) In Industrial Waste Gas Emissions (IGE) Case

\begin{tabular}{|c|c|c|c|c|c|c|}
\hline \multirow[b]{2}{*}{ Stochastic Baseline } & \multicolumn{6}{|c|}{ Changes in Endogenous Variables Compared with DBS (\%) } \\
\hline & $\begin{array}{l}\text { GDP } \\
\text { (eq1) }\end{array}$ & $\begin{array}{l}\text { IGE } \\
\text { (eq2) }\end{array}$ & $\begin{array}{c}\text { Levy Rate } \\
\text { (eq3) }\end{array}$ & $\begin{array}{c}\text { Industrial } \\
\text { Share } \\
\text { (eq4) }\end{array}$ & $\begin{array}{l}\text { Trade } \\
\text { (eq5) }\end{array}$ & $\begin{array}{l}\text { FDI } \\
\text { (eq6) }\end{array}$ \\
\hline $\begin{array}{l}\text { 1. Excluding trade } \\
\text { with error shocks } \\
\text { only }\end{array}$ & 0.76 & 8.06 & 9.17 & 0.07 & 0.00 & 97.06 \\
\hline $\begin{array}{l}\text { 2. Excluding trade } \\
\text { with error \& coef. } \\
\text { shocks }\end{array}$ & 0.87 & 8.59 & 9.64 & 0.08 & 0.00 & 99.82 \\
\hline $\begin{array}{l}\text { 3. Excluding FDI } \\
\text { with error shocks } \\
\text { only }\end{array}$ & 1.50 & 8.13 & 9.11 & 0.06 & 15.44 & 0.00 \\
\hline $\begin{array}{l}\text { 4. Excluding FDI } \\
\text { with error \& coef. } \\
\text { shocks }\end{array}$ & 1.59 & 8.65 & 9.68 & 0.05 & 16.38 & 0.00 \\
\hline $\begin{array}{l}\text { 5. Excluding levy } \\
\text { rates with error } \\
\text { shocks only }\end{array}$ & 1.48 & 7.58 & 0.00 & 0.06 & 15.51 & 101.34 \\
\hline $\begin{array}{l}\text { 6. Excluding levy } \\
\text { rates with error \& } \\
\text { coef. shocks }\end{array}$ & 1.62 & 8.12 & 0.00 & 0.07 & 17.04 & 108.05 \\
\hline $\begin{array}{l}\text { 7. Excluding levy } \\
\text { rates \& trade with } \\
\text { error shocks only }\end{array}$ & 0.82 & 7.37 & 0.00 & 0.06 & 0.00 & 98.35 \\
\hline $\begin{array}{l}8 . \text { Excluding levy } \\
\text { rates \& trade with } \\
\text { error \& coef. shocks }\end{array}$ & 0.79 & 7.60 & 0.00 & 0.06 & 0.00 & 101.75 \\
\hline $\begin{array}{l}\text { 9. Excluding levy } \\
\text { rates \& FDI with } \\
\text { error shocks only }\end{array}$ & 1.44 & 7.39 & 0.00 & 0.07 & 15.36 & 0.00 \\
\hline $\begin{array}{l}\text { 10. Excluding levy } \\
\text { rates \& FDI with } \\
\text { error \& coef. shocks }\end{array}$ & 1.54 & 7.97 & 0.00 & 0.08 & 16.17 & 0.00 \\
\hline
\end{tabular}


explain the obvious differences between the deterministically simulated values and the actual values of some endogenous variables such as FDI and trade as shown in Table 5.16 and 5.17. The result also suggests that nonlinear models such as the TEM should not be simply validated in terms of comparisons between the simulated values and the actual sample values. However, this does not imply that simulation procedures in this case would produce no useful results regarding model validation. As Howrey and Kelejian show mathematically, the differences between the simulated and the actual values are systematic and consistent in nature. Comparisons between the simulated values obtained from different scenarios and those of the corresponding baseline solutions, therefore, can generate meaningful information to examine model validity as stability and consistency.

The deterministic simulation results of the industrial wastewater pollution and the industrial waste gas emissions case based on above-mentioned comparisons are reported in Table 5.20 and 5.21, respectively. Table 5.16 shows that a $10 \%(20 \%)$ increase in trade values can lead to a $1.53 \%(2.93 \%)$ increase in wastewater discharges and a $0.36 \%$ $(0.69 \%)$ increase in levy rates. That is, a $1 \%$ increase in trade can lead to about $0.15 \%$ increase in wastewater pollution and $0.035 \%$ increase in emissions charge; these changes are close to those of comparative statics ( $0.188 \%$ and $0.056 \%$, see Table 5.11 and 5.13 ). The difference in magnitude between these results can be partly due to the fact that in comparative static analysis the effects that either are statistically insignificant or have a theoretically unexplainable sign are excluded from computation, while in model simulation all these effects are counted. Very likely for the same reason, while the comparative statics results suggest higher levy rates on wastewater pollution may lead to 
reduced trade and FDI inflows, the deterministic solution shows that higher a levy rate can have a negative impact on trade but its impact on FDI is positive.

The results of Scenario 7 and 8 in Table 5.20 suggest that if levy rates increase as trade expands at the same rate, wastewater pollution can be reduced and positive GDP growth can also be achieved. According to the outcome of Scenario 9 and 10 in the same table, however, an increase in levy rates and FDI together alone can result in a reduction not only in wastewater pollution but also in GDP levels. Combining these results, trade is hence essential to achieve coordinated development between the economy and the environment.

The deterministic simulation results in the industrial waste gas emissions case, as shown in Table 5.21, also conform with those reported in Section 5.6. As noted earlier, since levy rates on waste gas emissions present a negative relationship with GDP growth in this case during the study period, it is not surprising that an increase in trade and FDI can lead to higher GDP levels but lower levy rates. Therefore, it is not surprising either that an increase in trade and in levy rates can result in more waste gas emissions and higher GDP growth because the increase in emissions charge on waste gas is not strengthened but weakened by economic growth. Though a simultaneous increase in levy rates and FDI can lead to a reduction in waste gas emissions, economic growth in this case is almost insignificant. Therefore, in order to effectively combat air pollution, emissions charges should rise rather than decrease as the economy grows because this is in line with environment as a normal good. 
Table 5.20 Deterministic Simulation Results in Industrial Wastewater (IWW) Pollution Case

\begin{tabular}{|c|c|c|c|c|c|c|}
\hline \multirow{2}{*}{ Scenario } & \multicolumn{7}{|c|}{ Changes in Endogenous Variables (\%) } \\
\cline { 2 - 7 } & $\begin{array}{c}\text { GDP } \\
\text { (eq1) }\end{array}$ & $\begin{array}{c}\text { IWW } \\
\text { (eq2) }\end{array}$ & $\begin{array}{c}\text { Levy Rate } \\
\text { (eq3) }\end{array}$ & $\begin{array}{c}\text { Industrial } \\
\text { Share } \\
\text { (eq4) }\end{array}$ & $\begin{array}{c}\text { Trade } \\
\text { (eq5) }\end{array}$ & $\begin{array}{c}\text { FDI } \\
\text { (eq6) }\end{array}$ \\
\hline $\begin{array}{c}\text { 1. A 10\% increase in } \\
\text { trade values }\end{array}$ & 1.71 & 1.53 & 0.36 & 0.04 & 10.00 & 1.79 \\
\hline $\begin{array}{c}\text { 2. A 20\% increase in } \\
\text { trade values }\end{array}$ & 3.30 & 2.93 & 0.69 & 0.07 & 20.00 & 3.46 \\
\hline $\begin{array}{c}\text { 3. A 10\% increase in } \\
\text { FDI inflows }\end{array}$ & 0.25 & 0.22 & 0.05 & 0.01 & 1.40 & 10.00 \\
\hline $\begin{array}{c}\text { 4. A 20\% increase in } \\
\text { FDI inflows }\end{array}$ & 0.47 & 0.42 & 0.10 & 0.01 & 2.69 & 20.00 \\
\hline $\begin{array}{c}\text { 5. A 10\% increase in } \\
\text { levy rates }\end{array}$ & -0.84 & -5.54 & 10.00 & 0.01 & -0.40 & 1.58 \\
\hline $\begin{array}{c}\text { 6. A 20\% increase in } \\
\text { levy rates }\end{array}$ & -1.60 & -10.32 & 20.00 & 0.01 & -0.76 & 3.04 \\
\hline $\begin{array}{c}\text { 7. A 10\% increase in } \\
\text { levy rates and in } \\
\text { trade values }\end{array}$ & 0.96 & -3.81 & 10.00 & 0.04 & 10.00 & 3.41 \\
\hline $\begin{array}{c}\text { 8. A 20\% increase in } \\
\text { levy rates and in } \\
\text { trade values }\end{array}$ & 1.85 & -7.17 & 20.00 & 0.08 & 20.00 & 6.62 \\
\hline $\begin{array}{c}\text { 9. A 10\% increase in } \\
\text { levy rates and in FDI } \\
\text { inflows }\end{array}$ & -0.63 & -5.34 & 10.00 & 0.01 & 0.77 & 10.00 \\
\hline $\begin{array}{c}\text { 10. A 20\% increase } \\
\text { in levy rates and in } \\
\text { FDI inflows }\end{array}$ & -1.20 & -9.96 & 20.00 & 0.02 & 1.47 & 20.00 \\
\hline
\end{tabular}


Table 5.21 Deterministic Simulation Results in Industrial Gas Emissions (IGE) Case

\begin{tabular}{|c|c|c|c|c|c|c|}
\hline \multirow{2}{*}{ Scenario } & \multicolumn{7}{|c|}{ Changes in Endogenous Variables (\%) } \\
\cline { 2 - 7 } & $\begin{array}{c}\text { GDP } \\
\text { (eq1) }\end{array}$ & $\begin{array}{c}\text { IGE } \\
\text { (eq2) }\end{array}$ & $\begin{array}{c}\text { Levy Rate } \\
\text { (eq3) }\end{array}$ & $\begin{array}{c}\text { Industrial } \\
\text { Share } \\
\text { (eq4) }\end{array}$ & $\begin{array}{c}\text { Trade } \\
\text { (eq5) }\end{array}$ & $\begin{array}{c}\text { FDI } \\
\text { (eq6) }\end{array}$ \\
\hline $\begin{array}{c}\text { 1. A 10\% increase in } \\
\text { trade values }\end{array}$ & 2.13 & 1.99 & -0.99 & 0.03 & 10.00 & 2.33 \\
\hline $\begin{array}{c}\text { 2. A 20\% increase in } \\
\text { trade values }\end{array}$ & 4.12 & 3.85 & -1.88 & 0.06 & 20.00 & 4.50 \\
\hline $\begin{array}{c}\text { 3. A 10\% increase in } \\
\text { FDI inflows }\end{array}$ & 0.32 & 0.30 & -0.15 & 0.00 & 1.45 & 10.00 \\
\hline $\begin{array}{c}\text { 4. A 20\% increase in } \\
\text { FDI inflows }\end{array}$ & 0.61 & 0.57 & -0.29 & 0.01 & 2.79 & 20.00 \\
\hline $\begin{array}{c}\text { 5. A 10\% increase in } \\
\text { levy rates }\end{array}$ & -0.27 & -1.61 & 10.00 & 0.00 & -0.30 & -0.83 \\
\hline $\begin{array}{c}\text { 6. A 20\% increase in } \\
\text { levy rates }\end{array}$ & -0.52 & -3.05 & 20.00 & 0.00 & -0.57 & -1.58 \\
\hline $\begin{array}{c}\text { 7. A 10\% increase in } \\
\text { levy rates and in } \\
\text { trade values }\end{array}$ & 1.90 & 0.25 & 10.00 & 0.03 & 10.00 & 1.47 \\
\hline $\begin{array}{c}\text { 8. A 20\% increase in } \\
\text { levy rates and in } \\
\text { trade values }\end{array}$ & 3.66 & 0.48 & 20.00 & 0.06 & 20.00 & 2.83 \\
\hline $\begin{array}{c}\text { 9. A 10\% increase in } \\
\text { levy rates and in FDI } \\
\text { inflows }\end{array}$ & 0.07 & -1.31 & 10.00 & 0.01 & 1.27 & 10.00 \\
\hline $\begin{array}{c}\text { 10. A 20\% increase } \\
\text { in levy rates and in } \\
\text { FDI inflows }\end{array}$ & 0.13 & -2.50 & 20.00 & 0.01 & 2.44 & 20.00 \\
\hline
\end{tabular}




\subsubsection{Stochastic Error Solution}

The purpose of simulation with stochastic errors is to assess the stability of the TEM model and the impacts of uncertainty on model performance. Stability implies that the endogenous variables of a model approach closely their equilibrium values or a particular solution of the model over time and space, given the values of the exogenous variables and the stochastic error terms. According to Labys (1973), the nature of stability properties of an econometric model constitutes an important measure of its validity, and the behavior of a valid model should conform to the same pattern whether or not stochastic error shocks are included.

As Howrey and Kelejian (1971) point out, the deterministic simulation of a model with nonlinear endogenous variables provides results systematically diverging from actual observations. The stochastic baseline results also show a consistently systematic deviation from the actual values (see Tables 5.16 and 5.17) and from those of the deterministic baselines (see Tables 5.18 and 5.19). All the stochastic solutions have greater average means and smaller average deviations (though why there exists such a systematic difference between the stochastic and the deterministic solutions requires

more research). That is, given the nature of error shocks as a combination of all missing variables of the TEM system, the total effect of the missing variables on each of the endogenous variables in the model is positive. Similar to the deterministic simulation case, such systematic differences should not affect the comparisons between the stochastic simulated results of different scenarios and those of the corresponding stochastic baseline solutions. 
The stochastic error solutions for the industrial wastewater pollution and the industrial waste gas emissions case are summarized in Table 5.22 and 5.23, respectively. The figures in these tables are changes in average means of the endogenous variables compared with their corresponding stochastic baseline solutions. Compared with the deterministic solutions in Table 5.20 and 5.21, the stochastic error simulation results are very close to deterministic ones except for the results for the FDI variables. A significant difference between the stochastic and the deterministic solution for the FDI variable is not surprising given that FDI is the most unpredictable and uncertain endogenous variable in the TEM system as indicated by the summary statistics of the variables in Table 5.2. Hence, the TEM model is reasonably stable to error structure shocks and the impacts of uncertainty on model performance are, in general, not significant.

\subsubsection{Stochastic Error and Coefficient Solution}

In addition to error shocks, uncertainties of the estimated coefficients of the model are also incorporated in the stochastic simulations to test the robustness of the estimated values of those coefficients. Economists have long been interested in the behavior of an econometric model where the coefficients are treated as random variables (Naylor 1971). Early studies along this line encountered serious difficulty in solving the model when its coefficients were shocked. Using EViews 4, simulations with additional coefficient shocks can be readily conducted by linking the simulation model to the existing estimated model. No doubt the stability of a model to coefficient shocks is another important measure of its validity, because if the solution of the model is sensitive to coefficient perturbations, validity as credibility of the model will be obviously questionable. 
The results of this stochastic solution are shown in Table 5.24 and 5.25. In comparison with the results in Table 5.18 and 5.23, random draws of the values of coefficients do not create obvious deviations in outcomes for most endogenous variables in both the industrial wastewater pollution and the industrial waste gas emissions cases. Again, the FDI variable is an exception because of the uncertain nature of the variable itself. Therefore, it can be concluded that the model is rather robust to changes in the estimated values of the coefficients.

In summary, the TEM system behaves fairly consistently in all the deterministic and the stochastic simulations and shows reasonable stability to both the error and the coefficient shocks. It is also worth noting that, in both the deterministic and the stochastic simulations, the solution of the TEM model converges quickly. Hence, the existence, stability and convergence conditions for the TEM system would appear to be computationally supported.

\subsection{Conclusions}

Using Chinese provincial-level panel data, the TEM model has been estimated employing three estimation procedures. These approaches include a 2SLS estimator with no fixed or random effect, a fixed effect 2SLS estimator, and a random effect 2SLS estimator. Empirical results suggest that the 2SLS estimator with no fixed or random effects appears to work best for the Chinese model application. Model validation and simulation further shows that this non-linear simultaneous equations TEM model and its 2SLS estimation results are reasonably robust. 
Examination of the empirical interactions between trade and the environment confirms the importance of using a simultaneous model to identify the sources of these influences. For instance, results show that increased trade can lead to increased wastewater discharges through a scale effect, but trade can also lead to reduced wastewater discharges through its income effect. Similarly, an emissions charge may have both a direct negative impact on trade from a reduced economic scale and an indirect negative impact also from the reduced economic scale but via its impact on FDIs. These results suggest that a tradeoff between economic growth and environmental protection might have taken place in China during the period examined. 
Table 5.22 Stochastic Error Simulation Results in Industrial Wastewater (IWW) Pollution Case

\begin{tabular}{|c|c|c|c|c|c|c|}
\hline \multirow{2}{*}{ Scenario } & \multicolumn{7}{|c|}{ Changes in Endogenous Variables (\%) } \\
\cline { 2 - 7 } & $\begin{array}{c}\text { GDP } \\
\text { (eq1) }\end{array}$ & $\begin{array}{c}\text { IWW } \\
\text { (eq2) }\end{array}$ & $\begin{array}{c}\text { Levy Rate } \\
\text { (eq3) }\end{array}$ & $\begin{array}{c}\text { Industrial } \\
\text { Share } \\
\text { (eq4) }\end{array}$ & $\begin{array}{c}\text { Trade } \\
\text { (eq5) }\end{array}$ & $\begin{array}{c}\text { FDI } \\
\text { (eq6) }\end{array}$ \\
\hline $\begin{array}{c}\text { 1. A 10\% increase in } \\
\text { trade values }\end{array}$ & 1.74 & 1.54 & 0.41 & 0.02 & 10.00 & 1.42 \\
\hline $\begin{array}{c}\text { 2. A 20\% increase in } \\
\text { trade values }\end{array}$ & 3.40 & 3.28 & 0.80 & 0.05 & 20.00 & 4.36 \\
\hline $\begin{array}{c}\text { 3. A 10\% increase in } \\
\text { FDI inflows }\end{array}$ & 0.28 & 0.27 & 0.11 & 0.01 & 1.26 & 10.00 \\
\hline $\begin{array}{c}\text { 4. A 20\% increase in } \\
\text { FDI inflows }\end{array}$ & 0.39 & 0.08 & 0.08 & 0.01 & 2.13 & 20.00 \\
\hline $\begin{array}{c}\text { 5. A 10\% increase in } \\
\text { levy rates }\end{array}$ & -0.82 & -5.42 & 10.00 & -0.01 & -0.50 & -3.73 \\
\hline $\begin{array}{c}\text { 6. A 20\% increase in } \\
\text { levy rates }\end{array}$ & -1.55 & -9.77 & 20.00 & 0.02 & -1.21 & -3.99 \\
\hline $\begin{array}{c}\text { 7. A 10\% increase in } \\
\text { levy rates and in } \\
\text { trade values }\end{array}$ & 0.91 & -3.94 & 10.00 & 0.06 & 10.00 & 5.32 \\
\hline $\begin{array}{c}\text { 8. A 20\% increase in } \\
\text { levy rates and in } \\
\text { trade values }\end{array}$ & 1.77 & -7.54 & 20.00 & 0.08 & 20.00 & 8.13 \\
\hline $\begin{array}{c}\text { 9. A 10\% increase in } \\
\text { levy rates and in FDI } \\
\text { inflows }\end{array}$ & -0.58 & -5.67 & 10.00 & 0.00 & 1.36 & 10.00 \\
\hline $\begin{array}{c}\text { 10. A 20\% increase } \\
\text { in levy rates and in } \\
\text { FDI inflows }\end{array}$ & -1.11 & -9.80 & 20.00 & 0.02 & 2.01 & 20.00 \\
\hline
\end{tabular}


Table 5.23 Stochastic Error Simulation Results in Industrial Gas Emissions (IGE) Case

\begin{tabular}{|c|c|c|c|c|c|c|}
\hline \multirow{2}{*}{ Scenario } & \multicolumn{7}{|c|}{ Changes in Endogenous Variables (\%) } \\
\cline { 2 - 7 } & $\begin{array}{c}\text { GDP } \\
\text { (eq1) }\end{array}$ & $\begin{array}{c}\text { IGE } \\
\text { (eq2) }\end{array}$ & $\begin{array}{c}\text { Levy Rate } \\
\text { (eq3) }\end{array}$ & $\begin{array}{c}\text { Industrial } \\
\text { Share } \\
\text { (eq4) }\end{array}$ & $\begin{array}{c}\text { Trade } \\
\text { (eq5) }\end{array}$ & $\begin{array}{c}\text { FDI } \\
\text { (eq6) }\end{array}$ \\
\hline $\begin{array}{c}\text { 1. A 10\% increase in } \\
\text { trade values }\end{array}$ & 2.18 & 1.96 & -0.91 & 0.02 & 10.00 & 2.22 \\
\hline $\begin{array}{c}\text { 2. A 20\% increase in } \\
\text { trade values }\end{array}$ & 4.11 & 3.83 & -1.83 & 0.06 & 20.00 & 5.27 \\
\hline $\begin{array}{c}\text { 3. A 10\% increase in } \\
\text { FDI inflows }\end{array}$ & 0.30 & 0.48 & -0.09 & 0.01 & 1.28 & 10.00 \\
\hline $\begin{array}{c}\text { 4. A 20\% increase in } \\
\text { FDI inflows }\end{array}$ & 0.64 & 0.67 & -0.14 & 0.02 & 2.79 & 20.00 \\
\hline $\begin{array}{c}\text { 5. A 10\% increase in } \\
\text { levy rates }\end{array}$ & -0.37 & -1.88 & 10.00 & 0.01 & -0.23 & -0.80 \\
\hline $\begin{array}{c}\text { 6. A 20\% increase in } \\
\text { levy rates }\end{array}$ & -0.52 & -3.18 & 20.00 & -0.01 & -0.30 & -2.12 \\
\hline $\begin{array}{c}\text { 7. A 10\% increase in } \\
\text { levy rates and in } \\
\text { trade values }\end{array}$ & 1.83 & 0.16 & 10.00 & 0.04 & 10.00 & 0.55 \\
\hline $\begin{array}{c}\text { 8. A 20\% increase in } \\
\text { levy rates and in } \\
\text { trade values }\end{array}$ & 3.62 & 0.26 & 20.00 & 0.05 & 20.00 & 0.43 \\
\hline $\begin{array}{c}\text { 9. A 10\% increase in } \\
\text { levy rates and in FDI } \\
\text { inflows }\end{array}$ & 0.00 & -1.30 & 10.00 & 0.00 & 0.98 & 10.00 \\
\hline $\begin{array}{c}\text { 10. A 20\% increase } \\
\text { in levy rates and in } \\
\text { FDI inflows }\end{array}$ & 0.13 & -2.28 & 20.00 & 0.02 & 2.22 & 20.00 \\
\hline
\end{tabular}


Table 5.24 Stochastic Error Coefficient Simulation Results in Industrial Wastewater (IWW) Pollution Case

\begin{tabular}{|c|c|c|c|c|c|c|}
\hline \multirow{2}{*}{ Scenario } & \multicolumn{7}{|c|}{ Changes in Endogenous Variables (\%) } \\
\cline { 2 - 7 } & $\begin{array}{c}\text { GDP } \\
\text { (eq1) }\end{array}$ & $\begin{array}{c}\text { IWW } \\
\text { (eq2) }\end{array}$ & $\begin{array}{c}\text { Levy Rate } \\
\text { (eq3) }\end{array}$ & $\begin{array}{c}\text { Industrial } \\
\text { Share } \\
\text { (eq4) }\end{array}$ & $\begin{array}{c}\text { Trade } \\
\text { (eq5) }\end{array}$ & $\begin{array}{c}\text { FDI } \\
\text { (eq6) }\end{array}$ \\
\hline $\begin{array}{c}\text { 1. A 10\% increase in } \\
\text { trade values }\end{array}$ & 1.75 & 1.60 & 0.58 & 0.04 & 10.00 & 2.64 \\
\hline $\begin{array}{c}\text { 2. A 20\% increase in } \\
\text { trade values }\end{array}$ & 3.38 & 2.72 & 0.77 & 0.08 & 20.00 & 5.56 \\
\hline $\begin{array}{c}\text { 3. A 10\% increase in } \\
\text { FDI inflows }\end{array}$ & 0.16 & 0.09 & 0.00 & 0.03 & 1.51 & 10.00 \\
\hline $\begin{array}{c}\text { 4. A 20\% increase in } \\
\text { FDI inflows }\end{array}$ & 0.37 & 0.23 & -0.09 & 0.03 & 2.40 & 20.00 \\
\hline $\begin{array}{c}\text { 5. A 10\% increase in } \\
\text { levy rates }\end{array}$ & -0.71 & -5.60 & 10.00 & 0.00 & 0.22 & 1.76 \\
\hline $\begin{array}{c}\text { 6. A 20\% increase in } \\
\text { levy rates }\end{array}$ & -1.57 & -10.46 & 20.00 & 0.01 & -0.08 & 2.99 \\
\hline $\begin{array}{c}\text { 7. A 10\% increase in } \\
\text { levy rates and in } \\
\text { trade values }\end{array}$ & 0.80 & -4.22 & 10.00 & 0.04 & 10.00 & 2.84 \\
\hline $\begin{array}{c}\text { 8. A 20\% increase in } \\
\text { levy rates and in } \\
\text { trade values }\end{array}$ & 1.64 & -7.94 & 20.00 & 0.07 & 20.00 & 5.50 \\
\hline $\begin{array}{c}\text { 9. A 10\% increase in } \\
\text { levy rates and in FDI } \\
\text { inflows }\end{array}$ & -0.60 & -5.29 & 10.00 & 0.01 & 1.02 & 10.00 \\
\hline $\begin{array}{c}\text { 10. A 20\% increase } \\
\text { in levy rates and in } \\
\text { FDI inflows }\end{array}$ & -1.24 & -10.01 & 20.00 & 0.02 & 1.75 & 20.00 \\
\hline
\end{tabular}


Table 5.25 Stochastic Error Coefficient Simulation Results in Industrial Gas Emissions (IGE) Case

\begin{tabular}{|c|c|c|c|c|c|c|}
\hline \multirow{2}{*}{ Scenario } & \multicolumn{7}{|c|}{ Changes in Endogenous Variables (\%) } \\
\cline { 2 - 7 } & $\begin{array}{c}\text { GDP } \\
\text { (eq1) }\end{array}$ & $\begin{array}{c}\text { IGE } \\
\text { (eq2) }\end{array}$ & $\begin{array}{c}\text { Levy Rate } \\
\text { (eq3) }\end{array}$ & $\begin{array}{c}\text { Industrial } \\
\text { Share } \\
\text { (eq4) }\end{array}$ & $\begin{array}{c}\text { Trade } \\
\text { (eq5) }\end{array}$ & $\begin{array}{c}\text { FDI } \\
\text { (eq6) }\end{array}$ \\
\hline $\begin{array}{c}\text { 1. A 10\% increase in } \\
\text { trade values }\end{array}$ & 2.11 & 2.06 & -0.98 & 0.04 & 10.00 & 5.56 \\
\hline $\begin{array}{c}\text { 2. A 20\% increase in } \\
\text { trade values }\end{array}$ & 4.05 & 3.76 & -1.73 & 0.05 & 20.00 & 5.05 \\
\hline $\begin{array}{c}\text { 3. A 10\% increase in } \\
\text { FDI inflows }\end{array}$ & 0.20 & 0.35 & -0.07 & 0.02 & 0.96 & 10.00 \\
\hline $\begin{array}{c}\text { 4. A 20\% increase in } \\
\text { FDI inflows }\end{array}$ & 0.71 & 1.17 & -0.38 & 0.02 & 3.17 & 20.00 \\
\hline $\begin{array}{c}\text { 5. A 10\% increase in } \\
\text { levy rates }\end{array}$ & -0.30 & -1.49 & 10.00 & 0.01 & -0.60 & -0.42 \\
\hline $\begin{array}{c}\text { 6. A 20\% increase in } \\
\text { levy rates }\end{array}$ & -0.55 & -3.08 & 20.00 & -0.01 & -0.72 & -2.43 \\
\hline $\begin{array}{c}\text { 7. A 10\% increase in } \\
\text { levy rates and in } \\
\text { trade values }\end{array}$ & 1.89 & 0.33 & 10.00 & 0.05 & 10.00 & 1.70 \\
\hline $\begin{array}{c}\text { 8. A 20\% increase in } \\
\text { levy rates and in } \\
\text { trade values }\end{array}$ & 3.66 & 0.42 & 20.00 & 0.07 & 20.00 & 2.34 \\
\hline $\begin{array}{c}\text { 9. A 10\% increase in } \\
\text { levy rates and in FDI } \\
\text { inflows }\end{array}$ & -0.11 & -1.42 & 10.00 & 0.00 & 0.22 & 10.00 \\
\hline $\begin{array}{c}\text { 10. A 20\% increase } \\
\text { in levy rates and in } \\
\text { FDI inflows }\end{array}$ & 0.09 & -2.49 & 20.00 & 0.01 & 2.28 & 20.00 \\
\hline
\end{tabular}




\section{Chapter 6}

\section{POLICY IMPLICATIONS AND CONCLUSIONS}

\subsection{Introduction}

The relation between trade and the environment is an important issue in many developing countries. This is particularly true for China. On one hand, economic development requires that China liberalize its trade and integrate itself into the global economy. On the other hand, China has realized that adequate efforts should be made to improve its increasingly deteriorating environment in order to achieve sustainable economic development. China's dilemma, given the lack of a more comprehensive perspective, resembles that of this study: (1) what are the environmental implications of increased trade? and (2) what are the trade implications of stricter environmental policies? The importance of the present effort is to study these questions based on a simultaneous trade and the environment model that employs a provincial panel data set. The major findings, policy implications, and conclusions of the study are summarized in this chapter.

\subsection{Major Findings}

Increased trade can lead to greater industrial wastewater pollution, and industrial waste gas, $\mathrm{CO}_{2}$, and particle emissions. This increase in pollution is due to a tradeinduced economic scale effect. That is, increased trade can cause an expansion of economic activities, and assuming the nature of these activities to be unchanged, the total amount of pollution generated would increase. However, as suggested in the wastewater 
pollution case, this increase in pollution could be alleviated by the trade-induced income effect, but this would happen only when an effective environmental policy is in place. In addition, no evidence has been found in this study that China may have a comparative advantage in pollution-intensive goods.

An effective emissions charge would have a negative impact on trade, though the impact is very small. This negative effect comes from a reduced economic scale resulting from this environmental policy. A reduced economic scale would have a direct negative impact on trade and an indirect impact via its negative influence on FDI. However, this negative trade effect can not be identified when pollution control proves to be ineffective.

The findings concerning the impact of trade on emissions charges is mixed. If a higher income level means stricter environmental enforcement as identified in the wastewater pollution case, then trade could lead to a higher emissions charge through an income effect. Otherwise, this effect would be negative.

No direct impact of an emissions charge on reducing FDI has been confirmed in this analysis, suggesting that differences in environmental regulations would not adversely affect foreign firms to invest in China. This may also imply that provinces need not tend to compete with one another for FDI by lowering their environmental standards. However, an effective emissions charge may have an indirect impact on FDI since an effective charge would lead to reduced emissions and hence to lowered GDP levels.

China's pollution levy system is an effective approach for reducing wastewater control. Concerning air emissions control, however, the levy system seems to be less effective; the effectiveness is observed only in the $\mathrm{SO}_{2}$ emissions case. This finding is consistent with the particular efforts that China has made to control these two types of 
pollution. According to Dong and Holt (2001), between 1991 and 1995, China invested 16 billion $\mathrm{RMB}$ yuan on controlling $\mathrm{SO}_{2}$ emissions and 27 billion $\mathrm{RMB}$ yuan on industrial wastewater treatment. The former accounts for 43 percent of China's total investment in air pollution control and the latter for 69 percent of the total in water pollution control over the same period. It is also found that levy rates on wastewater discharge rise as income increases, while levy rates on waste gas emissions demonstrate a negative relation with income. This result suggests that local governments are not willing to enforce environmental regulations on air pollution control that can be considered as strictly as on water pollution control. An economic explanation is that water pollution is easy to monitor and that the damage caused is local. Since air pollution is transboundary and difficult to monitor, local governments might have the tendency to receive a "free ride".

The present findings also confirm the existence of an environmental Kuznets curve: an inverted-U relationship between the amount of industrial wastewater discharges and GDP levels. However, this relationship is not identified between air emissions and GDP levels. As suggested earlier, wastewater pollution is more effectively controlled in China than air pollution. This finding would imply that the total amount of pollution could be decreased as the scale of economic activities increases, but only when an effective environmental policy is in place. The finding could contribute to the existing environmental Kuznets literature in two aspects. First, it shows for the first time that an inverted-U relationship may also exist between pollution and economic scales, both measured in total quantities. Second, it explicitly associates the existence of an inverted$\mathrm{U}$ relationship with the effectiveness of environmental regulations. The latter is further 
supported by the results of the reduced sample estimation where data from the three municipalities were deleted. Once the coefficient estimates of levy rates on waste gas emissions become statistically significant, an inverted-U relationship between air emissions and GDP levels is also present in most air pollution cases. No adequate explanation exists as to why China's levy system seems to be effective as an air pollution control instrument when the three municipalities are excluded from the analysis.

State-owned enterprises are found to be less environmentally efficient. In all the examined cases, an increase in the output share of state-owned enterprises would positively increase the amount of pollution discharges, suggesting that those firms would indeed be more successful in neglecting environmental regulations.

Education levels of individuals appear to be an important factor in the successful enforcement of environmental regulations. A decrease in the illiteracy and semi-illiteracy rate would lead to a higher levy rate on both wastewater and waste gas discharges, and hence would reduce pollution.

\subsection{Policy Implications}

Trade may lead to increased pollution via expanded economic activity, but the negative environmental impact of trade can be minimized and even cancelled by supporting domestic environmentally-friendly industries that achieve comparative advantage in less polluting goods and by imposing stricter environmental regulations. This may require China to develop a series of industrial policies that are not only appropriate for a WTO member country but also would benefit environmentally supportive industries. These policies should not be a simple means of subsidy or 
protection that conflict with WTO principles. Instead, China should pursue competitive markets, develop a related management system, and provide assistance to environmentally friendly industries through appropriate means of financing, technological development, and distribution of R\&D results. At the same time, in order to mitigate the negative environmental impacts of trade, the production and export of highly pollution-intensive products must be strictly limited. Efforts could be aimed at upgrading technology and improving production efficiency so that the domestic environment does not suffer because of export growth. In addition, the import of advanced technology and environmentally compatible technology should be encouraged while imports that harm the environment or pertain to hazardous wastes should be discouraged and, if possible, banned.

China also needs to seize the green opportunities that result from its accession to the WTO to upgrade its own environmental standards, to strengthen environmental legislation, and to improve law enforcement. An improvement in environmental quality and a decrease in the volume of pollution discharges will be possible only when effective environmental regulations and strict low enforcement are in place. Hence, efforts could be made to fill important "responsibility vacuums" at provincial, national, and international levels. The infrastructure required to govern trade, investment, and finance should provide adequate coverage of environmental concerns. And the government's ability at national and provincial levels to practice environmental management should meet the challenges posed by an accelerated increase in trade and foreign direct investment inflows. 
Individuals as well as public interest groups in China should be influenced to be more aware of and more empowered to deal with international trade and environmental issues. The experience of developed countries shows that local communities can provide policy recommendations on sustainable development, can monitor environmental law enforcement, and can influence local and national governments and foreign countries to improve their behavior. In addition, the awareness of citizens and their successful involvement also depends on their educational attainment. Therefore, it is important for China to increase government expenditures on education, to make education affordable for the poor, and to reduce the nation's illiteracy and semi-illiteracy rates.

Though an environmental policy can have a negative effect on economic growth and hence on trade and FDI inflows, this is not always the case. The revisionist theory suggests that efficient environmental regulations may actually stimulate innovation, efficiency gains, economic growth and competitiveness. The government should thus compose environmental policies that deal with trade and environmental problem based on a more holistic approach. Policies should be made to provide incentives for firms to improve economic efficiency by innovation or adoption of the state-of-the-art technology. It has been suggested that state-owned enterprises are not only economically but also environmentally inefficient. While deepening the reform of SOEs, local and central governments should further promote the development of collective and private enterprises. The inner provinces in particular should create more favorable economic policies to boost non-state-owned enterprises.

China's accession to the WTO will undoubtedly lead to a remarkable increase in FDI inflows. It has also been suggested that a lower environmental standard and lenient 
law enforcement would offer no extra attraction to foreign investors. On the contrary, both local and the central governments should make substantial efforts to reduce the negative impact of FDI on the environment. Specifically, authorization should be given only to foreign firms that will adopt new technologies that minimize pollution. Production facilities that employ the latest in pollution reduction technology also benefit from higher capital productivity. In addition, incentives should be provided to those firms that minimize their pollution levels in order that their production technology could serve as learning for domestic firms in areas of environmental protection.

\subsection{Conclusions}

Interactions between trade and the environment have become an important theme in economic research, because of the pressure that the accelerated pace of globalization has placed on environment and trade. Not only is world trade increasing rapidly but also global industrialization related to trade has spawned severe environmental degradation; this is particularly true for developing countries. Attempts to analyze the linkages between these areas are many but have taken opposite positions, dominated either by examining the impact of environmental regulations on trade or by investigating the impact of trade on the environment. This study is an ambitious attempt to fill this literature gap by reviewing existing economic studies of the major environmental and trade issues and the methods necessary to analyze those issues first, and then by highlighting an expanded simultaneous trade and environment model of China. The present simultaneous trade and environment model extends beyond Dean's framework by incorporating an international trade and an FDI inflow equation. Hence, the present 
model enables one not only to investigate the impact of trade on environmental variables and vice versa, but also to divide those impacts into scale, composition, and technique effects. In addition, this model has also evaluated the existence of the environmental Kuznets curve.

The results of the study provide useful insights in understanding the interrelationships between trade and the environment in general and for China in particular. They also demonstrate the effectiveness of a simultaneous equations models for achieving these results. Concerning limitations of the study, the proposed simultaneous equations model is a highly stylized simplification of the Chinese provincial economy and has obvious imperfections. For example, the negative impact of pollution on economic activity is neglected. Similarly, the model fails to reflect possible positive impacts that environmental regulations may have on an economy. In addition, the environmental data used in the study have evident limitations. As already noted, pollution data are limited to industrial sources. Therefore, the implication of pollution generated from consumption and other sectors is totally neglected. Besides, the pollution levy rates computed in the study are not consistent in nature due to the changes in China's levy system adopted during the period 1987-95. And, these levy rates are a very rough proxy for emissions prices. Further more, the levy system is only one of China's many pollution prevention and control measures (Dong and Holt 2001). Exclusion of other measures in the model could possibly lead to results that are incomplete and possibly misleading. The results reported in this study are directional rather than precise.

The research implications of this study are as follows. First, there is a need for more case-specific empirical studies on trade and environmental issues. As already noted, 
interactions between trade and the environment can best be addressed on a case-by-case basis that allow little generalization. In order to generate meaningful policy implications and provide pertinent guidelines for policy makers to achieve coordinated development between the economy, trade and the environment, future research should be directed to more specific case studies. Second, both more theoretical and more empirical studies are required to investigate the impact of environmental degradation on trade and economic growth, i.e. sustainable development. There are many publications that explain how trade can affect the environment, and also many studies on how environmental policies would affect international trade. However, our knowledge of the trade and economic consequences of environmental degradation is still relatively limited. Third, greater efforts should be made to investigate trade and environment issues using disaggregate industrial-level data such as those employed in input-output models and CGE models. Since the environmental impact of production differs from industry to industry and environmental policies have different impacts on different industries, CGE models enable one to examine the trade and environment relationship at the industry level and hence to produce more detailed and more accurate analyses of this relationship. And lastly, more theoretical and empirical research is also needed to incorporate a spatial element into the investigation of trade and environment issues. These issues often include reference space or location. Yet, in most of the trade and environment literature, location is not part of the analysis, mostly because appropriate data do not exist. Inclusion of a spatial dimension would no doubt better our understanding of the nature of the problem. Further application of the present modeling approach in China as well as in other countries thus depends on the quality of data that would improve policy analysis and impact forecasts. 


\section{REFERENCES}

Abbott, P. C. and S. L. Haley (1988), "International Trade theory and Natural Resource Concepts", in Sutton, J. D. (eds.), Agricultural Trade and Natural Resources: Discovering the Critical Linkages, Lynne Rienner Publishers, Inc., Boulder \&London.

Abrego, L., C. Perroni, J. Whalley, and R. M. Wigle (1997), "Trade and Environment: Bargaining Outcomes from Linked Negotiations", NBER Working Paper No. W6216, October.

Adams, F. G. and J. R. Behrman (1976), Econometric Models of World Agricultural Commodity Markets: Cocoa, Coffee, Tea, Wool, Cotton, Sugar, Wheat, Rice. Cambridge, Mass: Balling publishing Co.

Alemdar, N. M. and S. Ozyildirim (1998), "A genetic game of trade, growth and externalities", Journal of Economic Dynamics and Control 22: 811-832.

Aliber, R. Z. (1970) "A theory of direct foreign investment", in Kindleberger, C. P. (ed.), The International Corporation, Cambridge: MIT Press, pp. 17-34.

Almon, C. and A. Ruiz-Moncago (1991), "Simulation of a Mexico-USA Free Trade Agreement", Economic Systems Research Vol. 3(1): 93-98.

Amemiya, T. (1977) "The maximum likelihood and the nonlinear three stage least squares estimator in the general nonlinear simultaneous equation model", Econometrics 45, 955-968.

Amemiya, T. (1985) Advanced Econometrics. Cambridge: Harvard University Press.

Anderson, J. E. (1979), “A Theoretical Foundation for the Gravity Equation", American Economic Review (March): 106-16.

Anderson, J. E. and J. P. Neary (1992a), "Trade reform under Quotas, partial rent Retention and tariffs," Economica 60(January): 57-76.

Anderson, J. E. and J. P. Neary (1992b), "A New Approach to Evaluating Trade Policy," Working Paper WPS 1022, International Economics Department, The World Bank, November.

Anderson, J.E. and B. Blackhurst (Eds.) (1992) The Greening of World Trade Issues, Harvester Wheatsheaf, Hertfordshire.

Anderson, K. (1992a) "The Standard Welfare Economics of Policies Affecting Trade and the Environment," in Anderson and Blackhusrt (eds.) op. Cit.

Anderson, K. (1992b), "Effects on the environmental and welfare of liberalizing world trade: the cases of coal and food", in Anderson, K. and R. Blackhurst (eds.) op. Cit.

Antweiler, W., B. R. Copeland, and M. S. Taylor (1998), "Is Free Trade Good for the Environment?" NBER Working Paper No. W6707, August.

Arden-Clarke, C. (1991) The General Agreement on Tariffs and Trade, Environmental protection and Sustainable Development, World Wildlife Fund for Nature, Gland, Switzerland.

Asafu-Adjaye, J. (1999), "The environment and development: theory and empirical evidence", International Journal of Development Planning Literature 14 (1): 117134.

Audley, J. J. (1997), Green Politics and Global Trade, Washington, D. C.: Georgetown University Press. 
Aukrust, O. (1970), "Prim I: a model of the price and income distribution mechanism of an open economy", The Review of Income and Wealth 16 No. 1: 51-78.

Ayres, R. U. and A. V. Kneese (1969), "Production, Consumption, and Externalities", American Economic Review 59(3): 282-297.

Azevedo, M. P. (1982), "Trade in Hazardous Substances: An Examination of US Regulation," in S. Rubin, ed., Environment and Trade. New Jersey: Allanheld, Osmun and Co.

Ballard, C. L. and S. G. Medema (1993), "The Marginal Efficiency Effects of Taxes and Subsidies in the Presence of Externalities: A Computable General Equilibrium Approach," Journal of Public Economics 52 (Sep.): 199-216.

Ballard, Charles L. and Inkvo Cheong (1997), "The Effects of Economic Integration in the Pacific Rim: A Computational General Equilibrium Analysis", Journal of Asian Economics 8(4).

Baltagi, B. H. (1981) "Simultaneous equations with error components", Journal of Econometrics, 17: 189-200.

Baltagi, B. H. (1984) "A Monte Carlo study for pooling time series of cross-section data in the simultaneous equations model", International Economic Review, 23: 603624.

Baltagi, B. H. (1995) Econometric Analysis of Panel Data, New York: John Wiley and Sons.

Barbier, E. B. and M. Rauscher (1994), "Trade, Tropical Reforestation and policy Interventions," Environmental and Resource Economics, 4 (Jan.): 75-90.

Barker, T. S. (1972), "Foreign trade in multisectoral models ", Brody, A. and A. P. Carter (eds.), Input-Output Techniques, Amsterdam: North-Holland Publishing Compang.

Barrett S. (1997), "The Strategy of Trade Sanctions in International Environmental Agreements," Resource and Energy Economics 19 (4): 345-361.

Barrett, S. (1990), "Macroeconomic Policy Reforms and Third World Soil Conservation," mimeo.

Barrett, S. (1994a), "Self-Enforcing International Environmental Agreements," Oxford Economic Paper 46, 878-894.

Barrett, S. (1994b) "Strategic Environmental Policy and International Trade", Journal of Public Economics, 54(3), 325-338.

Batey, P. W. J. (1985), "Input-Output Models for Regional Demographic-E conomic Analysis: Some Structural Comparisons", Environment and Planning A. Vol. 17: 73-99.

Batey, P. W. J. and M. J. Weeks (1989), "The Effects of Household Disaggregation in Extended Input-Output Models", Miller et al (eds), Frontiers of Input-Output Analysis, New York: Oxford University Press.

Baumol, W. J. (1971), "Environmental Protection, International Spillovers and Trade", Wicksell Lecture, Stockholm: Almquist and Wicksell.

Baumol, W. J. and D. F. Bradford (1972), "Detrimental Externalities and Non-convexity of the Production Set", Economoca 39: 160-76.

Baumol, W., and W.E. Oates (1975), The Theory of Environmental Policy, New Jersey: Prentice-Hall.

Baumol, W., and W.E. Oates (1988), The Theory of Environmental Policy, second edition, New York: Cambridge University Press. 
BEA (Bureau of Economic Analysis, 2000), Survey of Current Business, August, pp: 132.

Beghin J., S. Dessus, D. Roland-Holst, and D. van der Mensbrugghe (1996), "Prototype CGE Model for the Trade and the Environment Program. Technical Specification." OECD Development Centre Technical Papers No 116, Paris.

Beghin, J, S. Dessus, D. Roland-Holst, D. Van der Mesbrugge(1997a), "The Trade and Environment Nexus in Mexican Agriculture. A General Equilibrium Analysis," Agricultural Economics, Vol. 17, No. 2-3: 115-132.

Beghin, J., D. Roland-Holst, and D. van der Mensbrugghe (1994), "A Survey of the Trade and Environment Nexus: Global Dimensions" OECD Economic Studies 23 (winter 1994): 167-92.

Beghin, J., D. Roland-Holst, and D. van der Mensbrugghe (1995), "Trade Liberalization and the Environment in the Pacific Basin: Coordinated Approaches to Mexican Trade and Environment Policy", American Journal of Agricultural Economics 77 (1995): 778-785.

Beghin, J., D. Roland-Holst, and D. van der Mensbrugghe (1997b), "Trade and Pollution Linkages: Piecemeal Reform and Optimal Intervention", Canadian Journal of Economics, Vol. 30: 442-455.

Bergstrand, J. H. (1985), "The Gravity Equation in International Trade: Some Microeconomic Foundations and Empirical Evidence", Review of Economics and Statistics Vol. 67: 474-81.

Bhagwati, J. (1971), "The Generalized Theory of Distortions and Welfare", in Bhagwati, J. et al. Eds., Trade, Balance of Payments and Growth, Papers in International Economics in Honor of Charles P. Kindleberger, Amsterdam: North-Holland Publishing Compang, 69-90.

Bhagwati, J. (1993a), "The case for Free Trade", Scientific American 269: 42-49.

Bhagwati, J. (1993b), "Trade and the Environment: The False Conflict?" Zaelke, D. P. Orbuch and R. F. Housman (eds.), Trade and the Environment: Law, Economics, and Policy, Washingten, DC: Island Press.

Bhagwati, J. (1994) "Free Trade: Old and New Challenges", Economic Journal, 104, 231-246.

Bhagwati, J. and H. T. Oatrick (1990), Aggressive Unilateralism: America's 301 Trade Policy and the World Trading System, Ann Arbor: University of Michigan Press.

Bhagwati,J .(1971)"The Generalised Theory of Distortions and Welfare", in J. Bhagwati et al. (Eds.) Trade, Balance of Payments and Growth, North-Holland, Amsterdam.

Birdsall, N., and D. Wheeler. "Trade Policy and Industrial Pollution in Latin America" Where are the Pollution Havens?" in P. Low ed. (1992), op citum: 159-168.

Blackhurst, R. and A. Subramanian (1992), "Promoting multilateral cooperation on the environment", Anderson, K. and K. Blackhurst (eds.), The Greening of World Trade Issues, New York: Harvester Wheatsheaf.

Blackhurst,R.(1977), "International Trade and Domestic Environmental Policies in a Growing World Economy," in R. Blackhurst, et al., International Relations in a Changing World. Geneva: Sythoff-Leiden.

Blizer, C. R., R. S. Eckaus, S. Lahiri and A. Meeraus (1990), ‘ A general Equilibrium Analysis of Carbon Emission Reatrictions on Economic Growth in a Developing Country', paper presented at a Workshop on Economic/Energy/Environmental 
Mondeling for Climate Policy Analysis, the World Bank, Washington, D. C., October.

Bockstael, N. E. (1996), "Modeling Economics and Ecology: The Importance of a Spatial Perspective”, American Journal of Agricultural Economics 78: 1168-1180.

Boero, G, R. Clarke and A. Winters (1991) The Macroeconomic Consequences of Controlling Greenhouse Gases: A Survey, Department of Environment Environmental Economics Research Series, HNSO, London.

Bovenberg, A. L., and L. H. Goulder. " Optimal Environmental Taxation in the Presence of Other Taxes: General Equilibrium Analyses," American Economic Review 86 (1996): 985-1000.

Bowen, H. (1983), "Changes in the International Distribution of Resources and Their Impact on US Comparative Advantage," Review of Economics and Statistics Vol. 65:402-414.

Bowland, B. J. "Marginal Benefits of Trade and Environmental Policy: Valuing Air Pollution and Health in a Developing Country." Thesis. North Carolina State University, Raleigh, 1997.

Boyd, R. K. Krutilla and W. K. Viscusi (1995), "Energy Taxation as a Policy Instrument to Reduce CO2 Emissions: A Net Benefit Analysis," Journal of Environmental Economics and Mangaemnt, 29 (Jan.): 1-24.

Brander, J. and B. Spencer (1985) "Export Subsidies and International Market Share Rivalry", Journal of International Economics, 18,83-100.

Brander, J. and S. Taylor (1997), "International trade Between Consumer and Conservationist Countries," Resource and Energy Economics 19(4): 267-297.

Brecher, R. A. and E. E. Choudhri (1988), "The factor content of consumption in Canada and the United States: a two-country test of the Heckscher-Ohlin-Vanek model", Feenstra, R. C. (ed). Empirical Methods for International Trade, Cambridge: MIT Press.

Brody, A. and A. P. Carter (eds) (1972), Input-Output Techniques: Proceedings of the Fifth International Conference on Input-Output Techniques. Amsterdam: NorthHolland Publishing Company.

Brown, B. W. (1983) "The identification problem in systems nonlinear in the variables", Econometrica, Vol. 51 (1), pp. 175-196.

Bulmer-Thomas, V. (1982), Input-Output Analysis in Developing Countries, New York: John Wiley \&Sons LTD.

Burniaux, J. -M., J. P. Mantin, G. Nicoletti, and J. O. martins (1991a), " The Costs of Policies to Reduce Global Emissions of $\mathrm{CO}_{2}$ : "Initial Simulation Results with GREEN”, Working Paper No. 103, Economics and Statistics Department, OECD, Paris, June.

Burniaux, J. -M., J. P. Mantin, G. Nicoletti, and J. O. martins (1991b), “ GREEN-A Multi-Sector, Multi-region Dynamic General Equilibrium Madel for Qulti-region Dynamic General Equilibrium Madel for Quantifyinf the Costs of Curbing $\mathrm{CO}_{2}$ Emissions: A Technical Manual", Working Paper No. 104, Economics and Statistics Department, OECD, Paris, June.

Cambridge, Department of Applied Economics (1962), "A Computable Model Of Economic Growth:, A Programme for Growth Vol. 1, London: Chapman and Hall. 
Cambridge, Department of Applied Economics (1970), "Exploring 1972: with special reference to the balance of payments", A Programme for Growth Vol. 9, London: Chapman and Hall.

Carlstrom, Charles T., and Timothy S. Fuerst (1997), "Agency Costs, Net Worth, and Business Fluctuations: A Computable General Equilibrium Analysis," American Economic Review, Vol. 87, No. 5: 893-910.

Carraro, c. and D. Siniscalco (1992), "Environmental Innovation policy and International Competition", Environmental and Resource Economics 2(2): 183-200.

Carraro,C. And D. Siniscalco (1993) "Strategies for the International Protection of the Environment" Journal of Public Economics, Vol. 52: 309-328.

Carson, R. T., Y. Jeon and D. R. McCubbin (1997) "The relationship between air pollution emissions and income: US Data", Environment and Development Economics 2: 433-450.

Carter, T.R., J.H. Porter, and M.L. Parry (1991), "Climate Warming and Potential in Europe", Global Environmental Change, Sept.: 291-312.

Cesar, H. (1993) The Comedy and tragedy of the Commons, Ph.D. Thesis, EUI, Florence.

Chapman,D.(1991), "Environmental Standards and International Trade in Automobiles and Copper: the Case for a Social Tariff," Natural Resources Journal Vol. 31, No.3, 449-462.

Chen, C. (1997) "Foreign direct investment and trade: an empirical investigation of the evidence from China", Working Paper, Chinese Economies Research Centre, The University of Adelaide, Adelaide, Australia.

Chen, C. (1997), "Provincial characteristic and foreign direct investment location decision within China", Working Paper, Chinese Economies Research Centro, The University of Adelaide, Adelaide, Australia.

Chichilnisky, G. (1994), "North-South Trade and the Globe Environment," American Economic Review, 84. (Sep.): 851-875.

Chomitz, K. M., and D. A. Gray (1996), "Roads, Land Use, and Deforestation: A Spatial Model Applied to Belize", World Bank Economic Review, Vol. 10(3): 487-512.

Chomitz, K. M., C. Griffiths, and J. Puri (1999), "Fuel Prices, Woodlands and Woodfuel Markets in the Sahel," Fredriksson, P. G. (ed), Trade, Global Policy, and the Environment, World Bank Discussion Paper No. 402.

Clegg, J. (1992),"Explaining foreign direct investment flows", in Buckley, P. J., and Casson, m. (eds. ), Multinational Enterprises in the Would Economy: Essays in Honour of John Dunning, Aldershot: Edward Elgar, pp. 54-74.

Cohen, B.C., W.C. Labys, and P. Eliste (2001), "An Econometric Time-Series Analysis of Global $\mathrm{CO}_{2}$ Concentrations and Emissions," International Journal of Environment and Pollution, Vol. 15(4): 371-385.

Conrad, K. (1993a) "Taxes and Subsidies for Pollution-Intensive industries as Trade Policy", Journal of Environmental Economics and Management, 25, 121-135.

Conrad, K. (1993b) "Optimal Environmental Policy for Oligopolistic Industries in an Open Economy", Department of Economics Discussion Paper 476-93, University of Mannheim. 
Copeland, B. R. (1991), "International Trade in Waste products in the Presence of Illegal Disposal," Journal of Environmental Economics and Management, Vol. 20, No. 2, $143-62$.

Copeland, B. R. (1994) "International Trade and the Environment: Policy Reform in a Polluted Small Open Economy", Journal of Environmental Economics and Management, 26, 44-65.

Copeland, B. R. and M. S. Taylor (1994), "North-South trade and the Environment," Quarterly Journal of Economics, 109: 755-87.

Copeland, B. R. and M. S. Taylor (1995a), "Trade and the Environment: A Partial Synthesis", American Journal of Agricultural Economics 77(3): 765-771.

Copeland, B. R. and M. S. Taylor (1997a), "The Trade-Induced Degradation Hypothesis," Resource and Energy Economics 19 (4): 321-344.

Copeland, B. R. and M. Scott Taylor (1995b), "Trade and Transboundary Pollution," American Economic Review 85(4): 716-737.

Copeland, B. R. and M. Scott Taylor (1995c), "Trade, Nonconvexities and the Environment," Department of Economics, University of British Columbia, UBC discussion paper no. 95-19, July.

Copeland, B. R., and M. S. Taylor (1995d), "Trade, Spatial Separation, and the Environment”, NBER Working Paper No. W5242, August.

Copeland, B. R., and M. S. Taylor (1997b), "A Simple Model of Trade, Capital Mobility, and the Environment", NBER Working Paper No. W5898, January.

Copeland, B. R., and M. S. Taylor (1999), "Trade, Spatial Separation, and the Environment", Journal of International Economics 47: 137-168.

Crandall, R. W. (1981), "Pollution Controls and Productivity Growth in Basic Industries", Cowing, T. and R. Stevenson (eds.), Productivity Measurements in Regulated Industries, New York: Academic Press.

Cropper, M. and W. Oates (1992) "Environmental Economics: a Survey", Journal of Economic Literature, 30,675-740.

CSP (China Statistical Press, 1999), China Statistical Yearbook 1998, Beijing, China.

Culem, C. G. (1988) "The location determinants of direct investments among industrialized countries",

Cumberland, J. D. (1979), "Interreginal Pollution Spillovers and Consistency of Environmental Policy", in H. Siebert, ed., Reginal Environmental Policy: The Economic Issue. New York: University Press.

Cumberland, J. D. (1981). 'Efficiency and Equity in Interregional Environmental Management', Review of Reginal Studies 2,1-9

Cumberland, J. H. and B. N. Stram (1976), "Empirical Application of Input-Output models to Environmental Problems", Advances in Input-Output Analysis, ed. by Polenske, K. R. and J. V. Skolka, Ballinger Publishing Company, Cambridge, Mass.

D’Arge, R. (1971), "International Trade, Domestic Income, and Environmental Controls," in A. Kneese, ed., Managing the Environment. NY: Praeger.

Daly, H. E. (1993a), "The Perils of Free Trade", Scientific American 269: 50-57.

Daly, H. E. (1993b), "Problems with Free Trade: Neoclassical and Steady-State Perspectives", Zaelke, D. P. Orbuch and R. F. Housman (eds.), Trade and the Environment: Law, Economics, and Policy, Washingten, DC: Island Press. 
Darwin, R., M. Tsigas, J. Lewandrowski, and A. Raneses (1995), World Agriculture and Climate Change: Economic Adaptation, United States Department of Agriculture: An Economic Research Service Report.

Dasgupta, P., R. Eastwood, and G. Heal (1978), "Resource Management in a Trading Economy", Quarterly Journal of Economics 92: 297-306.

Dasgupta, S., H. Wang and D. Wheeler (1997), "Surviving success: Policy reform and the future of industrial pollution in China", Working Paper, the World Bank, Washington, D.C.

Davar, E. (1994), The Renewal of Classical General Equilibrium Theory and Complete Input-Output System Models, Vermont: Ashgate Publishing Company.

Davies, Rob, Jørn Rattsø, and Ragnar Torvik (1998), "Short-Run Consequences of Trade liberalization: A Computable General Equilibrium Model of Zimbabwe," Journal of Policy Modeling, Vol. 20, No. 3: 305-333.

De Boer, I. (1994), 'Trade and the environment: a brief survey of current theoretical issues', Ch. 7 in E. C. van Ierland (Ed.) International Environmental Economics: Theories, Methods and Applications the Climate Change, International Trade and Acidification, Elsevier, Amsterdam.

Dean, J. (1992)'Trade and Environment: A Survey of the Literature", Ch. 2 in Low (ed.), International Trade and the Environment, World Bank Discussion Paper No. 159, Washington, D.C.

Dean, J. M. (1999) "testing the impact of trade liberalization on the environment: theory and evidence", in Fredriksson, P.G. (ed.), Trade, Globe Policy, and the Environment, World Bank Discussion Paper No. 402, Washington, DC: World Bank.

Deardorff, A. V. (1998), "Determinants of Bilateral Trade: Does Gravity Work in a Neoclassical World?" Frankel, J. A. (ed.), The Regionalization of the World Economy, Chicago: University of Chicago Press.

Denison, E. (1979), Accounting for Slower Economic Growth, Washington, DC: the Brookings Institution.

Dervis, K., J. de Melo, and S. Robinson (1982), "General Equilibrium Models for Development policy", A World Bank Research Publication. Washington, DC: The World Bank.

Despotakis, V. K. (1991), Sustainble development planning using geographic information systems, Unpublished Ph. D. Thesis, Department of Economics and Econometrics, Amsterdam: Free University.

Despotakis, V. K., M. Giaoutzi and P. Nijkamp (1993), "Dynamic GIS Models for Regional Sustainable Development", Fischer, M. M. and P. Nijkamp (eds), Geographic Information Systems, Spatial Modelling, and Policy Evaluation, pp. 235-61, Berlin: Springer-Verlag.

Dessus, S., and M. Bussolo(1998), "Is There a Trade-off between Trade Liberalization and Pollution Abatement? A Computable General Equilibrium Assessment Applied to Costa Rica," Journal of Policy Modeling 20: 11-31.

Diao, X. and T. L. Roe (1997), "Enbodied Pollution and Trade: A Two-Country General Equilibrium Model"' Journal of Economic Development Vol. 22(1): 57-77.

Dixit, A. and V. Norman (1980), Theory of International Trade, Cambridge: Cambridge University Press. 
Dockner, E. J. and N. V. Long (1993), "International pollution control: cooperative versus noncooperative strategies", Journal of Environmental Economics and Management 25: 13-29.

Dragun, A.K. and C. Tisdell (1999), Sustainable Agriculture and Environment: Globalization and the Impact of Trade Liberalization, Northampton, MA: Edward Elgar Publishing.

Duchin, F. (1989), "An Input-Output Approach to Analyzing the Future Economic Implications of Technological Change", Miller et al (eds), Frontiers of Input-Output Analysis, New York: Oxford University Press.

Duerksen, C. and H. J. Leonard (1980), "Environmental Regulations and the Location of Industries: an International Perspective," Columbia Journal of World Business, Summer, Vol. 15(2): 52-68.

Dunmore, J. and J. Langley (1988), "Discussion: Conceptual and Empirical Needs for Integrating Resources and Trade Analysis," in J.Sutton, ed., Agricultural Trade and Natural Resources: Discovering the Critical Linkages. Boulder, CO: Lynne Rienner.

Durbin, A. (1995), “ Trade and the Environment: The North-South Divide”, Environment 37(7): 16-24.

Earson, C. (1976), Implications for the Trade and investment of Developing Countries of US Environmental Controls. NY: UNCTAD.

Ecchia, G. and M. Mariotti (1994) "A Survey on Environmental Policy: Technological Innovation and Strategic Issues" Nota di Lavoro 44.94, FEEM, Milan.

Edmonds, et al. (1997), "Return to the 1990s: The Cost of Mitigating United States Carbon Emissions in the Post-2000 Period", Draft Manuscript, Washington, DC: Pacific Northwest Laboratory.

Eldor, R. and D. Levin (1990), "Trade Liberalization and Domestic Monopoly: A Welfare Analysis", International Economic Review Vol. 30, No. 4.

Emerson, M. J. (1976), "Interregional Trade Effects in Static Dynamic Input-Output Models," Advances in Input-Output Analysis, ed. by Polenske, K. R. and J. V. Skolka, Ballinger Publishing Company, Cambridge, Mass.

Enke, S. (1951), “Equilibrium among Spatially Separated Markets Solution by Electric Analogue", Econometrica 19: 40-48.

EPA Trade and Environment Committee (1991), Minutes of Aug. 5, 1991 Meeting, Aug. 6, 1991.

Erickson, C. and S. Karuvilla (1994), "Labor costs and the social dumping debate in the European Union", Industrial and Labor Relations Review, 48, pp: 28-47.

Eskeland, G. S., and A. E. Harrison. " Moving to Greener Pastures? Multinationals and the Pollution-Haven Hypothesis." Policy Research Working Paper No 1744, The World Bank, Washington D. C., 1997.

Espinosa, J. A. and V. K. Smith (1995), "Measuring the Environmental Consequences of Trade Policy: A Non-Market CGE Analysis," American Journal of Agricultural Economics 77 (Aug.): 772-777.

Eswaran, H. and E. Van den Berg (1992), "Impact of Doubling of Atmospheric $\mathrm{CO}_{2}$ on Length of Growing Season in the Indian Subcontinent", Pedologie, 43(3): 289-96. 
Evans, M. K. andL. R. Klein (1969), "Short and long term simulations with the Wharton model," Conference on Econometric Models of Cyclical Behavior, Harvard University, November 14-15.

Eviews 4.0 User's Guide 1994-2000, Irvine, CA: Quantitative Micro Software, LLC.

Feichtinger, G. (ed.) (1982), Optimal Control Theory and Economic Analysis, Amsterdam: North-Holland Publishing Company.

Felder, S. and T. F. Rutherford(1993), "Unilateral $\mathrm{CO}_{2}$ Reductions and Carbon Leakage: The Consequences of International Trade in Oil and Basic Materials", Journal of Environmental Economics and Management, Vol. 25, No. 2, 162-76.

Field, B. C. (1994), Environmental Economics: An Introduction, New York: McGrawHill, Inc.

Fischer, M., H. J. Scholten, and D. Unwin (eds.), (1996), Spatial Analytical Perspectives on GIS, Bristol: Taylor \& Francis Inc.

Fisher, F. M. (1976), The identification problem in econometrics, New York: Krieger.

Folmer, H P. V. Mouche, and S. Ragland (1993) "Interconnected Games and International Environmental Problems", Environmental and Resource Economocs,3,313-336.

Forssell, O. and K.R. Polenske (1998), "Introduction: Input-Output and Environment", Economic Systems Research, Vol. 10 (2): 91-97.

Forsund, F. R. (1985), "Input-Output models, national economic models, and the environment", Kneese, A. V. and J. L. Sweeney (eds.), Handbook of Natural Resource and Energy Economics Vol. 1, Amsterdam: Elsevier.

Fox, Maggie (1999) "Chinese cities' bad air imperils children—study", Reuters new release, January 2, 1999.

Frankel, J. A. and D. Romer (1999) "Does trade cause growth?" The American Economic Review Vol. 89 No. 3: 379-399.

Frechtling, D. C. and E. Horvath (1999), "Estimating the Multiplier Effects of Tourism Expenditures on a Local Economy through a Regional Input-Output Model", Journal of Travel Research Vol. 37 (4): 324-333.

Fredriksson, P. G. ed, Trade, Global Policy, and the Environment, World Bank Discussion Paper No. 402, The World bank, Washington, D. C.

Freeman, A. M. III (1993), The Measurement of Environmental and Resource Values: Theory and Methods, Washington, D. C. : Resource for the Future.

French, H. F. (1993), "Reconciling Trade and the Environment", in L. R. Brown et al, editors, State of the world-1993, W. W. Norton \& compang, New York.

Friedman, J. W. (1986), Game Theory with Applications to Economics, New York: Oxford University Press.

Frysinger, S. P., D. A. Copperman, and J. P. Levantino (1996), "Environmental Decision Support System (EDSS): An Open Architecture Integrating Modeling and GIS", Goodchild, M. F. et al eds, GIS and Environmental Modeling: Progress and Research Issues, Fort Collins: GIS World, Inc.

Gale, I. V. and R. Lewis (1995), "Trade Liberalization and Pollution: An Input-Output Study of Carbon Dioxide Emissions in Mexico", Economic Systems Research Vol. 7: 309-321.

GATT (1971), Industrial Pollution Control and International Trade, GATT Studies in International Trade No.1. 
Ginsburgh, Victor and Michiel Keyzer (1997), "The Structure of Applied General Equilibrium Models, Cambridge," Mass: MIT Press.

Glomsrod, S., H. Vennemo, and T. Johnson (1992), " Stablization of Emissions of $\mathrm{CO}_{2}$ :

A Computable General Equilibrium Assessment", Scandinavian Journal of Economics 94 (1): 53-69

Goldfeld, S. M. and R.E. Quandt (1972), Nonlinear Methods in Econometrics, Amsterdam: North-Holland

Goodchild, M. F., B. O. Parks, and L. T. Steyaert (eds.), (1993), Environmental Modeling with GIS, New York: Oxford University Press.

Goodchild, M. F., L. T. Steyaert, B. O. Parks, C. Johnston, D. Maidment, M. Crane, and S. Glendinning, eds, (1996), GIS and Environmental Modeling: Progress and Research Issues, Fort Collins: GIS World, Inc.

Granger, C. W. J. and T. Terasvirta (1994), Modeling Nonlinear Relationships, Oxford: Oxford University Press.

Greene, W. H. (1997), Econometric Analysis, Third Edition, Upper Saddle River, New Jersey: Pretice-hall.

Grossman, G. M. and A. B. Krueger (1993), "Environmental Impacts of a North American Free Trade Agreement," in P. Garber, editor The Mexico-US Free trade Agreement, (Cambridge, Ma.: MIT Press).

Grossman, G. M., and A. B. Krueger. "Environmental Impact of a North American Free Trade Agreement," CEPR Discussion Paper 644 (1992), London.

Grubel, H. G. (1976), "Some Effects of Environmental Controls on International Trade: The Heckscher-Ohlin Model", Walter, I. (eds.), Studies in International Environmental Economics, New York: John Wiley \& Sons.

Haley, S. L. and P. M. Dixit (1988), Economic Welfare Analysis: An Application to the SWOPSIM Modeling Framework, Agriculture and Trade Analysis Division, Economic Research Service, U. S. Department of Agriculture, Staff Report No. AGES871215.

Hallam, C. A., J. M. Salinsbury, K. J. Lanfear, and W. A. Battaglin (eds.), (1996), Proceedings of the AWRA Annual Symposium, GIS and Water Resources, American Water Resources Association, Herndon, Virginia, TPS-96-3, 482pp.

Hamitton, C. and L. A. Winters (1992), "Opening up International Trade with Eastern Europe", Economic Policy 14: 77-116.

Harrison, G. W., T. F. Rutherford, and J. Wooton (1989), "The Economic Impact of the European Community," American Economic Review Papers and Proceedings 79(May): 288-94.

Harrison, G. W., T. F. Rutherford, and J. Wooton (1991), "An Empirical Database for a General Equilibrium Model of the European Community," Empirical Economics 16(Jan.): 95-120.

Hartman, R., M Hug and D. Wheeler (1996) "Why paper mills clean up: survey evidence from four Asian countries", World Bank, Policy Research Working Paper.

Hartog, H. den and A. Houweling (1976), "Pollution, Pollution Abatement, and the Economic Structure of the Netherlands," Advances in Input-Output Analysis, ed. by Polenske, K. R. and J. V. Skolka, Ballinger Publishing Company, Cambridge, Mass.

Harvey, A. C. (1994), Time Series Models, Cambridge: The MIT Press. 
Hauptmann, H. (1982), "Stackelberg Strategies and an Embargo Game”, Feichtinger, G. (ed.), Optimal Control Theory and Economic Analysis, Amsterdam: North-Holland Publishing Company.

Hazilla, M. and R. J. Kopp (1990), "Social Cost of Environmental Quality Regulations: A general Equilibrium Analysis," Journal of Political Economy 98 (Aug.):853-73.

Head, K. and J. Ries (1996) "Inter-city competition for foreign investment: static and dynamic effects of China's incentive areas, " Journal of Urban Economics 40 (1): 38-60.

Heckscher, E. F. and B. Ohlin (1991) Heckscher-Ohlin Trade Theory, Cambridge, MA: The MIT Press.

Helpman ,E. And P. Krugman (1989) Trade Policy and Market Structure, MIT Press, Cambridge, Ma.

Helpman, E. and P. Krugman (1985), Market Structure and Foreign Trade, Cambridge, Ma: MIT Press.

Hennipman, P. (1995), Welfare Economics and the Theory of Economic Policy, Vermont: Edward Elgar.

Hettige, H., P. Martin, M. Singh and D. Wheeler. “ IPPS: The Industrial Pollution Projection Project," Policy Research Working Paper 1431, The World Bank, Washington D. C., 1995.

Hettige, H., R. E. B. Lucas, and David Wheeler. "The Toxic Intensity of Industrial Production: Global Patterm, Trends and Trade Policy," American Economic Review Papers and Proceedings 82 (1992): 478-481.

Hirsch, S. (1976) "An international trade and investment theory of the firm", Oxford Economic Papers 28, pp, 258-270.

Hirschfield, A. F. G., P. J. B. Brown, and J. Marsden (1993), Information System for Policy Evaluation: A Prototype GIS for Urban Programme Impact Appraisal in St. Helens, North-West England.

Hirschman, A. U. (1958), The Strategy of Economic Development, New Haven: Yale University Press.

Hoel, M. (1991), "The effect of unilateral actions taken by one country", Journal of Environmental Economics and Management 20 (1): 55-70.

Hoel, M. (1994) " Environmental Policy as a Game Between Governments When Plant Locations Are Endogenous" paper presented to 21 st Annula EARIE Conference, Crete, September 4-6 1994.

Hoeller, P. A. Dean, and J. Nicolaisen (1991) " Macroeconomic Implications of Reducing Greenhouse Gas Emissions: a Survey of Empirical Studies" OECD Economic Studies, 16,45-78.

Hopkins, T. D. (1992),"Regulation and jobs-Sorting Out the Consequences", Prepared for the American Petroleum Institute, Washington, DC, Oct.

Housman, R. and D. Zaelke (1992), "Trade, Environment, and Sustainable Development: A Primer", Hastings International and Comparative Law Review, 15 (4): 535-612.

Howrey, E. P. and H. H. Kelejian (1971), "Simulation Versus Analytical Solutions: The Case of Econometric Models", Naylor, T. H., Computer Simulation Experiments with Models of Economic Systems, New York: John Wiley \& Sons, INC.

Hsiao, C. (1986) Analysis of Panel Data, New Your: Cambridge University Press. 
Hudson, S. (1993) 'Trade, Environment and the Pursuit of Sustainable Development", McAlpine, J. C. and P. LeDonne eds, The Greening of World Trade, A Report to EPA from EPA Trade and Environment Committee, Printed by the US Government Printing Office.

Jackson, J. H. (1992), "World Trade Rules and Environmental Policies: Congruence or Conflict?", Washington and Lee Law Review, 49 (4): 1227-78.

Jaffe, A. B., S. R. Peterson, P. R. Portney, and P. N. Stavins (1995), "Environmental regulation and the Competitiveness of US Manufacturing: What Does the Evidence tell Us?" Journal of Economic Literature 33, 132-163.

Jha, V., A. Markandya, and R. Vossenaar (1999), Reconciling Trade and the Environment, Northampton, MA: Edward Elgar Publishing.

Jian, T., J.D. Sachs, and A. Warner (1996) "Trends in regional income inequality in China", Chinese Economic Review.

Jones, R. W. (1956), "Factor Proportions and the Heckscher-Ohlin Theorem", Review of Economis Studies 24: 1-10.

Jorgenson, D. W> and P. J. Wilcoxen (1990), "Intertemporal General Equilibrium Modeling of U. S. Environmental Regulation", Journal of Policy Modeling 12 No. 4: 715-744.

Jorgenson, D. W> and P. J. Wilcoxen (1993), "Energy, The Environment, And Economic Growth", Kneese, A. V. and J. L. Sweeney (eds.), Handbook of Natural Resource and Energy Economics Vol. III, Amsterdam: Elsevier.

Josling, T. (1993), "Of Models and Measures: Some Thougths on the Use and Abuse of Policy Indicators," in Shane, M. D. and H. von Witzke, editors, Public Goods, the Environment, and International Trade, USDA, Staff Report No. AGES9314.

Just, R. E. and G. C. Rausser (1992), "Environmental and Agricultural Policy Linkages and Reforms in the United States Under the GATT", American Journal of Agricultural Economics Vol. 766-74.

Kaderjak, P. and J. Powell (eds). Economics for Environment Policy in Transition Economies. Edward Elgar Publishing, Cheltenham, 1997.

Kaempfer, William H., Martin T. Ross, and Thomas F. Rutherford(1997)., "Tariffication of a Distorted Economy: A CGE Analysis", Review of Development Economics, Vol. 1 Issue 2

Kalt, J. P. (1989), "Exhaustible Resource price Policy, International Trade, and Intertemporal Welfare", Journal of Environmental Economics and Management, Vol. 17, No. 2, 109-26.

Keeler, E., M. Spence, and R. Zeckhauser (1971), "The Optimal Control of Pollution,” Journal of Economic Theory 4, 19-34.

Kelejian, H. H. (1971), "Two-Stage least squares and econometric systems linear in parameters but nonlinear in the endogenous variables", Journal of the American Statistical Association, Vol. 66 (334): 373-374.

Keller, C. P. and J. D. Strapp (1996), "Multicriteria Decision Support for Land Reform Using GIS and API", Goodchild, M. F. et al eds, GIS and Environmental Modeling: Progress and Research Issues, Fort Collins: GIS World, Inc.

Kennedy, P. (1992) A Gude to Econometrics, $3^{\text {rd }}$ edition, Cambridge: The MIT Press.

Kennedy, P.W. (1994) "Equilibrium Pollution Taxes in Open Economics with Imperfect Competition", Journal of Environmental Economics and Management, 27, 49-63. 
Kinal, T. and K. Lahiri (1990) "A computational algorithm for multiple equation models with panel data", Economics Letters, 34: 143-146.

Kinal, T. and K. Lahiri (1993) "On the estimation of simultaneous-equations errorcomponents models with an application to a model of developing country foreign trade", Journal of Applied Econometrics Vol. 8: 81-92.

Kinsey, J. D. and J. P. Houck (1993), "The Growing Demand for Food Quality: Implications for International Trade," in Shane, M. D. and H. von Witzke, editors, Public Goods, the Environment, and International Trade, USDA, Staff Report No. AGES9314.

Klein, L. R. and M. K. Evans (1969), Econometric Gaming, London: The Macmillan Co.

Klein, L. R. and R. M. Young (1980), An Introdustion to Econometric Forecasting and Forecasting Models, Lexington: D.C. Heath and Company.

Knodgen, G. (1979), "Environment and Industrial Siting: Results of an Empirical Survey of Investment by West German Industry in Developing Countries," Zeitschrift fur Umweltpolitik 2.

Kohn, R. (1991), "Global Pollution: A Hecksher-Ohlin-Samuelson Model of Pigouvan Taxation", Eastern Economic Journal X V II (3): 337-343.

Kohon, H. (1996), "Public Investment Criteria for a Comprehensive Transport System Using an Interregional Input-Output Programming Model", van den Bergh et al (eds), Recent Advances in Spatial Equilibrium Modeling: Methodology and Applications, Berlin: Springer-Verlag.

Kojima, K. (1976) Direct Foreign Investment: a Japanese Model of Multinational Business Operations, London: Groom Helm.

Kravis, I. B. and R. E. Lipsey (1882) "The location of overseas production and production for export by U.S. Multinational firms", Journal of International Economics 12, pp. 201-223.

Kreps, D. M. (1990), Game Theory and Economic Modelling, Oxford: Oxford University Press.

Krugman, P. (1991), Geography and Trade, Cambridge, Ma: MIT Press.

Krugman, P. R. and M. Obstfeld (1997), International Economics: Theory and Policy, New York: Addison-Wesley.

Krutilla, K. (1991), "Environmental Regulation in an Open Economy", Journal of Environmental Economics and Management, Vol. 20, No. 2, 127-42.

Labys, W. C. (1973), Dynamic Commodity Models: Specification, Estimation, and Simulation, Lexington: D.C Heath and Company.

Labys, W. C. (ed.) (1975), Quantitative models of Commodity Markets, Cambridge: Ballinger Publishing Company.

Labys, W. C. (1999), Modeling Mineral and Energy Markets, Boston: Kluwer Academic Publishers.

Labys, W. C. (2000) "Can World market volatility upset the U.S. economy?" Economic Directions, Latrobe, PA: Saint Vincent College's Alex G. McKenna economic education series, vol. 10 (2), April, 2000.

Labys, W. C.and P. K. Pollack (1984), Commodity Models for Forecasting and Policy Analysis, New York : Nichols Pub. Co. 
Labys, W. C., T. Takayama, and N, D. Uri, eds, (1989), Quantitative Methods for Market-Oriented Economic Analysis over Space and Time, Aldershot: Gower Publishing Compang Limited.

Labys, W. C. and C. W. Yang (1991), "Advances in Spatial Equilibrium Modeling of Mineral and Energy”, International Regional Science Review 14: 61-94.

Lakahmanan, T. R. and R. Bolton (1986), "Regional energy and environmental analysis", Nijkamp, P. (ed), Handbook of Regional and Urban Economics, vol. 1: Regional Economics, pp. 581-628, Amsterdam: North-Holland.

Lardy, N. R. (1992) Foreign trade and economic reform in China 1978-1990, Cambridge: Cambridge University Press.

Lardy, N. R. (1995) "The role of foreign trade and investment in China's economic transformation", The China Quarterly 144:1074-75.

Leamer, E. E. (1980), “The Leontief Paradox Reconsidered”, Journal of Political Economy 88: 495-503.

Leamer, E. E. (1984), Sources of International Comparative Advantage: Theory and Evidence. Cambridge: MIT Press.

Leamer, E. E. and J. Levinsohn (1995), "International Trade Theory: The Evidence", Grossman, G. M. and K. Rogoff (eds.), Handbook of International Economics Vol. III, Amsterdam: Elsevier.

Leamer, E. E. and R. M. Stern (1970) Quantitative International Economics, Boson, MA: Allyn and Bacon, Inc.

Lee, H. and D. Roland-Holst (1994), "International Trade and the Transfer of Environment Cost and Benefits", Francois, J. and K. Reinert, eds, Applied Trade Policy Modeling, Cambridge: Cambridge University Press.

Lee, H. and D. Roland-Holst (1997), " The Environment and Walfare Implication of Trade and Tax Policy," Journal of Development Economics 52 (1): 65-82.

Lee, T. J. and R. A. Pielke (1996), "GIS and Atmospheric Modeling: A Case Study", Goodchild, M. F. et al. eds, GIS and Environmental Modeling: Progress and Research Issues, Fort Collins: GIS World, Inc.

Leemans, R. , and A.M. Solomon (1993), "Modeling the Potential Change in Yield and Distribution of the Earth's Crops Under a Warmed Climate", Climate Research, 3: 79-96.

Leonard, H. J. (1988), Pollution and the Struggle for the World Product. NY: Cambridge.

Leontief, W. W., A. P. Carter and P. A. Petri (1977), The Future of the World Economy, Oxford: Oxford University Press.

Leontief, W.W. (1951), The Structure of American Economy: 1919-1939, New York: Oxford University Press.

Leontief, W.W. (1973), "National income, economic structure, and environmental externalities", in M. Moss (ed.) The Measurement of Economic and Social Performance, Studies in Income and Wealth, Vol. 38, New York: National Bureau of Economic Research.

Leontief, W.W. (1986), Input-Output Economics, New York: Oxford University Press.

Leontief, W.W. and D. Ford (1972), "Air pollution and the economic structure: empirical results of input-output computations", in A. Brody and A.P. Carter (eds.), InputOutput Techniques, Amsterdam: North-Holland.

Leontief, W.W.(1966), Input-Output Economics, New York: Oxford University Press. 
Leontief, W.W.(1970), "Environmental repercussions and the economic structure: an input-output approach", The Review of Economics and Statistics 52: 262-271.

Levin, J. (1998), "Structural Adjustment and Poverty: The Case of Kenya," (Thesis), Göteborgs University, Sweden.

Li, F. and J. Li (1999) Foreign Investment in China, London: MacMillan Press Ltd.

Lluch, C. and A. A. Powell (1975), "International Comparisons of Expenditure Patters," European Economic Review 15(4): 786-797.

Long, N. V., and H. Siebert (1991) " Institutional competition Versus Ex-ante Harmonization- the Case of Environmental Policy", Journal of Institutional and Theoretical Economics, 147, 296-312.

Lopez, R. and M. Nikletschek (1991), "Dual Economic Growth in Poor Tropical Areas," Journal of Development Economics 36: 189-211.

Lopez, Ramon (1994), "The Environment as a Factor of Production: The Effects of Economic Growth and Trade Liberalization", Journal of Environmental Economics and Management, Vol. 27, No. 2, 163-84.

Low, P. (Ed.) (1992) International Trade and the Environment, World Bank Discussion Paper No. 159, Washington, D.C.

Low, P. and A. Yeats (1992) "Do Dirty Industries Migrate?" in P. Low ed., Op Citum, 89-104.

Lucas, R. E. B., D. Wheeler, and H. Hettige. "Economic Development. Environment Regulation and the International migration of Toxic Industrial Pollution: 19601988," in Low, P. ed. International trade and the Environment. World Bank Discussion Papers 159, Washington D. C., 1992, 67-86.

Luptacik, M. and U. Schubert (1982), “ Optimal Investment Policy in Productive Capacity and Pollution Abatement Processes in a Growing Economy", Feichtinger, G. (ed.), Optimal Control Theory and Economic Analysis, Amsterdam: NorthHolland Publishing Compang.

Maddala, G. S. (1987), "Recent developments in the econometrics of panel data analysis", Transportation Research-A, 21: 303-326.

Maestad, O. (1998), " On the efficiency of green trade policy", Environmental and Resource Economics 11(1): 1-18.

Magee, S., and W.F. Ford (1972), "Environmental Pollution, the Terms of Trade, and the Balance of Payments of the United States," Kyklos 25, 101-18.

Magnus, J. R. (1982), "Multivariate error components analysis of linear and nonlinear regression models by maximum likelihood," Journal of Econometrics, 19: 239-285.

Maguire, D. J., M. F. Goodchild, D. W. Rhind (eds.), (1991), Geographical Information Systems: Principles and Applications (2 volumes), London: Longman, and New York Wiley.

Maidment, D. R. (1996), “Environmental Modeling within GIS”, Goodchild, M. F. et al eds, GIS and Environmental Modeling: Progress and Research Issues, Fort Collins: GIS World, Inc.

Mailath, G. J. (1998), "Do People Play Nash Equilibrium? Lessons From Evolutionary Game Theory", Journal of Economic Literature Vol. XxxVI, pp. 1347-1374.

Manne, A. S. (1992), "Global 2100: Alternative Scenarios for Reducing Carbon Emissions", Working Papers No. 111, Department of Economics and Statistics, OECD, Paris. 
Manne, A. S. and R. G. Richels (1991a), "Global CO2 Emission Reductions - the Impacts of Rising Energy Costs”, The Energy Journal 12 (1): 87-107.

Manne, A. S. and R. G. Richels (1991b), "International Trade in Carbon Emission Rights: A Decomposition Procedure”, American Economic Review 81 (2): 135139.

Manne, A. S. and R. G. Richels (1992), Buying Greenhouse Insurance: The Economic Costs of $\mathrm{CO}_{2}$ Emission Limits, Cambridge, MA: The MIT Press.

Manne, A.S. and R. Richels (1996), "The Berlin Mandate: The Cost of Meeting Post2000 Targets and Timetables", Energy Policy 24(3), 205-210.

Mariano, R., T. Schuermann and M.J. Weeks (2000), Simulation-based Inference in Econometrics: Methods and Applications, Cambridge: Cambridge University Press.

Marimon, R. and A. Scott (2001), Computatational Methods for the Study of Dynamic Economics, New York: Oxford University Press.

Markandya, A. and J. Richardson (1990), “The Debt Crisis, Structural Adjustment, and the Environment," London Environmental Economics Centre, mimeo.

Markusen, J., E. Morey and N. Olewiler (1993), "Environmental Policy When Market Structure and Plant Location Are Endogenous", Journal of Environmental Economics and Management, 24, 69-86.

Markusen, J. (1975a) “ Cooperative Control of International Pollution and Common Property Resources", Quarterly Journal of Economics, 89, 618-632.

Markusen, J. (1975b), "International Externalities and Optimal Tax Structures", Jounal of International Economics, 5, 15-29.

Markusen, J. (1997), "Costly Pollution Abatement, Competitiveness, and Plant Location Decisions," Resource and Energy Economics 19, 299-320.

Markusen, J. R. (1975), “International Externalities and Optimal Tax Structures”, Journal of International Economics Vol. 5, 15-29.

Markusen, J. R., J. R. Melvin, W. H. Kaempfer, and K. E. Maskus (1995), International Trade: Theory and Evidence, New York: McGraw-Hill, Inc., p7.

Markusen, J., E. Morey and N. Olewiler (1992) "Non-cooprative Equilibria in Regional Environmental Policies When Plant Locations Are Endogenous”, NBER Working Paper 4051.

Martin, W. E., R. H. Patrick, and B. Tolwinski (1993), "A Dynamic Game of a Transboundary Pollutant with Asymmetric Players", Journal of Environmental Economics and Management 25 (1): 1-12.

Maskus, Keith E. and Denise Eby Konan (1997), "Trade Liberalization in Egypt," Review of Development Economics, Vol. 1 Issue 3.

McAlpine, J. and P. Le Donne (1993), The Greening of World Trade, Library of Congress, Document no. 93-83602, Washington, D. C.: U. S. Government Printing Office.

McCounell, K. E. and T.T. Phipps (1987), "Identification of preference parameters in hedonic models: Consumer demands with non linear budgets," Journal of Urban Economics 22, 35-52.

McGuire, M. (1982), "Regulation, Factor Rewards, and International Trade," Journal of Public Economics 17: 335-354. 
Meadows, D., D. Meadows, J. Randers and W. W. Behrens III (1972), Limits to Growth, New York: Universe Books.

Melvin, J. R. (1968), "Production and Trade with Two Factor and Three Goods", American Economic Review 63: 1249-1268.

Merrifield, J. (1988), “The Impact of Selected Abatement Strategies on Transnational Pollution, the Terms of Trade, and Factor Rewards: a General Equilibrium Approach," Journal of Environmental Economics and Management, 15, 259-284.

Miller, R. E. , K. R. Polenske, and A. Z. Rose (eds) (1989), Frontiers of Input-Output Analysis, New York: Oxford University Press.

Mills, G. (1984), Optimization in Economic Analysis, London: George Allen \& Unwin.

Mills, T. C. (1990), Time series techniques for economists, Cambridge; Cambridge University Press.

Minford, Patrick, Jonathan Riley and Eric Nowell (1997), "Trade, Technology and Labour Markets in the World Economy, 1970-90: A Computable General Equilibrium Analysis," The Journal of Development Studies, Vol. 34, No. 2.

Motta, M. and J-F Thisse (1993a) "Does Environmental Dumping Lead to Relocation ?" Nota di Lavoro 77.93 FEEM, Milan.

Motta, M. and J-F Thisse (1993b) "Minimum Quality Standard as an Environmental Policy: Domestic and International Effects", Nota di Lavora 20.93, FEEM, Milan.

Murrell, P. (1990), "The Nature of Socialist Economics: Lessons from East European Foreign Trade, Princeton University Press.

Muzondo, T.R., et al. (1990), "Public Policy and the Environment: A Survey of the Literature,” IMF Working Papers No. 90/56, Washington, DC, June.

Myerson, R. B. (1999), "Nash Equilibrium and the History of Economic Theory", Journal of Economic Literature Vol. xxxVII, pp. 1067-1082.

Naylor, T. H. (ed.) (1969), The Design of Computer Simulation Experiments, Durham, N.C.: Duke University Press.

Naylor, T. H. (1971), Computer Simulation Experiments with Models of Economic Systems, New York: John Wiley \& Sons, Inc.

Neganban, B., C. Fonyo, K. L. Campbell, J. W. Jones, W. G. Boggess, G. Kiker, E. Hamouda, E. Flaig, and H. Lal (1996), "LOADSS: A GIS-Based Decision Support System for Regional Environmental Planning”, Goodchild, M. F. et al. eds, GIS and Environmental Modeling: Progress and Research Issues, Fort Collins: GIS World, Inc.

NEPA (1992), Pollution Charges in China, Beijing: National Environmental Protection Agency (NEPA).

NEPA (1994), The Pollution Levy System, Beijing: China Environmental Science Press.

NEPA (1997), 1996 Report on the Environment in China, Beijing: National Environmental Protection Agency (NEPA).

NEPA (1998), China Environmental Yearbook 1997, Beijing: China Environmental Yearbook Press.

Nerlove, M., D. M. Grether, J. L. Carvalho (1979), Analysis of Economic Time Series: A Synthesis, New Your: Academic Press.

NI, C. (1998), A Two Perspective Study on the Modern Chinese Economy: Foreign Direct Investment and Regional Development, Dissertation, West Virginia University. 
Nijkamp, P, ed, (1986), Handbook of Regional and Urban Economics, Volume 1: Regional Economics, Amsterdam: North-Holland.

Nijkamp, P. and A. Reggiani (1989), "Spatial Interaction and Input-Output Models: A Dynamic Stochastic Multiobjective Framework", Miller et al (eds), Frontiers of Input-Output Analysis, New York: Oxford University Press.

Nordhaus, W. D. and G. W. Yohe (1983), "Future Carbon Dioxide Emissions from Fossil Fuels," Chapter 2.1 in Climate Change: Report of the carbon Dioxide Assessment Committee, Washington, D.C.: National Academy Press.

Oates, W. E. and R. M. Schwab (1988), "Economic Competition among Jurisdiction Efficiency Enhancing or Didtortion Inducing?", Journal of Public Economics 35: 333-354.

Oates, W. E., P. R. Portney and A. M. McGarland (1989), "The Net Benefits of Incentive Based Regulation: A Case Study of Environmental Standard Setting," American Economic Review 59(Dec.): 1233-1242.

Oates, W., K. Palmer and P. R. Portney (1994) " Environmental Regulation and International Competitiveness: Thinking About the Porter Hypothesis", Discussion Paper 94-02, Resources for he Future, Washington.

OECD (1982), Macro-Economic Evaluation of Environmental Programmes, Paris.

OECD (1985), The Macro-economic Impact of Environmental Expenditure, OECD Publications, Printed in Paris.

OECD (1994), The Environmental Effects of Trade, OECD Publications, Printed in Paris.

Ozaki, I. , M. Kuroda, and M. Shimizu (1995), "Towards an international input-output model: Fact-findings on trade patterns and production technologies", Klein, L. R. and F.-C. Ruo (eds), Modelling Global Change, New York: United Nations University Press

Panagariya, A., K. Palmer, W. Oates and A. Krupnick (1993) " Toward and Integrated Theory of Open Economy Environmental and Trade Policy", Working Paper No 93-8, Department of Economics, University of Maryland.

Panchamukhi, V. R. (1976), "A Multisectoral and Multicountry Model for Planning ECAFE Production and Trade", Polenske, K. R. and J. V. Skolka (eds.) Advances in Input-Output Analysis, Cambridge: Ballinger Publishing Company.

Pargal, S. and D. Wheeler (1996), "Informal environmental regulation of industrial pollution in developing countries: evidence from Indonesia", Journal of Political Economy, Vol.104 (6):1314-27.

Park, S.H. and W.C. Labys (1999), Industrial Development and Environmental Degradation: A Source Book on the Origins of Global Pollution, Northampton, MA: Edward Elgar.

Parke, W. (1982), "An algorithm for FIML and 3SLS estimation of large nonlinear models", Econometrica, Vol. 50 (1): 81-95.

Pasurka, C. A. (1984), "The Short run Impact of Environmental Protection Costs on US Product Prices", Journal of Environmental Economics and Management 11: 380-90.

Pasurka, C. A. (1985), "Environmental Control Costs and US Effective Rates of Protection," Public Finance Quarterly 13(2): 161-182.

Pearce, D. (1992) "Should the GATT Be Reformed for Environmental Reasons?" CSERGE Working Paper GEC 92-06. 
Pearce, D. and R. Turner (1990), Economics of Natural Resources and the Environment. London: Harvester Wheatsheaf.

Pearce, W. D., and J. J. Warford (1993), World without End. Economics, Environment, and Sustainable Development. New York: Oxford University Press.

Pearson, C. (1982), Environmental Policies and Their Trade Implications for Developing Countries, with Special Reference to Fish and Shellfish, Fruit and Vegetables. UNCTAD.

Pearson, C. (1985), Down to Business: Multinational Corporations, the Environment, and Development. Washington DC: World Resource Institute.

Pearson, C. (1987), Multinational Corporations, Environment, and the Third World. Durham: Duke Univ. Press.

Pearson, C. S. (1993), “ The Trade and Environment Nexus: What Is New Since'72?”, Zaelke, D. et al. eds. Trade and the Environment: Law, Economics, and Policy, Washington, D. C.: Island Press.

Perroni, C. and R. M. Wigle (1994), "International Trade and Environment Quality: How Important are the Linkages?" Canadian Journal of Economics, XXVII No.3: 55167.

Pethig, R. (1976) " Pollution, Welfare and Environmental Policy in the Theory of Comparative Advantage", Journal of Environmental Economics and Management, 2, 160-169.

Pethig, R. (1993) " Non-cooperative Natonal Environmental Policies and Capital Mobility", in J. Braden, H. Folmer and T. Ulen (eds.) "Environmental Policy with Economics and Political Integration: The European Community and the United States", Edward Elgar.

Petri, P. A. (1976), “A Multilateral Model of Japanese-American Trade”, Polenske, K. R. and J. V. Skolka (eds.), Advances in Input-Output Analysis, Cambridge: Ballinger Publishing Company,

Piggott, J., J. Whalley and R. Wigle (1992), "International Linkages and Carbon Reduction Incentives," in K. Anderson and R. Blackhurst, editors, The Greening of World Trade Issues (Ann Arbor: University of Michigan Press).

Pollak, R. A. and T. J. Wales (1981), "Demographic Variable in Demand Analysis," Econometrica 49(Nov.): 1533-1551.

Porter, M. E. (1990) The competitive advantage of nations, New York: The Free Press.

Porter, M. E. and C. van der Linde (1995), "Toward a New Conception of the Environment-Competitiveness Relationship," Journal of Economic Perspectives 9, 97-118.

Prasad, K. N. and A. M. Swaminathan (1992), "Trade Strategies and Development India and Iran", Economic Systems Research Vol. 4: 87-101.

Prucha, I. R. (1985), "Maximum likelihood and instrumental variable estimation in simultaneous equation systems with error components," International Economic Review. 26(2): 491-506.

Public Research Institute (1976), The Effects of Effluent Discharge Limitations on Foreign Trade in Selected Industries (Report to the US National Commission on Water Quality, Arlington, VA). 
Puttock, G. D. and M. Sabourin (1992), "International Trade in Forest Products: An Overview", International Agricultural Trade Research Consortium, St. Petersburg, Fl.

Qu, G. (1991), Environmental Management in China, Beijing: UNEP and China Environmental Science Press.

Rauscher, M. (1991a), "Foreign Trade and the Environment", Siebert, H. eds., Environmental Scarcity; The International Dimension, Institut Fuer Weltwirtschaft an der Universitaet Kiel, Tuebingen: Mohr.

Rauscher, M. (1991b), "National Environmental Policies and the Effects of Economic Integration”, Eur. J. Polit. Econ. 7: 313-29.

Rauscher, M. (1992) " Economic Integration and the Environment: Effect on Members and Non-Members" Environmental and Resource Economics, 2, 221-236.

Rauscher, M. (1993a)" On Ecological Dumping”, in C. Carraro (ed.) Trade, Innovation and the Environment, Kluwer, Dordrecht

Rauscher, M. (1993b)" Environmental Regulation and International Capital Allocation", Nota di Lavoro 79.93, FEEM, Milan.

Recardo, D. (1817), The Principles of Political Economy and Taxation, first published in 1817, reprinted by Homewood: Irwin, 1963.

Repetto, R. (1995), “Jobs, Competitiveness and Environmental Regulation: What Are the Real Issues? Washington, D.C.: World resources Institute.

Reuber, G. L. (1973) Private foreign investment development, Oxford: Clarendon Press.

Rich, K.M., A. Winter-Nelson, and G.C. Nelson (1997), "Political Feasibility of Structural Adjustment in Africa: An Application of SAM Multipliers," World Development, Vol. 25, No. 12: 2105-2114.

Richardson, J. D. and J. H. Mutti (1977), “International Competitive Displacement from Environmental Control," Journal of Environmental Economics and Management 4, 135-152.

Richardson, J. D., and J. H. Mutti, (1976), "Industrial Development through Environmental Control: The International Competitive Aspect," in I Walter, ed. Studies in International Environmental Economics. NY: Wiley.

Robertson, D. (1992) “ Trade and the Environment: Harmonization and Technical Standards ",Ch. 17 in Low (ed.) op.cit.

Robison, H. D. (1988), "Industrial Pollution Abatement: the Impact on the Balance of Trade," Canadian Journal of Economics 21(1) (Feb.): 187-199.

Rock, M. T., "Pollution Intensity of GDP and Trade Policy; Can the World Bank Be Wrong?," World Development 24(3) (1996): 471-79.

Rose, A., M. M. Tompkins, D. Lim, O. Frias, and J. Benavides (1994), "Coal Use in the People's Republic of China", Vol. 2: The Economic Effects of Constraining Coal Utilization, ANL/DIS/TM-22, Argonne National Laboratory, Argonne, Illinois.

Rotmans, J. (1998), "global Change and Subtainable Decelopment: Towards an Integrated Conceptual Model", Schellnhuber, H.-J. and V. Wenzel (eds.0, Earth System Analysis: Integrating Science for Sustainability, Berlin, Heidelberg: Springer-Verlag.

Runge, C. F. (1990), "Trade Proteectionism and Environmental Regulations: The New Nontariff Barriers", Northwestern Journal of International Law \& Business, 11 (1): 47-61. 
Runge, C. F. (1993) "Economic Trade and Environmental Protection" in J. Braden, H. Folmer and T. Ulen (eds.) Environmental Policy with Economic and Political Integration: The European Community and the United States, Edward Elgar.

Runge, C. F. (1993), "International Public Goods, Export Subsidies, and the Harmonization of Environmental Regulations," in Shane, M. D. and H. von Witzke, editors, Public Goods, the Environment, and International Trade, USDA, Staff Report No. AGES9314.

Samuelson, P. A. (1939), "The Gains from International Trade", Canadian Journal of Economics and political science 5: 195-205

Samuelson, P. A. (1952), "Spatial Price Equilibrium and Linear Programming", American Economic Review 42: 283-303.

Samuelson, P. A. (1962), “ The Gains from International Trade Onece Again”, Economic Journal 72: 820-829.

Sankey, J. (1989), "Domestically Prohibited Goods and Hazardous Substances-a New GATT Working group is Established," Journal of World Trade 23(6): 99-108.

Saunders, J. O. (1994), "NAFTA and the North American Agreement on Environmental Cooperation: A New Model for International Collaboration on Trade and the Environment", Colorado Journal of International Environmental Law and Policy, 5 (2): 273-304.

Schellnhuber, H. J. and V. Wenzel (eds.) (1998), Earth System Analysis: Integrating Science for Sustainability, Berlin: Springer-Verlag.

Scherr, S. J. (1987), Hazardous Exports: US and International policy Developments," in C. Pearson, Multinational Corporations, Environment, and the Third World. Durham: Duke Univ. Press.

Schmidt, P. (1990) "Three-stage least squares with different instruments for different equations", Journal of Econometrics 43, 389-394.

Schneider, K. and D. Wellisch (1997), 'Eco-Dumping, Capital Mobility, and International Trade', Environmental and Resource Economics 10: 387-404.

Segerson, K. (1988), "Natural Resource Concepts in Trade Analysis", Sutton, J. D. (eds.), Agricultural Trade and Natural Resources: Discovering the Critical Linkages, Boulder \& London: Lynne Rienner Publishers, Inc.

Selden, T. M. and D. Song (1994), 'Environmental quality and development: Is there a Kuznets curve for air pollution emissions?" Journal of Environmental Economics and Management 27: 147-162.

Shafik, N. and S. Bandyopadhyay (1992) "Economic growth and environmental quality: time series and cross-country evidence", Background Paper for the World Development Report 1992, The World Bank, Washington, DC.

Shibli, A. and A. Markandya (1995), "Industrial Pollution control Policies in Asia: How successful are the strategies?" Asia Journal of Environmental Management, Vol. 3 (2).

Shockley, F., and J. S. Ebelling (1997), "The Economic Impact on Colusa County of a Cut in the Supply of Water to the Glenn Colusa Irrigation District", International Journal of Public Administration Vol. 20, Iss. 8/9: 1513-1528.

Siebert, H. (1973), "Comparative Advantage and Environmental Policy: A Note", Zeittschrift fuer Nationaloekonomie Vol. 34, 397-402. 
Siebert, H. (1977), "Environmental Quality and the Gains from Trade", Kyklos 30(4): 657-673.

Siebert, H. (1985), "Spatial Aspects of Environmental Economics," in A. Kneese and J. Sweeney, eds., Handbook of Natural Resource and Energy Economics. NY: NorthHolland.

Siebert, H. (1991), “ Europe'92. Decentralizing Environmental Policy in the Single Market" Environmental and Resource Economics, 1, 271-288.

Siebert, H. (1992), "Economics of the Environment: Theory and Policy, Berlin: SpringerVerlag.

Siebert, H., J. Eichberger, R. Gronych, and R. Pethig (1980), Trade and Environment: A Theoretical Enquiry, New York: Elsevier Scientific Publishing Company.

Simpson, D. and R. Bradford (1993) " Taxing Variable Costs: Environmental Regulation as Industrial Policy”, Discussion Paper Enr 93-12, Resources for the Future, Washington.

Sinn, H.-W. (1994), 'HowMuch Europe? Subsidiarity, Centralization and Fiscal Competition', Scottish Journal of Political Economy 41: 85-107.

Siriwardana, Mahinda (1998), "Can Policy-Makers Learn from History? A General Equilibrium Analysis of the Recovery Policies of the 1930s Great Depression in Australia," Journal of Policy Modeling, Vol. 20, No. 3: 361-392.

Smith, B. and A. Ulph (1982), "The Impact of Environmental Policies in Developed Countries on the Trade of the Developing Countries," Environment and Development in Asia and the Pacific, UNEP Reports and Proceedings Series 6, Nairobi.

Smith, V. K. (1992), "Environmental Costing for Agriculture: Will It Be Standard Fare in the Farm Bill of 2000?" American Journal of Agricultural Economics, 74 (Dec.): $1076-1088$.

Smith, V. K. and J. A. Espinosa (1995), "Environmental and Trade Policies: Some Methodological Lessons," Working Paper.

Snape, W. (1994), "Searching for GATT's Environmental Miranda: Are 'Process Standard' Getting Due Process?”, Cornell International Law Journal 27(3): 777815.

Snidal, D. (1985), “Coordination Versus Prisoners' Dilemma: Implications for International Cooperation and Regimes", The American Political Science Review 79: 923-42.

Spanos, A. (1986), Statistical Foundations of Econometric Modelling, Cambridge: Cambridge University Press.

Stewart, F. and P. Streeten (1972), "Little-Mirrless methods and project appraisal", Bulletin of the Oxford University Institute of Economics and Statistics 34: 75-92.

Stewart, R. B. (1993), "Environmental Regulation and International Competitiveness", Yale Law Journal, June, 102(8): 2039-2106.

Stokes, B. (1992), “ On the Brink”, National Journal 29 (Feb): 504-509.

Suri, V. and D. Chapman (1998), "Economic growth, trade and energy: implications for environmental Kuznets curve", Ecological Economics 25: 195-208.

Symons, E. J., J. L. R. Proops and P. W. Gay (1990), Carbon Taxes, Consumer Demand and Carbon Dioxide Emission: A Simulation Analysis for the UK, Department of Economics and Mangement Science, University of Keele, Staffs. 
Syrquin, M. (1989), "Patterns of structural change", in Chenery, H. and T.N. Srinivasan (eds.), Handbook of Development Economics Vol. 1, Amsterdam: North-Holland.

Takayama, T. and A. D. Woodland (1970), "Equivalence of Price and Quantity Formulations of Spatial Equilibrium: Purified Duality in Quadratic and Concave Programming”, Econometrica 38: 889-906.

Takayama, T. and G. Judge (1964), “Equilibrium Among Spatially Separated Markets: A Reformulation”, Econometrica 32: 510-524.

Ten Raa, T. (1995), Linear Analysis of Competitive Economics, Herfordshire: Harvester Wheatsheaf.

Thomas, V. *1983), "Welfare Analysis of Pollution Control with Spatial Altternative", Alternatives", Urban Studies 20: 219-27.

Thoss, R. (1976), "A Generalized Input-Output model for Residuals Management", Advances in Input-Output Analysis, ed. by Polenske, K. R. and J. V. Skolka, Ballinger Publishing Company, Cambridge, Mass.

Thurman, W. N. (1991), “ Applied General Equilibrium Welfare Analysis”, American Journal of Agricultural Economics Vol. 73: 1508-16.

Tinbergen, J. (1962), Shaping the World Economy-Suggestions for an International Economic Policy, The Twentieth Century Fund.

Tirole, J. (1989) The Theory of Industrial Organization, MIT Press, Cambridge, Ma.

Tobey, J. (1990), "The Effects of Domestic Environmental Policies on Patterns of World trade: an Empirical Test," Kyklos 43(2): 191-209.

Tobey, J. A. (1993), "Effects of Domestic Environmental Policy on Patterns of International Trade", Shane, M. D. and H. van Witzke eds., The Environment, Government Policies, and International Trade: A Proceedings, USDA: Staff Report No. AGES 9314.

Tokoyama, K., Y. Kobayashi, Y. Murakami, and J. Tsukui (1976), "Structure of trade, production, and Development", Advances in Input-Output Analysis, ed. by Polenske, K. R. and J. V. Skolka, Ballinger Publishing Company, Cambridge, Mass.

Torii, Y., S-J. Shim, and Y. Akiyama (1989), "Effects of Tariff Reductions on Trade in the Asia-Pacific Region”, Miller, R. E., K. R. Polenske, and A. Z. Rose (eds.), Frontiers of Input-Output Analysis, Oxford: Oxford University Press.

Torries, T. F. (1998), Evaluating Mineral Projects: Applications and Misconceptions, Littleton, CO: Society for Mining, Metallurgy, and Exploration, Inc.

Trefler, D. (1994), "The case of the missing trade and other HOV mysteries", University of Toronto, mimeo.

Tudini, A. (1993) "Trade and Environment: the Issue of Process and Production Methods", Nota di Lavoro 7.93,FEEM, Milan.

U. S. Environmental Protection Agency (1992), "The Clean Air Marketplace: New Business Opportunities Created by the Clean Air Act Amendments-Summary of Conference Proceedings", Washington, D. C., Office of Air and Radiation, July 24, 1992.

Ugelow, J. (1982), "A Survey of Recent Studies on Costs of Pollution Control and the Effects on Trade," in S. Rubin, ed., Environmental Trade. New Jersey: Allanheld, Osmum, and Co. 
Ulph, A. (1992) “ The Choice of Environmental Policy Instruments and Strategic International Trade" in R. Pethig (ed.) Conflicts and Cooperation in Managing Environmental Resources, Springer-Verlag, Berlin.

Ulph, A. (1993a) "Environmental Policy and Strategic International Trade" Discussion Papers in Economics and Econometrics 9304, University of Southampton.

Ulph, A. (1993a) "Environmental Policy and Strategic International Trade" Discussion Papers in Economics and Econometrics 9304, University of Southampton.

Ulph, A. (1993b) "Environmental Policy, Plant Location and Government Protection" in C. Carraro (ed.) Trade, Innovation and the Environment, Kluwer, Dordrecht.

Ulph, A. (1993c) "Environmental Policy and International Trade When Governments and Producers Act Strategically", Discussion Paper in Economics and Economics 9318, University of Southampton.

Ulph, A. (1993d) "Strategic Environmental Policy, International Trade and the Single European Market" in J. Braden,,H. Folmer and T. Ulen(eds.) Environmental Policy with Economic and Political Integration: The European Community and the United States, Edward Elgar.

Ulph, A. (1994), "Environmental policy and International Trade: A Survey of Recent Economic Analysis," Discussion Papers in Economics and Econometrics No. 9423, Department of Economics, University of Southampton.

Ulph, A. (1996), "Environmental Policy and International Trade when Governments and Producers Act Strategically," Journal of Environmental Economics and Management, Vol. 30, No. 3, 265-81.

Ulph, A. and D. Ulph (1994) "Trade, Strategic Innovation and Strategic Environmental Policy- A General Analysis" Discussion Paper in Economics and Econometrics 9416, University of Southampton.

Ulph, A. and L. Valentini (1997), "Plant location and Strategic Environmental Policy with Intersectoral Linkages," Resource and Energy Economics 19(4): 363-383.

USDOC (1975), The Effects of Pollution Abatement on International Trade-III.

Van Beers, C. and J. C. J. M. van den Bergh (1996), “ An Overview of Methodological Approaches in the Analysis of Trade and Environment", Journal of World Trade 30(1): 143-67.

Van Beers, C. and J. C. J. M. van den Bergh (1997), “ An Empirical Multi-Country Analysis of the Impact of Environmental Regulations on Foreign Trade Flows"', KYKLOS vol. 50(1): 29-46.

Van den Bergh, J. C. J. M., P. Nijkamp, and P. Rietveld, eds, (1996), Recent Advances in Spatial Equilibrium Modelling: Methodology and Applications, New York: Springer.

Van der Linden, J. A. and J. Oosterhaven (1995), "European Community Intercountry Input-Output Relations: Construction Method and Main Results for 1965-85", Economic Systems Research Vol. 7(3): 249-70.

Van Ierland, E. C. (1993), Macroeconomic Analysis of Environmental Policy, Amsterdam: Elsevier.

Vanberg, V. (1993), "A Constitutional Political Economy Perspective on International Trade," in Shane, M. D. and H. von Witzke, editors, Public Goods, the Environment, and International Trade, USDA, Staff Report No. AGES9314. 
Vanek, J. (1968), "The Factor Proportions Theory: the n-Factor Case”, Kyklos 21: 749756.

Vasavada, U., R. Saint-Louis, and G. Debailleul (1993), "The Conflict Between Trade Policy and Environmental Policy in Agriculture," in Shane, M. D. and H. von Witzke, editors, Public Goods, the Environment, and International Trade, USDA, Staff Report No. AGES9314.

Verdier, T. (1993) " Strategic Trade and the Regulation of Pollution by Performance or Design Standard", Nota di Lavoro 58.93, FEEM, Milan.

Vernon, R. (1996) "International investment and international trade in the product cycle", Quarterly Journal of Economics 80, pp. 190-207.

Veugelers, R. (1991),'Location determinants and Rankings of host countries", Kyklos 44, PP. 363-382.

Vincent, J. R. (1997) "Testing for environmental Kuznets curves within a developing country", Environment and Development Economics 2: 417-431.

Waelbroeck, J. and Y. Guillaume (1970), "Price Response of foreign trade and domestic supply and input-output planning for a very open economy", Carter, A. O. and A. Brody (eds.), Contributions to Input-Output Analysis Vol. 1, Amsterdam: NorthHolland.

Wager, J. (1995), "Environmental Planning for a World Heritage Site: Case Study of Angkor, Campodia", Journal of Environmental Planning and Management.

Wall, H. J. (1999), "Using the Gravity Model to Estimate the Costs of Protection", Federal Reserve Bank of St. Louis Review 81(1): 33-40.

Walter, I. (1973), "The Pollution Content of American Trade," Western Economic Journal 11, 61-70.

Walter, I. (1974), "Pollution and Protection: U. S. Environmental Controls as Competitive Distortions," Weltwirtsch. Arch., 1974. 110(1), 104-13.

Walter, I. (1975), International Economics of Pollution, New York: John Wiley \& Sons.

Walter, I. (1976), Studies in International Environmental Economics, New York: John Wiley \& Sons.

Walter, I. (1982), "Environmentally Induced Industrial Relocation to Developing Countries," in S. Rubin, ed., Environmental Trade. New Jersey: Allanheld, Osmum, and Co., 67-101.

Walter, I. and J. Ugelow (1979), "Environmental Policies in Developing Countries," Ambio, 8(2,3), 102-09.

Wang, H. and D. Wheeler (1996) "Pricing Industrial Pollution in China: an Econometric Analysis of the Levy System".

Warford, J. (1989), "Environmental Management and Economic Policy in Developing Countries," in G. Schram and J. Warford, eds., Environmental Management and Economic Development. Baltimore: Johns Hopkins University.

Wellisch, D. (1995), 'Locational Choices of Firms and Decentralized Environmental Policy with Various Instruments', Journal of Urban Economics 37, 290-310.

West, G. R. (1986), “A Stochastic analysis of an input-output model”, Econometric 54(2): 363-374.

Whalley, J. (1991), "The Interface Between Environmental and trade Policies," Economic Journal 101, 180-189. 
Whalley, J. “Trade and Environment Beyond Singapore.” NBER Working Paper No 5768, Cambridge, MA, September 1996.

Whalley, J. and R. Wigle (1991), “ The International Incidence of Carbon Taxes", Dornbusch, R. and J. Poterba eds., E conomic Policy Responses to Global Warming, Cambridge, MA: MIT Press.

Whalley, J. and R. Wigle (1991), "Cutting $\mathrm{CO}_{2}$ Emissions: The Effects of Alternative policy Approaches," The Energy Journal, 12(1).

Wheeler, D. and Mody, A. (1992) "International investment Location decision: the case of U.S. firms", Journal of International Economics 33, pp. 57-76.

Wilson, A. G., J. D. Coelho, S. M. Macgill, and H. C. W. L. Williams (1981), Optimization in Locational and Transport Analysis, New York: John Wiley \& Sons.

Withagen, C. (1985), Economic Theory and International Trade in Exhaustible Resources, Berlin: Springer-Verlag.

World Bank (1992), World Development Report 1992, New York: Oxford University Press.

World Bank (1997a), Clear Water, Blue Skies: China's Environment in the New Century.

World Bank (1997b), China Engaged: Integration with Global Economy, Washington, D.C.

World Bank. "Chile: Managing Environmental Problems. Economic Analysis of Selected Issues." Report No. 13061-CH, Washington D. C., 1994.

WTO (1996), Annual Report 1996, Vol. 1, WTO.

Wu, C. H. (2000) "Trade and Sustainability: A China Perspective", Working Paper, World Resource Institute.

Xia, Y. (1995) "Study on China's control measures to the transfer of foreign wastes and pollution intensive industries through trade and investment", paper prepared for the Working Group on Trade and Environment, Winnipeg, Canada.

Xing, Y. and C. D. Kolstad (1996),"Environment and Trade: A Review of Theory and Issues," University of California Santa Barbara, Department of Economics Working Paper \#2-96,Santa Barbara, CA.

Yao, Y. et al. (1994), Outlook for China Economic and Social Development, Two Volumes, Institute of Quantitative and Technical Economics, Chinese Academy of Social Science, Beijing.

Yezer, A. and A. Philipson (1974), "Influence of Environmental Considerations on Agriculture and Industrial Decisions to Locate outside of the Continental US," Public Interest Economics Center.

Yohe, G. W. (1979), "The Backward Incidence of Pollution Control—Some Comparative Statics in General Equilibrium", Journal of Environmental Economics and Management 6: 187-198.

Zhang, Z. (1999), "Is China taking actions to limit its greenhouse gas emissions?" in J. Goldemberg and W. Reid (eds.), Promoting Development while Limiting Greenhouse Gas Emissions, UN Development Programmed, New York.

Zhong Xiang Zhang (1998), "Macroeconomic Effects of CO2 Emission Limits: A Computable General Equilibrium Analysis for China," Journal of Policy Modeling, Vol. 20, No. 2: 213-250. 


\section{Appendix A: Flowgraph and Comparative Statics Results}

\section{A.1 The effects of a trade policy on emissions}

Flowgraph analysis

Open path from dt to $\mathrm{dT}$ :

$$
\begin{aligned}
& \mathrm{E}_{1}(\mathrm{dt} \rightarrow \mathrm{dT} \rightarrow \mathrm{dY} \rightarrow \mathrm{dE})=\mathrm{W}_{\mathrm{t}} \mathrm{hA}^{\prime} \mathrm{f}_{\mathrm{Y}} \\
& \mathrm{E}_{2}(\mathrm{dt} \rightarrow \mathrm{dT} \rightarrow \mathrm{dS} \rightarrow \mathrm{dE})=\mathrm{W}_{\mathrm{t}} \mathrm{Z}_{\mathrm{T}} \mathrm{f}_{\mathrm{S}} \\
& \mathrm{E}_{3}(\mathrm{dt} \rightarrow \mathrm{dT} \rightarrow \mathrm{dY} \rightarrow \mathrm{dr} \rightarrow \mathrm{dE})=\mathrm{W}_{\mathrm{t}} \mathrm{hA} \mathrm{\prime}^{\prime} \mathrm{g}_{\mathrm{Y}} \mathrm{f}_{\mathrm{r}} \\
& \mathrm{E}_{4}(\mathrm{dt} \rightarrow \mathrm{dT} \rightarrow \mathrm{dY} \rightarrow \mathrm{dS} \rightarrow \mathrm{dE})=\mathrm{W}_{\mathrm{t}} \mathrm{hA}^{\prime} \mathrm{Z}_{\mathrm{Y}} \mathrm{f}_{\mathrm{S}}
\end{aligned}
$$

Relavent loops in the system:

$$
\begin{aligned}
& \mathrm{L}_{1}(\mathrm{dT} \rightarrow \mathrm{dY} \rightarrow \mathrm{dT})=\mathrm{hA}{ }^{\prime} \mathrm{W}_{\mathrm{Y}} \\
& \mathrm{L}_{2}(\mathrm{dT} \rightarrow \mathrm{dY} \rightarrow \mathrm{dF} \rightarrow \mathrm{dT})=\mathrm{hA}^{\prime} \mathrm{V}_{\mathrm{Y}} \mathrm{W}_{\mathrm{F}} \\
& \mathrm{L}_{3}(\mathrm{dT} \rightarrow \mathrm{dS} \rightarrow \mathrm{dE} \rightarrow \mathrm{dY} \rightarrow \mathrm{dT})=\mathrm{Z}_{\mathrm{T}} \mathrm{f}_{\mathrm{S}} \mathrm{Ah}_{\mathrm{E}} \mathrm{W}_{\mathrm{Y}} \\
& \mathrm{L}_{4}(\mathrm{dT} \rightarrow \mathrm{dS} \rightarrow \mathrm{dE} \rightarrow \mathrm{dY} \rightarrow \mathrm{dF} \rightarrow \mathrm{dT})=\mathrm{Z}_{\mathrm{T}} \mathrm{f}_{\mathrm{S}} \mathrm{Ah}_{\mathrm{E}} \mathrm{V}_{\mathrm{Y}} \mathrm{W}_{\mathrm{F}} \\
& \mathrm{L}_{5}(\mathrm{dY} \rightarrow \mathrm{dE} \rightarrow \mathrm{dY})=\mathrm{f}_{\mathrm{Y}} \mathrm{Ah}_{\mathrm{E}} \\
& \mathrm{L}_{6}(\mathrm{dY} \rightarrow \mathrm{dr} \rightarrow \mathrm{dE} \rightarrow \mathrm{dY})=\mathrm{g}_{\mathrm{Y}} \mathrm{f}_{\mathrm{r}} \mathrm{Ah}_{\mathrm{E}} \\
& \mathrm{L}_{7}(\mathrm{dY} \rightarrow \mathrm{dS} \rightarrow \mathrm{dE} \rightarrow \mathrm{dY})=\mathrm{Z}_{\mathrm{Y}} \mathrm{f}_{\mathrm{S}} \mathrm{Ah}_{\mathrm{E}} \\
& \mathrm{L}_{8}(\mathrm{dT} \rightarrow \mathrm{dY} \rightarrow \mathrm{dr} \rightarrow \mathrm{dF} \rightarrow \mathrm{dT})=\mathrm{hA}^{\prime} \mathrm{g}_{\mathrm{Y}} \mathrm{V}_{\mathrm{r}} \mathrm{W}_{\mathrm{F}} \\
& \mathrm{L}_{9}(\mathrm{dE} \rightarrow \mathrm{dr} \rightarrow \mathrm{dE})=\mathrm{g}_{\mathrm{E}} \mathrm{f}_{\mathrm{r}} \\
& \mathrm{L}_{10}(\mathrm{dT} \rightarrow \mathrm{dY} \rightarrow \mathrm{dE} \rightarrow \mathrm{dr} \rightarrow \mathrm{dF} \rightarrow \mathrm{dT})=\mathrm{hA}^{\prime} \mathrm{f}_{\mathrm{Y}} \mathrm{g}_{\mathrm{E}} \mathrm{V}_{\mathrm{r}} \mathrm{W}_{\mathrm{F}} \\
& \mathrm{L}_{11}(\mathrm{dT} \rightarrow \mathrm{dY} \rightarrow \mathrm{dS} \rightarrow \mathrm{dE} \rightarrow \mathrm{dr} \rightarrow \mathrm{dF} \rightarrow \mathrm{dT})=\mathrm{hA}^{\prime} \mathrm{Z}_{\mathrm{Y}} \mathrm{f}_{\mathrm{S}} \mathrm{g}_{\mathrm{E}} \mathrm{V}_{\mathrm{r}} \mathrm{W}_{\mathrm{F}} \\
& \mathrm{L}_{12}(\mathrm{dT} \rightarrow \mathrm{dS} \rightarrow \mathrm{dE} \rightarrow \mathrm{dr} \rightarrow \mathrm{dF} \rightarrow \mathrm{dT})=\mathrm{Z}_{\mathrm{T}} \mathrm{f}_{\mathrm{S}} \mathrm{g}_{\mathrm{E}} \mathrm{V}_{\mathrm{r}} \mathrm{W}_{\mathrm{F}} \\
& \mathrm{A}_{\mathrm{c}} \mathrm{cor}
\end{aligned}
$$

According to Heise (Heise, D.R., 1975, Causal Analysis, New York: John Wiley \& Sons, pp: 62), the total effect of a trade policy on emissons can be determined as follows:

$$
\frac{d E}{d t}=\left[\frac{\left(E_{1}+E_{2}+E_{3}+E_{4}\right)\left(1-L_{1}\right)\left(1-L_{2}\right) \cdots\left(1-L_{12}\right)}{\left(1-L_{1}\right)\left(1-L_{2}\right) \cdots\left(1-L_{12}\right)}\right]^{*}
$$

where $*$ is a special operation in which the multiplications in the numerator and in the denominator are carried out before division, terms are deleted if they multiply the effects of touching paths, and division is carried out only after such terms have been deleted. In addition, it not difficult to find out that the denominator derived from such operation is the determinant of the system, $|\Delta|$. Therefore, equation A1 becomes:

$$
\begin{aligned}
\frac{d E}{d t} & =|\Delta|^{-1}\left(E_{1}+E_{2}+E_{3}+E_{4}\right)\left(1-\sum_{i=1}^{12} L_{i}+L_{1} L_{9}+L_{2} L_{9}\right) \\
& =|\Delta|^{-1}\left(E_{1}+E_{2}+E_{3}+E_{4}\right) \\
& =|\Delta|^{-1} W_{t}\left[f_{S} Z_{T}+h A^{\prime}\left(f_{r} g_{Y}+f_{Y}+f_{S} Z_{Y}\right)\right]
\end{aligned}
$$

\section{Comparative statics}

The result shown in equation (A2) can also be obtained by applying comparative statics to system equation (4-13). The comparative statics procedure is as follows. 


$$
\begin{aligned}
& \frac{d E}{d t}=|\Delta|^{-1}\left|\begin{array}{cccccc}
1 & 0 & 0 & 0 & -h A^{\prime} & 0 \\
-f_{Y} & 0 & -f_{r}-f_{S} & 0 & 0 \\
-g_{Y} & 0 & 1 & 0 & 0 & 0 \\
-Z_{Y} & 0 & 0 & 1 & -Z_{T} & 0 \\
-W_{Y} & W_{t} & 0 & 0 & 1 & -W_{F} \\
-V_{Y} & 0 & -V_{r} & 0 & 0 & 1
\end{array}\right|=|\Delta|^{-1}(-1)^{5+2} \mathrm{~W}_{\mathrm{t}}\left|\begin{array}{ccccc}
1 & 0 & 0 & -h A^{\prime} 0 \\
-f_{Y}-f_{r}-f_{S} & 0 & 0 \\
-g_{Y} & 1 & 0 & 0 & 0 \\
-Z_{Y} & 0 & 1 & -Z_{T} & 0 \\
-V_{Y}-V_{r} & 0 & 0 & 1
\end{array}\right| \\
& =|\Delta|^{-1}\left(-\mathrm{W}_{\mathrm{t}}\right)(-1)^{5+5}\left|\begin{array}{cccc}
1 & 0 & 0 & -h A^{\prime} \\
-f_{Y}-f_{r}-f_{S} & 0 \\
-g_{Y} & 1 & 0 & 0 \\
-Z_{Y} & 0 & 1 & -Z_{T}
\end{array}\right| \\
& =|\Delta|^{-1}\left(-\mathrm{W}_{\mathrm{t}}\right)\left\{(-1)^{2+2}\left(-f_{r}\right)\left|\begin{array}{ccc}
1 & 0-h A^{\prime} \\
g_{Y} & 0 & 0 \\
-Z_{Y} & 1-Z_{T}
\end{array}\right|+(-1)^{2+3}\left|\begin{array}{lll}
1 & 0 & -h A^{\prime} \\
-f_{Y}-f_{S} & 0 \\
-Z_{Y} & 1 & -Z_{T}
\end{array}\right|\right\} \\
& =|\Delta|^{-1} W_{t}\left[f_{S} Z_{T}+h A^{\prime}\left(f_{r} g_{Y}+f_{Y}+f_{S} Z_{Y}\right)\right]
\end{aligned}
$$

\section{A.2 The effects of a trade policy on FDI}

Flowgraph analysis

Open paths from dt to dFDI:

$$
\begin{aligned}
& \mathrm{E}_{1}(\mathrm{dt} \rightarrow \mathrm{dT} \rightarrow \mathrm{dY} \rightarrow \mathrm{dFDI})=\mathrm{W}_{\mathrm{t}} \mathrm{hA} \mathrm{A}^{\prime} \mathrm{V}_{\mathrm{Y}} \\
& \mathrm{E}_{2}(\mathrm{dt} \rightarrow \mathrm{dT} \rightarrow \mathrm{dS} \rightarrow \mathrm{dE} \rightarrow \mathrm{dY} \rightarrow \mathrm{dFDI})=\mathrm{W}_{\mathrm{t}} \mathrm{Z}_{\mathrm{T}} \mathrm{f}_{\mathrm{S}} \mathrm{Ah}_{\mathrm{E}} \mathrm{V}_{\mathrm{Y}} \\
& \mathrm{E}_{3}(\mathrm{dt} \rightarrow \mathrm{dT} \rightarrow \mathrm{dS} \rightarrow \mathrm{dE} \rightarrow \mathrm{dr} \rightarrow \mathrm{dFDI})=\mathrm{W}_{\mathrm{t}} \mathrm{Z}_{\mathrm{T}} \mathrm{f}_{\mathrm{S}} \mathrm{g}_{\mathrm{E}} \mathrm{V}_{\mathrm{Y}} \\
& \mathrm{E}_{4}(\mathrm{dt} \rightarrow \mathrm{dT} \rightarrow \mathrm{dY} \rightarrow \mathrm{dr} \rightarrow \mathrm{dFDI})=\mathrm{W}_{\mathrm{t}} \mathrm{hA} \mathrm{A}^{\prime} \mathrm{g}_{\mathrm{Y}} \mathrm{V}_{\mathrm{r}} \\
& \mathrm{E}_{5}(\mathrm{dt} \rightarrow \mathrm{dT} \rightarrow \mathrm{dY} \rightarrow \mathrm{dE} \rightarrow \mathrm{dr} \rightarrow \mathrm{dFDI})=\mathrm{W}_{\mathrm{t}} \mathrm{hA}{ }^{\prime} \mathrm{f}_{\mathrm{Y}} \mathrm{g}_{\mathrm{E}} \mathrm{V}_{\mathrm{r}} \\
& \mathrm{E}_{6}(\mathrm{dt} \rightarrow \mathrm{dT} \rightarrow \mathrm{dY} \rightarrow \mathrm{dS} \rightarrow \mathrm{dE} \rightarrow \mathrm{dr} \rightarrow \mathrm{dFDI})=\mathrm{W}_{\mathrm{t}} \mathrm{hA}^{\prime} \mathrm{Z}_{\mathrm{Y}} \mathrm{f}_{\mathrm{S}} \mathrm{g}_{\mathrm{E}} \mathrm{V}_{\mathrm{r}} \\
& \mathrm{E}_{7}(\mathrm{dt} \rightarrow \mathrm{dT} \rightarrow \mathrm{dS} \rightarrow \mathrm{dE} \rightarrow \mathrm{dY} \rightarrow \mathrm{dr} \rightarrow \mathrm{dFDI})=\mathrm{W}_{\mathrm{t}} \mathrm{Z}_{\mathrm{T}} \mathrm{f}_{\mathrm{S}} \mathrm{Ah}_{\mathrm{E}} \mathrm{g}_{\mathrm{Y}} \mathrm{V}_{\mathrm{r}}
\end{aligned}
$$

The total effect of a trade policy on FDI:

$$
\begin{aligned}
\frac{d F D I}{d t}= & =\left[\frac{\left(E_{1}+E_{2}+\cdots+E_{7}\right)\left(1-L_{1}\right)\left(1-L_{2}\right) \cdots\left(1-L_{12}\right)}{\left(1-L_{1}\right)\left(1-L_{2}\right) \cdots\left(1-L_{12}\right)}\right]^{*} \\
= & |\Delta|^{-1}\left(E_{1}+E_{2}+\cdots+E_{7}\right)\left(1-\sum_{i=1}^{12} L_{i}+L_{1} L_{9}+L_{2} L_{9}\right) \\
= & |\Delta|^{-1}\left(E_{1}+E_{2}+\cdots+E_{7}-E_{1} L_{9}\right) \\
= & |\Delta|^{-1} W_{t}\left[\mathrm{hA}^{\prime}\left(\mathrm{f}_{\mathrm{S}} \mathrm{g}_{\mathrm{E}} \mathrm{V}_{\mathrm{r}} \mathrm{Z}_{\mathrm{Y}}+\mathrm{f}_{\mathrm{S}} \mathrm{g}_{\mathrm{E}} \mathrm{V}_{\mathrm{r}}+\mathrm{V}_{\mathrm{Y}}+\mathrm{g}_{\mathrm{Y}} \mathrm{V}_{\mathrm{r}}-\mathrm{f}_{\mathrm{r}} \mathrm{g}_{\mathrm{E}} \mathrm{V}_{\mathrm{Y}}\right)\right. \\
& +\mathrm{Z}_{\mathrm{T}}\left(\mathrm{Ah}_{\mathrm{E}}\left(\mathrm{f}_{\mathrm{S}} \mathrm{V}_{\mathrm{Y}}+\mathrm{Ah}_{\mathrm{E}} \mathrm{f}_{\mathrm{S}} \mathrm{g}_{\mathrm{Y}} \mathrm{V}_{\mathrm{r}}+\mathrm{f}_{\mathrm{S}} \mathrm{g}_{\mathrm{E}} \mathrm{V}_{\mathrm{r}}\right)\right]
\end{aligned}
$$




\section{Comparative statics}

The result shown in equation (A3) can also be obtained by applying comparative statics to system equation (4-13). To save space, the comparative statics procedure is not reported here.

\section{A.3 The effects of a trade policy on emissions charges}

Flowgraph analysis

Open paths from dt to dr:

$$
\begin{aligned}
& \mathrm{E}_{1}(\mathrm{dt} \rightarrow \mathrm{dT} \rightarrow \mathrm{dS} \rightarrow \mathrm{dE} \rightarrow \mathrm{dr})=\mathrm{W}_{\mathrm{t}} \mathrm{Z}_{\mathrm{T}} \mathrm{f}_{\mathrm{S}} \mathrm{g}_{\mathrm{E}} \\
& \mathrm{E}_{2}(\mathrm{dt} \rightarrow \mathrm{dT} \rightarrow \mathrm{dY} \rightarrow \mathrm{dS} \rightarrow \mathrm{dE} \rightarrow \mathrm{dr})=\mathrm{W}_{\mathrm{t}} \mathrm{hA}^{\prime} \mathrm{Z}_{\mathrm{Y}} \mathrm{f}_{\mathrm{S}} \mathrm{g}_{\mathrm{E}} \\
& \mathrm{E}_{3}(\mathrm{dt} \rightarrow \mathrm{dT} \rightarrow \mathrm{dY} \rightarrow \mathrm{dE} \rightarrow \mathrm{dr})=\mathrm{W}_{\mathrm{t}} \mathrm{hA} \mathrm{A}^{\prime} \mathrm{f}_{\mathrm{Y}} \mathrm{g}_{\mathrm{E}} \\
& \mathrm{E}_{4}(\mathrm{dt} \rightarrow \mathrm{dT} \rightarrow \mathrm{dY} \rightarrow \mathrm{dr})=\mathrm{W}_{\mathrm{t}} \mathrm{h}^{\prime} \mathrm{g}_{\mathrm{Y}} \\
& \mathrm{E}_{5}(\mathrm{dt} \rightarrow \mathrm{dT} \rightarrow \mathrm{dS} \rightarrow \mathrm{dE} \rightarrow \mathrm{dY} \rightarrow \mathrm{dr})=\mathrm{W}_{\mathrm{t}} \mathrm{Z}_{\mathrm{T}} \mathrm{f}_{\mathrm{S}} \mathrm{Ah}_{\mathrm{E}} \mathrm{g}_{\mathrm{Y}}
\end{aligned}
$$

The total effect of a trade policy on emissions charges:

$$
\begin{aligned}
\frac{d r}{d t} & =\left[\frac{\left(E_{1}+E_{2}+\cdots+E_{5}\right)\left(1-L_{1}\right)\left(1-L_{2}\right) \cdots\left(1-L_{12}\right)}{\left(1-L_{1}\right)\left(1-L_{2}\right) \cdots\left(1-L_{12}\right)}\right]^{*} \\
& =|\Delta|^{-1}\left(E_{1}+E_{2}+\cdots+E_{5}\right)\left(1-\sum_{i=1}^{12} L_{i}+L_{1} L_{9}+L_{2} L_{9}\right) \\
& =|\Delta|^{-1}\left(E_{1}+E_{2}+\cdots+E_{5}\right) \\
& =|\Delta|^{-1} W_{t}\left[Z_{\mathrm{T}}\left(\mathrm{f}_{\mathrm{S}} \mathrm{g}_{\mathrm{E}}+\mathrm{Ah}_{\mathrm{E}} \mathrm{f}_{\mathrm{S}} \mathrm{g}_{\mathrm{Y}}\right)+\mathrm{hA}^{\prime}\left(\mathrm{f}_{\mathrm{S}} \mathrm{g}_{\mathrm{E}} \mathrm{Z}_{\mathrm{Y}}+\mathrm{f}_{\mathrm{Y}} \mathrm{g}_{\mathrm{E}}+\mathrm{g}_{\mathrm{Y}}\right)\right]
\end{aligned}
$$

\section{A.4 The effects of an emissons charge on FDI}

Flowgaph analysis

Open paths from dr to dFDI:

$$
\begin{aligned}
& \mathrm{E}_{1}(\mathrm{dr} \rightarrow \mathrm{dFDI})=\mathrm{V}_{\mathrm{r}} \\
& \mathrm{E}_{2}(\mathrm{dr} \rightarrow \mathrm{dE} \rightarrow \mathrm{dY} \rightarrow \mathrm{dF})=\mathrm{f}_{\mathrm{r}} \mathrm{Ah}_{\mathrm{E}} \mathrm{V}_{\mathrm{Y}}
\end{aligned}
$$

The total effect of an emissions charge on FDI:

$$
\begin{aligned}
\frac{d F D I}{d r} & =\left[\frac{\left(E_{1}+E_{2}\right)\left(1-L_{1}\right)\left(1-L_{2}\right) \cdots\left(1-L_{12}\right)}{\left(1-L_{1}\right)\left(1-L_{2}\right) \cdots\left(1-L_{12}\right)}\right]^{*} \\
& =|\Delta|^{-1}\left(E_{1}+E_{2}\right)\left(1-\sum_{i=1}^{12} L_{i}+L_{1} L_{9}+L_{2} L_{9}\right) \\
& =|\Delta|^{-1}\left(E_{1}+E_{2}-E_{1} L_{1}-E_{1} L_{3}-E_{1} L_{5}-E_{1} L_{7}\right) \\
& =|\Delta|^{-1}\left\{\mathrm{~V}_{\mathrm{r}}\left[1-\mathrm{hA}^{\prime} \mathrm{W}_{\mathrm{Y}}-\mathrm{Ah}_{\mathrm{E}}\left(\mathrm{f}_{\mathrm{S}} \mathrm{W}_{\mathrm{Y}} \mathrm{Z}_{\mathrm{T}}+\mathrm{f}_{\mathrm{Y}}+\mathrm{f}_{\mathrm{S}} \mathrm{Z}_{\mathrm{Y}}\right)\right]+\mathrm{Ah}_{\mathrm{E}} \mathrm{f}_{\mathrm{r}} \mathrm{V}_{\mathrm{Y}}\right\}
\end{aligned}
$$

\section{A.5 The effects of an emissions charge on trade}

Flowgraph analysis

Open paths from dr to dT:

$$
\begin{aligned}
& \mathrm{E}_{1}(\mathrm{dr} \rightarrow \mathrm{dF} \rightarrow \mathrm{dT})=\mathrm{V}_{\mathrm{r}} \mathrm{W}_{\mathrm{F}} \\
& \mathrm{E}_{2}(\mathrm{dr} \rightarrow \mathrm{dE} \rightarrow \mathrm{dY} \rightarrow \mathrm{dT})=\mathrm{f}_{\mathrm{r}} \mathrm{Ah}_{\mathrm{E}} \mathrm{W}_{\mathrm{Y}} \\
& \mathrm{E}_{3}(\mathrm{dr} \rightarrow \mathrm{dE} \rightarrow \mathrm{dY} \rightarrow \mathrm{dF} \rightarrow \mathrm{dT})=\mathrm{f}_{\mathrm{r}} \mathrm{Ah}_{\mathrm{E}} \mathrm{V}_{\mathrm{Y}} \mathrm{W}_{\mathrm{F}}
\end{aligned}
$$

The total effect of an emissions charge on trade: 


$$
\begin{aligned}
\frac{d T}{d r} & =\left[\frac{\left(E_{1}+E_{2}+E_{3}\right)\left(1-L_{1}\right)\left(1-L_{2}\right) \cdots\left(1-L_{12}\right)}{\left(1-L_{1}\right)\left(1-L_{2}\right) \cdots\left(1-L_{12}\right)}\right]^{*} \\
& =|\Delta|^{-1}\left(E_{1}+E_{2}+E_{3}\right)\left(1-\sum_{i=1}^{12} L_{i}+L_{1} L_{9}+L_{2} L_{9}\right) \\
& =|\Delta|^{-1}\left(E_{1}+E_{2}+E_{3}-E_{1} L_{5}-E_{1} L_{7}\right) \\
& =|\Delta|^{-1}\left[\mathrm{~V}_{\mathrm{r} \mathrm{W}_{\mathrm{F}}}\left(1-\mathrm{Ah}_{\mathrm{E}} \mathrm{f}_{\mathrm{Y}}-\mathrm{Ah}_{\mathrm{E}} \mathrm{f}_{\mathrm{S}} \mathrm{Z}_{\mathrm{Y}}\right)+\mathrm{Ah}_{\mathrm{E}}\left(\mathrm{f}_{\mathrm{r}} \mathrm{W}_{\mathrm{Y}}+\mathrm{f}_{\mathrm{r}} \mathrm{V}_{\mathrm{Y}} \mathrm{W}_{\mathrm{F}}\right)\right]
\end{aligned}
$$




\title{
Appendix B: Eviews Codes for 2SLS, 2SLS with Fixed Effects and EC2SLS
}

\author{
B.1 2SLS estimation \\ ' 2SLS regression \\ ' load the data \\ open c:Imyfiles $187-95-d a t a 2 . w f 1$ \\ scalar $\mathrm{N}=28$ \\ scalar $\mathrm{T}=9$ \\ !NT $=\mathrm{N}^{*} \mathrm{~T}$
}

smpl 1 !NT

'Create a group of instruments for the model to be estimated

' $X s, \quad X=$ instruments

group x0 $\log (\mathrm{l}) \log (\mathrm{k}) \log (\mathrm{soe}) \log (\mathrm{c}) \log (\mathrm{pd}) \log (\mathrm{tax}) \log (\mathrm{er}) \log (\mathrm{ti}) \log (\mathrm{pgdp} 1) \log (\mathrm{rmt}) \log (\mathrm{ed})$ $\log (\text { tn })^{\star} \log ($ tp) $\log (\mathrm{cfdi1}) \log (\mathrm{s} 1) \log (\mathrm{v}) \log (\mathrm{n})$

group xs $\log (\mathrm{l}) \log (\mathrm{k}) \log (\mathrm{soe}) \log (\mathrm{c}) \log (\mathrm{pd}) \log (\mathrm{tax}) \log (\mathrm{er}) \log (\mathrm{ti}) \log (\mathrm{pgdp} 1) \log (\mathrm{rmt}) \log (\mathrm{ed})$ $\log (\mathrm{tn})^{\star} \log (\mathrm{tp}) \log (\mathrm{cfdi1}) \log (\mathrm{s} 1) \log (\mathrm{v}) \log (\mathrm{n}) \mathrm{d} d \mathrm{t}$

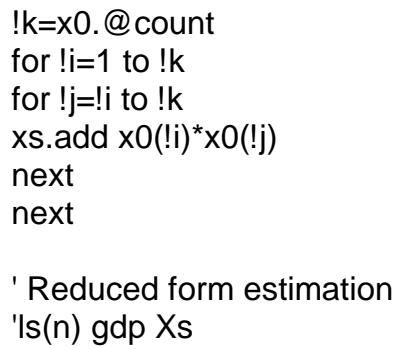




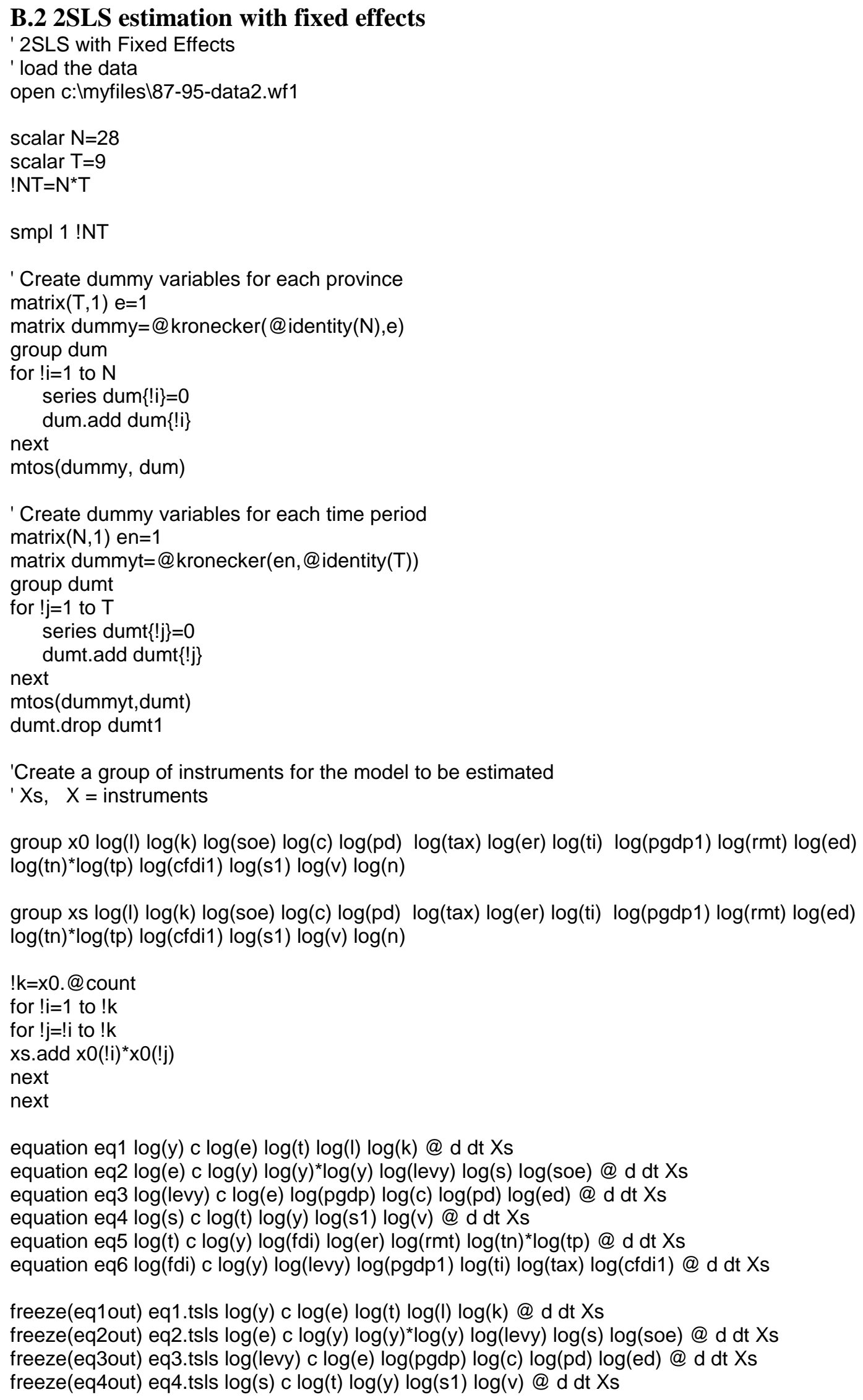


freeze(eq5out) eq5.tsls $\log (\mathrm{t}) \mathrm{c} \log (\mathrm{y}) \log (\mathrm{fdi}) \log (\mathrm{er}) \log (\mathrm{rmt}) \log (\mathrm{tn})^{\star} \log (\mathrm{tp})$ @ d dt Xs

freeze(eq6out) eq6.tsls log(fdi) c log(y) $\log ($ levy) $\log$ (pgdp1) $\log ($ ti) $\log (\operatorname{tax}) \log ($ cfdi1) @ d dt Xs

show qu1out

show qu2out

show qu3out

show qu4out

show qu5out

show qu6out

stop

\section{B.3 2SLS estimation with random effects (EC2SLS)}

' EC2SLS using transformed data

' load the data

open c:Imyfiles|87-95-data2.wf1

scalar $\mathrm{N}=28$

scalar $\mathrm{T}=9$

!NT $=\mathrm{N}^{*} \mathrm{~T}$

smpl 1 !NT

'Create the groups and matrices for the model to be estimated

' ydep, $y=$ dependent variables

' Ws, $W=$ RHS variables

' $X s, \quad X=$ instruments

' $Z s, \quad Z=$ instruments that are not RHS variables

' Compute various matrices needed

$\operatorname{matrix}(T, 1) \mathrm{e}=1$

$\operatorname{matrix}(\mathrm{N}, 1)$ en $=1$

matrix Abar=@kronecker(@identity $(\mathrm{N}) / \mathrm{T}, \mathrm{e}^{\star} @$ transpose $\left.(\mathrm{e})\right)$

matrix Dbar=@kronecker(en*@transpose(en), @identity $(\mathrm{T}) / \mathrm{N})$

scalar oneont $=1 /$ !NT

sym(!NT) Jbar=oneont

' Form the matrices $\mathrm{C}_{1}{ }^{*} \mathrm{C} 1$ ', $\mathrm{C} 2{ }^{*} \mathrm{C} 2$ ', $\mathrm{C}^{*}{ }^{*} 3^{\prime}$

matrix ccp1=Abar-Jbar

matrix ccp2=Dbar-Jbar

matrix ccp3=@identity $($ NT)-ccp1-Dbar

' Remove the means from all variables

' Loop over the series names

for \%var y e levy s t fdi cfdi1 I k soe tax er ti c pd pgdp1 rmt ed $n$ s1 v pgdp

series $\mathrm{t}\{\% \mathrm{var}\}=\log (\% \mathrm{var})$-@mean(log(\%var $))$

next

series ttarif $=\log (\mathrm{tn})^{*} \log (\mathrm{tp})-@ m e a n\left(\log (\mathrm{tn})^{*} \log (\mathrm{tp})\right)$

series ty2 $=\log (\mathrm{y})^{\star} \log (\mathrm{y})-@ m e a n\left(\log (\mathrm{y})^{\star} \log (\mathrm{y})\right)$

group $x 0 \log (\mathrm{l}) \log (\mathrm{k}) \log (\mathrm{soe}) \log (\mathrm{c}) \log (\mathrm{pd}) \log (\mathrm{tax}) \log (\mathrm{er}) \log (\mathrm{ti}) \log (\mathrm{pgdp} 1) \log (\mathrm{rmt}) \log (\mathrm{ed})$ $\log (\mathrm{tn})^{\star} \log (\mathrm{tp}) \log (\mathrm{cfdi1}) \log (\mathrm{s} 1) \log (\mathrm{v}) \log (\mathrm{n})$

group $x 1$

!k=x0.@count 


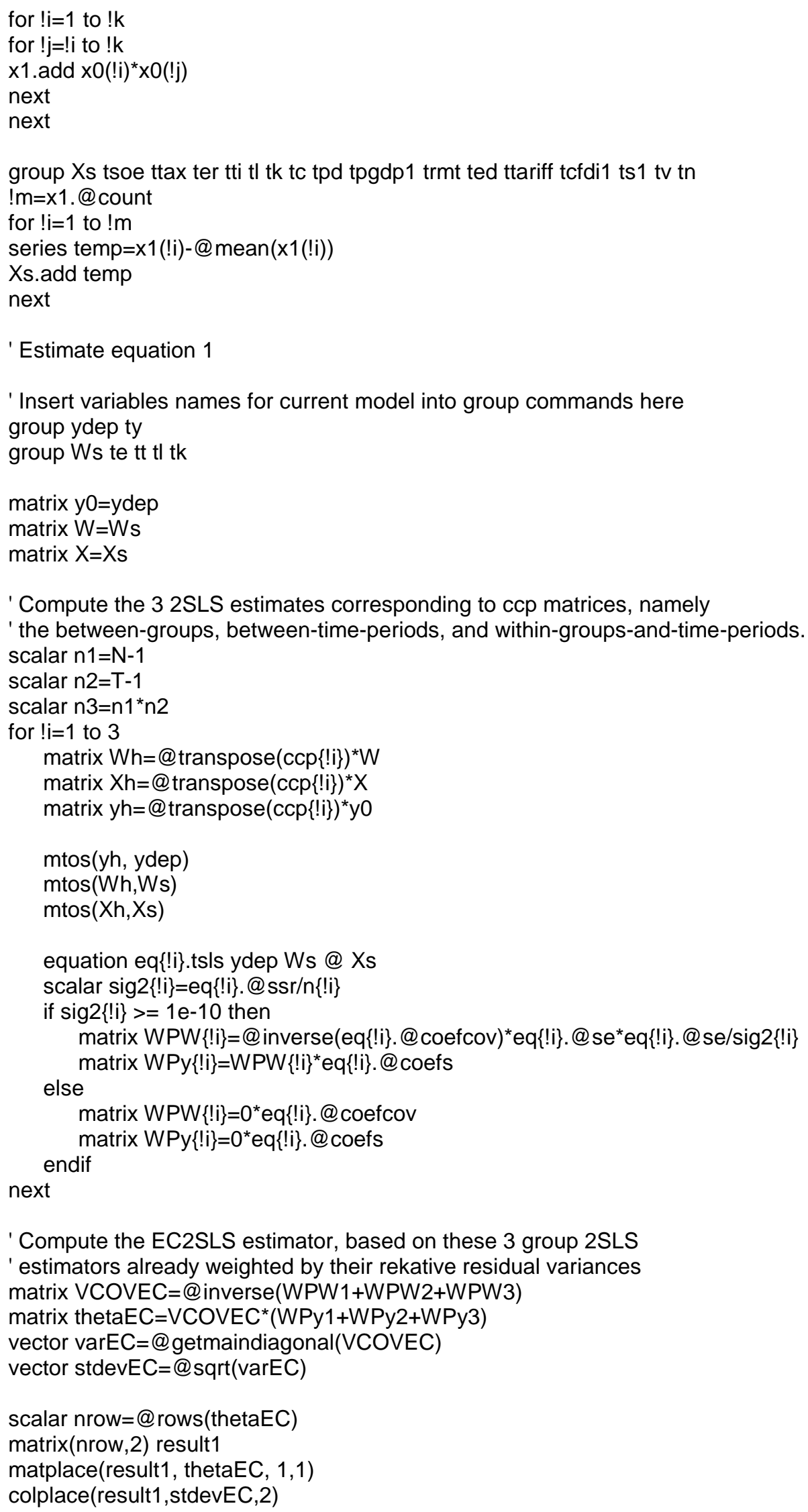

' Compute the EC2SLS estimator, based on these 3 group 2SLS

' estimators already weighted by their rekative residual variances matrix VCOVEC=@inverse(WPW1+WPW2+WPW3)

matrix thetaEC $=$ VCOVEC* ${ }^{*}$ WPy1+WPy2+WPy3)

vector varEC=@getmaindiagonal(VCOVEC)

vector stdevEC=@sqrt(varEC)

scalar nrow=@rows(thetaEC)

matrix (nrow,2) result1

matplace(result1, thetaEC, 1,1)

colplace(result1, stdevEC,2) 
result1.displayname EC2SLS Estimates for eq1

show result1

' Estimate equation 2

' Insert variables names for current model into group commands here group ydep te

group Ws ty ty2 tlevy ts tsoe

matrix y0=ydep

matrix $\mathrm{W}=\mathrm{Ws}$

matrix $\mathrm{X}=\mathrm{Xs}$

' Compute the 3 2SLS estimates corresponding to ccp matrices, namely

' the between-groups, between-time-periods, and within-groups-and-time-periods.

scalar $\mathrm{n} 1=\mathrm{N}-1$

scalar $\mathrm{n} 2=\mathrm{T}-1$

scalar $\mathrm{n} 3=\mathrm{n} 1{ }^{*} \mathrm{n} 2$

for $! i=1$ to 3

matrix Wh=@transpose $(\operatorname{ccp}\{! i\})^{*} \mathrm{~W}$

matrix Xh=@transpose $(\operatorname{ccp}\{! i\})^{*} \mathrm{X}$

matrix $y h=@$ transpose $(\operatorname{ccp}\{! i\})^{*} y 0$

mtos(yh, ydep)

mtos(Wh,Ws)

$\operatorname{mtos}(\mathrm{Xh}, \mathrm{Xs})$

equation eq\{!i\}.tsls ydep Ws @ Xs

scalar sig2 $\{! i\}=e q\{! i\} . @ s s r / n\{! i\}$

if sig2 $\{! i\}>=1 \mathrm{e}-10$ then

matrix WPW $\{! i\}=@$ inverse(eq $\{\text { li\}.@coefcov })^{*} e q\{! i\} . @ s e^{*} e q\{! i\} . @ s e / s i g 2\{l i\}$

else

matrix WPy $\{! i\}=W P W\{! i\}{ }^{*}$ eq $\{$ li\}.@coefs

matrix WPW $\{! i\}=0^{*} e q\{! i\}$ @coefcov

matrix WPy $\{! i\}=0 * e q\{! i\}$ @coefs

endif

next

' Compute the EC2SLS estimator, based on these 3 group 2SLS

' estimators already weighted by their rekative residual variances

matrix VCOVEC=@inverse(WPW1+WPW2+WPW3)

matrix thetaEC $=$ VCOVEC ${ }^{*}(\mathrm{WPy} 1+\mathrm{WPy} 2+\mathrm{WPy} 3)$

vector varEC=@getmaindiagonal(VCOVEC)

vector stdevEC=@sqrt(varEC)

scalar nrow=@rows (thetaEC)

matrix(nrow,2) result2

matplace(result2, thetaEC, 1,1)

colplace(result2,stdevEC,2)

result2.displayname EC2SLS Estimates for eq2

show result2

' Estimate equation 3

' Insert variables names for current model into group commands here

group ydep tlevy

group Ws te tpgdp tc tpd ted 
matrix y0=ydep

matrix $W=W s$

matrix $X=X s$

' Compute the 3 2SLS estimates corresponding to ccp matrices, namely

' the between-groups, between-time-periods, and within-groups-and-time-periods.

scalar $\mathrm{n} 1=\mathrm{N}-1$

scalar $\mathrm{n} 2=\mathrm{T}-1$

scalar $n 3=n 1^{*} n 2$

for $! i=1$ to 3

matrix Wh=@transpose $(\operatorname{ccp}\{! i\})^{*} \mathrm{~W}$

matrix Xh=@transpose $(\operatorname{ccp}\{! i\})^{\star} X$

matrix $y h=@$ transpose $(\operatorname{ccp}\{! i\})^{*} y 0$

mtos(yh, ydep)

mtos(Wh,Ws)

$\operatorname{mtos}(\mathrm{Xh}, \mathrm{Xs})$

equation eq\{!i\}.tsls ydep Ws @Xs

scalar sig2 $\{! i\}=e q\{! i\}$ @ssr $/ \mathrm{n}\{! \mathrm{i}\}$

if sig2 $\{! i\}>=1 \mathrm{e}-10$ then

matrix WPW $\{! i\}=@$ inverse(eq $\{\text { li\}.@coefcov })^{*} e q\{! i\} . @ s e^{*} e q\{! i\} . @ s e / s i g 2\{! i\}$

else matrix WPy $\{! i\}=W P W\{! i\}^{*} e q\{! i\}$ @coefs

matrix WPW $\{! i\}=0^{*} e q\{! i\}$.@coefcov

endif

matrix WPy $\{! i\}=0 *$ eq $\{$ i $\}$ @coefs

next

' Compute the EC2SLS estimator, based on these 3 group 2SLS

' estimators already weighted by their relative residual variances

matrix VCOVEC=@inverse(WPW1+WPW2+WPW3)

matrix thetaEC $=$ VCOVEC $*$ WPy1+WPy2+WPy3)

vector varEC=@getmaindiagonal(VCOVEC)

vector stdevEC=@sqrt(varEC)

scalar nrow=@rows(thetaEC)

matrix (nrow,2) result3

matplace (result3, thetaEC, 1,1)

colplace(result3,stdevEC,2)

result3.displayname EC2SLS Estimates for eq3

show result3

' Estimate equation 4

' Insert variables names for current model into group commands here

group ydep ts

group Ws tt ty ts $1 \mathrm{tv}$

matrix y0=ydep

matrix $W=W s$

matrix $\mathrm{X}=\mathrm{Xs}$

' Compute the 3 2SLS estimates corresponding to ccp matrices, namely

' the between-groups, between-time-periods, and within-groups-and-time-periods. scalar $\mathrm{n} 1=\mathrm{N}-1$

scalar $\mathrm{n} 2=\mathrm{T}-1$ 


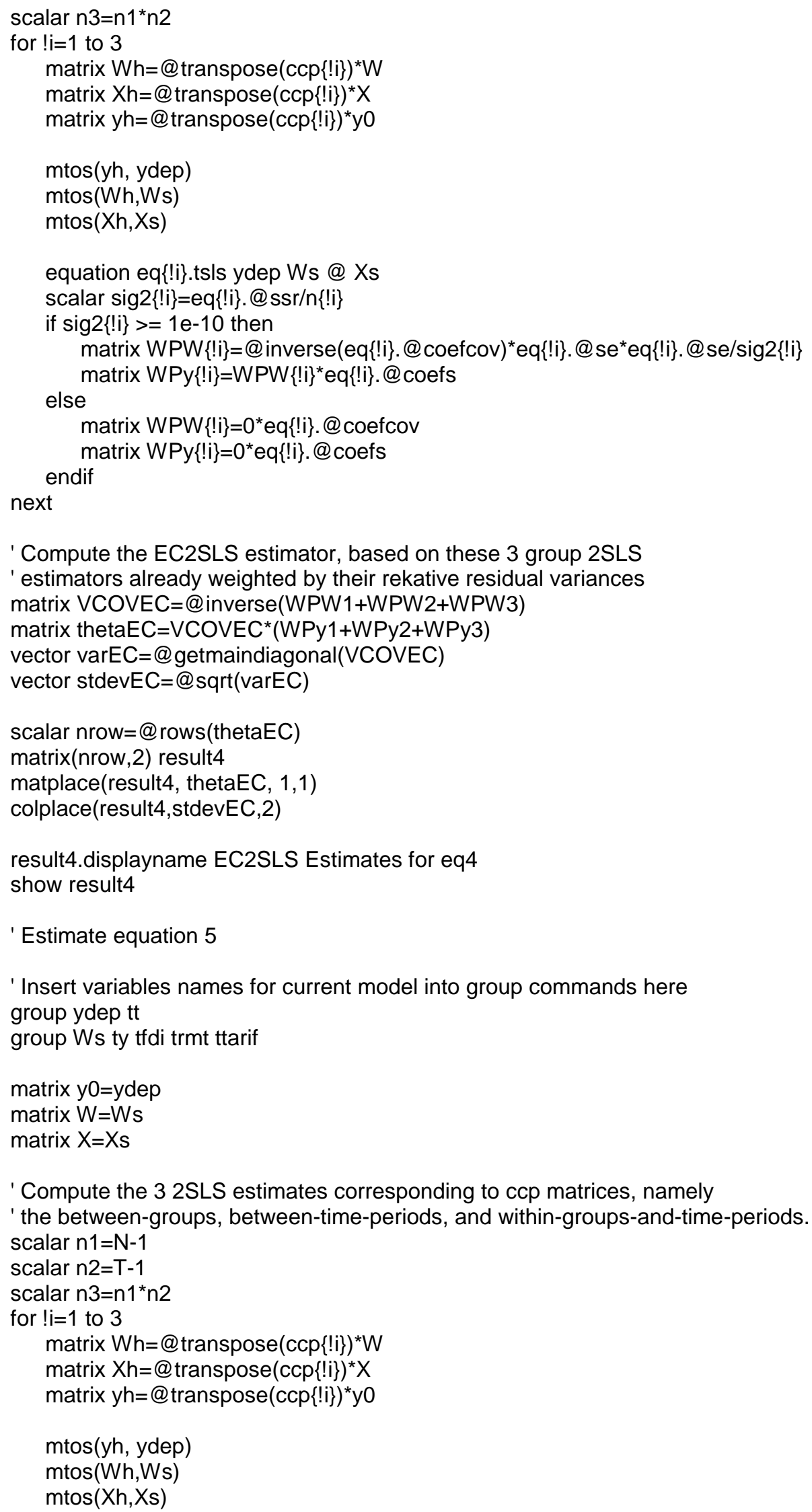

' Compute the 3 2SLS estimates corresponding to ccp matrices, namely ' the between-groups, between-time-periods, and within-groups-and-time-periods. scalar $\mathrm{n} 1=\mathrm{N}-1$ 


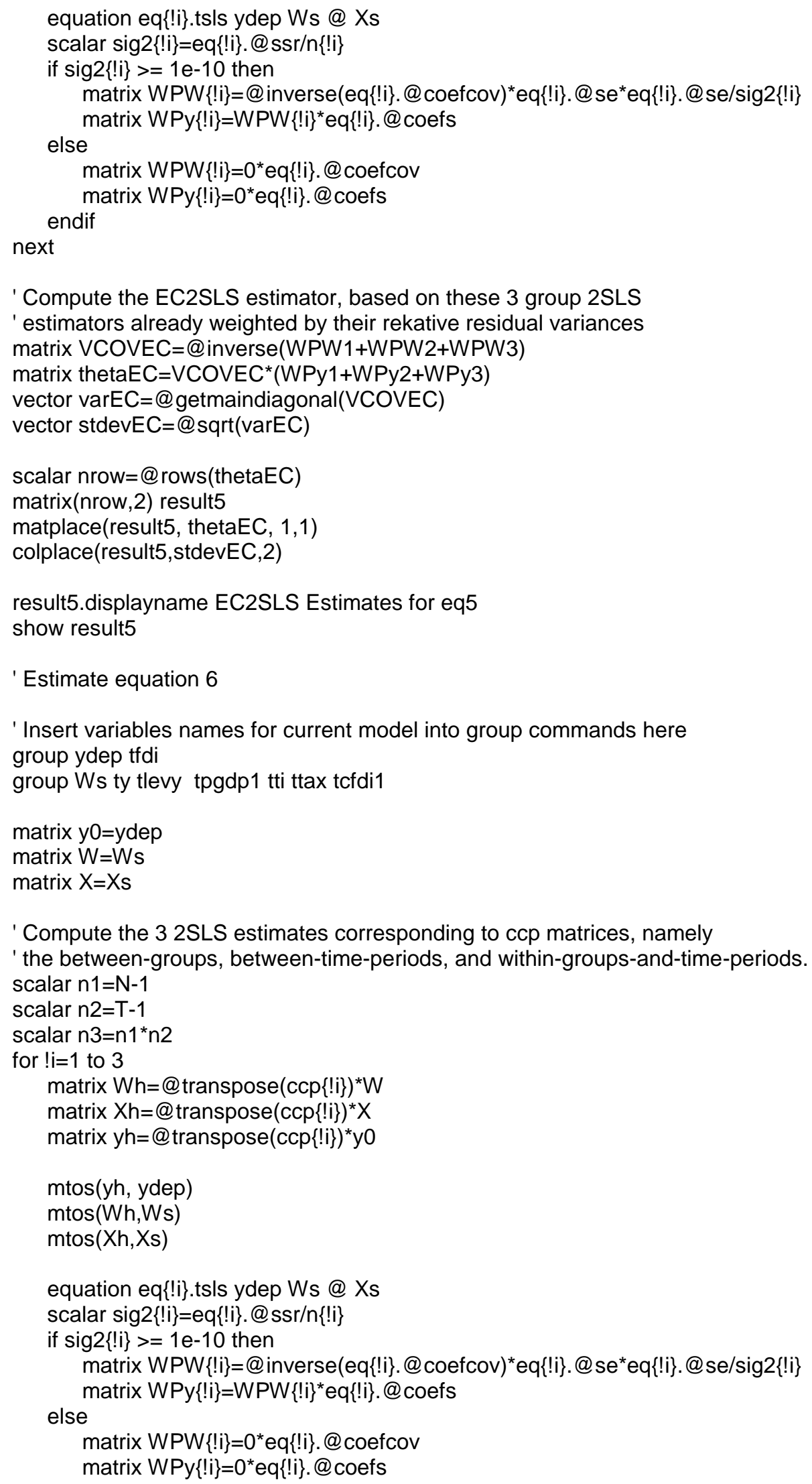




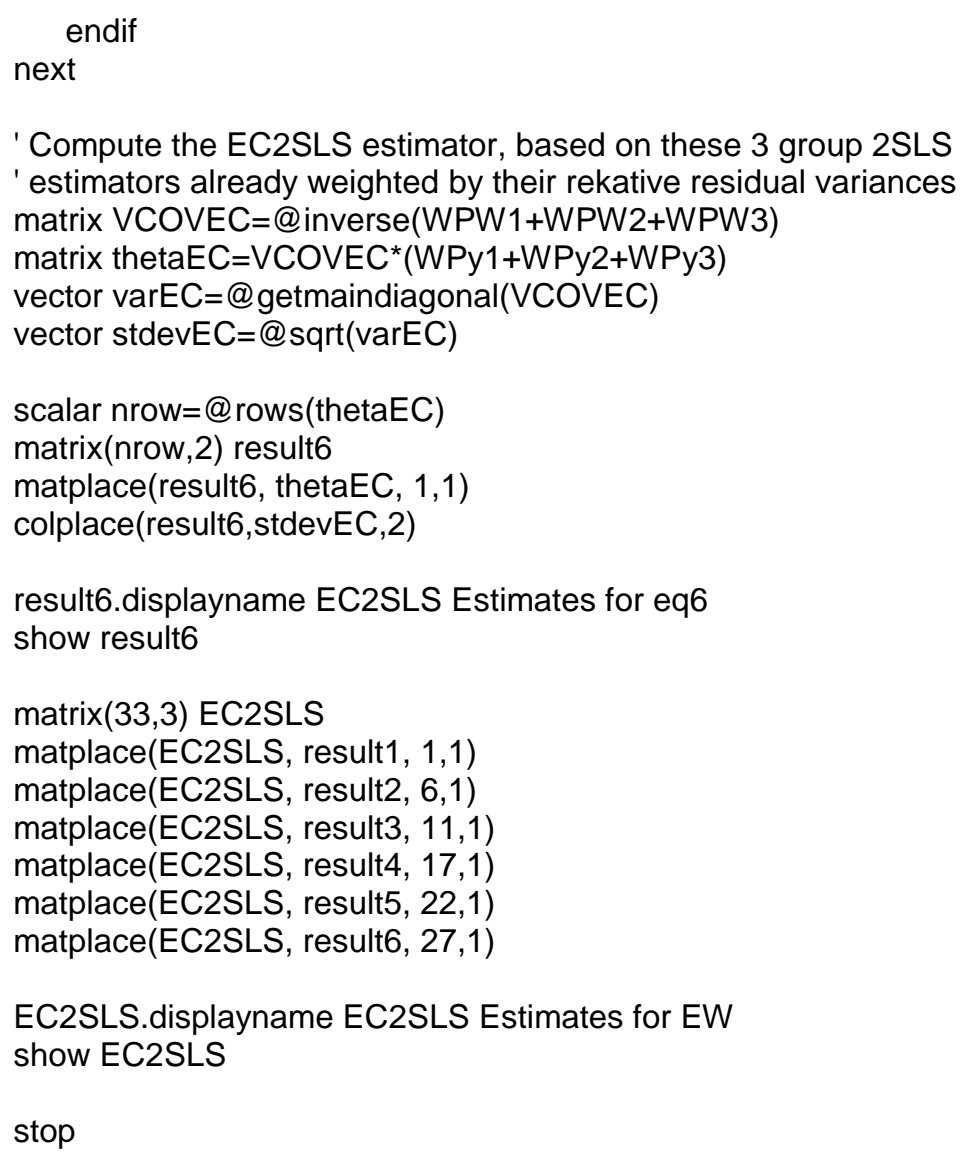




\section{Appendix C: 2SLS Fixed Effects Estimation Results}

Table C-1 2SLS Estimates with Fixed Time and Individual Effects (Industrial Wastewater Case)

\begin{tabular}{|c|c|c|c|c|c|c|}
\hline & \multicolumn{3}{|c|}{ Dependent } & \multicolumn{3}{|c|}{ Variable } \\
\hline & $\begin{array}{c}\text { GDP } \\
(\log Y) \\
(1) \\
\end{array}$ & $\begin{array}{l}\text { IWW } \\
(\log E) \\
(2)\end{array}$ & $\begin{array}{c}\text { Levy rate } \\
\text { on IWW } \\
(\log r) \\
(3)\end{array}$ & $\begin{array}{c}\text { Industrial share } \\
(\log S) \\
(4)\end{array}$ & $\begin{array}{l}\text { Trade } \\
(\log T) \\
(5)\end{array}$ & $\begin{array}{c}\text { FDI } \\
(\log \text { FDI }) \\
(6)\end{array}$ \\
\hline \multicolumn{7}{|l|}{ Constant } \\
\hline $\begin{array}{l}\text { GDP } \\
(\log Y) \\
\end{array}$ & & $\begin{array}{c}1.493 \\
(5.521) \\
\end{array}$ & & $\begin{array}{c}0.064 \\
(1.467) \\
\end{array}$ & $\begin{array}{c}0.977 \\
(6.097) \\
\end{array}$ & $\begin{array}{c}3.558 \\
(1.353) \\
\end{array}$ \\
\hline $\begin{array}{l}\text { GDP Square } \\
\left(\log ^{2} Y\right)\end{array}$ & & $\begin{array}{c}-0.042 \\
(-2.717)\end{array}$ & & & & \\
\hline $\begin{array}{l}\text { Income } \\
(\log (Y / P))\end{array}$ & & & $\begin{array}{c}0.813 \\
(4.215)\end{array}$ & & & \\
\hline $\begin{array}{l}\text { Emissions } \\
(\mathrm{IWW})(\log \mathrm{E})\end{array}$ & $\begin{array}{c}0.149 \\
(2.781) \\
\end{array}$ & & $\begin{array}{c}-0.819 \\
(-4.655) \\
\end{array}$ & & & \\
\hline $\begin{array}{l}\text { Levy Rate on } \\
\text { IWW }(\log r)\end{array}$ & & $\begin{array}{c}-0.154 \\
(-5.226) \\
\end{array}$ & & & & $\begin{array}{c}0.629 \\
(1.536) \\
\end{array}$ \\
\hline $\begin{array}{l}\text { Industrial output } \\
\text { share }(\log S)\end{array}$ & & $\begin{array}{c}0.262 \\
(2.472) \\
\end{array}$ & & & & \\
\hline $\begin{array}{l}\text { Trade } \\
(\log T)\end{array}$ & $\begin{array}{c}0.101 \\
(3.626) \\
\end{array}$ & & & $\begin{array}{c}0.012 \\
(0.859) \\
\end{array}$ & & \\
\hline $\begin{array}{l}\text { FDI } \\
(\log \text { FDI })\end{array}$ & & & & & $\begin{array}{c}0.004 \\
(0.322) \\
\end{array}$ & \\
\hline $\begin{array}{l}\begin{array}{l}\text { Labor } \\
(\log L)\end{array} \\
\end{array}$ & $\begin{array}{c}0.064 \\
(0.372) \\
\end{array}$ & & & & & \\
\hline $\begin{array}{l}\text { Capital } \\
(\log K) \\
\end{array}$ & $\begin{array}{c}0.463 \\
(6.539) \\
\end{array}$ & & & & & \\
\hline $\begin{array}{l}\text { State-owned } \\
\text { Enterprises } \\
\text { (log SOE) }\end{array}$ & & $\begin{array}{c}0.405 \\
(6.302)\end{array}$ & & & & \\
\hline $\begin{array}{l}\text { Citizen } \\
\text { Complaints } \\
\text { (log C) }\end{array}$ & & & $\begin{array}{c}0.035 \\
(1.204)\end{array}$ & & & \\
\hline $\begin{array}{l}\text { Education } \\
\text { (log ed) }\end{array}$ & & & $\begin{array}{c}0.295 \\
(1.314)\end{array}$ & & & \\
\hline $\begin{array}{l}\text { Population } \\
\text { Density } \\
\text { (log PD) }\end{array}$ & & & $\begin{array}{c}3.709 \\
(3.345)\end{array}$ & & & \\
\hline $\begin{array}{l}\text { Industrial } \\
\text { Share }_{-1} \\
\left(\log S_{-1}\right)\end{array}$ & & & & $\begin{array}{c}0.863 \\
(20.571)\end{array}$ & & \\
\hline $\begin{array}{l}\text { Investments } \\
(\log \mathrm{V})\end{array}$ & & & & $\begin{array}{c}0.018 \\
(1.090) \\
\end{array}$ & & \\
\hline $\begin{array}{l}\text { Remoteness } \\
(\log R)\end{array}$ & & & & & $\begin{array}{c}-0.099 \\
(-1.422) \\
\end{array}$ & \\
\hline \multicolumn{7}{|l|}{$\begin{array}{l}\text { Exchange rate } \\
(\log E \text { R) }\end{array}$} \\
\hline $\begin{array}{l}\text { Tariffs } \\
(\log T N * \log T P)\end{array}$ & & & & & $\begin{array}{c}0.152 \\
(1.716) \\
\end{array}$ & \\
\hline $\begin{array}{l}\text { Cumulative FDI } \\
\left(\log \mathrm{CFDI}_{-1}\right)\end{array}$ & & & & & & $\begin{array}{c}-0.205 \\
(-1.954) \\
\end{array}$ \\
\hline $\begin{array}{l}\text { Road intensity } \\
(\log T I)\end{array}$ & & & & & & $\begin{array}{c}-1.483 \\
(-0.836) \\
\end{array}$ \\
\hline $\begin{array}{l}\text { Tax rate } \\
(\log \text { Tax })\end{array}$ & & & & & & $\begin{array}{c}-0.304 \\
(-0.592) \\
\end{array}$ \\
\hline $\begin{array}{l}\text { GDP per capita } \\
\left(\log _{\text {PGDP }} \text { ) }\right.\end{array}$ & & & & & & $\begin{array}{c}-4.010 \\
(-1.476) \\
\end{array}$ \\
\hline \multicolumn{7}{|l|}{$\begin{array}{l}\text { Regional } \\
\text { Dummy D }\end{array}$} \\
\hline \multicolumn{7}{|l|}{$\begin{array}{l}\text { Time Dummy } \\
\text { DT }\end{array}$} \\
\hline Adjusted $\mathrm{R}^{2}$ & 0.996 & 0.994 & 0.816 & 0.980 & 0.988 & 0.862 \\
\hline Observations & 252 & 252 & 252 & 252 & 252 & 252 \\
\hline
\end{tabular}


Table C-2 2SLS Estimates with Fixed Individual Effects (Industrial Wastewater Case)

\begin{tabular}{|c|c|c|c|c|c|c|}
\hline & \multicolumn{3}{|c|}{ Dependent } & \multicolumn{3}{|c|}{ Variable } \\
\hline & $\begin{array}{c}\text { GDP } \\
(\log Y) \\
(1)\end{array}$ & $\begin{array}{l}\text { IWW } \\
(\log E) \\
(2)\end{array}$ & $\begin{array}{c}\text { Levy rate } \\
\text { on IWW } \\
(\log r) \\
(3)\end{array}$ & $\begin{array}{c}\text { Industrial share } \\
(\log S) \\
(4)\end{array}$ & $\begin{array}{c}\text { Trade } \\
(\log \mathrm{T}) \\
(5)\end{array}$ & $\begin{array}{c}\text { FDI } \\
(\log \text { FDI }) \\
(6)\end{array}$ \\
\hline \multicolumn{7}{|l|}{ Constant } \\
\hline $\begin{array}{l}\text { GDP } \\
(\log Y)\end{array}$ & & $\begin{array}{c}-0.738 \\
(-3.691) \\
\end{array}$ & & $\begin{array}{l}0.020 \\
(0.771) \\
\end{array}$ & $\begin{array}{l}1.216 \\
(9.110) \\
\end{array}$ & $\begin{array}{c}8.402 \\
(4.846) \\
\end{array}$ \\
\hline $\begin{array}{l}\text { GDP Square } \\
\left(\log ^{2} Y\right)\end{array}$ & & $\begin{array}{c}0.041 \\
(2.533) \\
\end{array}$ & & & & \\
\hline $\begin{array}{l}\text { Income } \\
(\log (Y / P))\end{array}$ & & & $\begin{array}{c}0.120 \\
(1.076)\end{array}$ & & & \\
\hline $\begin{array}{l}\text { Emissions } \\
(\mathrm{IWW})(\log \mathrm{E})\end{array}$ & $\begin{array}{c}0.137 \\
(2.091) \\
\end{array}$ & & $\begin{array}{c}-0.526 \\
(-3.279) \\
\end{array}$ & & & \\
\hline $\begin{array}{l}\text { Levy Rate on } \\
\text { IWW (log r) }\end{array}$ & & $\begin{array}{c}-0.138 \\
(-4.034)\end{array}$ & & & & $\begin{array}{c}0.036 \\
(0.081)\end{array}$ \\
\hline $\begin{array}{l}\text { Industrial output } \\
\text { share }(\log S)\end{array}$ & & $\begin{array}{c}0.505 \\
(3.973) \\
\end{array}$ & & & & \\
\hline $\begin{array}{l}\text { Trade } \\
(\log T)\end{array}$ & $\begin{array}{c}0.328 \\
(11.907)\end{array}$ & & & $\begin{array}{c}0.006 \\
(0.387)\end{array}$ & & \\
\hline $\begin{array}{l}\text { FDI } \\
(\log \text { FDI) }\end{array}$ & & & & & $\begin{array}{c}0.018 \\
(1.622)\end{array}$ & \\
\hline $\begin{array}{l}\text { Labor } \\
(\log L)\end{array}$ & $\begin{array}{c}-0.004 \\
(-0.020) \\
\end{array}$ & & & & & \\
\hline $\begin{array}{l}\text { Capital } \\
(\log K)\end{array}$ & $\begin{array}{c}0.243 \\
(10.348) \\
\end{array}$ & & & & & \\
\hline $\begin{array}{l}\text { State-owned } \\
\text { Enterprises } \\
\text { (log SOE) }\end{array}$ & & $\begin{array}{c}0.210 \\
(2.833)\end{array}$ & & & & \\
\hline $\begin{array}{l}\text { Citizen } \\
\text { Complaints } \\
(\log C)\end{array}$ & & & $\begin{array}{c}0.013 \\
(0.415)\end{array}$ & & & \\
\hline $\begin{array}{l}\text { Education } \\
(\log \text { ed) }\end{array}$ & & & $\begin{array}{c}0.412 \\
(1.820)\end{array}$ & & & \\
\hline $\begin{array}{l}\text { Population } \\
\text { Density } \\
(\log \text { PD) }\end{array}$ & & & $\begin{array}{c}-0.209 \\
(-0.290)\end{array}$ & & & \\
\hline $\begin{array}{l}\text { Industrial } \\
\text { Share }_{-1} \\
\left(\log S_{-1}\right)\end{array}$ & & & & $\begin{array}{c}0.797 \\
(19.773)\end{array}$ & & \\
\hline $\begin{array}{l}\text { Investments } \\
(\log V)\end{array}$ & & & & $\begin{array}{c}0.059 \\
(4.239) \\
\end{array}$ & & \\
\hline $\begin{array}{l}\text { Remoteness } \\
(\log R)\end{array}$ & & & & & $\begin{array}{c}-0.053 \\
(-0.952) \\
\end{array}$ & \\
\hline \multicolumn{7}{|l|}{$\begin{array}{l}\text { Exchange rate } \\
(\log E \text { E) }\end{array}$} \\
\hline $\begin{array}{l}\text { Tariffs } \\
(\log T N * \log T P)\end{array}$ & & & & & $\begin{array}{c}-0.020 \\
(-0.739) \\
\end{array}$ & \\
\hline $\begin{array}{l}\text { Cumulative FDI } \\
\left(\log C I_{-1}\right)\end{array}$ & & & & & & $\begin{array}{c}-0.185 \\
(-1.851)\end{array}$ \\
\hline $\begin{array}{l}\text { Road intensity } \\
(\log T I)\end{array}$ & & & & & & $\begin{array}{c}-3.726 \\
(-1.934)\end{array}$ \\
\hline $\begin{array}{l}\text { Tax rate } \\
(\log \text { Tax })\end{array}$ & & & & & & $\begin{array}{c}-0.499 \\
(-1.457) \\
\end{array}$ \\
\hline $\begin{array}{l}\text { GDP per capita } \\
\left(\log _{\text {PGDP }}\right)\end{array}$ & & & & & & $\begin{array}{c}-3.866 \\
(-1.893) \\
\end{array}$ \\
\hline \multicolumn{7}{|l|}{$\begin{array}{l}\text { Regional } \\
\text { Dummy D }\end{array}$} \\
\hline \multicolumn{7}{|l|}{$\begin{array}{l}\text { Time Dummy } \\
\text { DT }\end{array}$} \\
\hline Adjusted $\mathrm{R}^{2}$ & 0.992 & 0.990 & 0.785 & 0.973 & 0.987 & 0.829 \\
\hline Observations & 252 & 252 & 252 & 252 & 252 & 252 \\
\hline
\end{tabular}


Table C-3 2SLS Estimates with Fixed Time Effects (Industrial Wastewater Case)

\begin{tabular}{|c|c|c|c|c|c|c|}
\hline & \multicolumn{3}{|c|}{ Dependent } & \multicolumn{3}{|c|}{ Variable } \\
\hline & $\begin{array}{c}\text { GDP } \\
(\log Y) \\
(1)\end{array}$ & $\begin{array}{c}\text { IWW } \\
(\log E) \\
(2)\end{array}$ & $\begin{array}{c}\text { Levy rate } \\
\text { on IWW } \\
(\log r) \\
\text { (3) }\end{array}$ & $\begin{array}{c}\text { Industrial share } \\
(\log S) \\
(4)\end{array}$ & $\begin{array}{c}\text { Trade } \\
(\log \mathrm{T}) \\
(5)\end{array}$ & $\begin{array}{c}\text { FDI } \\
(\log \text { FDI }) \\
(6)\end{array}$ \\
\hline \multicolumn{7}{|l|}{ Constant } \\
\hline $\begin{array}{l}\text { GDP } \\
(\log Y)\end{array}$ & & $\begin{array}{c}2.239 \\
(9.560) \\
\end{array}$ & & $\begin{array}{c}0.003 \\
(0.320) \\
\end{array}$ & $\begin{array}{c}0.670 \\
(10.328) \\
\end{array}$ & $\begin{array}{c}1.065 \\
(7.028) \\
\end{array}$ \\
\hline $\begin{array}{l}\text { GDP Square } \\
\left(\log ^{2} Y\right)\end{array}$ & & $\begin{array}{c}-0.087 \\
(-4.410)\end{array}$ & & & & \\
\hline $\begin{array}{l}\text { Income } \\
(\log (\mathrm{Y} / \mathrm{P}))\end{array}$ & & & $\begin{array}{c}0.349 \\
(5.102) \\
\end{array}$ & & & \\
\hline $\begin{array}{l}\text { Emissions } \\
\text { (IWW) (log E) }\end{array}$ & $\begin{array}{c}0.092 \\
(5.820)\end{array}$ & & $\begin{array}{c}-0.047 \\
(-1.359) \\
\end{array}$ & & & \\
\hline $\begin{array}{l}\text { Levy Rate on } \\
\text { IWW }(\log r)\end{array}$ & & $\begin{array}{c}-0.624 \\
(-11.573)\end{array}$ & & & & $\begin{array}{c}0.530 \\
(2.361)\end{array}$ \\
\hline $\begin{array}{l}\text { Industrial output } \\
\text { share }(\log S)\end{array}$ & & $\begin{array}{c}0.200 \\
(1.874)\end{array}$ & & & & \\
\hline $\begin{array}{l}\text { Trade } \\
(\log T)\end{array}$ & $\begin{array}{c}0.092 \\
(9.266)\end{array}$ & & & $\begin{array}{c}0.005 \\
(1.425) \\
\end{array}$ & & \\
\hline $\begin{array}{l}\text { FDI } \\
(\log \text { FDI })\end{array}$ & & & & & $\begin{array}{c}0.150 \\
(5.041) \\
\end{array}$ & \\
\hline $\begin{array}{l}\text { Labor } \\
(\log \mathrm{L})\end{array}$ & $\begin{array}{c}0.315 \\
(21.630)\end{array}$ & & & & & \\
\hline $\begin{array}{l}\text { Capital } \\
(\log K)\end{array}$ & $\begin{array}{c}0.551 \\
(25.574) \\
\end{array}$ & & & & & \\
\hline $\begin{array}{l}\text { State-owned } \\
\text { Enterprises } \\
\text { (log SOE) }\end{array}$ & & $\begin{array}{c}0.123 \\
(1.529)\end{array}$ & & & & \\
\hline $\begin{array}{l}\text { Citizen } \\
\text { Complaints } \\
(\log C)\end{array}$ & & & $\begin{array}{c}-0.172 \\
(-3.843)\end{array}$ & & & \\
\hline $\begin{array}{l}\text { Education } \\
(\log \text { ed })\end{array}$ & & & $\begin{array}{c}-0.323 \\
(-3.718) \\
\end{array}$ & & & \\
\hline $\begin{array}{l}\text { Population } \\
\text { Density } \\
\text { (log PD) }\end{array}$ & & & $\begin{array}{c}0.109 \\
(4.109)\end{array}$ & & & \\
\hline $\begin{array}{l}\text { Industrial } \\
\text { Share }_{-1} \\
\left(\log \mathrm{S}_{-1}\right)\end{array}$ & & & & $\begin{array}{c}0.919 \\
(79.656)\end{array}$ & & \\
\hline $\begin{array}{l}\text { Investments } \\
(\log V)\end{array}$ & & & & $\begin{array}{c}0.003 \\
(0.299) \\
\end{array}$ & & \\
\hline $\begin{array}{l}\text { Remoteness } \\
(\log R)\end{array}$ & & & & & $\begin{array}{c}-0.745 \\
(-11.438) \\
\end{array}$ & \\
\hline \multicolumn{7}{|l|}{$\begin{array}{l}\text { Exchange rate } \\
(\log E R)\end{array}$} \\
\hline $\begin{array}{l}\text { Tariffs } \\
(\operatorname{LogTN} * \log \mathrm{TP})\end{array}$ & & & & & $\begin{array}{c}0.021 \\
(0.314)\end{array}$ & \\
\hline $\begin{array}{l}\text { Cumulative FDI } \\
\left(\log \text { CFDI }_{-1}\right)\end{array}$ & & & & & & $\begin{array}{c}0.322 \\
(5.208)\end{array}$ \\
\hline $\begin{array}{l}\text { Road intensity } \\
(\log T I)\end{array}$ & & & & & & $\begin{array}{c}0.739 \\
(6.201)\end{array}$ \\
\hline $\begin{array}{l}\text { Tax rate } \\
(\log \text { Tax })\end{array}$ & & & & & & $\begin{array}{c}0.158 \\
(0.506)\end{array}$ \\
\hline $\begin{array}{l}\text { GDP per capita } \\
\left(\log \text { PGDP }_{-1}\right)\end{array}$ & & & & & & $\begin{array}{c}0.293 \\
(1.361) \\
\end{array}$ \\
\hline \multicolumn{7}{|l|}{$\begin{array}{l}\text { Regional } \\
\text { Dummy D }\end{array}$} \\
\hline \multicolumn{7}{|l|}{$\begin{array}{l}\text { Time Dummy } \\
\text { DT }\end{array}$} \\
\hline Adjusted $\mathrm{R}^{2}$ & 0.990 & 0.900 & 0.370 & 0.978 & 0.877 & 0.814 \\
\hline Observations & 252 & 252 & 252 & $\begin{array}{l}252 \\
\end{array}$ & $\begin{array}{l}252 \\
\end{array}$ & $\begin{array}{c}251+ \\
252\end{array}$ \\
\hline
\end{tabular}


Table C-4 2SLS Estimates with Fixed Time and Individual Effects (Industrial Gas Emissions (IGE) Case)

\begin{tabular}{|c|c|c|c|c|c|c|}
\hline & \multicolumn{3}{|c|}{ Dependent } & \multicolumn{3}{|c|}{ Variable } \\
\hline & $\begin{array}{c}\text { GDP } \\
(\log Y) \\
(1)\end{array}$ & $\begin{array}{c}\text { IGE } \\
(\log E) \\
(2)\end{array}$ & $\begin{array}{c}\text { Levy rate } \\
\text { on IGE } \\
(\log r) \\
\text { (3) }\end{array}$ & $\begin{array}{c}\text { Industrial share } \\
(\log S) \\
(4)\end{array}$ & $\begin{array}{c}\text { Trade } \\
(\log \mathrm{T}) \\
(5)\end{array}$ & $\begin{array}{c}\text { FDI } \\
(\log \text { FDI }) \\
(6)\end{array}$ \\
\hline \multicolumn{7}{|l|}{ Constant } \\
\hline $\begin{array}{l}\text { GDP } \\
(\log Y)\end{array}$ & & $\begin{array}{c}2.247 \\
(3.934) \\
\end{array}$ & & $\begin{array}{c}0.064 \\
(1.467) \\
\end{array}$ & $\begin{array}{c}0.977 \\
(6.097)\end{array}$ & $\begin{array}{c}4.487 \\
(1.734)\end{array}$ \\
\hline $\begin{array}{l}\text { GDP Square } \\
\left(\log ^{2} Y\right)\end{array}$ & & $\begin{array}{c}-0.101 \\
(-3.150)\end{array}$ & & & & \\
\hline $\begin{array}{l}\text { Income } \\
(\log (Y / P))\end{array}$ & & & $\begin{array}{c}1.780 \\
(6.948) \\
\end{array}$ & & & \\
\hline $\begin{array}{l}\text { Emissions } \\
(\mathrm{IGE})(\log \mathrm{E})\end{array}$ & $\begin{array}{c}0.078 \\
(3.110) \\
\end{array}$ & & $\begin{array}{c}-0.872 \\
(-7.371) \\
\end{array}$ & & & \\
\hline $\begin{array}{l}\text { Levy Rate on } \\
\text { IGE }(\log r)\end{array}$ & & $\begin{array}{c}-0.291 \\
(-7.058)\end{array}$ & & & & $\begin{array}{c}-0.020 \\
(-0.072)\end{array}$ \\
\hline $\begin{array}{l}\text { Industrial output } \\
\text { share }(\log S)\end{array}$ & & $\begin{array}{c}0.329 \\
(1.484) \\
\end{array}$ & & & & \\
\hline $\begin{array}{l}\text { Trade } \\
(\log T)\end{array}$ & $\begin{array}{c}0.091 \\
(3.269) \\
\end{array}$ & & & $\begin{array}{c}0.012 \\
(0.859) \\
\end{array}$ & & \\
\hline $\begin{array}{l}\text { FDI } \\
(\log \text { FDI })\end{array}$ & & & & & $\begin{array}{c}0.004 \\
(0.322)\end{array}$ & \\
\hline $\begin{array}{l}\text { Labor } \\
(\log L) \\
\end{array}$ & $\begin{array}{c}0.067 \\
(0.396) \\
\end{array}$ & & & & & \\
\hline $\begin{array}{l}\text { Capital } \\
(\log K)\end{array}$ & $\begin{array}{c}0.513 \\
(7.641)\end{array}$ & & & & & \\
\hline $\begin{array}{l}\text { State-owned } \\
\text { Enterprises } \\
\text { (log SOE) }\end{array}$ & & $\begin{array}{c}-0.151 \\
(-1.110)\end{array}$ & & & & \\
\hline $\begin{array}{l}\text { Citizen } \\
\text { Complaints } \\
\text { (log C) }\end{array}$ & & & $\begin{array}{c}0.085 \\
(2.142)\end{array}$ & & & \\
\hline $\begin{array}{l}\begin{array}{l}\text { Education } \\
\text { (log ed) }\end{array} \\
\end{array}$ & & & $\begin{array}{c}0.158 \\
(0.515) \\
\end{array}$ & & & \\
\hline $\begin{array}{l}\text { Population } \\
\text { Density } \\
\text { (log PD) }\end{array}$ & & & $\begin{array}{c}6.389 \\
(4.107)\end{array}$ & & & \\
\hline $\begin{array}{l}\text { Industrial } \\
\text { Share } \\
\left(\log S_{-1}\right)\end{array}$ & & & & $\begin{array}{c}0.863 \\
(20.571)\end{array}$ & & \\
\hline $\begin{array}{l}\text { Investments } \\
(\log V)\end{array}$ & & & & $\begin{array}{c}0.018 \\
(1.090) \\
\end{array}$ & & \\
\hline $\begin{array}{l}\text { Remoteness } \\
(\log R)\end{array}$ & & & & & $\begin{array}{c}-0.099 \\
(-1.422) \\
\end{array}$ & \\
\hline \multicolumn{7}{|l|}{$\begin{array}{l}\text { Exchange rate } \\
(\log E \text { E })\end{array}$} \\
\hline $\begin{array}{l}\text { Tariffs } \\
(\log T N * \log \mathrm{TP})\end{array}$ & & & & & $\begin{array}{c}0.152 \\
(1.716) \\
\end{array}$ & \\
\hline $\begin{array}{l}\text { Cumulative FDI } \\
\left(\log \text { CFDI }_{-1}\right)\end{array}$ & & & & & & $\begin{array}{c}-0.235 \\
(-2.267) \\
\end{array}$ \\
\hline $\begin{array}{l}\text { Road intensity } \\
(\log T I)\end{array}$ & & & & & & $\begin{array}{c}-1.732 \\
(-0.977) \\
\end{array}$ \\
\hline $\begin{array}{l}\text { Tax rate } \\
(\log \text { Tax })\end{array}$ & & & & & & $\begin{array}{c}-0.268 \\
(-0.521) \\
\end{array}$ \\
\hline $\begin{array}{l}\text { GDP per capita } \\
\left(\log _{\text {PGDP }}\right)\end{array}$ & & & & & & $\begin{array}{c}-4.511 \\
(-1.671) \\
\end{array}$ \\
\hline \multicolumn{7}{|l|}{$\begin{array}{l}\text { Regional } \\
\text { Dummy D }\end{array}$} \\
\hline \multicolumn{7}{|l|}{$\begin{array}{l}\text { Time Dummy } \\
\text { DT }\end{array}$} \\
\hline Adjusted $\mathrm{R}^{2}$ & 0.996 & 0.957 & 0.691 & 0.980 & 0.988 & 0.861 \\
\hline Observations & 252 & 252 & 252 & 252 & 252 & 252 \\
\hline
\end{tabular}


Table C-5 2SLS Estimates with Fixed Individual Effects (Industrial Gas Emissions Case)

\begin{tabular}{|c|c|c|c|c|c|c|}
\hline & \multicolumn{3}{|c|}{ Dependent } & \multicolumn{3}{|c|}{ Variable } \\
\hline & $\begin{array}{c}\text { GDP } \\
(\log Y) \\
(1)\end{array}$ & $\begin{array}{c}\text { IGE } \\
(\log E) \\
(2)\end{array}$ & $\begin{array}{c}\text { Levy rate } \\
\text { on IGE } \\
(\log r) \\
(3)\end{array}$ & $\begin{array}{c}\text { Industrial share } \\
(\log S) \\
(4)\end{array}$ & $\begin{array}{c}\text { Trade } \\
(\log \mathrm{T}) \\
(5)\end{array}$ & $\begin{array}{c}\text { FDI } \\
(\log \text { FDI }) \\
(6)\end{array}$ \\
\hline \multicolumn{7}{|l|}{ Constant } \\
\hline $\begin{array}{l}\text { GDP } \\
(\log Y)\end{array}$ & & $\begin{array}{c}0.544 \\
(1.526) \\
\end{array}$ & & $\begin{array}{l}0.020 \\
(0.771) \\
\end{array}$ & $\begin{array}{l}1.216 \\
(9.110) \\
\end{array}$ & $\begin{array}{c}8.432 \\
(5.235) \\
\end{array}$ \\
\hline $\begin{array}{l}\text { GDP Square } \\
\left(\log ^{2} Y\right)\end{array}$ & & $\begin{array}{c}-0.038 \\
(-1.335) \\
\end{array}$ & & & & \\
\hline $\begin{array}{l}\text { Income } \\
(\log (Y / P))\end{array}$ & & & $\begin{array}{c}0.233 \\
(1.433)\end{array}$ & & & \\
\hline $\begin{array}{l}\text { Emissions } \\
\text { (IGE) (log E) }\end{array}$ & $\begin{array}{c}0.133 \\
(4.158) \\
\end{array}$ & & $\begin{array}{c}-0.730 \\
(-5.802) \\
\end{array}$ & & & \\
\hline $\begin{array}{l}\text { Levy Rate on } \\
\text { IGE }(\log r)\end{array}$ & & $\begin{array}{c}-0.242 \\
(-6.354)\end{array}$ & & & & $\begin{array}{c}-0.344 \\
(-1.263)\end{array}$ \\
\hline $\begin{array}{l}\text { Industrial output } \\
\text { share }(\log S)\end{array}$ & & $\begin{array}{c}0.489 \\
(2.242) \\
\end{array}$ & & & & \\
\hline $\begin{array}{l}\text { Trade } \\
(\log T)\end{array}$ & $\begin{array}{c}0.300 \\
(10.912)\end{array}$ & & & $\begin{array}{c}0.006 \\
(0.387)\end{array}$ & & \\
\hline $\begin{array}{l}\text { FDI } \\
(\log \text { FDI) }\end{array}$ & & & & & $\begin{array}{c}0.018 \\
(1.622)\end{array}$ & \\
\hline $\begin{array}{l}\text { Labor } \\
(\log L)\end{array}$ & $\begin{array}{c}-0.131 \\
(-0.712) \\
\end{array}$ & & & & & \\
\hline $\begin{array}{l}\text { Capital } \\
(\log K)\end{array}$ & $\begin{array}{c}0.232 \\
(10.329) \\
\end{array}$ & & & & & \\
\hline $\begin{array}{l}\text { State-owned } \\
\text { Enterprises } \\
\text { (log SOE) }\end{array}$ & & $\begin{array}{c}-0.244 \\
(-1.911)\end{array}$ & & & & \\
\hline $\begin{array}{l}\text { Citizen } \\
\text { Complaints } \\
(\log C)\end{array}$ & & & $\begin{array}{c}0.077 \\
(1.743)\end{array}$ & & & \\
\hline $\begin{array}{l}\text { Education } \\
(\log \text { ed) }\end{array}$ & & & $\begin{array}{c}0.778 \\
(2.412)\end{array}$ & & & \\
\hline $\begin{array}{l}\text { Population } \\
\text { Density } \\
\text { (log PD) }\end{array}$ & & & $\begin{array}{c}-2.241 \\
(-2.255)\end{array}$ & & & \\
\hline $\begin{array}{l}\text { Industrial } \\
\text { Share }_{-1} \\
\left(\log S_{-1}\right)\end{array}$ & & & & $\begin{array}{c}0.797 \\
(19.773)\end{array}$ & & \\
\hline $\begin{array}{l}\text { Investments } \\
(\log V)\end{array}$ & & & & $\begin{array}{c}0.059 \\
(4.239) \\
\end{array}$ & & \\
\hline $\begin{array}{l}\text { Remoteness } \\
(\log R)\end{array}$ & & & & & $\begin{array}{c}-0.053 \\
(-0.952) \\
\end{array}$ & \\
\hline \multicolumn{7}{|l|}{$\begin{array}{l}\text { Exchange rate } \\
(\log E \text { E) }\end{array}$} \\
\hline $\begin{array}{l}\text { Tariffs } \\
(\log T N * \log T P)\end{array}$ & & & & & $\begin{array}{c}-0.020 \\
(-0.739) \\
\end{array}$ & \\
\hline $\begin{array}{l}\text { Cumulative FDI } \\
\left(\log C I_{-1}\right)\end{array}$ & & & & & & $\begin{array}{c}-0.212 \\
(-2.134)\end{array}$ \\
\hline $\begin{array}{l}\text { Road intensity } \\
(\log T I)\end{array}$ & & & & & & $\begin{array}{c}-3.444 \\
(-1.781) \\
\end{array}$ \\
\hline $\begin{array}{l}\text { Tax rate } \\
(\log \text { Tax })\end{array}$ & & & & & & $\begin{array}{c}-0.401 \\
(-1.156) \\
\end{array}$ \\
\hline $\begin{array}{l}\text { GDP per capita } \\
\left(\log _{\text {PGDP }}\right)\end{array}$ & & & & & & $\begin{array}{c}-3.914 \\
(-1.982) \\
\end{array}$ \\
\hline \multicolumn{7}{|l|}{$\begin{array}{l}\text { Regional } \\
\text { Dummy D }\end{array}$} \\
\hline \multicolumn{7}{|l|}{$\begin{array}{l}\text { Time Dummy } \\
\text { DT }\end{array}$} \\
\hline Adjusted $\mathrm{R}^{2}$ & 0.992 & 0.955 & 0.605 & 0.973 & 0.987 & 0.830 \\
\hline Observations & 252 & 252 & 252 & 252 & 252 & 252 \\
\hline
\end{tabular}


Table C-6 2SLS Estimates with Fixed Time Effects (Industrial Gas Emissions Case)

\begin{tabular}{|c|c|c|c|c|c|c|}
\hline & \multicolumn{3}{|c|}{ Dependent } & \multicolumn{3}{|c|}{ Variable } \\
\hline & $\begin{array}{c}\text { GDP } \\
(\log Y) \\
(1)\end{array}$ & $\begin{array}{c}\text { IGE } \\
(\log E) \\
(2)\end{array}$ & $\begin{array}{c}\text { Levy rate } \\
\text { on IGE } \\
(\log r) \\
(3)\end{array}$ & $\begin{array}{c}\text { Industrial share } \\
(\log S) \\
(4)\end{array}$ & $\begin{array}{c}\text { Trade } \\
(\log \mathrm{T}) \\
(5)\end{array}$ & $\begin{array}{c}\text { FDI } \\
(\log \text { FDI }) \\
(6)\end{array}$ \\
\hline \multicolumn{7}{|l|}{ Constant } \\
\hline $\begin{array}{l}\text { GDP } \\
(\log Y)\end{array}$ & & $\begin{array}{c}0.774 \\
(2.872) \\
\end{array}$ & & $\begin{array}{c}0.003 \\
(0.320) \\
\end{array}$ & $\begin{array}{c}0.670 \\
(10.328) \\
\end{array}$ & $\begin{array}{c}1.117 \\
(7.114) \\
\end{array}$ \\
\hline $\begin{array}{l}\text { GDP Square } \\
\left(\log ^{2} Y\right)\end{array}$ & & $\begin{array}{c}0.008 \\
(0.341) \\
\end{array}$ & & & & \\
\hline $\begin{array}{l}\text { Income } \\
(\log (Y / P))\end{array}$ & & & $\begin{array}{c}-0.296 \\
(-3.665)\end{array}$ & & & \\
\hline $\begin{array}{l}\text { Emissions } \\
\text { (IGE) (log E) }\end{array}$ & $\begin{array}{c}0.057 \\
(3.782) \\
\end{array}$ & & $\begin{array}{c}0.003 \\
(0.057) \\
\end{array}$ & & & \\
\hline $\begin{array}{l}\text { Levy Rate on } \\
\text { IGE }(\log r)\end{array}$ & & $\begin{array}{c}-0.207 \\
(-3.459)\end{array}$ & & & & $\begin{array}{c}0.070 \\
(0.351)\end{array}$ \\
\hline $\begin{array}{l}\text { Industrial output } \\
\text { share }(\log S)\end{array}$ & & $\begin{array}{c}0.648 \\
(5.148) \\
\end{array}$ & & & & \\
\hline $\begin{array}{l}\text { Trade } \\
(\log T)\end{array}$ & $\begin{array}{c}0.117 \\
(11.368)\end{array}$ & & & $\begin{array}{c}0.005 \\
(1.425)\end{array}$ & & \\
\hline $\begin{array}{l}\text { FDI } \\
(\log \text { FDI) }\end{array}$ & & & & & $\begin{array}{c}0.150 \\
(5.041)\end{array}$ & \\
\hline $\begin{array}{l}\text { Labor } \\
(\log L)\end{array}$ & $\begin{array}{c}0.365 \\
(33.192) \\
\end{array}$ & & & & & \\
\hline $\begin{array}{l}\text { Capital } \\
(\log K)\end{array}$ & $\begin{array}{c}0.521 \\
(20.077) \\
\end{array}$ & & & & & \\
\hline $\begin{array}{l}\text { State-owned } \\
\text { Enterprises } \\
\text { (log SOE) }\end{array}$ & & $\begin{array}{c}0.603 \\
(6.337)\end{array}$ & & & & \\
\hline $\begin{array}{l}\text { Citizen } \\
\text { Complaints } \\
(\log C)\end{array}$ & & & $\begin{array}{c}0.033 \\
(0.610)\end{array}$ & & & \\
\hline $\begin{array}{l}\text { Education } \\
(\log \text { ed) }\end{array}$ & & & $\begin{array}{c}-0.204 \\
(-1.849)\end{array}$ & & & \\
\hline $\begin{array}{l}\text { Population } \\
\text { Density } \\
\text { (log PD) }\end{array}$ & & & $\begin{array}{c}-0.012 \\
(-0.432)\end{array}$ & & & \\
\hline $\begin{array}{l}\text { Industrial } \\
\text { Share }_{-1} \\
\left(\log S_{-1}\right)\end{array}$ & & & & $\begin{array}{c}0.919 \\
(79.656)\end{array}$ & & \\
\hline $\begin{array}{l}\text { Investments } \\
(\log V)\end{array}$ & & & & $\begin{array}{c}0.003 \\
(0.299) \\
\end{array}$ & & \\
\hline $\begin{array}{l}\text { Remoteness } \\
(\log R)\end{array}$ & & & & & $\begin{array}{c}-0.745 \\
(-11.438) \\
\end{array}$ & \\
\hline \multicolumn{7}{|l|}{$\begin{array}{l}\text { Exchange rate } \\
(\log E \text { E) }\end{array}$} \\
\hline $\begin{array}{l}\text { Tariffs } \\
(\log T N * \log T P)\end{array}$ & & & & & $\begin{array}{c}0.021 \\
(0.314) \\
\end{array}$ & \\
\hline $\begin{array}{l}\text { Cumulative FDI } \\
\left(\log \mathrm{CFDI}_{-1}\right)\end{array}$ & & & & & & $\begin{array}{c}0.334 \\
(5.337)\end{array}$ \\
\hline $\begin{array}{l}\text { Road intensity } \\
(\log T I)\end{array}$ & & & & & & $\begin{array}{c}0.732 \\
(6.066)\end{array}$ \\
\hline $\begin{array}{l}\text { Tax rate } \\
(\log \text { Tax })\end{array}$ & & & & & & $\begin{array}{c}0.121 \\
(0.384) \\
\end{array}$ \\
\hline $\begin{array}{l}\text { GDP per capita } \\
\left(\log _{\text {PGDP }}\right)\end{array}$ & & & & & & $\begin{array}{c}0.525 \\
(2.645) \\
\end{array}$ \\
\hline \multicolumn{7}{|l|}{$\begin{array}{l}\text { Regional } \\
\text { Dummy D }\end{array}$} \\
\hline \multicolumn{7}{|l|}{$\begin{array}{l}\text { Time Dummy } \\
\text { DT }\end{array}$} \\
\hline Adjusted $\mathrm{R}^{2}$ & 0.989 & 0.770 & 0.155 & 0.978 & 0.877 & 0.810 \\
\hline Observations & 252 & 252 & 252 & 252 & 252 & 252 \\
\hline
\end{tabular}


Appendix D: EC2SLS Estimation Results

Table D-1 EC2SLS Estimates (Industrial Wastewater (IWW) Case)

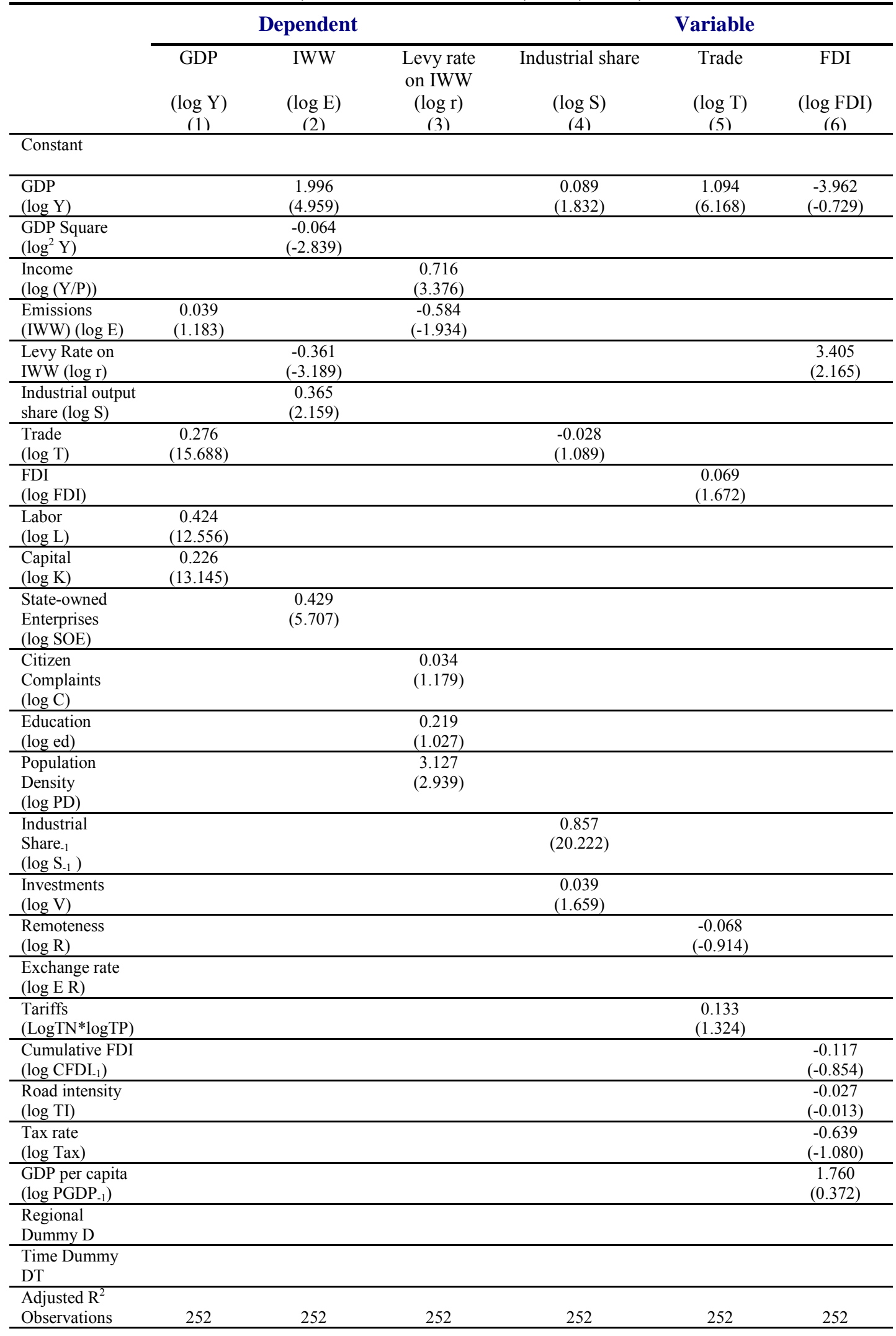


Table D-2 EC2SLS Estimates (Industrial Gas Emissions (IGE) Case)

\begin{tabular}{|c|c|c|c|c|c|c|}
\hline & \multicolumn{3}{|c|}{ Dependent } & \multicolumn{3}{|c|}{ Variable } \\
\hline & $\begin{array}{c}\text { GDP } \\
(\log Y) \\
(1)\end{array}$ & $\begin{array}{c}\text { IGE } \\
(\log E) \\
(2)\end{array}$ & $\begin{array}{c}\text { Levy rate } \\
\text { on IGE } \\
(\log r) \\
(3)\end{array}$ & $\begin{array}{c}\text { Industrial share } \\
\qquad \begin{array}{c}(\log S) \\
(4)\end{array}\end{array}$ & $\begin{array}{c}\text { Trade } \\
(\log \mathrm{T}) \\
(5)\end{array}$ & $\begin{array}{c}\text { FDI } \\
(\log \text { FDI }) \\
(6)\end{array}$ \\
\hline \multicolumn{7}{|l|}{ Constant } \\
\hline $\begin{array}{l}\text { GDP } \\
(\log Y)\end{array}$ & & $\begin{array}{c}2.307 \\
(3.186)\end{array}$ & & $\begin{array}{c}0.089 \\
(1.832)\end{array}$ & $\begin{array}{c}1.094 \\
(6.168)\end{array}$ & $\begin{array}{c}2.734 \\
(0.743)\end{array}$ \\
\hline $\begin{array}{l}\text { GDP Square } \\
\left(\log ^{2} Y\right)\end{array}$ & & $\begin{array}{c}-0.108 \\
(-2.754)\end{array}$ & & & & \\
\hline $\begin{array}{l}\text { Income } \\
(\log (\mathrm{Y} / \mathrm{P}))\end{array}$ & & & $\begin{array}{c}1.662 \\
(5.174) \\
\end{array}$ & & & \\
\hline $\begin{array}{l}\text { Emissions } \\
(\mathrm{IGE})(\log \mathrm{E})\end{array}$ & $\begin{array}{c}0.261 \\
(7.744)\end{array}$ & & $\begin{array}{c}-0.632 \\
(-1.554)\end{array}$ & & & \\
\hline $\begin{array}{l}\text { Levy Rate on } \\
\text { IGE }(\log r)\end{array}$ & & $\begin{array}{c}-0.083 \\
(-0.810)\end{array}$ & & & & $\begin{array}{c}0.756 \\
(1.135)\end{array}$ \\
\hline $\begin{array}{l}\text { Industrial output } \\
\text { share }(\log S)\end{array}$ & & $\begin{array}{c}0.153 \\
(0.579)\end{array}$ & & & & \\
\hline $\begin{array}{l}\text { Trade } \\
(\log T)\end{array}$ & $\begin{array}{c}0.246 \\
(15.961) \\
\end{array}$ & & & $\begin{array}{c}-0.028 \\
(-1.089) \\
\end{array}$ & & \\
\hline $\begin{array}{l}\text { FDI } \\
(\log \text { FDI })\end{array}$ & & & & & $\begin{array}{c}0.069 \\
(1.672)\end{array}$ & \\
\hline $\begin{array}{l}\text { Labor } \\
(\log L)\end{array}$ & $\begin{array}{c}0.351 \\
(15.073) \\
\end{array}$ & & & & & \\
\hline $\begin{array}{l}\text { Capital } \\
(\log K)\end{array}$ & $\begin{array}{c}0.194 \\
(15.789)\end{array}$ & & & & & \\
\hline $\begin{array}{l}\text { State-owned } \\
\text { Enterprises } \\
\text { (log SOE) }\end{array}$ & & $\begin{array}{c}-0.092 \\
(-0.646)\end{array}$ & & & & \\
\hline $\begin{array}{l}\text { Citizen } \\
\text { Complaints } \\
(\log C)\end{array}$ & & & $\begin{array}{c}0.084 \\
(2.135)\end{array}$ & & & \\
\hline $\begin{array}{l}\text { Education } \\
(\log \text { ed) }\end{array}$ & & & $\begin{array}{c}0.150 \\
(0.514) \\
\end{array}$ & & & \\
\hline $\begin{array}{l}\text { Population } \\
\text { Density } \\
\text { (log PD) }\end{array}$ & & & $\begin{array}{c}4.822 \\
(2.412)\end{array}$ & & & \\
\hline $\begin{array}{l}\text { Industrial } \\
\text { Share }_{-1} \\
\left(\operatorname{log~S}_{-1}\right)\end{array}$ & & & & $\begin{array}{c}0.857 \\
(20.222)\end{array}$ & & \\
\hline $\begin{array}{l}\text { Investments } \\
(\log V)\end{array}$ & & & & $\begin{array}{c}0.029 \\
(1.659)\end{array}$ & & \\
\hline $\begin{array}{l}\text { Remoteness } \\
(\log R)\end{array}$ & & & & & $\begin{array}{c}-0.068 \\
(-0.914) \\
\end{array}$ & \\
\hline \multicolumn{7}{|l|}{$\begin{array}{l}\text { Exchange rate } \\
(\log \text { E R) }\end{array}$} \\
\hline $\begin{array}{l}\text { Tariffs } \\
(\log T N * \log T P)\end{array}$ & & & & & $\begin{array}{c}0.132 \\
(1.324) \\
\end{array}$ & \\
\hline $\begin{array}{l}\text { Cumulative FDI } \\
\left(\log _{\text {CFDI }}\right)\end{array}$ & & & & & & $\begin{array}{c}-0.249 \\
(-2.398) \\
\end{array}$ \\
\hline $\begin{array}{l}\text { Road intensity } \\
(\log T I)\end{array}$ & & & & & & $\begin{array}{c}-1.875 \\
(-1.061) \\
\end{array}$ \\
\hline $\begin{array}{l}\text { Tax rate } \\
(\log \text { Tax }) \\
\end{array}$ & & & & & & $\begin{array}{c}-0.472 \\
(-0.922) \\
\end{array}$ \\
\hline $\begin{array}{l}\text { GDP per capita } \\
\left(\log _{\text {PGDP }}\right)\end{array}$ & & & & & & $\begin{array}{c}-3.481 \\
(-0.990) \\
\end{array}$ \\
\hline $\begin{array}{l}\text { Regional } \\
\text { Dummy D }\end{array}$ & & & & & & \\
\hline $\begin{array}{l}\text { Time Dummy } \\
\text { DT }\end{array}$ & & & & & & \\
\hline $\begin{array}{l}\text { Adjusted } \mathrm{R}^{2} \\
\text { Observations }\end{array}$ & 252 & 252 & 252 & 252 & 252 & 252 \\
\hline
\end{tabular}


Table D-3 EC2SLS Estimates $\left(\mathrm{CO}_{2}\right.$ Emissions Case)

\begin{tabular}{|c|c|c|c|c|c|c|}
\hline & \multicolumn{3}{|c|}{ Dependent } & \multicolumn{3}{|c|}{ Variable } \\
\hline & $\begin{array}{c}\text { GDP } \\
(\log Y) \\
(1)\end{array}$ & $\begin{array}{c}\mathrm{CO}_{2} \\
(\log \mathrm{E}) \\
(2) \\
\end{array}$ & $\begin{array}{c}\text { Levy rate } \\
\text { on IGE } \\
(\log r) \\
(3)\end{array}$ & $\begin{array}{c}\text { Industrial share } \\
(\log S) \\
(4)\end{array}$ & $\begin{array}{c}\text { Trade } \\
(\log \mathrm{T}) \\
(5)\end{array}$ & $\begin{array}{c}\text { FDI } \\
(\log \text { FDI }) \\
(6)\end{array}$ \\
\hline \multicolumn{7}{|l|}{ Constant } \\
\hline $\begin{array}{l}\text { GDP } \\
(\log Y)\end{array}$ & & $\begin{array}{c}1.387 \\
(2.521)\end{array}$ & & $\begin{array}{c}0.089 \\
(1.832)\end{array}$ & $\begin{array}{c}1.094 \\
(6.168)\end{array}$ & $\begin{array}{c}2.734 \\
(0.743)\end{array}$ \\
\hline $\begin{array}{l}\text { GDP Square } \\
\left(\log ^{2} Y\right)\end{array}$ & & $\begin{array}{c}-0.040 \\
(-1.334)\end{array}$ & & & & \\
\hline $\begin{array}{l}\text { Income } \\
(\log (Y / P))\end{array}$ & & & $\begin{array}{c}1.924 \\
(3.812)\end{array}$ & & & \\
\hline $\begin{array}{l}\text { Emissions } \\
\left(\mathrm{CO}_{2}\right)(\log \mathrm{E})\end{array}$ & $\begin{array}{c}0.256 \\
(7.628)\end{array}$ & & $\begin{array}{c}-1.198 \\
(-1.421)\end{array}$ & & & \\
\hline $\begin{array}{l}\text { Levy Rate on } \\
\text { IGE }(\log r)\end{array}$ & & $\begin{array}{c}-0.045 \\
(-0.575)\end{array}$ & & & & $\begin{array}{c}0.756 \\
(1.135)\end{array}$ \\
\hline $\begin{array}{l}\text { Industrial output } \\
\text { share }(\log S)\end{array}$ & & $\begin{array}{c}-0.045 \\
(-0.221) \\
\end{array}$ & & & & \\
\hline $\begin{array}{l}\text { Trade } \\
(\log T) \\
\end{array}$ & $\begin{array}{c}0.299 \\
(26.367) \\
\end{array}$ & & & $\begin{array}{c}-0.028 \\
(-1.089) \\
\end{array}$ & & \\
\hline $\begin{array}{l}\text { FDI } \\
(\log \text { FDI })\end{array}$ & & & & & $\begin{array}{c}0.069 \\
(1.672) \\
\end{array}$ & \\
\hline $\begin{array}{l}\text { Labor } \\
(\log L)\end{array}$ & $\begin{array}{c}0.338 \\
(14.375)\end{array}$ & & & & & \\
\hline $\begin{array}{l}\text { Capital } \\
(\log K)\end{array}$ & $\begin{array}{c}0.154 \\
(14.156)\end{array}$ & & & & & \\
\hline $\begin{array}{l}\text { State-owned } \\
\text { Enterprises } \\
\text { (log SOE) }\end{array}$ & & $\begin{array}{c}0.102 \\
(0.949)\end{array}$ & & & & \\
\hline $\begin{array}{l}\text { Citizen } \\
\text { Complaints } \\
\text { (log C) }\end{array}$ & & & $\begin{array}{l}0.106 \\
(2.157)\end{array}$ & & & \\
\hline $\begin{array}{l}\text { Education } \\
(\log \text { ed) }\end{array}$ & & & $\begin{array}{c}-0.087 \\
(-0.218) \\
\end{array}$ & & & \\
\hline $\begin{array}{l}\text { Population } \\
\text { Density } \\
\text { (log PD) }\end{array}$ & & & $\begin{array}{c}4.331 \\
(2.084)\end{array}$ & & & \\
\hline $\begin{array}{l}\text { Industrial } \\
\text { Share }_{-1} \\
\left(\log \mathrm{S}_{-1}\right)\end{array}$ & & & & $\begin{array}{c}0.857 \\
(20.222)\end{array}$ & & \\
\hline $\begin{array}{l}\text { Investments } \\
(\log V)\end{array}$ & & & & $\begin{array}{c}0.029 \\
(1.659) \\
\end{array}$ & & \\
\hline $\begin{array}{l}\text { Remoteness } \\
(\log R)\end{array}$ & & & & & $\begin{array}{c}-0.068 \\
(-0.914) \\
\end{array}$ & \\
\hline \multicolumn{7}{|l|}{$\begin{array}{l}\text { Exchange rate } \\
(\log \text { E R) }\end{array}$} \\
\hline $\begin{array}{l}\text { Tariffs } \\
(\log T N * \log T P)\end{array}$ & & & & & $\begin{array}{c}0.132 \\
(1.324) \\
\end{array}$ & \\
\hline $\begin{array}{l}\text { Cumulative FDI } \\
\left(\log _{\text {CFDI }}\right)\end{array}$ & & & & & & $\begin{array}{c}-0.249 \\
(-2.398) \\
\end{array}$ \\
\hline $\begin{array}{l}\text { Road intensity } \\
(\log T I)\end{array}$ & & & & & & $\begin{array}{c}-1.875 \\
(-1.061) \\
\end{array}$ \\
\hline $\begin{array}{l}\text { Tax rate } \\
(\log \text { Tax })\end{array}$ & & & & & & $\begin{array}{c}-0.472 \\
(-0.922) \\
\end{array}$ \\
\hline $\begin{array}{l}\text { GDP per capita } \\
\left(\log _{\text {PGDP }}\right)\end{array}$ & & & & & & $\begin{array}{c}-3.481 \\
(-0.990)\end{array}$ \\
\hline \multicolumn{7}{|l|}{$\begin{array}{l}\text { Regional } \\
\text { Dummy D }\end{array}$} \\
\hline \multicolumn{7}{|l|}{$\begin{array}{l}\text { Time Dummy } \\
\text { DT } \\
\end{array}$} \\
\hline $\begin{array}{l}\text { Adjusted } \mathrm{R}^{2} \\
\text { Observations }\end{array}$ & 252 & 252 & 252 & 252 & 252 & 252 \\
\hline
\end{tabular}


Table D-4 EC2SLS Estimates ( $\mathrm{SO}_{2}$ Emissions Case)

\begin{tabular}{|c|c|c|c|c|c|c|}
\hline & \multicolumn{3}{|c|}{ Dependent } & \multicolumn{3}{|c|}{ Variable } \\
\hline & $\begin{array}{c}\text { GDP } \\
(\log Y) \\
(1)\end{array}$ & $\begin{array}{c}\mathrm{SO}_{2} \\
(\log \mathrm{E}) \\
(2)\end{array}$ & $\begin{array}{l}\text { Levy rate } \\
\text { on IGE } \\
(\log r) \\
\text { (3) }\end{array}$ & $\begin{array}{c}\text { Industrial share } \\
\qquad \begin{array}{c}(\log S) \\
(4)\end{array}\end{array}$ & $\begin{array}{c}\text { Trade } \\
(\log T) \\
(5)\end{array}$ & $\begin{array}{c}\text { FDI } \\
(\log \text { FDI }) \\
(6)\end{array}$ \\
\hline \multicolumn{7}{|l|}{ Constant } \\
\hline $\begin{array}{l}\text { GDP } \\
(\log Y)\end{array}$ & & $\begin{array}{c}2.974 \\
(4.011)\end{array}$ & & $\begin{array}{c}0.089 \\
(1.832)\end{array}$ & $\begin{array}{c}1.094 \\
(6.168)\end{array}$ & $\begin{array}{c}2.734 \\
(0.743)\end{array}$ \\
\hline $\begin{array}{l}\text { GDP Square } \\
\left(\log ^{2} Y\right)\end{array}$ & & $\begin{array}{c}-0.129 \\
(-3.191)\end{array}$ & & & & \\
\hline $\begin{array}{l}\text { Income } \\
(\log (Y / P))\end{array}$ & & & $\begin{array}{c}1.354 \\
(4.256)\end{array}$ & & & \\
\hline $\begin{array}{l}\text { Emissions } \\
\left(\mathrm{SO}_{2}\right)(\log \mathrm{E})\end{array}$ & $\begin{array}{c}0.184 \\
(5.848)\end{array}$ & & $\begin{array}{c}-0.009 \\
(-0.023)\end{array}$ & & & \\
\hline $\begin{array}{l}\text { Levy Rate on } \\
\text { IGE }(\log r)\end{array}$ & & $\begin{array}{c}-0.048 \\
(-0.454)\end{array}$ & & & & $\begin{array}{c}0.756 \\
(1.135)\end{array}$ \\
\hline $\begin{array}{l}\text { Industrial output } \\
\text { share }(\log S)\end{array}$ & & $\begin{array}{c}0.072 \\
(0.267) \\
\end{array}$ & & & & \\
\hline $\begin{array}{l}\text { Trade } \\
(\log T)\end{array}$ & $\begin{array}{c}0.292 \\
(20.510) \\
\end{array}$ & & & $\begin{array}{c}-0.028 \\
(-1.089) \\
\end{array}$ & & \\
\hline $\begin{array}{l}\text { FDI } \\
(\log \text { FDI })\end{array}$ & & & & & $\begin{array}{c}0.069 \\
(1.672) \\
\end{array}$ & \\
\hline $\begin{array}{l}\text { Labor } \\
(\log L)\end{array}$ & $\begin{array}{c}0.333 \\
(11.725)\end{array}$ & & & & & \\
\hline $\begin{array}{l}\text { Capital } \\
(\log K)\end{array}$ & $\begin{array}{c}0.190 \\
(15.562)\end{array}$ & & & & & \\
\hline $\begin{array}{l}\text { State-owned } \\
\text { Enterprises } \\
\text { (log SOE) }\end{array}$ & & $\begin{array}{c}-0.249 \\
(-1.718)\end{array}$ & & & & \\
\hline $\begin{array}{l}\text { Citizen } \\
\text { Complaints } \\
\text { (log C) }\end{array}$ & & & $\begin{array}{l}0.088 \\
(1.952)\end{array}$ & & & \\
\hline $\begin{array}{l}\text { Education } \\
\text { (log ed) }\end{array}$ & & & $\begin{array}{c}0.173 \\
(0.495)\end{array}$ & & & \\
\hline $\begin{array}{l}\text { Population } \\
\text { Density } \\
\text { (log PD) }\end{array}$ & & & $\begin{array}{c}2.520 \\
(1.245)\end{array}$ & & & \\
\hline $\begin{array}{l}\text { Industrial } \\
\text { Share }_{-1} \\
\left(\log \mathrm{S}_{-1}\right)\end{array}$ & & & & $\begin{array}{c}0.857 \\
(20.222)\end{array}$ & & \\
\hline $\begin{array}{l}\text { Investments } \\
(\log V)\end{array}$ & & & & $\begin{array}{c}0.029 \\
(1.659)\end{array}$ & & \\
\hline $\begin{array}{l}\text { Remoteness } \\
(\log R)\end{array}$ & & & & & $\begin{array}{c}-0.068 \\
(-0.914) \\
\end{array}$ & \\
\hline \multicolumn{7}{|l|}{$\begin{array}{l}\text { Exchange rate } \\
(\log E \mathrm{R})\end{array}$} \\
\hline $\begin{array}{l}\text { Tariffs } \\
(\operatorname{LogTN} * \log \mathrm{TP})\end{array}$ & & & & & $\begin{array}{c}0.132 \\
(1.324) \\
\end{array}$ & \\
\hline $\begin{array}{l}\text { Cumulative FDI } \\
\left(\log \text { CFDI }_{-1}\right)\end{array}$ & & & & & & $\begin{array}{c}-0.249 \\
(-2.398)\end{array}$ \\
\hline $\begin{array}{l}\text { Road intensity } \\
(\log T I)\end{array}$ & & & & & & $\begin{array}{c}-1.875 \\
(-1.061) \\
\end{array}$ \\
\hline $\begin{array}{l}\text { Tax rate } \\
(\log \text { Tax })\end{array}$ & & & & & & $\begin{array}{c}-0.472 \\
(-0.922) \\
\end{array}$ \\
\hline $\begin{array}{l}\text { GDP per capita } \\
\left(\log _{\text {PGDP }}\right)\end{array}$ & & & & & & $\begin{array}{c}-3.481 \\
(-0.990)\end{array}$ \\
\hline \multicolumn{7}{|l|}{$\begin{array}{l}\text { Regional } \\
\text { Dummy D }\end{array}$} \\
\hline \multicolumn{7}{|l|}{$\begin{array}{l}\text { Time Dummy } \\
\text { DT } \\
\end{array}$} \\
\hline $\begin{array}{l}\text { Adjusted } \mathrm{R}^{2} \\
\text { Observations }\end{array}$ & 252 & 252 & 252 & 252 & 252 & 252 \\
\hline
\end{tabular}


Table D-5 EC2SLS Estimates (Particle Emissions Case)

\begin{tabular}{|c|c|c|c|c|c|c|}
\hline & \multicolumn{3}{|c|}{ Dependent } & \multicolumn{3}{|c|}{ Variable } \\
\hline & $\begin{array}{c}\text { GDP } \\
(\log Y) \\
(1)\end{array}$ & $\begin{array}{l}\text { Particles } \\
(\log E) \\
(2)\end{array}$ & $\begin{array}{c}\text { Levy rate } \\
\text { on IGE } \\
(\log r) \\
(3)\end{array}$ & $\begin{array}{c}\text { Industrial share } \\
\qquad \begin{array}{c}(\log S) \\
(4)\end{array}\end{array}$ & $\begin{array}{c}\text { Trade } \\
(\log \mathrm{T}) \\
(5)\end{array}$ & $\begin{array}{c}\text { FDI } \\
(\log \text { FDI }) \\
(6)\end{array}$ \\
\hline \multicolumn{7}{|l|}{ Constant } \\
\hline $\begin{array}{l}\text { GDP } \\
(\log Y)\end{array}$ & & $\begin{array}{c}4.334 \\
(4.669)\end{array}$ & & $\begin{array}{c}0.089 \\
(1.832)\end{array}$ & $\begin{array}{c}1.094 \\
(6.168)\end{array}$ & $\begin{array}{c}2.734 \\
(0.743)\end{array}$ \\
\hline $\begin{array}{l}\text { GDP Square } \\
\left(\log ^{2} Y\right)\end{array}$ & & $\begin{array}{c}-0.281 \\
(-5.573)\end{array}$ & & & & \\
\hline $\begin{array}{l}\text { Income } \\
(\log (Y / P))\end{array}$ & & & $\begin{array}{c}1.386 \\
(4.811)\end{array}$ & & & \\
\hline $\begin{array}{l}\text { Emissions } \\
\text { (Partcle) (log E) }\end{array}$ & $\begin{array}{c}0.198 \\
(9.018)\end{array}$ & & $\begin{array}{c}0.215 \\
(1.019)\end{array}$ & & & \\
\hline $\begin{array}{l}\text { Levy Rate on } \\
\text { IGE }(\log r)\end{array}$ & & $\begin{array}{c}0.153 \\
(1.147)\end{array}$ & & & & $\begin{array}{c}0.756 \\
(1.135)\end{array}$ \\
\hline $\begin{array}{l}\text { Industrial output } \\
\text { share }(\log S)\end{array}$ & & $\begin{array}{c}0.357 \\
(1.051) \\
\end{array}$ & & & & \\
\hline $\begin{array}{l}\text { Trade } \\
(\log T)\end{array}$ & $\begin{array}{c}0.365 \\
(31.682)\end{array}$ & & & $\begin{array}{c}-0.028 \\
(-1.089)\end{array}$ & & \\
\hline $\begin{array}{l}\text { FDI } \\
(\log F D I)\end{array}$ & & & & & $\begin{array}{c}0.069 \\
(1.672) \\
\end{array}$ & \\
\hline $\begin{array}{l}\text { Labor } \\
(\log L)\end{array}$ & $\begin{array}{c}0.315 \\
(14.306)\end{array}$ & & & & & \\
\hline $\begin{array}{l}\text { Capital } \\
(\log K)\end{array}$ & $\begin{array}{c}0.164 \\
(20.163)\end{array}$ & & & & & \\
\hline $\begin{array}{l}\text { State-owned } \\
\text { Enterprises } \\
\text { (log SOE) }\end{array}$ & & $\begin{array}{c}-0.016 \\
(-0.090)\end{array}$ & & & & \\
\hline $\begin{array}{l}\text { Citizen } \\
\text { Complaints } \\
(\log C)\end{array}$ & & & $\begin{array}{l}0.085 \\
(1.920)\end{array}$ & & & \\
\hline $\begin{array}{l}\text { Education } \\
\text { (log ed) }\end{array}$ & & & $\begin{array}{c}0.074 \\
(0.217) \\
\end{array}$ & & & \\
\hline $\begin{array}{l}\text { Population } \\
\text { Density } \\
\text { (log PD) }\end{array}$ & & & $\begin{array}{c}1.909 \\
(1.150)\end{array}$ & & & \\
\hline $\begin{array}{l}\text { Industrial } \\
\text { Share }_{-1} \\
\left(\operatorname{log~S}_{-1}\right)\end{array}$ & & & & $\begin{array}{c}0.857 \\
(20.222)\end{array}$ & & \\
\hline $\begin{array}{l}\text { Investments } \\
(\log V)\end{array}$ & & & & $\begin{array}{c}0.029 \\
(1.659)\end{array}$ & & \\
\hline $\begin{array}{l}\text { Remoteness } \\
(\log R)\end{array}$ & & & & & $\begin{array}{c}-0.068 \\
(-0.914) \\
\end{array}$ & \\
\hline \multicolumn{7}{|l|}{$\begin{array}{l}\text { Exchange rate } \\
(\log E R)\end{array}$} \\
\hline $\begin{array}{l}\text { Tariffs } \\
(\operatorname{LogTN} * \log T P)\end{array}$ & & & & & $\begin{array}{c}0.132 \\
(1.324) \\
\end{array}$ & \\
\hline $\begin{array}{l}\text { Cumulative FDI } \\
\left(\log _{\text {CFDI }}\right)\end{array}$ & & & & & & $\begin{array}{c}-0.249 \\
(-2.398) \\
\end{array}$ \\
\hline $\begin{array}{l}\text { Road intensity } \\
(\log T I)\end{array}$ & & & & & & $\begin{array}{c}-1.875 \\
(-1.061) \\
\end{array}$ \\
\hline $\begin{array}{l}\text { Tax rate } \\
(\log \text { Tax }) \\
\end{array}$ & & & & & & $\begin{array}{c}-0.472 \\
(-0.922) \\
\end{array}$ \\
\hline $\begin{array}{l}\text { GDP per capita } \\
\left(\log _{\left.\text {PGDP }_{-1}\right)}\right.\end{array}$ & & & & & & $\begin{array}{c}-3.481 \\
(-0.990)\end{array}$ \\
\hline $\begin{array}{l}\text { Regional } \\
\text { Dummy D }\end{array}$ & & & & & & \\
\hline $\begin{array}{l}\text { Time Dummy } \\
\text { DT }\end{array}$ & & & & & & \\
\hline $\begin{array}{l}\text { Adjusted } \mathrm{R}^{2} \\
\text { Observations }\end{array}$ & 252 & 252 & 252 & 252 & 252 & 252 \\
\hline
\end{tabular}


Table D-6 EC2SLS Estimates (Dust Emissions Case)

\begin{tabular}{|c|c|c|c|c|c|c|}
\hline & \multicolumn{3}{|c|}{ Dependent } & \multicolumn{3}{|c|}{ Variable } \\
\hline & $\begin{array}{c}\text { GDP } \\
(\log Y) \\
(1)\end{array}$ & $\begin{array}{c}\text { Dust } \\
(\log E) \\
(2)\end{array}$ & $\begin{array}{c}\text { Levy rate } \\
\text { on IGE } \\
(\log r) \\
(3)\end{array}$ & $\begin{array}{c}\text { Industrial share } \\
\qquad \begin{array}{c}(\log S) \\
(4)\end{array}\end{array}$ & $\begin{array}{c}\text { Trade } \\
(\log \mathrm{T}) \\
(5)\end{array}$ & $\begin{array}{c}\text { FDI } \\
(\log \text { FDI }) \\
(6)\end{array}$ \\
\hline \multicolumn{7}{|l|}{ Constant } \\
\hline $\begin{array}{l}\text { GDP } \\
(\log Y)\end{array}$ & & $\begin{array}{c}1.044 \\
(0.744)\end{array}$ & & $\begin{array}{c}0.089 \\
(1.832)\end{array}$ & $\begin{array}{c}1.094 \\
(6.168)\end{array}$ & $\begin{array}{c}2.734 \\
(0.743)\end{array}$ \\
\hline $\begin{array}{l}\text { GDP Square } \\
\left(\log ^{2} Y\right)\end{array}$ & & $\begin{array}{c}-0.011 \\
(-0.148)\end{array}$ & & & & \\
\hline $\begin{array}{l}\text { Income } \\
(\log (Y / P))\end{array}$ & & & $\begin{array}{c}1.163 \\
(3.060)\end{array}$ & & & \\
\hline $\begin{array}{l}\text { Emissions } \\
\text { (Dust) (log E) }\end{array}$ & $\begin{array}{c}0.155 \\
(5.671)\end{array}$ & & $\begin{array}{c}0.236 \\
(0.831)\end{array}$ & & & \\
\hline $\begin{array}{l}\text { Levy Rate on } \\
\text { IGE }(\log r)\end{array}$ & & $\begin{array}{c}0.248 \\
(1.236)\end{array}$ & & & & $\begin{array}{c}0.756 \\
(1.135)\end{array}$ \\
\hline $\begin{array}{l}\text { Industrial output } \\
\text { share }(\log S)\end{array}$ & & $\begin{array}{l}-0.333 \\
(0.649)\end{array}$ & & & & \\
\hline $\begin{array}{l}\text { Trade } \\
(\log T)\end{array}$ & $\begin{array}{c}0.263 \\
(16.481)\end{array}$ & & & $\begin{array}{c}-0.028 \\
(-1.089)\end{array}$ & & \\
\hline $\begin{array}{l}\text { FDI } \\
(\log F D I)\end{array}$ & & & & & $\begin{array}{c}0.069 \\
(1.672) \\
\end{array}$ & \\
\hline $\begin{array}{l}\text { Labor } \\
(\log L)\end{array}$ & $\begin{array}{c}0.311 \\
(9.565)\end{array}$ & & & & & \\
\hline $\begin{array}{l}\text { Capital } \\
(\log K)\end{array}$ & $\begin{array}{c}0.290 \\
(14.594)\end{array}$ & & & & & \\
\hline $\begin{array}{l}\text { State-owned } \\
\text { Enterprises } \\
\text { (log SOE) }\end{array}$ & & $\begin{array}{c}0.156 \\
(0.568)\end{array}$ & & & & \\
\hline $\begin{array}{l}\text { Citizen } \\
\text { Complaints } \\
(\log C)\end{array}$ & & & $\begin{array}{c}0.072 \\
(1.429)\end{array}$ & & & \\
\hline $\begin{array}{l}\text { Education } \\
\text { (log ed) }\end{array}$ & & & $\begin{array}{c}0.152 \\
(0.442) \\
\end{array}$ & & & \\
\hline $\begin{array}{l}\text { Population } \\
\text { Density } \\
\text { (log PD) }\end{array}$ & & & $\begin{array}{c}2.148 \\
(1.279)\end{array}$ & & & \\
\hline $\begin{array}{l}\text { Industrial } \\
\text { Share }_{-1} \\
\left(\operatorname{log~S}_{-1}\right)\end{array}$ & & & & $\begin{array}{c}0.857 \\
(20.222)\end{array}$ & & \\
\hline $\begin{array}{l}\text { Investments } \\
(\log V)\end{array}$ & & & & $\begin{array}{c}0.029 \\
(1.659)\end{array}$ & & \\
\hline $\begin{array}{l}\text { Remoteness } \\
(\log R)\end{array}$ & & & & & $\begin{array}{c}-0.068 \\
(-0.914) \\
\end{array}$ & \\
\hline \multicolumn{7}{|l|}{$\begin{array}{l}\text { Exchange rate } \\
(\log E R)\end{array}$} \\
\hline $\begin{array}{l}\text { Tariffs } \\
(\operatorname{LogTN} * \log T P)\end{array}$ & & & & & $\begin{array}{c}0.132 \\
(1.324) \\
\end{array}$ & \\
\hline $\begin{array}{l}\text { Cumulative FDI } \\
\left(\log _{\text {CFDI }}\right)\end{array}$ & & & & & & $\begin{array}{c}-0.249 \\
(-2.398) \\
\end{array}$ \\
\hline $\begin{array}{l}\text { Road intensity } \\
(\log T I)\end{array}$ & & & & & & $\begin{array}{c}-1.875 \\
(-1.061) \\
\end{array}$ \\
\hline $\begin{array}{l}\text { Tax rate } \\
(\log \text { Tax) } \\
\end{array}$ & & & & & & $\begin{array}{c}-0.472 \\
(-0.922) \\
\end{array}$ \\
\hline $\begin{array}{l}\text { GDP per capita } \\
\left(\log _{\left.\text {PGDP }_{-1}\right)}\right.\end{array}$ & & & & & & $\begin{array}{c}-3.481 \\
(-0.990)\end{array}$ \\
\hline $\begin{array}{l}\text { Regional } \\
\text { Dummy D }\end{array}$ & & & & & & \\
\hline $\begin{array}{l}\text { Time Dummy } \\
\text { DT }\end{array}$ & & & & & & \\
\hline $\begin{array}{l}\text { Adjusted } \mathrm{R}^{2} \\
\text { Observations }\end{array}$ & 252 & 252 & 252 & 252 & 252 & 252 \\
\hline
\end{tabular}




\section{Appendix E: Linear Model 2SLS Results}

Table E-1Linear Model 2SLS Estimates (Idustrial Wastewater Discharge (IWW) Case)

\begin{tabular}{|c|c|c|c|c|c|c|}
\hline & \multicolumn{3}{|c|}{ Dependent } & \multicolumn{3}{|c|}{ Variable } \\
\hline & $\begin{array}{c}\text { GDP } \\
(\log Y) \\
(1)\end{array}$ & $\begin{array}{c}\text { IWW } \\
(\log E) \\
(2)\end{array}$ & $\begin{array}{c}\text { Levy rate } \\
\text { on IGE } \\
(\log r) \\
\text { (3) }\end{array}$ & $\begin{array}{c}\text { Industrial share } \\
(\log S) \\
(4)\end{array}$ & $\begin{array}{l}\text { Trade } \\
(\log T) \\
(5)\end{array}$ & $\begin{array}{c}\text { FDI } \\
(\log \text { FDI }) \\
(6)\end{array}$ \\
\hline Constant & $\begin{array}{c}-1.298 \\
(-10.640)\end{array}$ & $\begin{array}{c}-2.192 \\
(-2.432)\end{array}$ & $\begin{array}{c}3.294 \\
(5.346)\end{array}$ & $\begin{array}{c}0.222 \\
(3.313)\end{array}$ & $\begin{array}{l}13.350 \\
(4.722)\end{array}$ & $\begin{array}{c}-1.689 \\
(-1.160)\end{array}$ \\
\hline $\begin{array}{l}\text { GDP } \\
(\log Y)\end{array}$ & & $\begin{array}{c}1.187 \\
(27.042)\end{array}$ & & $\begin{array}{c}-0.013 \\
(-1.163)\end{array}$ & $\begin{array}{c}0.471 \\
(5.515)\end{array}$ & $\begin{array}{c}1.134 \\
(6.093)\end{array}$ \\
\hline $\begin{array}{l}\text { GDP Square } \\
\left(\log ^{2} Y\right)\end{array}$ & & & & & & \\
\hline $\begin{array}{l}\text { Income } \\
(\log (\mathrm{Y} / \mathrm{P}))\end{array}$ & & & $\begin{array}{c}0.328 \\
(4.600)\end{array}$ & & & \\
\hline $\begin{array}{l}\text { Emissions } \\
\text { (IWW) (log E) }\end{array}$ & $\begin{array}{c}0.153 \\
(6.061) \\
\end{array}$ & & $\begin{array}{c}0.056 \\
(1.496) \\
\end{array}$ & & & \\
\hline $\begin{array}{l}\text { Levy Rate on } \\
\text { IWW }(\log r)\end{array}$ & & $\begin{array}{c}-0.329 \\
(-2.480)\end{array}$ & & & & $\begin{array}{c}-0.629 \\
(-0.836)\end{array}$ \\
\hline $\begin{array}{l}\text { Industrial output } \\
\text { share }(\log S)\end{array}$ & & $\begin{array}{c}-0.262 \\
(-1.396)\end{array}$ & & & & \\
\hline $\begin{array}{l}\text { Trade } \\
(\log T)\end{array}$ & $\begin{array}{c}0.175 \\
(9.643) \\
\end{array}$ & & & $\begin{array}{c}0.007 \\
(1.316)\end{array}$ & & \\
\hline $\begin{array}{l}\text { FDI } \\
(\log \text { FDI) }\end{array}$ & & & & & $\begin{array}{c}0.283 \\
(5.715) \\
\end{array}$ & \\
\hline $\begin{array}{l}\text { Labor } \\
(\log \mathrm{L})\end{array}$ & $\begin{array}{c}0.333 \\
(13.525)\end{array}$ & & & & & \\
\hline $\begin{array}{l}\text { Capital } \\
(\log K)\end{array}$ & $\begin{array}{c}0.332 \\
(14.637)\end{array}$ & & & & & \\
\hline $\begin{array}{l}\text { State-owned } \\
\text { Enterprises } \\
\text { (log SOE) }\end{array}$ & & $\begin{array}{c}0.612 \\
(7.359)\end{array}$ & & & & \\
\hline $\begin{array}{l}\text { Citizen } \\
\text { Complaints } \\
(\log C)\end{array}$ & & & $\begin{array}{c}-0.153 \\
(-2.723)\end{array}$ & & & \\
\hline $\begin{array}{l}\text { Education } \\
(\log \text { ed })\end{array}$ & & & $\begin{array}{c}-0.273 \\
(-3.066) \\
\end{array}$ & & & \\
\hline $\begin{array}{l}\text { Population } \\
\text { Density } \\
\text { (log PD) }\end{array}$ & & & $\begin{array}{c}0.063 \\
(1.983)\end{array}$ & & & \\
\hline $\begin{array}{l}\text { Industrial } \\
\text { Share } \\
\left(\log S_{-1}\right)\end{array}$ & & & & $\begin{array}{c}0.914 \\
(59.739)\end{array}$ & & \\
\hline $\begin{array}{l}\text { Investments } \\
(\log V)\end{array}$ & & & & $\begin{array}{c}0.024 \\
(1.859) \\
\end{array}$ & & \\
\hline $\begin{array}{l}\text { Remoteness } \\
(\log R)\end{array}$ & & & & & $\begin{array}{c}-0.341 \\
(-3.431) \\
\end{array}$ & \\
\hline $\begin{array}{l}\text { Exchange rate } \\
(\log E \mathrm{R})\end{array}$ & & & & & $\begin{array}{c}-0.695 \\
(-1.825)\end{array}$ & \\
\hline $\begin{array}{l}\text { Tariffs } \\
(\operatorname{LogTN} * \log \mathrm{TP})\end{array}$ & & & & & $\begin{array}{c}-0.101 \\
(-1.267) \\
\end{array}$ & \\
\hline $\begin{array}{l}\text { Cumulative FDI } \\
\left(\log \text { CFDI }_{-1}\right)\end{array}$ & & & & & & $\begin{array}{c}0.363 \\
(4.163) \\
\end{array}$ \\
\hline $\begin{array}{l}\text { Road intensity } \\
(\log T I)\end{array}$ & & & & & & $\begin{array}{c}0.611 \\
(3.047)\end{array}$ \\
\hline $\begin{array}{l}\text { Tax rate } \\
(\log \text { Tax })\end{array}$ & & & & & & $\begin{array}{c}-0.072 \\
(-0.383)\end{array}$ \\
\hline $\begin{array}{l}\text { GDP per capita } \\
\left(\log \text { PGDP }_{-1}\right)\end{array}$ & & & & & & $\begin{array}{c}0.617 \\
(1.976) \\
\end{array}$ \\
\hline $\begin{array}{l}\text { Regional } \\
\text { Dummy D }\end{array}$ & & & & $\begin{array}{c}-0.012 \\
(-1.572)\end{array}$ & $\begin{array}{c}0.451 \\
(4.336)\end{array}$ & $\begin{array}{c}0.523 \\
(2.204)\end{array}$ \\
\hline $\begin{array}{l}\text { Time Dummy } \\
\text { DT }\end{array}$ & & & & & $\begin{array}{c}0.143 \\
(1.722)\end{array}$ & $\begin{array}{c}-0.874 \\
(-4.683)\end{array}$ \\
\hline $\begin{array}{l}\text { Adjusted } \mathrm{R}^{2} \\
\text { Observations }\end{array}$ & $\begin{array}{l}0.981 \\
252\end{array}$ & $\begin{array}{l}0.795 \\
252\end{array}$ & $\begin{array}{l}0.327 \\
252\end{array}$ & $\begin{array}{l}0.968 \\
252\end{array}$ & $\begin{array}{c}0.865 \\
252\end{array}$ & $\begin{array}{l}0.784 \\
252\end{array}$ \\
\hline
\end{tabular}


Table E-2Linear Model 2SLS Estimates (Idustrial Waste Gas Emissions (IGE) Case)

\begin{tabular}{|c|c|c|c|c|c|c|}
\hline & \multicolumn{3}{|c|}{ Dependent } & \multicolumn{3}{|c|}{ Variable } \\
\hline & $\begin{array}{c}\text { GDP } \\
(\log Y) \\
(1)\end{array}$ & $\begin{array}{c}\text { IGE } \\
(\log E) \\
(2)\end{array}$ & $\begin{array}{c}\text { Levy rate } \\
\text { on IGE } \\
(\log r) \\
\text { (3) }\end{array}$ & $\begin{array}{c}\text { Industrial share } \\
(\log S) \\
(4)\end{array}$ & $\begin{array}{l}\text { Trade } \\
(\log T) \\
(5)\end{array}$ & $\begin{array}{c}\text { FDI } \\
\left(\log _{(6)} \text { FDI }\right)\end{array}$ \\
\hline Constant & $\begin{array}{c}-1.689 \\
(-15.772)\end{array}$ & $\begin{array}{c}-6.552 \\
(-8.925)\end{array}$ & $\begin{array}{c}0.163 \\
(0.187)\end{array}$ & $\begin{array}{c}0.222 \\
(3.313)\end{array}$ & $\begin{array}{l}13.350 \\
(4.722)\end{array}$ & $\begin{array}{c}-1.829 \\
(-1.345)\end{array}$ \\
\hline $\begin{array}{l}\text { GDP } \\
(\log Y)\end{array}$ & & $\begin{array}{c}0.794 \\
(16.811)\end{array}$ & & $\begin{array}{c}-0.013 \\
(-1.163)\end{array}$ & $\begin{array}{c}0.471 \\
(5.515)\end{array}$ & $\begin{array}{c}0.845 \\
(3.925)\end{array}$ \\
\hline $\begin{array}{l}\text { GDP Square } \\
\left(\log ^{2} Y\right)\end{array}$ & & & & & & \\
\hline $\begin{array}{l}\text { Income } \\
(\log (\mathrm{Y} / \mathrm{P}))\end{array}$ & & & $\begin{array}{c}-0.402 \\
(-4.829) \\
\end{array}$ & & & \\
\hline $\begin{array}{l}\text { Emissions } \\
(\mathrm{IGE})(\log \mathrm{E})\end{array}$ & $\begin{array}{c}0.202 \\
(7.534) \\
\end{array}$ & & $\begin{array}{c}0.116 \\
(2.156) \\
\end{array}$ & & & \\
\hline $\begin{array}{l}\text { Levy Rate on } \\
\text { IGE }(\log r)\end{array}$ & & $\begin{array}{c}0.368 \\
(3.658) \\
\end{array}$ & & & & $\begin{array}{c}0.798 \\
(1.597) \\
\end{array}$ \\
\hline $\begin{array}{l}\text { Industrial output } \\
\text { share }(\log S)\end{array}$ & & $\begin{array}{c}1.040 \\
(6.027) \\
\end{array}$ & & & & \\
\hline $\begin{array}{l}\text { Trade } \\
(\log T)\end{array}$ & $\begin{array}{c}0.222 \\
(15.080)\end{array}$ & & & $\begin{array}{c}0.007 \\
(1.316)\end{array}$ & & \\
\hline $\begin{array}{l}\text { FDI } \\
(\log \text { FDI) }\end{array}$ & & & & & $\begin{array}{c}0.283 \\
(5.715)\end{array}$ & \\
\hline $\begin{array}{l}\text { Labor } \\
(\log L)\end{array}$ & $\begin{array}{c}0.385 \\
(26.302) \\
\end{array}$ & & & & & \\
\hline $\begin{array}{l}\text { Capital } \\
(\log K)\end{array}$ & $\begin{array}{c}0.225 \\
(11.980) \\
\end{array}$ & & & & & \\
\hline $\begin{array}{l}\text { State-owned } \\
\text { Enterprises } \\
\text { (log SOE) }\end{array}$ & & $\begin{array}{c}0.633 \\
(6.185)\end{array}$ & & & & \\
\hline $\begin{array}{l}\text { Citizen } \\
\text { Complaints } \\
(\log C)\end{array}$ & & & $\begin{array}{c}0.079 \\
(1.220)\end{array}$ & & & \\
\hline $\begin{array}{l}\text { Education } \\
\text { (log ed) }\end{array}$ & & & $\begin{array}{c}-0.143 \\
(-1.024)\end{array}$ & & & \\
\hline $\begin{array}{l}\text { Population } \\
\text { Density } \\
\text { (log PD) }\end{array}$ & & & $\begin{array}{c}-0.038 \\
(-1.128)\end{array}$ & & & \\
\hline $\begin{array}{l}\text { Industrial } \\
\text { Share }_{-1} \\
\left(\log S_{-1}\right)\end{array}$ & & & & $\begin{array}{c}0.914 \\
(59.739)\end{array}$ & & \\
\hline $\begin{array}{l}\text { Investments } \\
(\log V)\end{array}$ & & & & $\begin{array}{c}0.024 \\
(1.859) \\
\end{array}$ & & \\
\hline $\begin{array}{l}\text { Remoteness } \\
(\log R)\end{array}$ & & & & & $\begin{array}{c}-0.341 \\
(-3.431) \\
\end{array}$ & \\
\hline $\begin{array}{l}\text { Exchange rate } \\
(\log E R)\end{array}$ & & & & & $\begin{array}{c}-0.695 \\
(-1.825) \\
\end{array}$ & \\
\hline $\begin{array}{l}\text { Tariffs } \\
(\log T N * \log T P)\end{array}$ & & & & & $\begin{array}{c}-0.101 \\
(-1.267) \\
\end{array}$ & \\
\hline $\begin{array}{l}\text { Cumulative FDI } \\
\left(\log _{\text {CFDI }}\right)\end{array}$ & & & & & & $\begin{array}{c}0.405 \\
(4.486) \\
\end{array}$ \\
\hline $\begin{array}{l}\text { Road intensity } \\
(\log T I)\end{array}$ & & & & & & $\begin{array}{c}0.709 \\
(3.331)\end{array}$ \\
\hline $\begin{array}{l}\text { Tax rate } \\
(\log \text { Tax })\end{array}$ & & & & & & $\begin{array}{c}-0.283 \\
(-1.314) \\
\end{array}$ \\
\hline $\begin{array}{l}\text { GDP per capita } \\
\left(\log _{\left.\text {PGDP }_{-1}\right)}\right.\end{array}$ & & & & & & $\begin{array}{c}0.737 \\
(2.260)\end{array}$ \\
\hline $\begin{array}{l}\text { Regional } \\
\text { Dummy D }\end{array}$ & & & & $\begin{array}{c}-0.012 \\
(-1.572) \\
\end{array}$ & $\begin{array}{c}0.451 \\
(4.336)\end{array}$ & $\begin{array}{c}0.242 \\
(1.430) \\
\end{array}$ \\
\hline $\begin{array}{l}\text { Time Dummy } \\
\text { DT }\end{array}$ & & & & & $\begin{array}{c}0.143 \\
(1.722) \\
\end{array}$ & $\begin{array}{c}-0.866 \\
(-4.641) \\
\end{array}$ \\
\hline $\begin{array}{l}\text { Adjusted R }{ }^{2} \\
\text { Observations }\end{array}$ & $\begin{array}{l}0.980 \\
252\end{array}$ & $\begin{array}{l}0.674 \\
252\end{array}$ & $\begin{array}{l}0.079 \\
252\end{array}$ & $\begin{array}{l}0.968 \\
252\end{array}$ & $\begin{array}{l}0.865 \\
252\end{array}$ & $\begin{array}{l}0.780 \\
252\end{array}$ \\
\hline
\end{tabular}


Table E-3Linear Model 2SLS Estimates $\left(\mathrm{CO}_{2}\right.$ Emissions Case)

\begin{tabular}{|c|c|c|c|c|c|c|}
\hline & \multicolumn{3}{|c|}{ Dependent } & \multicolumn{3}{|c|}{ Variable } \\
\hline & $\begin{array}{l}\text { GDP } \\
(\log Y) \\
(1)\end{array}$ & $\begin{array}{c}\mathrm{CO}_{2} \\
(\log \mathrm{E}) \\
(2)\end{array}$ & $\begin{array}{c}\text { Levy rate } \\
\text { on IGE } \\
(\log r) \\
(3)\end{array}$ & $\begin{array}{c}\text { Industrial share } \\
(\log S) \\
(4)\end{array}$ & $\begin{array}{c}\text { Trade } \\
(\log \mathrm{T}) \\
(5)\end{array}$ & $\begin{array}{c}\text { FDI } \\
(\underset{(6)}{\log F D I)}\end{array}$ \\
\hline Constant & $\begin{array}{l}-1.255 \\
(-9.617)\end{array}$ & $\begin{array}{c}-8.596 \\
(-10.803)\end{array}$ & $\begin{array}{c}0.921 \\
(1.232)\end{array}$ & $\begin{array}{c}0.222 \\
(3.313)\end{array}$ & $\begin{array}{l}13.350 \\
(4.722)\end{array}$ & $\begin{array}{c}-1.829 \\
(-1.345)\end{array}$ \\
\hline $\begin{array}{l}\text { GDP } \\
(\log Y)\end{array}$ & & $\begin{array}{c}0.852 \\
(21.190)\end{array}$ & & $\begin{array}{c}-0.013 \\
(-1.163)\end{array}$ & $\begin{array}{c}0.471 \\
(5.515)\end{array}$ & $\begin{array}{c}0.845 \\
(3.925)\end{array}$ \\
\hline $\begin{array}{l}\text { GDP Square } \\
\left(\log ^{2} Y\right)\end{array}$ & & & & & & \\
\hline $\begin{array}{l}\text { Income } \\
(\log (\mathrm{Y} / \mathrm{P}))\end{array}$ & & & $\begin{array}{c}-0.413 \\
(-4.931)\end{array}$ & & & \\
\hline $\begin{array}{l}\text { Emissions } \\
\left(\mathrm{CO}_{2}\right)(\log \mathrm{E})\end{array}$ & $\begin{array}{c}0.178 \\
(7.764) \\
\end{array}$ & & $\begin{array}{c}0.050 \\
(1.509) \\
\end{array}$ & & & \\
\hline $\begin{array}{l}\text { Levy Rate on } \\
\text { IGE }(\log r)\end{array}$ & & $\begin{array}{c}0.149 \\
(1.425)\end{array}$ & & & & $\begin{array}{c}0.798 \\
(1.597)\end{array}$ \\
\hline $\begin{array}{l}\text { Industrial output } \\
\text { share }(\log S)\end{array}$ & & $\begin{array}{c}0.749 \\
(4.578)\end{array}$ & & & & \\
\hline $\begin{array}{l}\text { Trade } \\
(\log T)\end{array}$ & $\begin{array}{c}0.239 \\
(18.561)\end{array}$ & & & $\begin{array}{c}0.007 \\
(1.316)\end{array}$ & & \\
\hline $\begin{array}{l}\text { FDI } \\
(\log \text { FDI) }\end{array}$ & & & & & $\begin{array}{c}0.283 \\
(5.715) \\
\end{array}$ & \\
\hline $\begin{array}{l}\text { Labor } \\
(\log L)\end{array}$ & $\begin{array}{c}0.389 \\
(27.753) \\
\end{array}$ & & & & & \\
\hline $\begin{array}{l}\text { Capital } \\
(\log K)\end{array}$ & $\begin{array}{c}0.216 \\
(11.421)\end{array}$ & & & & & \\
\hline $\begin{array}{l}\text { State-owned } \\
\text { Enterprises } \\
\text { (log SOE) }\end{array}$ & & $\begin{array}{c}0.751 \\
(9.905)\end{array}$ & & & & \\
\hline $\begin{array}{l}\text { Citizen } \\
\text { Complaints } \\
\text { (log C) }\end{array}$ & & & $\begin{array}{c}0.072 \\
(1.139)\end{array}$ & & & \\
\hline $\begin{array}{l}\text { Education } \\
\text { (log ed) }\end{array}$ & & & $\begin{array}{c}-0.198 \\
(-1.469) \\
\end{array}$ & & & \\
\hline $\begin{array}{l}\text { Population } \\
\text { Density } \\
(\log \text { PD) }\end{array}$ & & & $\begin{array}{c}-0.020 \\
(-0.611)\end{array}$ & & & \\
\hline $\begin{array}{l}\text { Industrial } \\
\text { Share }_{-1} \\
\left(\log S_{-1}\right)\end{array}$ & & & & $\begin{array}{c}0.914 \\
(59.739)\end{array}$ & & \\
\hline $\begin{array}{l}\text { Investments } \\
(\log V)\end{array}$ & & & & $\begin{array}{c}0.024 \\
(1.859) \\
\end{array}$ & & \\
\hline $\begin{array}{l}\text { Remoteness } \\
(\log R)\end{array}$ & & & & & $\begin{array}{c}-0.341 \\
(-3.431) \\
\end{array}$ & \\
\hline $\begin{array}{l}\text { Exchange rate } \\
(\log E \text { R) }\end{array}$ & & & & & $\begin{array}{c}-0.695 \\
(-1.825) \\
\end{array}$ & \\
\hline $\begin{array}{l}\text { Tariffs } \\
(\log T N * \log \mathrm{TP})\end{array}$ & & & & & $\begin{array}{c}-0.101 \\
(-1.267) \\
\end{array}$ & \\
\hline $\begin{array}{l}\text { Cumulative FDI } \\
\left(\log \text { CFDI }_{-1}\right)\end{array}$ & & & & & & $\begin{array}{c}0.405 \\
(4.486) \\
\end{array}$ \\
\hline $\begin{array}{l}\text { Road intensity } \\
(\log \mathrm{TI})\end{array}$ & & & & & & $\begin{array}{c}0.709 \\
(3.331) \\
\end{array}$ \\
\hline $\begin{array}{l}\text { Tax rate } \\
(\log \text { Tax })\end{array}$ & & & & & & $\begin{array}{c}-0.283 \\
(-1.314) \\
\end{array}$ \\
\hline $\begin{array}{l}\text { GDP per capita } \\
\left(\log _{\text {PGDP }}\right)\end{array}$ & & & & & & $\begin{array}{c}0.737 \\
(2.260) \\
\end{array}$ \\
\hline $\begin{array}{l}\text { Regional } \\
\text { Dummy D }\end{array}$ & & & & $\begin{array}{c}-0.012 \\
(-1.572) \\
\end{array}$ & $\begin{array}{c}0.451 \\
(4.336) \\
\end{array}$ & $\begin{array}{c}0.242 \\
(1.430) \\
\end{array}$ \\
\hline $\begin{array}{l}\text { Time Dummy } \\
\text { DT }\end{array}$ & & & & & $\begin{array}{c}0.143 \\
(1.722) \\
\end{array}$ & $\begin{array}{c}-0.866 \\
(-4.641) \\
\end{array}$ \\
\hline $\begin{array}{l}\text { Adjusted } \mathrm{R}^{2} \\
\text { Observations }\end{array}$ & $\begin{array}{l}0.981 \\
252\end{array}$ & $\begin{array}{l}0.745 \\
252 \\
\end{array}$ & $\begin{array}{l}0.112 \\
252\end{array}$ & $\begin{array}{l}0.968 \\
252\end{array}$ & $\begin{array}{l}0.865 \\
252\end{array}$ & $\begin{array}{l}0.780 \\
252\end{array}$ \\
\hline
\end{tabular}


Table E-4 Linear Model 2SLS Estimates ( $\mathrm{SO}_{2}$ Emissions Case)

\begin{tabular}{|c|c|c|c|c|c|c|}
\hline & \multicolumn{3}{|c|}{ Dependent } & \multicolumn{3}{|c|}{ Variable } \\
\hline & $\begin{array}{c}\text { GDP } \\
(\log Y) \\
(1)\end{array}$ & $\begin{array}{c}\mathrm{SO}_{2} \\
(\log \mathrm{E}) \\
(2)\end{array}$ & $\begin{array}{c}\text { Levy rate } \\
\text { on IGE } \\
(\log r) \\
\text { (3) }\end{array}$ & $\begin{array}{c}\text { Industrial share } \\
(\log S) \\
(4)\end{array}$ & $\begin{array}{l}\text { Trade } \\
(\log \mathrm{T}) \\
(5)\end{array}$ & $\begin{array}{c}\text { FDI } \\
(\underset{(6)}{\log \text { FDI })}\end{array}$ \\
\hline Constant & $\begin{array}{c}-2.435 \\
(-13.728) \\
\end{array}$ & $\begin{array}{c}5.251 \\
(3.921) \\
\end{array}$ & $\begin{array}{c}0.297 \\
(0.287) \\
\end{array}$ & $\begin{array}{c}0.222 \\
(3.313) \\
\end{array}$ & $\begin{array}{l}13.350 \\
(4.722) \\
\end{array}$ & $\begin{array}{c}-1.829 \\
(-1.345) \\
\end{array}$ \\
\hline $\begin{array}{l}\text { GDP } \\
(\log Y)\end{array}$ & & $\begin{array}{c}0.886 \\
(11.344)\end{array}$ & & $\begin{array}{c}-0.013 \\
(-1.163)\end{array}$ & $\begin{array}{c}0.471 \\
(5.515)\end{array}$ & $\begin{array}{c}0.845 \\
(3.925)\end{array}$ \\
\hline $\begin{array}{l}\text { GDP Square } \\
\left(\log ^{2} Y\right)\end{array}$ & & & & & & \\
\hline $\begin{array}{l}\text { Income } \\
(\log (Y / P))\end{array}$ & & & $\begin{array}{c}-0.394 \\
(-4.547)\end{array}$ & & & \\
\hline $\begin{array}{l}\text { Emissions } \\
\left(\mathrm{SO}_{2}\right)(\log \mathrm{E}) \\
\end{array}$ & $\begin{array}{c}0.106 \\
(3.994) \\
\end{array}$ & & $\begin{array}{c}0.057 \\
(1.230) \\
\end{array}$ & & & \\
\hline $\begin{array}{l}\text { Levy Rate on } \\
\text { IGE }(\log r)\end{array}$ & & $\begin{array}{c}0.136 \\
(0.917) \\
\end{array}$ & & & & $\begin{array}{c}0.798 \\
(1.597) \\
\end{array}$ \\
\hline $\begin{array}{l}\text { Industrial output } \\
\text { share }(\log \mathrm{S})\end{array}$ & & $\begin{array}{c}-0.137 \\
(-0.668) \\
\end{array}$ & & & & \\
\hline $\begin{array}{l}\text { Trade } \\
(\log T)\end{array}$ & $\begin{array}{c}0.246 \\
(17.373) \\
\end{array}$ & & & $\begin{array}{c}0.007 \\
(1.316) \\
\end{array}$ & & \\
\hline $\begin{array}{l}\text { FDI } \\
(\log \text { FDI })\end{array}$ & & & & & $\begin{array}{c}0.283 \\
(5.715) \\
\end{array}$ & \\
\hline $\begin{array}{l}\text { Labor } \\
(\log L)\end{array}$ & $\begin{array}{c}0.392 \\
(18.000)\end{array}$ & & & & & \\
\hline $\begin{array}{l}\text { Capital } \\
(\log K)\end{array}$ & $\begin{array}{c}0.250 \\
(12.065)\end{array}$ & & & & & \\
\hline $\begin{array}{l}\text { State-owned } \\
\text { Enterprises } \\
\text { (log SOE) }\end{array}$ & & $\begin{array}{c}0.595 \\
(4.223)\end{array}$ & & & & \\
\hline $\begin{array}{l}\text { Citizen } \\
\text { Complaints } \\
(\log C)\end{array}$ & & & $\begin{array}{l}0.076 \\
(1.201)\end{array}$ & & & \\
\hline $\begin{array}{l}\begin{array}{l}\text { Education } \\
\text { (log ed) }\end{array} \\
\end{array}$ & & & $\begin{array}{c}-0.196 \\
(-1.481) \\
\end{array}$ & & & \\
\hline $\begin{array}{l}\text { Population } \\
\text { Density } \\
\text { (log PD) }\end{array}$ & & & $\begin{array}{l}-0.029 \\
(-0.815)\end{array}$ & & & \\
\hline $\begin{array}{l}\text { Industrial } \\
\text { Share }-1 \\
\left(\operatorname{log~S}_{-1}\right) \\
\end{array}$ & & & & $\begin{array}{c}0.914 \\
(59.739)\end{array}$ & & \\
\hline $\begin{array}{l}\text { Investments } \\
(\log V)\end{array}$ & & & & $\begin{array}{c}0.024 \\
(1.859) \\
\end{array}$ & & \\
\hline $\begin{array}{l}\text { Remoteness } \\
(\log \mathrm{R})\end{array}$ & & & & & $\begin{array}{c}-0.341 \\
(-3.431) \\
\end{array}$ & \\
\hline $\begin{array}{l}\text { Exchange rate } \\
(\log E \text { R })\end{array}$ & & & & & $\begin{array}{c}-0.695 \\
(-1.825) \\
\end{array}$ & \\
\hline $\begin{array}{l}\text { Tariffs } \\
(\log T N * \log T P)\end{array}$ & & & & & $\begin{array}{c}-0.101 \\
(-1.267) \\
\end{array}$ & \\
\hline $\begin{array}{l}\text { Cumulative FDI } \\
\left(\log \text { CFDI }_{-1}\right)\end{array}$ & & & & & & $\begin{array}{c}0.405 \\
(4.486) \\
\end{array}$ \\
\hline $\begin{array}{l}\text { Road intensity } \\
(\log T I)\end{array}$ & & & & & & $\begin{array}{c}0.709 \\
(3.331) \\
\end{array}$ \\
\hline $\begin{array}{l}\text { Tax rate } \\
(\log \text { Tax }) \\
\end{array}$ & & & & & & $\begin{array}{c}-0.283 \\
(-1.314) \\
\end{array}$ \\
\hline $\begin{array}{l}\text { GDP per capita } \\
\left(\log _{\left.\text {PGDP }_{-1}\right)}\right.\end{array}$ & & & & & & $\begin{array}{c}0.737 \\
(2.260) \\
\end{array}$ \\
\hline $\begin{array}{l}\text { Regional } \\
\text { Dummy D }\end{array}$ & & & & $\begin{array}{c}-0.012 \\
(-1.572) \\
\end{array}$ & $\begin{array}{c}0.451 \\
(4.336) \\
\end{array}$ & $\begin{array}{c}0.242 \\
(1.430) \\
\end{array}$ \\
\hline $\begin{array}{l}\text { Time Dummy } \\
\text { DT }\end{array}$ & & & & & $\begin{array}{c}0.143 \\
(1.722) \\
\end{array}$ & $\begin{array}{c}-0.866 \\
(-4.641) \\
\end{array}$ \\
\hline $\begin{array}{l}\text { Adjusted } \mathrm{R}^{2} \\
\text { Observations }\end{array}$ & $\begin{array}{l}0.975 \\
252\end{array}$ & $\begin{array}{l}0.518 \\
252\end{array}$ & $\begin{array}{l}0.098 \\
252\end{array}$ & $\begin{array}{l}0.968 \\
252\end{array}$ & $\begin{array}{l}0.865 \\
252\end{array}$ & $\begin{array}{l}0.780 \\
252\end{array}$ \\
\hline
\end{tabular}


Table E-5 Linear Model 2SLS Estimates (Particle Emissions Case)

\begin{tabular}{|c|c|c|c|c|c|c|}
\hline & \multicolumn{3}{|c|}{ Dependent } & \multicolumn{3}{|c|}{ Variable } \\
\hline & $\begin{array}{c}\text { GDP } \\
(\log Y) \\
(1)\end{array}$ & $\begin{array}{l}\text { Particles } \\
(\log E) \\
(2)\end{array}$ & $\begin{array}{l}\text { Levy rate } \\
\text { on IGE } \\
(\log r) \\
\text { (3) }\end{array}$ & $\begin{array}{c}\text { Industrial share } \\
\qquad(\log S) \\
(4)\end{array}$ & $\begin{array}{l}\text { Trade } \\
(\log T) \\
(5)\end{array}$ & $\begin{array}{c}\text { FDI } \\
(\log \text { FDI }) \\
(6)\end{array}$ \\
\hline Constant & $\begin{array}{c}-2.834 \\
(-19.470)\end{array}$ & $\begin{array}{c}0.935 \\
(0.733)\end{array}$ & $\begin{array}{c}1.053 \\
(1.090)\end{array}$ & $\begin{array}{c}0.222 \\
(3.313)\end{array}$ & $\begin{array}{l}13.350 \\
(4.722)\end{array}$ & $\begin{array}{c}-1.829 \\
(-1.345)\end{array}$ \\
\hline $\begin{array}{l}\text { GDP } \\
(\log Y)\end{array}$ & & $\begin{array}{c}0.845 \\
(15.660)\end{array}$ & & $\begin{array}{c}-0.013 \\
(-1.163)\end{array}$ & $\begin{array}{c}0.471 \\
(5.515)\end{array}$ & $\begin{array}{c}0.845 \\
(3.925)\end{array}$ \\
\hline $\begin{array}{l}\text { GDP Square } \\
\left(\log ^{2} Y\right)\end{array}$ & & & & & & \\
\hline $\begin{array}{l}\text { Income } \\
(\log (Y / P))\end{array}$ & & & $\begin{array}{c}-0.419 \\
(-4.913)\end{array}$ & & & \\
\hline $\begin{array}{l}\text { Emissions } \\
\text { (Particle) (log E) }\end{array}$ & $\begin{array}{c}0.133 \\
(8.422) \\
\end{array}$ & & $\begin{array}{c}0.013 \\
(0.338) \\
\end{array}$ & & & \\
\hline $\begin{array}{l}\text { Levy Rate on } \\
\text { IGE }(\log r)\end{array}$ & & $\begin{array}{c}0.353 \\
(2.254)\end{array}$ & & & & $\begin{array}{c}0.798 \\
(1.597)\end{array}$ \\
\hline $\begin{array}{l}\text { Industrial output } \\
\text { share }(\log S)\end{array}$ & & $\begin{array}{c}0.386 \\
(1.511)\end{array}$ & & & & \\
\hline $\begin{array}{l}\text { Trade } \\
(\log T)\end{array}$ & $\begin{array}{c}0.260 \\
(19.985)\end{array}$ & & & $\begin{array}{c}0.007 \\
(1.316) \\
\end{array}$ & & \\
\hline $\begin{array}{l}\text { FDI } \\
(\log \text { FDI) }\end{array}$ & & & & & $\begin{array}{c}0.283 \\
(5.715)\end{array}$ & \\
\hline $\begin{array}{l}\text { Labor } \\
(\log L)\end{array}$ & $\begin{array}{c}0.389 \\
(28.700)\end{array}$ & & & & & \\
\hline $\begin{array}{l}\text { Capital } \\
(\log K)\end{array}$ & $\begin{array}{c}0.238 \\
(12.146)\end{array}$ & & & & & \\
\hline $\begin{array}{l}\text { State-owned } \\
\text { Enterprises } \\
\text { (log SOE) }\end{array}$ & & $\begin{array}{c}1.129 \\
(8.464)\end{array}$ & & & & \\
\hline $\begin{array}{l}\text { Citizen } \\
\text { Complaints } \\
\text { (log C) }\end{array}$ & & & $\begin{array}{c}0.065 \\
(1.044)\end{array}$ & & & \\
\hline $\begin{array}{l}\text { Education } \\
\text { (log ed) }\end{array}$ & & & $\begin{array}{c}-0.230 \\
(-1.683) \\
\end{array}$ & & & \\
\hline $\begin{array}{l}\text { Population } \\
\text { Density } \\
\text { (log PD) }\end{array}$ & & & $\begin{array}{c}-0.008 \\
(-0.288)\end{array}$ & & & \\
\hline $\begin{array}{l}\text { Industrial } \\
\text { Share } 1 \\
\left(\log S_{-1}\right)\end{array}$ & & & & $\begin{array}{c}0.914 \\
(59.739)\end{array}$ & & \\
\hline $\begin{array}{l}\text { Investments } \\
(\log V)\end{array}$ & & & & $\begin{array}{c}0.024 \\
(1.859) \\
\end{array}$ & & \\
\hline $\begin{array}{l}\text { Remoteness } \\
(\log R)\end{array}$ & & & & & $\begin{array}{c}-0.341 \\
(-3.431) \\
\end{array}$ & \\
\hline $\begin{array}{l}\text { Exchange rate } \\
(\log E \mathrm{R})\end{array}$ & & & & & $\begin{array}{c}-0.695 \\
(-1.825) \\
\end{array}$ & \\
\hline $\begin{array}{l}\text { Tariffs } \\
(\log T N * \log T P)\end{array}$ & & & & & $\begin{array}{c}-0.101 \\
(-1.267) \\
\end{array}$ & \\
\hline $\begin{array}{l}\text { Cumulative FDI } \\
\left(\log \text { CFDI }_{-1}\right)\end{array}$ & & & & & & $\begin{array}{c}0.405 \\
(4.486)\end{array}$ \\
\hline $\begin{array}{l}\text { Road intensity } \\
(\log T I)\end{array}$ & & & & & & $\begin{array}{c}0.709 \\
(3.331) \\
\end{array}$ \\
\hline $\begin{array}{l}\text { Tax rate } \\
(\log \text { Tax })\end{array}$ & & & & & & $\begin{array}{c}-0.283 \\
(-1.314) \\
\end{array}$ \\
\hline $\begin{array}{l}\text { GDP per capita } \\
\left(\log _{\left.\text {PGDP }_{-1}\right)}\right.\end{array}$ & & & & & & $\begin{array}{c}0.737 \\
(2.260) \\
\end{array}$ \\
\hline $\begin{array}{l}\text { Regional } \\
\text { Dummy D }\end{array}$ & & & & $\begin{array}{c}-0.012 \\
(-1.572) \\
\end{array}$ & $\begin{array}{c}0.451 \\
(4.336) \\
\end{array}$ & $\begin{array}{c}0.242 \\
(1.430) \\
\end{array}$ \\
\hline $\begin{array}{l}\text { Time Dummy } \\
\text { DT }\end{array}$ & & & & & $\begin{array}{c}0.143 \\
(1.722) \\
\end{array}$ & $\begin{array}{c}-0.866 \\
(-4.641) \\
\end{array}$ \\
\hline $\begin{array}{l}\text { Adjusted } \mathrm{R}^{2} \\
\text { Observations }\end{array}$ & $\begin{array}{l}0.980 \\
252\end{array}$ & $\begin{array}{l}0.465 \\
252\end{array}$ & $\begin{array}{l}0.117 \\
252\end{array}$ & $\begin{array}{l}0.968 \\
252\end{array}$ & $\begin{array}{c}0.865 \\
252\end{array}$ & $\begin{array}{l}0.780 \\
252 \\
\end{array}$ \\
\hline
\end{tabular}


Table E-6 Linear Model 2SLS Estimates (Dust Emissions Case)

\begin{tabular}{|c|c|c|c|c|c|c|}
\hline & \multicolumn{3}{|c|}{ Dependent } & \multicolumn{3}{|c|}{ Variable } \\
\hline & $\begin{array}{c}\text { GDP } \\
(\log Y) \\
(1)\end{array}$ & $\begin{array}{l}\text { Dust } \\
(\log E) \\
(2)\end{array}$ & $\begin{array}{l}\text { Levy rate } \\
\text { on IGE } \\
(\log r) \\
\text { (3) }\end{array}$ & $\begin{array}{c}\text { Industrial share } \\
\qquad(\log S) \\
(4)\end{array}$ & $\begin{array}{l}\text { Trade } \\
(\log T) \\
(5)\end{array}$ & $\begin{array}{c}\text { FDI } \\
(\log \text { FDI }) \\
(6)\end{array}$ \\
\hline Constant & $\begin{array}{c}-2.520 \\
(-13.300)\end{array}$ & $\begin{array}{l}7.248 \\
(4.844)\end{array}$ & $\begin{array}{c}-2.286 \\
(-2.080)\end{array}$ & $\begin{array}{c}0.222 \\
(3.313)\end{array}$ & $\begin{array}{l}13.350 \\
(4.722)\end{array}$ & $\begin{array}{c}-1.829 \\
(-1.345)\end{array}$ \\
\hline $\begin{array}{l}\text { GDP } \\
(\log Y)\end{array}$ & & $\begin{array}{c}0.641 \\
(7.425)\end{array}$ & & $\begin{array}{c}-0.013 \\
(-1.163)\end{array}$ & $\begin{array}{c}0.471 \\
(5.515)\end{array}$ & $\begin{array}{c}0.845 \\
(3.925)\end{array}$ \\
\hline $\begin{array}{l}\text { GDP Square } \\
\left(\log ^{2} Y\right)\end{array}$ & & & & & & \\
\hline $\begin{array}{l}\text { Income } \\
(\log (Y / P))\end{array}$ & & & $\begin{array}{c}-0.139 \\
(-1.617)\end{array}$ & & & \\
\hline $\begin{array}{l}\text { Emissions } \\
\text { (Dust) (log E) }\end{array}$ & $\begin{array}{c}0.143 \\
(5.244) \\
\end{array}$ & & $\begin{array}{c}0.257 \\
(4.784) \\
\end{array}$ & & & \\
\hline $\begin{array}{l}\text { Levy Rate on } \\
\text { IGE }(\log r)\end{array}$ & & $\begin{array}{c}1.458 \\
(7.090)\end{array}$ & & & & $\begin{array}{c}0.798 \\
(1.597)\end{array}$ \\
\hline $\begin{array}{l}\text { Industrial output } \\
\text { share }(\log S)\end{array}$ & & $\begin{array}{c}-0.643 \\
(-2.226)\end{array}$ & & & & \\
\hline $\begin{array}{l}\text { Trade } \\
(\log T)\end{array}$ & $\begin{array}{c}0.214 \\
(12.611)\end{array}$ & & & $\begin{array}{c}0.007 \\
(1.316) \\
\end{array}$ & & \\
\hline $\begin{array}{l}\text { FDI } \\
(\log \text { FDI) }\end{array}$ & & & & & $\begin{array}{c}0.283 \\
(5.715)\end{array}$ & \\
\hline $\begin{array}{l}\text { Labor } \\
(\log L)\end{array}$ & $\begin{array}{c}0.321 \\
(10.867)\end{array}$ & & & & & \\
\hline $\begin{array}{l}\text { Capital } \\
(\log K)\end{array}$ & $\begin{array}{c}0.343 \\
(13.253)\end{array}$ & & & & & \\
\hline $\begin{array}{l}\text { State-owned } \\
\text { Enterprises } \\
\text { (log SOE) }\end{array}$ & & $\begin{array}{c}0.249 \\
(1.441)\end{array}$ & & & & \\
\hline $\begin{array}{l}\text { Citizen } \\
\text { Complaints } \\
\text { (log C) }\end{array}$ & & & $\begin{array}{c}0.067 \\
(1.042)\end{array}$ & & & \\
\hline $\begin{array}{l}\text { Education } \\
\text { (log ed) }\end{array}$ & & & $\begin{array}{l}-0.037 \\
(0.276) \\
\end{array}$ & & & \\
\hline $\begin{array}{l}\text { Population } \\
\text { Density } \\
\text { (log PD) }\end{array}$ & & & $\begin{array}{c}-0.072 \\
(-2.183)\end{array}$ & & & \\
\hline $\begin{array}{l}\text { Industrial } \\
\text { Share } 1 \\
\left(\log S_{-1}\right)\end{array}$ & & & & $\begin{array}{c}0.914 \\
(59.739)\end{array}$ & & \\
\hline $\begin{array}{l}\text { Investments } \\
(\log V)\end{array}$ & & & & $\begin{array}{c}0.024 \\
(1.859) \\
\end{array}$ & & \\
\hline $\begin{array}{l}\text { Remoteness } \\
(\log R)\end{array}$ & & & & & $\begin{array}{c}-0.341 \\
(-3.431) \\
\end{array}$ & \\
\hline $\begin{array}{l}\text { Exchange rate } \\
(\log E \mathrm{R})\end{array}$ & & & & & $\begin{array}{c}-0.695 \\
(-1.825) \\
\end{array}$ & \\
\hline $\begin{array}{l}\text { Tariffs } \\
(\log T N * \log T P)\end{array}$ & & & & & $\begin{array}{c}-0.101 \\
(-1.267) \\
\end{array}$ & \\
\hline $\begin{array}{l}\text { Cumulative FDI } \\
\left(\log \text { CFDI }_{-1}\right)\end{array}$ & & & & & & $\begin{array}{c}0.405 \\
(4.486)\end{array}$ \\
\hline $\begin{array}{l}\text { Road intensity } \\
(\log T I)\end{array}$ & & & & & & $\begin{array}{c}0.709 \\
(3.331) \\
\end{array}$ \\
\hline $\begin{array}{l}\text { Tax rate } \\
(\log \text { Tax })\end{array}$ & & & & & & $\begin{array}{c}-0.283 \\
(-1.314) \\
\end{array}$ \\
\hline $\begin{array}{l}\text { GDP per capita } \\
\left(\log _{\left.\text {PGDP }_{-1}\right)}\right.\end{array}$ & & & & & & $\begin{array}{c}0.737 \\
(2.260) \\
\end{array}$ \\
\hline $\begin{array}{l}\text { Regional } \\
\text { Dummy D }\end{array}$ & & & & $\begin{array}{c}-0.012 \\
(-1.572) \\
\end{array}$ & $\begin{array}{c}0.451 \\
(4.336) \\
\end{array}$ & $\begin{array}{c}0.242 \\
(1.430) \\
\end{array}$ \\
\hline $\begin{array}{l}\text { Time Dummy } \\
\text { DT }\end{array}$ & & & & & $\begin{array}{c}0.143 \\
(1.722) \\
\end{array}$ & $\begin{array}{c}-0.866 \\
(-4.641) \\
\end{array}$ \\
\hline $\begin{array}{l}\text { Adjusted } \mathrm{R}^{2} \\
\text { Observations }\end{array}$ & $\begin{array}{l}0.976 \\
252\end{array}$ & $\begin{array}{l}0.185 \\
252\end{array}$ & $\begin{array}{l}0.122 \\
252\end{array}$ & $\begin{array}{l}0.968 \\
252\end{array}$ & $\begin{array}{c}0.865 \\
252\end{array}$ & $\begin{array}{l}0.780 \\
252 \\
\end{array}$ \\
\hline
\end{tabular}




\section{Appendix F: 2SLS Results with Data from 1987-1993}

Table F-1 Industrial Wastewater Pollution (IWW) Case

\begin{tabular}{|c|c|c|c|c|c|c|}
\hline & \multicolumn{3}{|c|}{ Dependent } & \multicolumn{3}{|c|}{ Variable } \\
\hline & $\begin{array}{c}\text { GDP } \\
(\log Y) \\
(1)\end{array}$ & $\begin{array}{c}\text { IWW } \\
(\log E) \\
(2)\end{array}$ & $\begin{array}{c}\text { Levy rate } \\
\text { on IGE } \\
(\log r) \\
\text { (3) }\end{array}$ & $\begin{array}{c}\text { Industrial share } \\
(\log S) \\
(4)\end{array}$ & $\begin{array}{c}\text { Trade } \\
(\log \mathrm{T}) \\
(5)\end{array}$ & $\begin{array}{c}\text { FDI } \\
\left(\begin{array}{c}\log \text { FDI }) \\
(6)\end{array}\right.\end{array}$ \\
\hline Constant & $\begin{array}{c}-1.098 \\
(-8.521)\end{array}$ & $\begin{array}{c}-5.134 \\
(-3.499)\end{array}$ & $\begin{array}{c}5.161 \\
(8.571)\end{array}$ & $\begin{array}{c}0.274 \\
(3.494)\end{array}$ & $\begin{array}{l}10.194 \\
(3.485)\end{array}$ & $\begin{array}{c}-4.347 \\
(-1.993)\end{array}$ \\
\hline $\begin{array}{l}\text { GDP } \\
(\log Y) \\
\end{array}$ & & $\begin{array}{c}2.381 \\
(5.531) \\
\end{array}$ & & $\begin{array}{c}-0.023 \\
(-1.828) \\
\end{array}$ & $\begin{array}{c}0.780 \\
(12.052) \\
\end{array}$ & $\begin{array}{c}1.103 \\
(5.424) \\
\end{array}$ \\
\hline $\begin{array}{l}\text { GDP Square } \\
\left(\log ^{2} Y\right)\end{array}$ & & $\begin{array}{c}-0.100 \\
(-2.881)\end{array}$ & & & & \\
\hline $\begin{array}{l}\text { Income } \\
(\log (Y / P))\end{array}$ & & & $\begin{array}{c}0.319 \\
(3.789) \\
\end{array}$ & & & \\
\hline $\begin{array}{l}\text { Emissions } \\
\text { (IWW) (log E) }\end{array}$ & $\begin{array}{c}0.147 \\
(6.244) \\
\end{array}$ & & $\begin{array}{c}-0.063 \\
(-1.979) \\
\end{array}$ & & & \\
\hline $\begin{array}{l}\text { Levy Rate on } \\
\text { IWW }(\log r)\end{array}$ & & $\begin{array}{c}-0.604 \\
(-7.923)\end{array}$ & & & & $\begin{array}{c}0.270 \\
(0.851)\end{array}$ \\
\hline $\begin{array}{l}\text { Industrial output } \\
\text { share }(\log S)\end{array}$ & & $\begin{array}{c}0.083 \\
(0.529)\end{array}$ & & & & \\
\hline $\begin{array}{l}\text { Trade } \\
(\log T)\end{array}$ & $\begin{array}{c}0.160 \\
(9.484)\end{array}$ & & & $\begin{array}{c}0.004 \\
(0.723)\end{array}$ & & \\
\hline $\begin{array}{l}\text { FDI } \\
(\log \text { FDI) }\end{array}$ & & & & & $\begin{array}{c}0.099 \\
(3.203)\end{array}$ & \\
\hline $\begin{array}{l}\text { Labor } \\
(\log \mathrm{L})\end{array}$ & $\begin{array}{c}0.344 \\
(15.398)\end{array}$ & & & & & \\
\hline $\begin{array}{l}\text { Capital } \\
(\log K)\end{array}$ & $\begin{array}{c}0.318 \\
(14.706)\end{array}$ & & & & & \\
\hline $\begin{array}{l}\text { State-owned } \\
\text { Enterprises } \\
\text { (log SOE) }\end{array}$ & & $\begin{array}{c}0.279 \\
(2.696)\end{array}$ & & & & \\
\hline $\begin{array}{l}\text { Citizen } \\
\text { Complaints } \\
\text { (log C) }\end{array}$ & & & $\begin{array}{c}-0.218 \\
(-3.420)\end{array}$ & & & \\
\hline $\begin{array}{l}\text { Education } \\
\text { (log ed) }\end{array}$ & & & $\begin{array}{c}-0.424 \\
(-4.581) \\
\end{array}$ & & & \\
\hline $\begin{array}{l}\text { Population } \\
\text { Density } \\
\text { (log PD) }\end{array}$ & & & $\begin{array}{c}0.143 \\
(4.658)\end{array}$ & & & \\
\hline $\begin{array}{l}\text { Industrial } \\
\text { Share } \\
\left(\log S_{-1}\right)\end{array}$ & & & & $\begin{array}{c}0.907 \\
(54.651)\end{array}$ & & \\
\hline $\begin{array}{l}\text { Investments } \\
(\log \mathrm{V})\end{array}$ & & & & $\begin{array}{c}0.039 \\
(2.767) \\
\end{array}$ & & \\
\hline $\begin{array}{l}\text { Remoteness } \\
(\log R)\end{array}$ & & & & & $\begin{array}{c}-0.469 \\
(-4.352)\end{array}$ & \\
\hline $\begin{array}{l}\text { Exchange rate } \\
(\log E \mathrm{R})\end{array}$ & & & & & $\begin{array}{c}-0.194 \\
(-0.520)\end{array}$ & \\
\hline $\begin{array}{l}\text { Tariffs } \\
(\operatorname{LogTN} * \log \mathrm{TP})\end{array}$ & & & & & $\begin{array}{c}-0.012 \\
(-0.178) \\
\end{array}$ & \\
\hline $\begin{array}{l}\text { Cumulative FDI } \\
\left(\log C^{2} I_{-1}\right)\end{array}$ & & & & & & $\begin{array}{c}0.360 \\
(3.468) \\
\end{array}$ \\
\hline $\begin{array}{l}\text { Road intensity } \\
(\log T \mathrm{~T})\end{array}$ & & & & & & $\begin{array}{c}0.708 \\
(3.099)\end{array}$ \\
\hline $\begin{array}{l}\text { Tax rate } \\
(\log \text { Tax })\end{array}$ & & & & & & $\begin{array}{c}0.209 \\
(0.565)\end{array}$ \\
\hline $\begin{array}{l}\text { GDP per capita } \\
\left(\log _{\text {PGDP }}\right)\end{array}$ & & & & & & $\begin{array}{c}0.226 \\
(0.681)\end{array}$ \\
\hline $\begin{array}{l}\text { Regional } \\
\text { Dummy D }\end{array}$ & & & & $\begin{array}{c}-0.006 \\
(-0.714)\end{array}$ & $\begin{array}{c}0.588 \\
(4.849)\end{array}$ & $\begin{array}{c}0.446 \\
(1.851)\end{array}$ \\
\hline $\begin{array}{l}\text { Time Dummy } \\
\text { DT }\end{array}$ & & & & & $\begin{array}{c}0.024 \\
(0.311)\end{array}$ & $\begin{array}{c}-0.764 \\
(-4.091)\end{array}$ \\
\hline $\begin{array}{l}\text { Adjusted } \mathrm{R}^{2} \\
\text { Observations }\end{array}$ & $\begin{array}{l}0.981 \\
252\end{array}$ & $\begin{array}{l}0.843 \\
252\end{array}$ & $\begin{array}{c}0.426 \\
252\end{array}$ & $\begin{array}{l}0.966 \\
252\end{array}$ & $\begin{array}{c}0.880 \\
252\end{array}$ & $\begin{array}{l}0.755 \\
252\end{array}$ \\
\hline
\end{tabular}


Table F-2 Industrial Waste Gas Emissions (IGE) Case

\begin{tabular}{|c|c|c|c|c|c|c|}
\hline & \multicolumn{3}{|c|}{ Dependent } & \multicolumn{3}{|c|}{ Variable } \\
\hline & $\begin{array}{c}\text { GDP } \\
(\log Y) \\
(1)\end{array}$ & $\begin{array}{c}\text { IGE } \\
(\log E) \\
(2)\end{array}$ & $\begin{array}{c}\text { Levy rate } \\
\text { on IGE } \\
(\log r) \\
(3)\end{array}$ & $\begin{array}{l}\text { Industrial share } \\
\qquad \begin{array}{c}(\log S) \\
(4)\end{array}\end{array}$ & $\begin{array}{c}\text { Trade } \\
(\log \mathrm{T}) \\
(5)\end{array}$ & $\begin{array}{c}\text { FDI } \\
\left(\begin{array}{c}\log \text { FDI }) \\
(6)\end{array}\right.\end{array}$ \\
\hline Constant & $\begin{array}{c}-1.414 \\
(-13.065)\end{array}$ & $\begin{array}{l}-5.041 \\
(-5.193)\end{array}$ & $\begin{array}{c}1.514 \\
(1.965)\end{array}$ & $\begin{array}{c}0.274 \\
(3.494)\end{array}$ & $\begin{array}{l}10.194 \\
(3.485)\end{array}$ & $\begin{array}{c}-3.875 \\
(-1.907)\end{array}$ \\
\hline $\begin{array}{l}\text { GDP } \\
(\log Y)\end{array}$ & & $\begin{array}{c}0.639 \\
(2.192)\end{array}$ & & $\begin{array}{c}-0.023 \\
(-1.828)\end{array}$ & $\begin{array}{c}0.780 \\
(12.052)\end{array}$ & $\begin{array}{c}1.179 \\
(5.193)\end{array}$ \\
\hline $\begin{array}{l}\text { GDP Square } \\
\left(\log ^{2} Y\right)\end{array}$ & & $\begin{array}{c}0.020 \\
(0.812)\end{array}$ & & & & \\
\hline $\begin{array}{l}\text { Income } \\
(\log (\mathrm{Y} / \mathrm{P}))\end{array}$ & & & $\begin{array}{c}-0.431 \\
(-5.663)\end{array}$ & & & \\
\hline $\begin{array}{l}\text { Emissions } \\
\text { (IGE) }(\log E)\end{array}$ & $\begin{array}{c}0.171 \\
(9.379) \\
\end{array}$ & & $\begin{array}{c}0.020 \\
(0.339) \\
\end{array}$ & & & \\
\hline $\begin{array}{l}\text { Levy Rate on } \\
\text { IGE }(\log r)\end{array}$ & & $\begin{array}{c}-0.039 \\
(-0.530)\end{array}$ & & & & $\begin{array}{c}-0.165 \\
(-0.669)\end{array}$ \\
\hline $\begin{array}{l}\text { Industrial output } \\
\text { share }(\log S)\end{array}$ & & $\begin{array}{c}0.699 \\
(5.742)\end{array}$ & & & & \\
\hline $\begin{array}{l}\text { Trade } \\
(\log T)\end{array}$ & $\begin{array}{c}0.192 \\
(13.834)\end{array}$ & & & $\begin{array}{c}0.004 \\
(0.723)\end{array}$ & & \\
\hline $\begin{array}{l}\text { FDI } \\
(\log \text { FDI) }\end{array}$ & & & & & $\begin{array}{c}0.099 \\
(3.203) \\
\end{array}$ & \\
\hline $\begin{array}{l}\text { Labor } \\
(\log L)\end{array}$ & $\begin{array}{c}0.401 \\
(30.566) \\
\end{array}$ & & & & & \\
\hline $\begin{array}{l}\text { Capital } \\
(\log K)\end{array}$ & $\begin{array}{c}0.245 \\
(12.889)\end{array}$ & & & & & \\
\hline $\begin{array}{l}\text { State-owned } \\
\text { Enterprises } \\
\text { (log SOE) }\end{array}$ & & $\begin{array}{c}0.780 \\
(8.982)\end{array}$ & & & & \\
\hline $\begin{array}{l}\text { Citizen } \\
\text { Complaints } \\
\text { (log C) }\end{array}$ & & & $\begin{array}{c}0.040 \\
(1.005)\end{array}$ & & & \\
\hline $\begin{array}{l}\text { Education } \\
\text { (log ed) }\end{array}$ & & & $\begin{array}{c}-0.359 \\
(-3.428) \\
\end{array}$ & & & \\
\hline $\begin{array}{l}\text { Population } \\
\text { Density } \\
(\log \text { PD) }\end{array}$ & & & $\begin{array}{c}-0.041 \\
(-1.252)\end{array}$ & & & \\
\hline $\begin{array}{l}\text { Industrial } \\
\text { Share }_{-1} \\
\left(\log S_{-1}\right)\end{array}$ & & & & $\begin{array}{c}0.907 \\
(54.651)\end{array}$ & & \\
\hline $\begin{array}{l}\text { Investments } \\
(\log V)\end{array}$ & & & & $\begin{array}{c}0.039 \\
(2.767) \\
\end{array}$ & & \\
\hline $\begin{array}{l}\text { Remoteness } \\
(\log R)\end{array}$ & & & & & $\begin{array}{c}-0.469 \\
(--4.352) \\
\end{array}$ & \\
\hline $\begin{array}{l}\text { Exchange rate } \\
(\log E \text { R) }\end{array}$ & & & & & $\begin{array}{c}-0.194 \\
(-0.520) \\
\end{array}$ & \\
\hline $\begin{array}{l}\text { Tariffs } \\
(\log T N * \log \mathrm{TP})\end{array}$ & & & & & $\begin{array}{c}-0.012 \\
(-0.178) \\
\end{array}$ & \\
\hline $\begin{array}{l}\text { Cumulative FDI } \\
\left(\log \text { CFDI }_{-1}\right)\end{array}$ & & & & & & $\begin{array}{c}0.350 \\
(3.333)\end{array}$ \\
\hline $\begin{array}{l}\text { Road intensity } \\
(\log \mathrm{TI})\end{array}$ & & & & & & $\begin{array}{c}0.695 \\
(3.041) \\
\end{array}$ \\
\hline $\begin{array}{l}\text { Tax rate } \\
(\log \text { Tax })\end{array}$ & & & & & & $\begin{array}{c}0.177 \\
(0.483)\end{array}$ \\
\hline $\begin{array}{l}\text { GDP per capita } \\
\left(\log _{\text {PGDP }}\right)\end{array}$ & & & & & & $\begin{array}{c}0.294 \\
(0.957) \\
\end{array}$ \\
\hline $\begin{array}{l}\text { Regional } \\
\text { Dummy D }\end{array}$ & & & & $\begin{array}{c}-0.006 \\
(-0.714) \\
\end{array}$ & $\begin{array}{c}0.588 \\
(4.849) \\
\end{array}$ & $\begin{array}{c}0.480 \\
(2.032) \\
\end{array}$ \\
\hline $\begin{array}{l}\text { Time Dummy } \\
\text { DT }\end{array}$ & & & & & $\begin{array}{c}0.024 \\
(0.311) \\
\end{array}$ & $\begin{array}{c}-0.782 \\
(-4.195) \\
\end{array}$ \\
\hline $\begin{array}{l}\text { Adjusted } \mathrm{R}^{2} \\
\text { Observations }\end{array}$ & $\begin{array}{l}0.983 \\
252\end{array}$ & $\begin{array}{l}0.810 \\
252\end{array}$ & $\begin{array}{l}0.176 \\
252\end{array}$ & $\begin{array}{l}0.966 \\
252\end{array}$ & $\begin{array}{l}0.880 \\
252\end{array}$ & $\begin{array}{l}0.754 \\
252\end{array}$ \\
\hline
\end{tabular}


Table F-3 $\mathrm{CO}_{2}$ Emissions Case

\begin{tabular}{|c|c|c|c|c|c|c|}
\hline & \multicolumn{3}{|c|}{ Dependent } & \multicolumn{3}{|c|}{ Variable } \\
\hline & $\begin{array}{c}\text { GDP } \\
(\log Y) \\
(1)\end{array}$ & $\begin{array}{c}\mathrm{CO}_{2} \\
(\log \mathrm{E}) \\
(2)\end{array}$ & $\begin{array}{c}\text { Levy rate } \\
\text { on IGE } \\
(\log r) \\
\text { (3) }\end{array}$ & $\begin{array}{c}\text { Industrial share } \\
(\log S) \\
(4)\end{array}$ & $\begin{array}{c}\text { Trade } \\
(\log \mathrm{T}) \\
(5)\end{array}$ & $\begin{array}{c}\text { FDI } \\
(\underset{(6)}{\log \text { FDI })}\end{array}$ \\
\hline Constant & $\begin{array}{l}-1.037 \\
(-7.961) \\
\end{array}$ & $\begin{array}{c}-7.890 \\
(-6.453) \\
\end{array}$ & $\begin{array}{c}1.695 \\
(2.930) \\
\end{array}$ & $\begin{array}{c}0.274 \\
(3.494) \\
\end{array}$ & $\begin{array}{l}10.194 \\
(3.485) \\
\end{array}$ & $\begin{array}{c}-3.875 \\
(-1.907) \\
\end{array}$ \\
\hline $\begin{array}{l}\text { GDP } \\
(\log Y)\end{array}$ & & $\begin{array}{c}0.733 \\
(2.132) \\
\end{array}$ & & $\begin{array}{c}-0.023 \\
(-1.828) \\
\end{array}$ & $\begin{array}{c}0.780 \\
(12.052) \\
\end{array}$ & $\begin{array}{c}1.179 \\
(5.193) \\
\end{array}$ \\
\hline $\begin{array}{l}\text { GDP Square } \\
\left(\log ^{2} Y\right)\end{array}$ & & $\begin{array}{c}0.014 \\
(0.465) \\
\end{array}$ & & & & \\
\hline $\begin{array}{l}\text { Income } \\
(\log (\mathrm{Y} / \mathrm{P}))\end{array}$ & & & $\begin{array}{c}-0.438 \\
(-5.561) \\
\end{array}$ & & & \\
\hline $\begin{array}{l}\text { Emissions } \\
\left(\mathrm{CO}_{2}\right)(\log \mathrm{E}) \\
\end{array}$ & $\begin{array}{c}0.155 \\
(8.102) \\
\end{array}$ & & $\begin{array}{c}0.000 \\
(0.007) \\
\end{array}$ & & & \\
\hline $\begin{array}{l}\text { Levy Rate on } \\
\text { IGE }(\log r)\end{array}$ & & $\begin{array}{c}-0.032 \\
(-0.416)\end{array}$ & & & & $\begin{array}{c}-0.165 \\
(-0.669)\end{array}$ \\
\hline $\begin{array}{l}\text { Industrial output } \\
\text { share }(\log S)\end{array}$ & & $\begin{array}{c}0.575 \\
(3.909)\end{array}$ & & & & \\
\hline $\begin{array}{l}\text { Trade } \\
(\log T)\end{array}$ & $\begin{array}{c}0.208 \\
(15.594) \\
\end{array}$ & & & $\begin{array}{c}0.004 \\
(0.723) \\
\end{array}$ & & \\
\hline $\begin{array}{l}\text { FDI } \\
(\log F D I)\end{array}$ & & & & & $\begin{array}{c}0.099 \\
(3.203) \\
\end{array}$ & \\
\hline $\begin{array}{l}\text { Labor } \\
(\log L)\end{array}$ & $\begin{array}{c}0.403 \\
(27.704) \\
\end{array}$ & & & & & \\
\hline $\begin{array}{l}\text { Capital } \\
(\log K) \\
\end{array}$ & $\begin{array}{c}0.233 \\
(11.725) \\
\end{array}$ & & & & & \\
\hline $\begin{array}{l}\text { State-owned } \\
\text { Enterprises } \\
\text { (log SOE) }\end{array}$ & & $\begin{array}{c}0.856 \\
(8.505)\end{array}$ & & & & \\
\hline $\begin{array}{l}\text { Citizen } \\
\text { Complaints } \\
(\log C)\end{array}$ & & & $\begin{array}{c}0.038 \\
(0.955)\end{array}$ & & & \\
\hline $\begin{array}{l}\text { Education } \\
\text { (log ed) }\end{array}$ & & & $\begin{array}{c}-0.377 \\
(-3.677) \\
\end{array}$ & & & \\
\hline $\begin{array}{l}\text { Population } \\
\text { Density } \\
\text { (log PD) }\end{array}$ & & & $\begin{array}{c}-0.036 \\
(-1.178)\end{array}$ & & & \\
\hline $\begin{array}{l}\text { Industrial } \\
\text { Share }-1 \\
\left(\log S_{-1}\right)\end{array}$ & & & & $\begin{array}{c}0.907 \\
(54.651)\end{array}$ & & \\
\hline $\begin{array}{l}\text { Investments } \\
(\log V)\end{array}$ & & & & $\begin{array}{c}0.039 \\
(2.767) \\
\end{array}$ & & \\
\hline $\begin{array}{l}\text { Remoteness } \\
(\log R)\end{array}$ & & & & & $\begin{array}{c}-0.469 \\
(--4.352) \\
\end{array}$ & \\
\hline $\begin{array}{l}\text { Exchange rate } \\
(\log \text { E R) }\end{array}$ & & & & & $\begin{array}{c}-0.194 \\
(-0.520)\end{array}$ & \\
\hline $\begin{array}{l}\text { Tariffs } \\
(\log T N * \log \mathrm{TP})\end{array}$ & & & & & $\begin{array}{c}-0.012 \\
(-0.178)\end{array}$ & \\
\hline $\begin{array}{l}\text { Cumulative FDI } \\
\left(\log _{\text {CFDI }}\right)\end{array}$ & & & & & & $\begin{array}{c}0.350 \\
(3.333) \\
\end{array}$ \\
\hline $\begin{array}{l}\text { Road intensity } \\
(\log T I)\end{array}$ & & & & & & $\begin{array}{c}0.695 \\
(3.041) \\
\end{array}$ \\
\hline $\begin{array}{l}\text { Tax rate } \\
(\log \text { Tax })\end{array}$ & & & & & & $\begin{array}{c}0.177 \\
(0.483) \\
\end{array}$ \\
\hline $\begin{array}{l}\text { GDP per capita } \\
\left(\log _{\text {PGDP-1 }}\right)\end{array}$ & & & & & & $\begin{array}{c}0.294 \\
(0.957) \\
\end{array}$ \\
\hline $\begin{array}{l}\text { Regional } \\
\text { Dummy D }\end{array}$ & & & & $\begin{array}{c}-0.006 \\
(-0.714) \\
\end{array}$ & $\begin{array}{c}0.588 \\
(4.849) \\
\end{array}$ & $\begin{array}{c}0.480 \\
(2.032) \\
\end{array}$ \\
\hline $\begin{array}{l}\text { Time Dummy } \\
\text { DT }\end{array}$ & & & & & $\begin{array}{c}0.024 \\
(0.311) \\
\end{array}$ & $\begin{array}{c}-0.782 \\
(-4.195) \\
\end{array}$ \\
\hline $\begin{array}{l}\text { Adjusted } \mathrm{R}^{2} \\
\text { Observations }\end{array}$ & $\begin{array}{l}0.982 \\
252\end{array}$ & $\begin{array}{l}0.762 \\
252\end{array}$ & $\begin{array}{l}0.175 \\
252\end{array}$ & $\begin{array}{l}0.966 \\
252\end{array}$ & $\begin{array}{l}0.880 \\
252 \\
\end{array}$ & $\begin{array}{l}0.754 \\
252 \\
\end{array}$ \\
\hline
\end{tabular}


Table F-4 $\mathrm{SO}_{2}$ Emissions Case

\begin{tabular}{|c|c|c|c|c|c|c|}
\hline & \multicolumn{3}{|c|}{ Dependent } & \multicolumn{3}{|c|}{ Variable } \\
\hline & $\begin{array}{c}\text { GDP } \\
(\log Y) \\
(1)\end{array}$ & $\begin{array}{c}\mathrm{SO}_{2} \\
(\log \mathrm{E}) \\
(2)\end{array}$ & $\begin{array}{c}\text { Levy rate } \\
\text { on IGE } \\
(\log r) \\
\text { (3) }\end{array}$ & $\begin{array}{l}\text { Industrial share } \\
\qquad(\log S) \\
\text { (4) }\end{array}$ & $\begin{array}{c}\text { Trade } \\
(\log \mathrm{T}) \\
(5)\end{array}$ & $\begin{array}{c}\text { FDI } \\
(\underset{(6)}{\log \text { FDI })}\end{array}$ \\
\hline Constant & $\begin{array}{c}-1.815 \\
(-17.734)\end{array}$ & $\begin{array}{c}6.317 \\
(2.853)\end{array}$ & $\begin{array}{c}2.845 \\
(3.086)\end{array}$ & $\begin{array}{c}0.274 \\
(3.494) \\
\end{array}$ & $\begin{array}{l}10.194 \\
(3.485)\end{array}$ & $\begin{array}{c}-3.875 \\
(-1.907)\end{array}$ \\
\hline $\begin{array}{l}\text { GDP } \\
(\log Y)\end{array}$ & & $\begin{array}{c}0.821 \\
(1.179) \\
\end{array}$ & & $\begin{array}{c}-0.023 \\
(-1.828) \\
\end{array}$ & $\begin{array}{c}0.780 \\
(12.052) \\
\end{array}$ & $\begin{array}{c}1.179 \\
(5.193) \\
\end{array}$ \\
\hline $\begin{array}{l}\text { GDP Square } \\
\left(\log ^{2} Y\right)\end{array}$ & & $\begin{array}{c}0.011 \\
(0.190) \\
\end{array}$ & & & & \\
\hline $\begin{array}{l}\text { Income } \\
(\log (\mathrm{Y} / \mathrm{P}))\end{array}$ & & & $\begin{array}{c}-0.490 \\
(-6.087)\end{array}$ & & & \\
\hline $\begin{array}{l}\text { Emissions } \\
\left(\mathrm{SO}_{2}\right)(\log \mathrm{E})\end{array}$ & $\begin{array}{c}0.0 .59 \\
(4.124)\end{array}$ & & $\begin{array}{c}-0.066 \\
(-1.581)\end{array}$ & & & \\
\hline $\begin{array}{l}\text { Levy Rate on } \\
\text { IGE }(\log r)\end{array}$ & & $\begin{array}{c}-0.308 \\
(-2.784) \\
\end{array}$ & & & & $\begin{array}{c}-0.165 \\
(-0.669) \\
\end{array}$ \\
\hline $\begin{array}{l}\text { Industrial output } \\
\text { share }(\log S)\end{array}$ & & $\begin{array}{c}-0.334 \\
(-1.697)\end{array}$ & & & & \\
\hline $\begin{array}{l}\text { Trade } \\
(\log T)\end{array}$ & $\begin{array}{c}0.210 \\
(13.464)\end{array}$ & & & $\begin{array}{c}0.004 \\
(0.723)\end{array}$ & & \\
\hline $\begin{array}{l}\text { FDI } \\
(\log F D I)\end{array}$ & & & & & $\begin{array}{c}0.099 \\
(3.203) \\
\end{array}$ & \\
\hline $\begin{array}{l}\text { Labor } \\
(\log \mathrm{L})\end{array}$ & $\begin{array}{c}0.425 \\
(24.236) \\
\end{array}$ & & & & & \\
\hline $\begin{array}{l}\text { Capital } \\
(\log K) \\
\end{array}$ & $\begin{array}{c}0.274 \\
(12.811) \\
\end{array}$ & & & & & \\
\hline $\begin{array}{l}\text { State-owned } \\
\text { Enterprises } \\
\text { (log SOE) }\end{array}$ & & $\begin{array}{c}0.681 \\
(3.543)\end{array}$ & & & & \\
\hline $\begin{array}{l}\text { Citizen } \\
\text { Complaints } \\
(\log C)\end{array}$ & & & $\begin{array}{c}0.022 \\
(0.534)\end{array}$ & & & \\
\hline $\begin{array}{l}\text { Education } \\
\text { (log ed) }\end{array}$ & & & $\begin{array}{c}-0.443 \\
(-4.391) \\
\end{array}$ & & & \\
\hline $\begin{array}{l}\text { Population } \\
\text { Density } \\
\text { (log PD) }\end{array}$ & & & $\begin{array}{c}-0.008 \\
(-0.257)\end{array}$ & & & \\
\hline $\begin{array}{l}\text { Industrial } \\
\text { Share }_{-1} \\
\left(\log S_{-1}\right)\end{array}$ & & & & $\begin{array}{c}0.907 \\
(54.651)\end{array}$ & & \\
\hline $\begin{array}{l}\text { Investments } \\
(\log V)\end{array}$ & & & & $\begin{array}{c}0.039 \\
(2.767)\end{array}$ & & \\
\hline $\begin{array}{l}\text { Remoteness } \\
(\log R)\end{array}$ & & & & & $\begin{array}{c}-0.469 \\
(--4.352)\end{array}$ & \\
\hline $\begin{array}{l}\text { Exchange rate } \\
(\log E \text { R) }\end{array}$ & & & & & $\begin{array}{c}-0.194 \\
(-0.520) \\
\end{array}$ & \\
\hline $\begin{array}{l}\text { Tariffs } \\
(\log T N * \log \mathrm{TP})\end{array}$ & & & & & $\begin{array}{c}-0.012 \\
(-0.178) \\
\end{array}$ & \\
\hline $\begin{array}{l}\text { Cumulative FDI } \\
\left(\log C^{2} I_{-1}\right)\end{array}$ & & & & & & $\begin{array}{c}0.350 \\
(3.333)\end{array}$ \\
\hline $\begin{array}{l}\text { Road intensity } \\
(\log \mathrm{TI})\end{array}$ & & & & & & $\begin{array}{c}0.695 \\
(3.041) \\
\end{array}$ \\
\hline $\begin{array}{l}\text { Tax rate } \\
(\log \text { Tax })\end{array}$ & & & & & & $\begin{array}{c}0.177 \\
(0.483)\end{array}$ \\
\hline $\begin{array}{l}\text { GDP per capita } \\
\left(\log _{\text {PGDP }}\right)\end{array}$ & & & & & & $\begin{array}{c}0.294 \\
(0.957) \\
\end{array}$ \\
\hline $\begin{array}{l}\text { Regional } \\
\text { Dummy D }\end{array}$ & & & & $\begin{array}{c}-0.006 \\
(-0.714) \\
\end{array}$ & $\begin{array}{c}0.588 \\
(4.849) \\
\end{array}$ & $\begin{array}{c}0.480 \\
(2.032) \\
\end{array}$ \\
\hline $\begin{array}{l}\text { Time Dummy } \\
\text { DT }\end{array}$ & & & & & $\begin{array}{c}0.024 \\
(0.311) \\
\end{array}$ & $\begin{array}{c}-0.782 \\
(-4.195) \\
\end{array}$ \\
\hline $\begin{array}{l}\text { Adjusted } \mathrm{R}^{2} \\
\text { Observations }\end{array}$ & $\begin{array}{l}0.977 \\
252\end{array}$ & $\begin{array}{l}0.554 \\
252\end{array}$ & $\begin{array}{l}0.188 \\
252\end{array}$ & $\begin{array}{l}0.966 \\
252\end{array}$ & $\begin{array}{l}0.880 \\
252 \\
\end{array}$ & $\begin{array}{l}0.754 \\
252 \\
\end{array}$ \\
\hline
\end{tabular}


Table F-5 Particle Emissions Case

\begin{tabular}{|c|c|c|c|c|c|c|}
\hline & \multicolumn{3}{|c|}{ Dependent } & \multicolumn{3}{|c|}{ Variable } \\
\hline & $\begin{array}{c}\text { GDP } \\
(\log Y) \\
(1)\end{array}$ & $\begin{array}{c}\text { Particle } \\
(\log E) \\
(2)\end{array}$ & $\begin{array}{c}\text { Levy rate } \\
\text { on IGE } \\
(\log r) \\
\text { (3) }\end{array}$ & $\begin{array}{l}\text { Industrial share } \\
(\log S) \\
(4)\end{array}$ & $\begin{array}{c}\text { Trade } \\
(\log \mathrm{T}) \\
(5)\end{array}$ & $\begin{array}{c}\text { FDI } \\
(\log \text { FDI }) \\
(6)\end{array}$ \\
\hline Constant & $\begin{array}{c}-2.306 \\
(-17.645)\end{array}$ & $\begin{array}{c}0.960 \\
(0.517)\end{array}$ & $\begin{array}{c}2.056 \\
(2.304)\end{array}$ & $\begin{array}{c}0.274 \\
(3.494)\end{array}$ & $\begin{array}{l}10.194 \\
(3.485)\end{array}$ & $\begin{array}{c}-3.875 \\
(-1.907)\end{array}$ \\
\hline $\begin{array}{l}\text { GDP } \\
(\log Y)\end{array}$ & & $\begin{array}{c}0.734 \\
(1.527)\end{array}$ & & $\begin{array}{c}-0.023 \\
(-1.828)\end{array}$ & $\begin{array}{c}0.780 \\
(12.052)\end{array}$ & $\begin{array}{c}1.179 \\
(5.193)\end{array}$ \\
\hline $\begin{array}{l}\text { GDP Square } \\
\left(\log ^{2} Y\right)\end{array}$ & & $\begin{array}{c}0.016 \\
(0.366)\end{array}$ & & & & \\
\hline $\begin{array}{l}\text { Income } \\
(\log (Y / P))\end{array}$ & & & $\begin{array}{c}-0.458 \\
(-5.805)\end{array}$ & & & \\
\hline $\begin{array}{l}\text { Emissions } \\
\text { (Particle) (log E) }\end{array}$ & $\begin{array}{c}0.106 \\
(8.322) \\
\end{array}$ & & $\begin{array}{c}-0.021 \\
(-0.520) \\
\end{array}$ & & & \\
\hline $\begin{array}{l}\text { Levy Rate on } \\
\text { IGE }(\log r)\end{array}$ & & $\begin{array}{c}0.090 \\
(0.631)\end{array}$ & & & & $\begin{array}{c}-0.165 \\
(-0.669)\end{array}$ \\
\hline $\begin{array}{l}\text { Industrial output } \\
\text { share }(\log S)\end{array}$ & & $\begin{array}{c}0.245 \\
(1.002)\end{array}$ & & & & \\
\hline $\begin{array}{l}\text { Trade } \\
(\log T)\end{array}$ & $\begin{array}{c}0.222 \\
(15.879)\end{array}$ & & & $\begin{array}{c}0.004 \\
(0.723)\end{array}$ & & \\
\hline $\begin{array}{l}\text { FDI } \\
(\log \text { FDI) }\end{array}$ & & & & & $\begin{array}{c}0.099 \\
(3.203) \\
\end{array}$ & \\
\hline $\begin{array}{l}\text { Labor } \\
(\log \mathrm{L})\end{array}$ & $\begin{array}{c}0.407 \\
(29.775)\end{array}$ & & & & & \\
\hline $\begin{array}{l}\text { Capital } \\
(\log K)\end{array}$ & $\begin{array}{c}0.257 \\
(12.452)\end{array}$ & & & & & \\
\hline $\begin{array}{l}\text { State-owned } \\
\text { Enterprises } \\
\text { (log SOE) }\end{array}$ & & $\begin{array}{c}1.362 \\
(7.011)\end{array}$ & & & & \\
\hline $\begin{array}{l}\text { Citizen } \\
\text { Complaints } \\
(\log C)\end{array}$ & & & $\begin{array}{c}0.035 \\
(0.881)\end{array}$ & & & \\
\hline $\begin{array}{l}\text { Education } \\
\text { (log ed) }\end{array}$ & & & $\begin{array}{c}-0.407 \\
(-3.811) \\
\end{array}$ & & & \\
\hline $\begin{array}{l}\text { Population } \\
\text { Density } \\
\text { (log PD) }\end{array}$ & & & $\begin{array}{c}-0.033 \\
(-1.253)\end{array}$ & & & \\
\hline $\begin{array}{l}\text { Industrial } \\
\text { Share }_{-1} \\
\left(\log S_{-1}\right)\end{array}$ & & & & $\begin{array}{c}0.907 \\
(54.651)\end{array}$ & & \\
\hline $\begin{array}{l}\text { Investments } \\
(\log V)\end{array}$ & & & & $\begin{array}{c}0.039 \\
(2.767) \\
\end{array}$ & & \\
\hline $\begin{array}{l}\text { Remoteness } \\
(\log R)\end{array}$ & & & & & $\begin{array}{c}-0.469 \\
(--4.352) \\
\end{array}$ & \\
\hline $\begin{array}{l}\text { Exchange rate } \\
(\log E \text { R) }\end{array}$ & & & & & $\begin{array}{c}-0.194 \\
(-0.520) \\
\end{array}$ & \\
\hline $\begin{array}{l}\text { Tariffs } \\
(\log T N * \log T P)\end{array}$ & & & & & $\begin{array}{c}-0.012 \\
(-0.178) \\
\end{array}$ & \\
\hline $\begin{array}{l}\text { Cumulative FDI } \\
\left(\log \text { CFDI }_{-1}\right)\end{array}$ & & & & & & $\begin{array}{c}0.350 \\
(3.333) \\
\end{array}$ \\
\hline $\begin{array}{l}\text { Road intensity } \\
(\log T I)\end{array}$ & & & & & & $\begin{array}{c}0.695 \\
(3.041) \\
\end{array}$ \\
\hline $\begin{array}{l}\text { Tax rate } \\
(\log \text { Tax })\end{array}$ & & & & & & $\begin{array}{c}0.177 \\
(0.483) \\
\end{array}$ \\
\hline $\begin{array}{l}\text { GDP per capita } \\
\left(\log _{\left.\text {PGDP }_{-1}\right)}\right.\end{array}$ & & & & & & $\begin{array}{c}0.294 \\
(0.957) \\
\end{array}$ \\
\hline $\begin{array}{l}\text { Regional } \\
\text { Dummy D }\end{array}$ & & & & $\begin{array}{c}-0.006 \\
(-0.714) \\
\end{array}$ & $\begin{array}{c}0.588 \\
(4.849) \\
\end{array}$ & $\begin{array}{c}0.480 \\
(2.032)\end{array}$ \\
\hline $\begin{array}{l}\text { Time Dummy } \\
\text { DT }\end{array}$ & & & & & $\begin{array}{c}0.024 \\
(0.311) \\
\end{array}$ & $\begin{array}{c}-0.782 \\
(-4.195) \\
\end{array}$ \\
\hline $\begin{array}{l}\text { Adjusted } \mathrm{R}^{2} \\
\text { Observations }\end{array}$ & $\begin{array}{l}0.982 \\
252\end{array}$ & $\begin{array}{l}0.515 \\
252\end{array}$ & $\begin{array}{l}0.177 \\
252\end{array}$ & $\begin{array}{l}0.966 \\
252\end{array}$ & $\begin{array}{c}0.880 \\
252\end{array}$ & $\begin{array}{l}0.754 \\
252\end{array}$ \\
\hline
\end{tabular}


Table F-6 Dust Emissions Case

\begin{tabular}{|c|c|c|c|c|c|c|}
\hline & \multicolumn{3}{|c|}{ Dependent } & \multicolumn{3}{|c|}{ Variable } \\
\hline & $\begin{array}{c}\text { GDP } \\
(\log Y) \\
(1)\end{array}$ & $\begin{array}{c}\text { Dust } \\
(\log E) \\
(2)\end{array}$ & $\begin{array}{c}\text { Levy rate } \\
\text { on IGE } \\
(\log r) \\
\text { (3) }\end{array}$ & $\begin{array}{l}\text { Industrial share } \\
\qquad(\log S) \\
\text { (4) }\end{array}$ & $\begin{array}{c}\text { Trade } \\
(\log \mathrm{T}) \\
(5)\end{array}$ & $\begin{array}{c}\text { FDI } \\
(\underset{(6)}{\log \text { FDI })}\end{array}$ \\
\hline Constant & $\begin{array}{c}-1.807 \\
(-10.679)\end{array}$ & $\begin{array}{l}11.726 \\
(6.112)\end{array}$ & $\begin{array}{c}0.213 \\
(0.246)\end{array}$ & $\begin{array}{c}0.274 \\
(3.494) \\
\end{array}$ & $\begin{array}{l}10.194 \\
(3.485)\end{array}$ & $\begin{array}{c}-3.875 \\
(-1.907)\end{array}$ \\
\hline $\begin{array}{l}\text { GDP } \\
(\log Y)\end{array}$ & & $\begin{array}{c}0.209 \\
(0.349) \\
\end{array}$ & & $\begin{array}{c}-0.023 \\
(-1.828) \\
\end{array}$ & $\begin{array}{c}0.780 \\
(12.052) \\
\end{array}$ & $\begin{array}{c}1.179 \\
(5.193) \\
\end{array}$ \\
\hline $\begin{array}{l}\text { GDP Square } \\
\left(\log ^{2} Y\right)\end{array}$ & & $\begin{array}{c}0.049 \\
(0.987) \\
\end{array}$ & & & & \\
\hline $\begin{array}{l}\text { Income } \\
(\log (\mathrm{Y} / \mathrm{P}))\end{array}$ & & & $\begin{array}{c}-0.289 \\
(-3.390)\end{array}$ & & & \\
\hline $\begin{array}{l}\text { Emissions } \\
\text { (Dust) (log E) }\end{array}$ & $\begin{array}{c}0.067 \\
(3.195) \\
\end{array}$ & & $\begin{array}{c}0.107 \\
(2.282) \\
\end{array}$ & & & \\
\hline $\begin{array}{l}\text { Levy Rate on } \\
\text { IGE }(\log r)\end{array}$ & & $\begin{array}{c}0.406 \\
(3.773)\end{array}$ & & & & $\begin{array}{c}-0.165 \\
(-0.669)\end{array}$ \\
\hline $\begin{array}{l}\text { Industrial output } \\
\text { share }(\log S)\end{array}$ & & $\begin{array}{c}-1.328 \\
(-5.826)\end{array}$ & & & & \\
\hline $\begin{array}{l}\text { Trade } \\
(\log T)\end{array}$ & $\begin{array}{c}0.199 \\
(11.236)\end{array}$ & & & $\begin{array}{c}0.004 \\
(0.723)\end{array}$ & & \\
\hline $\begin{array}{l}\text { FDI } \\
(\log F D I)\end{array}$ & & & & & $\begin{array}{c}0.099 \\
(3.203) \\
\end{array}$ & \\
\hline $\begin{array}{l}\text { Labor } \\
(\log \mathrm{L})\end{array}$ & $\begin{array}{c}0.396 \\
(16.195) \\
\end{array}$ & & & & & \\
\hline $\begin{array}{l}\text { Capital } \\
(\log K) \\
\end{array}$ & $\begin{array}{c}0.318 \\
(13.002) \\
\end{array}$ & & & & & \\
\hline $\begin{array}{l}\text { State-owned } \\
\text { Enterprises } \\
\text { (log SOE) }\end{array}$ & & $\begin{array}{c}0.377 \\
(2.069)\end{array}$ & & & & \\
\hline $\begin{array}{l}\text { Citizen } \\
\text { Complaints } \\
(\log C)\end{array}$ & & & $\begin{array}{c}0.037 \\
(0.993)\end{array}$ & & & \\
\hline $\begin{array}{l}\text { Education } \\
\text { (log ed) }\end{array}$ & & & $\begin{array}{c}-0.271 \\
(-2.758) \\
\end{array}$ & & & \\
\hline $\begin{array}{l}\text { Population } \\
\text { Density } \\
\text { (log PD) }\end{array}$ & & & $\begin{array}{c}-0.064 \\
(-2.164)\end{array}$ & & & \\
\hline $\begin{array}{l}\text { Industrial } \\
\text { Share }_{-1} \\
\left(\log S_{-1}\right)\end{array}$ & & & & $\begin{array}{c}0.907 \\
(54.651)\end{array}$ & & \\
\hline $\begin{array}{l}\text { Investments } \\
(\log V)\end{array}$ & & & & $\begin{array}{c}0.039 \\
(2.767)\end{array}$ & & \\
\hline $\begin{array}{l}\text { Remoteness } \\
(\log R)\end{array}$ & & & & & $\begin{array}{c}-0.469 \\
(--4.352)\end{array}$ & \\
\hline $\begin{array}{l}\text { Exchange rate } \\
(\log E \text { R) }\end{array}$ & & & & & $\begin{array}{c}-0.194 \\
(-0.520) \\
\end{array}$ & \\
\hline $\begin{array}{l}\text { Tariffs } \\
(\log T N * \log \mathrm{TP})\end{array}$ & & & & & $\begin{array}{c}-0.012 \\
(-0.178) \\
\end{array}$ & \\
\hline $\begin{array}{l}\text { Cumulative FDI } \\
\left(\log C^{2} I_{-1}\right)\end{array}$ & & & & & & $\begin{array}{c}0.350 \\
(3.333)\end{array}$ \\
\hline $\begin{array}{l}\text { Road intensity } \\
(\log \mathrm{TI})\end{array}$ & & & & & & $\begin{array}{c}0.695 \\
(3.041) \\
\end{array}$ \\
\hline $\begin{array}{l}\text { Tax rate } \\
(\log \text { Tax })\end{array}$ & & & & & & $\begin{array}{c}0.177 \\
(0.483)\end{array}$ \\
\hline $\begin{array}{l}\text { GDP per capita } \\
\left(\log _{\text {PGDP }}\right)\end{array}$ & & & & & & $\begin{array}{c}0.294 \\
(0.957) \\
\end{array}$ \\
\hline $\begin{array}{l}\text { Regional } \\
\text { Dummy D }\end{array}$ & & & & $\begin{array}{c}-0.006 \\
(-0.714) \\
\end{array}$ & $\begin{array}{c}0.588 \\
(4.849) \\
\end{array}$ & $\begin{array}{c}0.480 \\
(2.032) \\
\end{array}$ \\
\hline $\begin{array}{l}\text { Time Dummy } \\
\text { DT }\end{array}$ & & & & & $\begin{array}{c}0.024 \\
(0.311) \\
\end{array}$ & $\begin{array}{c}-0.782 \\
(-4.195) \\
\end{array}$ \\
\hline $\begin{array}{l}\text { Adjusted } \mathrm{R}^{2} \\
\text { Observations }\end{array}$ & $\begin{array}{l}0.977 \\
252\end{array}$ & $\begin{array}{l}0.543 \\
252 \\
\end{array}$ & $\begin{array}{l}0.207 \\
252\end{array}$ & $\begin{array}{l}0.966 \\
252\end{array}$ & $\begin{array}{l}0.880 \\
252 \\
\end{array}$ & $\begin{array}{l}0.754 \\
252 \\
\end{array}$ \\
\hline
\end{tabular}




\section{Appendix G: 2SLS Results with Exclusion of Three Municipalities}

Table G-1 Industrial Wastewater Pollution (IWW) Case

\begin{tabular}{|c|c|c|c|c|c|c|}
\hline & \multicolumn{3}{|c|}{ Dependent } & \multicolumn{3}{|c|}{ Variable } \\
\hline & $\begin{array}{c}\text { GDP } \\
(\log Y) \\
(1)\end{array}$ & $\begin{array}{c}\text { IWW } \\
(\log E) \\
(2)\end{array}$ & $\begin{array}{c}\text { Levy rate } \\
\text { on IGE } \\
(\log r) \\
\text { (3) }\end{array}$ & $\begin{array}{c}\text { Industrial share } \\
(\log S) \\
(4)\end{array}$ & $\begin{array}{c}\text { Trade } \\
(\log \mathrm{T}) \\
(5)\end{array}$ & $\begin{array}{c}\text { FDI } \\
\left(\begin{array}{c}\log \text { FDI }) \\
(6)\end{array}\right.\end{array}$ \\
\hline Constant & $\begin{array}{c}-1.258 \\
(-11.314)\end{array}$ & $\begin{array}{c}-3.515 \\
(-2.516)\end{array}$ & $\begin{array}{c}5.071 \\
(7.047)\end{array}$ & $\begin{array}{c}0.223 \\
(4.111)\end{array}$ & $\begin{array}{c}9.781 \\
(3.823)\end{array}$ & $\begin{array}{c}-2.060 \\
(-1.459)\end{array}$ \\
\hline $\begin{array}{l}\text { GDP } \\
(\log Y)\end{array}$ & & $\begin{array}{c}2.381 \\
(6.310)\end{array}$ & & $\begin{array}{c}-0.011 \\
(-1.112)\end{array}$ & $\begin{array}{c}0.874 \\
(15.880)\end{array}$ & $\begin{array}{c}0.975 \\
(4.887))\end{array}$ \\
\hline $\begin{array}{l}\text { GDP Square } \\
\left(\log ^{2} Y\right)\end{array}$ & & $\begin{array}{c}-0.101 \\
(-3.320)\end{array}$ & & & & \\
\hline $\begin{array}{l}\text { Income } \\
(\log (Y / P))\end{array}$ & & & $\begin{array}{c}0.420 \\
(6.362) \\
\end{array}$ & & & \\
\hline $\begin{array}{l}\text { Emissions } \\
\text { (IWW) (log E) }\end{array}$ & $\begin{array}{c}0.141 \\
(5.927) \\
\end{array}$ & & $\begin{array}{c}-0.068 \\
(-1.582) \\
\end{array}$ & & & \\
\hline $\begin{array}{l}\text { Levy Rate on } \\
\text { IWW }(\log r)\end{array}$ & & $\begin{array}{c}-0.528 \\
(-6.255)\end{array}$ & & & & $\begin{array}{c}0.198 \\
(0.689)\end{array}$ \\
\hline $\begin{array}{l}\text { Industrial output } \\
\text { share }(\log S)\end{array}$ & & $\begin{array}{l}-0.422 \\
(2.357)\end{array}$ & & & & \\
\hline $\begin{array}{l}\text { Trade } \\
(\log T)\end{array}$ & $\begin{array}{c}0.148 \\
(9.154)\end{array}$ & & & $\begin{array}{c}0.006 \\
(1.181)\end{array}$ & & \\
\hline $\begin{array}{l}\text { FDI } \\
(\log \text { FDI) }\end{array}$ & & & & & $\begin{array}{c}0.054 \\
(2.223) \\
\end{array}$ & \\
\hline $\begin{array}{l}\text { Labor } \\
(\log \mathrm{L})\end{array}$ & $\begin{array}{c}0.351 \\
(13.836)\end{array}$ & & & & & \\
\hline $\begin{array}{l}\text { Capital } \\
(\log K)\end{array}$ & $\begin{array}{c}0.364 \\
(16.951) \\
\end{array}$ & & & & & \\
\hline $\begin{array}{l}\text { State-owned } \\
\text { Enterprises } \\
\text { (log SOE) }\end{array}$ & & $\begin{array}{c}0.230 \\
(3.543)\end{array}$ & & & & \\
\hline $\begin{array}{l}\text { Citizen } \\
\text { Complaints } \\
\text { (log C) }\end{array}$ & & & $\begin{array}{c}-0.207 \\
(-3.569)\end{array}$ & & & \\
\hline $\begin{array}{l}\text { Education } \\
(\log \text { ed })\end{array}$ & & & $\begin{array}{c}-0.341 \\
(-3.720) \\
\end{array}$ & & & \\
\hline $\begin{array}{l}\text { Population } \\
\text { Density } \\
\text { (log PD) }\end{array}$ & & & $\begin{array}{c}0.149 \\
(3.964)\end{array}$ & & & \\
\hline $\begin{array}{l}\text { Industrial } \\
\text { Share } \\
\left(\log S_{-1}\right)\end{array}$ & & & & $\begin{array}{c}0.915 \\
(68.501)\end{array}$ & & \\
\hline $\begin{array}{l}\text { Investments } \\
(\log \mathrm{V})\end{array}$ & & & & $\begin{array}{c}0.023 \\
(2.092) \\
\end{array}$ & & \\
\hline $\begin{array}{l}\text { Remoteness } \\
(\log R)\end{array}$ & & & & & $\begin{array}{c}-0.654 \\
(-6.786)\end{array}$ & \\
\hline $\begin{array}{l}\text { Exchange rate } \\
(\log E \mathrm{R})\end{array}$ & & & & & $\begin{array}{c}0.042 \\
(0.135)\end{array}$ & \\
\hline $\begin{array}{l}\text { Tariffs } \\
(\operatorname{LogTN} * \log \mathrm{TP})\end{array}$ & & & & & $\begin{array}{c}0.003 \\
(0.053)\end{array}$ & \\
\hline $\begin{array}{l}\text { Cumulative FDI } \\
\left(\log C^{2} I_{-1}\right)\end{array}$ & & & & & & $\begin{array}{c}0.370 \\
(3.911) \\
\end{array}$ \\
\hline $\begin{array}{l}\text { Road intensity } \\
(\log T I)\end{array}$ & & & & & & $\begin{array}{c}0.695 \\
(3.217)\end{array}$ \\
\hline $\begin{array}{l}\text { Tax rate } \\
(\log \text { Tax })\end{array}$ & & & & & & $\begin{array}{c}-0.033 \\
(-0.159)\end{array}$ \\
\hline $\begin{array}{l}\text { GDP per capita } \\
\left(\log \text { PGDP }_{-1}\right)\end{array}$ & & & & & & $\begin{array}{c}-0.615 \\
(-1.958) \\
\end{array}$ \\
\hline $\begin{array}{l}\text { Regional } \\
\text { Dummy D }\end{array}$ & & & & $\begin{array}{c}-0.010 \\
(-1.428)\end{array}$ & $\begin{array}{c}0.225 \\
(2.074)\end{array}$ & $\begin{array}{c}0.334 \\
(1.733)\end{array}$ \\
\hline $\begin{array}{l}\text { Time Dummy } \\
\text { DT }\end{array}$ & & & & & $\begin{array}{c}-0.013 \\
(-0.180)\end{array}$ & $\begin{array}{c}-0.851 \\
(-4.298)\end{array}$ \\
\hline Adjusted $\mathrm{R}^{2}$ & 0.983 & 0.823 & 0.334 & 0.968 & 0.911 & 0.793 \\
\hline Observations & 252 & 252 & 252 & 252 & 252 & 252 \\
\hline
\end{tabular}


Table G-2 Industrial Waste Gas Emissions (IGE) Case

\begin{tabular}{|c|c|c|c|c|c|c|}
\hline & \multicolumn{3}{|c|}{ Dependent } & \multicolumn{3}{|c|}{ Variable } \\
\hline & $\begin{array}{c}\text { GDP } \\
(\log Y) \\
(1)\end{array}$ & $\begin{array}{c}\text { IGE } \\
(\log E) \\
(2)\end{array}$ & $\begin{array}{c}\text { Levy rate } \\
\text { on IGE } \\
(\log r) \\
(3)\end{array}$ & $\begin{array}{c}\text { Industrial share } \\
(\log S) \\
(4)\end{array}$ & $\begin{array}{c}\text { Trade } \\
(\log \mathrm{T}) \\
(5)\end{array}$ & $\begin{array}{c}\text { FDI } \\
(\underset{(6)}{\log F D I)}\end{array}$ \\
\hline Constant & $\begin{array}{c}-1.574 \\
(-17.055)\end{array}$ & $\begin{array}{c}-8.840 \\
(-7.727)\end{array}$ & $\begin{array}{c}3.498 \\
(3.652)\end{array}$ & $\begin{array}{c}0.216 \\
(2.936)\end{array}$ & $\begin{array}{c}9.781 \\
(3.823)\end{array}$ & $\begin{array}{c}-0.259 \\
(-1.495)\end{array}$ \\
\hline $\begin{array}{l}\text { GDP } \\
(\log Y)\end{array}$ & & $\begin{array}{c}1.440 \\
(4.205)\end{array}$ & & $\begin{array}{c}-0.020 \\
(-1.632)\end{array}$ & $\begin{array}{c}0.874 \\
(15.880)\end{array}$ & $\begin{array}{c}1.088 \\
(4.819)\end{array}$ \\
\hline $\begin{array}{l}\text { GDP Square } \\
\left(\log ^{2} Y\right)\end{array}$ & & $\begin{array}{c}-0.051 \\
(-1.793)\end{array}$ & & & & \\
\hline $\begin{array}{l}\text { Income } \\
(\log (\mathrm{Y} / \mathrm{P}))\end{array}$ & & & $\begin{array}{c}-0.149 \\
(-2.003)\end{array}$ & & & \\
\hline $\begin{array}{l}\text { Emissions } \\
\text { (IGE) }(\log E)\end{array}$ & $\begin{array}{c}0.122 \\
(4 . .991) \\
\end{array}$ & & $\begin{array}{c}-0.157 \\
(-1.660) \\
\end{array}$ & & & \\
\hline $\begin{array}{l}\text { Levy Rate on } \\
\text { IGE }(\log r)\end{array}$ & & $\begin{array}{c}-0.284 \\
(-1.920)\end{array}$ & & & & $\begin{array}{c}-0.287 \\
(-1.267)\end{array}$ \\
\hline $\begin{array}{l}\text { Industrial output } \\
\text { share }(\log S)\end{array}$ & & $\begin{array}{c}1.340 \\
(9.390)\end{array}$ & & & & \\
\hline $\begin{array}{l}\text { Trade } \\
(\log T)\end{array}$ & $\begin{array}{c}0.181 \\
(12.356)\end{array}$ & & & $\begin{array}{c}0.005 \\
(1.062)\end{array}$ & & \\
\hline $\begin{array}{l}\text { FDI } \\
(\log \text { FDI) }\end{array}$ & & & & & $\begin{array}{c}0.054 \\
(2.223) \\
\end{array}$ & \\
\hline $\begin{array}{l}\text { Labor } \\
(\log L)\end{array}$ & $\begin{array}{c}0.438 \\
(25.337) \\
\end{array}$ & & & & & \\
\hline $\begin{array}{l}\text { Capital } \\
(\log K)\end{array}$ & $\begin{array}{c}0.289 \\
(14.334)\end{array}$ & & & & & \\
\hline $\begin{array}{l}\text { State-owned } \\
\text { Enterprises } \\
\text { (log SOE) }\end{array}$ & & $\begin{array}{c}0.706 \\
(8.545)\end{array}$ & & & & \\
\hline $\begin{array}{l}\text { Citizen } \\
\text { Complaints } \\
\text { (log C) }\end{array}$ & & & $\begin{array}{c}0.016 \\
(0.293)\end{array}$ & & & \\
\hline $\begin{array}{l}\text { Education } \\
\text { (log ed) }\end{array}$ & & & $\begin{array}{c}-0.321 \\
(-2.715) \\
\end{array}$ & & & \\
\hline $\begin{array}{l}\text { Population } \\
\text { Density } \\
(\log \text { PD) }\end{array}$ & & & $\begin{array}{c}0.086 \\
(2.094)\end{array}$ & & & \\
\hline $\begin{array}{l}\text { Industrial } \\
\text { Share }_{-1} \\
\left(\log S_{-1}\right)\end{array}$ & & & & $\begin{array}{c}0.921 \\
(54.605)\end{array}$ & & \\
\hline $\begin{array}{l}\text { Investments } \\
(\log V)\end{array}$ & & & & $\begin{array}{c}0.034 \\
(2.439) \\
\end{array}$ & & \\
\hline $\begin{array}{l}\text { Remoteness } \\
(\log R)\end{array}$ & & & & & $\begin{array}{c}-0.654 \\
(-6.786) \\
\end{array}$ & \\
\hline $\begin{array}{l}\text { Exchange rate } \\
(\log E \text { R) }\end{array}$ & & & & & $\begin{array}{c}0.042 \\
(0.135) \\
\end{array}$ & \\
\hline $\begin{array}{l}\text { Tariffs } \\
(\log T N * \log \mathrm{TP})\end{array}$ & & & & & $\begin{array}{c}0.003 \\
(0.053) \\
\end{array}$ & \\
\hline $\begin{array}{l}\text { Cumulative FDI } \\
\left(\log \text { CFDI }_{-1}\right)\end{array}$ & & & & & & $\begin{array}{c}0.354 \\
(3.753)\end{array}$ \\
\hline $\begin{array}{l}\text { Road intensity } \\
(\log \mathrm{TI})\end{array}$ & & & & & & $\begin{array}{c}0.668 \\
(3.106) \\
\end{array}$ \\
\hline $\begin{array}{l}\text { Tax rate } \\
(\log \text { Tax })\end{array}$ & & & & & & $\begin{array}{c}0.084 \\
(0.390) \\
\end{array}$ \\
\hline $\begin{array}{l}\text { GDP per capita } \\
\left(\log _{\text {PGDP }}\right)\end{array}$ & & & & & & $\begin{array}{c}0.639 \\
(2.266) \\
\end{array}$ \\
\hline $\begin{array}{l}\text { Regional } \\
\text { Dummy D }\end{array}$ & & & & $\begin{array}{c}-0.009 \\
(-1.191) \\
\end{array}$ & $\begin{array}{c}0.225 \\
(2.074) \\
\end{array}$ & $\begin{array}{c}0.394 \\
(2.128) \\
\end{array}$ \\
\hline $\begin{array}{l}\text { Time Dummy } \\
\text { DT }\end{array}$ & & & & & $\begin{array}{c}-0.013 \\
(-0.180) \\
\end{array}$ & $\begin{array}{c}-0.851 \\
(-4.316) \\
\end{array}$ \\
\hline $\begin{array}{l}\text { Adjusted } \mathrm{R}^{2} \\
\text { Observations }\end{array}$ & $\begin{array}{l}0.983 \\
252\end{array}$ & $\begin{array}{l}0.817 \\
252\end{array}$ & $\begin{array}{c}0.090 \\
252\end{array}$ & $\begin{array}{l}0.955 \\
252\end{array}$ & $\begin{array}{c}0.911 \\
252\end{array}$ & $\begin{array}{l}0.794 \\
252\end{array}$ \\
\hline
\end{tabular}


Table G-3 $\mathrm{CO}_{2}$ Emissions Case

\begin{tabular}{|c|c|c|c|c|c|c|}
\hline & \multicolumn{3}{|c|}{ Dependent } & \multicolumn{3}{|c|}{ Variable } \\
\hline & $\begin{array}{c}\text { GDP } \\
(\log Y) \\
(1)\end{array}$ & $\begin{array}{c}\mathrm{CO}_{2} \\
(\log \mathrm{E}) \\
(2)\end{array}$ & $\begin{array}{c}\text { Levy rate } \\
\text { on IGE } \\
(\log r) \\
\text { (3) }\end{array}$ & $\begin{array}{c}\text { Industrial share } \\
(\log S) \\
(4)\end{array}$ & $\begin{array}{c}\text { Trade } \\
(\log \mathrm{T}) \\
(5)\end{array}$ & $\begin{array}{c}\text { FDI } \\
(\underset{(6)}{\log \text { FDI })}\end{array}$ \\
\hline Constant & $\begin{array}{c}-1.255 \\
(-11.524) \\
\end{array}$ & $\begin{array}{l}-12.707 \\
(-11.917) \\
\end{array}$ & $\begin{array}{c}2.732 \\
(3.705) \\
\end{array}$ & $\begin{array}{c}0.216 \\
(2.936) \\
\end{array}$ & $\begin{array}{c}9.781 \\
(3.823) \\
\end{array}$ & $\begin{array}{c}-0.259 \\
(-1.495) \\
\end{array}$ \\
\hline $\begin{array}{l}\text { GDP } \\
(\log Y)\end{array}$ & & $\begin{array}{c}1.460 \\
(5.035) \\
\end{array}$ & & $\begin{array}{c}-0.020 \\
(-1.632) \\
\end{array}$ & $\begin{array}{c}0.874 \\
(15.880) \\
\end{array}$ & $\begin{array}{c}1.088 \\
(4.819) \\
\end{array}$ \\
\hline $\begin{array}{l}\text { GDP Square } \\
\left(\log ^{2} Y\right)\end{array}$ & & $\begin{array}{c}-0.049 \\
(-2.054) \\
\end{array}$ & & & & \\
\hline $\begin{array}{l}\text { Income } \\
(\log (\mathrm{Y} / \mathrm{P}))\end{array}$ & & & $\begin{array}{c}-0.170 \\
(-2.337) \\
\end{array}$ & & & \\
\hline $\begin{array}{l}\text { Emissions } \\
\left(\mathrm{CO}_{2}\right)(\log \mathrm{E}) \\
\end{array}$ & $\begin{array}{c}0.130 \\
(7.420) \\
\end{array}$ & & $\begin{array}{c}-0.115 \\
(-2.520) \\
\end{array}$ & & & \\
\hline $\begin{array}{l}\text { Levy Rate on } \\
\text { IGE }(\log r)\end{array}$ & & $\begin{array}{c}-0.229 \\
(-3.244)\end{array}$ & & & & $\begin{array}{c}-0.287 \\
(-1.267)\end{array}$ \\
\hline $\begin{array}{l}\text { Industrial output } \\
\text { share }(\log S)\end{array}$ & & $\begin{array}{c}1.391 \\
(10.074)\end{array}$ & & & & \\
\hline $\begin{array}{l}\text { Trade } \\
(\log T)\end{array}$ & $\begin{array}{c}0.191 \\
(14.098) \\
\end{array}$ & & & $\begin{array}{c}0.005 \\
(1.062) \\
\end{array}$ & & \\
\hline $\begin{array}{l}\text { FDI } \\
(\log F D I)\end{array}$ & & & & & $\begin{array}{c}0.054 \\
(2.223) \\
\end{array}$ & \\
\hline $\begin{array}{l}\text { Labor } \\
(\log L)\end{array}$ & $\begin{array}{c}0.430 \\
(27.357) \\
\end{array}$ & & & & & \\
\hline $\begin{array}{l}\text { Capital } \\
(\log K) \\
\end{array}$ & $\begin{array}{c}0.277 \\
(13.673) \\
\end{array}$ & & & & & \\
\hline $\begin{array}{l}\text { State-owned } \\
\text { Enterprises } \\
\text { (log SOE) }\end{array}$ & & $\begin{array}{c}0.888 \\
(12.668)\end{array}$ & & & & \\
\hline $\begin{array}{l}\text { Citizen } \\
\text { Complaints } \\
(\log C)\end{array}$ & & & $\begin{array}{c}0.022 \\
(0.360)\end{array}$ & & & \\
\hline $\begin{array}{l}\text { Education } \\
\text { (log ed) }\end{array}$ & & & $\begin{array}{c}-0.288 \\
(-2.161) \\
\end{array}$ & & & \\
\hline $\begin{array}{l}\text { Population } \\
\text { Density } \\
\text { (log PD) }\end{array}$ & & & $\begin{array}{c}0.071 \\
(2.258)\end{array}$ & & & \\
\hline $\begin{array}{l}\text { Industrial } \\
\text { Share }-1 \\
\left(\log S_{-1}\right)\end{array}$ & & & & $\begin{array}{c}0.921 \\
(54.605)\end{array}$ & & \\
\hline $\begin{array}{l}\text { Investments } \\
(\log V)\end{array}$ & & & & $\begin{array}{c}0.034 \\
(2.439) \\
\end{array}$ & & \\
\hline $\begin{array}{l}\text { Remoteness } \\
(\log R)\end{array}$ & & & & & $\begin{array}{c}-0.654 \\
(-6.786) \\
\end{array}$ & \\
\hline $\begin{array}{l}\text { Exchange rate } \\
(\log \text { E R) }\end{array}$ & & & & & $\begin{array}{c}0.042 \\
(0.135)\end{array}$ & \\
\hline $\begin{array}{l}\text { Tariffs } \\
(\log T N * \log T P)\end{array}$ & & & & & $\begin{array}{c}0.003 \\
(0.053)\end{array}$ & \\
\hline $\begin{array}{l}\text { Cumulative FDI } \\
\left(\log _{\text {CFDI }}\right)\end{array}$ & & & & & & $\begin{array}{c}0.354 \\
(3.753) \\
\end{array}$ \\
\hline $\begin{array}{l}\text { Road intensity } \\
(\log T I)\end{array}$ & & & & & & $\begin{array}{c}0.668 \\
(3.106) \\
\end{array}$ \\
\hline $\begin{array}{l}\text { Tax rate } \\
(\log \text { Tax })\end{array}$ & & & & & & $\begin{array}{c}0.084 \\
(0.390) \\
\end{array}$ \\
\hline $\begin{array}{l}\text { GDP per capita } \\
\left(\log _{\text {PGDP-1 }}\right)\end{array}$ & & & & & & $\begin{array}{c}0.639 \\
(2.266) \\
\end{array}$ \\
\hline $\begin{array}{l}\text { Regional } \\
\text { Dummy D }\end{array}$ & & & & $\begin{array}{c}-0.009 \\
(-1.191) \\
\end{array}$ & $\begin{array}{c}0.225 \\
(2.074) \\
\end{array}$ & $\begin{array}{c}0.394 \\
(2.128) \\
\end{array}$ \\
\hline $\begin{array}{l}\text { Time Dummy } \\
\text { DT }\end{array}$ & & & & & $\begin{array}{c}-0.013 \\
(-0.180) \\
\end{array}$ & $\begin{array}{c}-0.851 \\
(-4.316) \\
\end{array}$ \\
\hline $\begin{array}{l}\text { Adjusted } \mathrm{R}^{2} \\
\text { Observations }\end{array}$ & $\begin{array}{l}0.984 \\
252\end{array}$ & $\begin{array}{l}0.832 \\
252\end{array}$ & $\begin{array}{l}0.070 \\
252\end{array}$ & $\begin{array}{l}0.955 \\
252\end{array}$ & $\begin{array}{l}0.911 \\
252 \\
\end{array}$ & $\begin{array}{c}0.794 \\
252 \\
\end{array}$ \\
\hline
\end{tabular}


Table G-4 Industrial $\mathrm{SO}_{2}$ Emissions Case

\begin{tabular}{|c|c|c|c|c|c|c|}
\hline & \multicolumn{3}{|c|}{ Dependent } & \multicolumn{3}{|c|}{ Variable } \\
\hline & $\begin{array}{c}\text { GDP } \\
(\log Y) \\
(1)\end{array}$ & $\begin{array}{c}\mathrm{SO}_{2} \\
(\log \mathrm{E}) \\
(2)\end{array}$ & $\begin{array}{c}\text { Levy rate } \\
\text { on IGE } \\
(\log r) \\
(3)\end{array}$ & $\begin{array}{c}\text { Industrial share } \\
\qquad(\log S) \\
(4)\end{array}$ & $\begin{array}{c}\text { Trade } \\
(\log \mathrm{T}) \\
(5)\end{array}$ & $\begin{array}{c}\text { FDI } \\
\left(\begin{array}{c}\log \text { FDI }) \\
(6)\end{array}\right.\end{array}$ \\
\hline Constant & $\begin{array}{c}-1.761 \\
(-16.114)\end{array}$ & $\begin{array}{c}3.873 \\
(1.714)\end{array}$ & $\begin{array}{c}4.085 \\
(5.012)\end{array}$ & $\begin{array}{c}0.216 \\
(2.936)\end{array}$ & $\begin{array}{c}9.781 \\
(3.823)\end{array}$ & $\begin{array}{c}-0.259 \\
(-1.495)\end{array}$ \\
\hline $\begin{array}{l}\text { GDP } \\
(\log Y)\end{array}$ & & $\begin{array}{l}1.260 \\
(2.119)\end{array}$ & & $\begin{array}{c}-0.020 \\
(-1.632)\end{array}$ & $\begin{array}{c}0.874 \\
(15.880)\end{array}$ & $\begin{array}{c}1.088 \\
(4.819)\end{array}$ \\
\hline $\begin{array}{l}\text { GDP Square } \\
\left(\log ^{2} Y\right)\end{array}$ & & $\begin{array}{c}-0.025 \\
(-0.500)\end{array}$ & & & & \\
\hline $\begin{array}{l}\text { Income } \\
(\log (\mathrm{Y} / \mathrm{P}))\end{array}$ & & & $\begin{array}{c}-0.214 \\
(-2.890)\end{array}$ & & & \\
\hline $\begin{array}{l}\text { Emissions } \\
\left(\mathrm{SO}_{2}\right)(\log \mathrm{E})\end{array}$ & $\begin{array}{c}0.030 \\
(2.241) \\
\end{array}$ & & $\begin{array}{c}-0.127 \\
(-3.724) \\
\end{array}$ & & & \\
\hline $\begin{array}{l}\text { Levy Rate on } \\
\text { IGE }(\log r)\end{array}$ & & $\begin{array}{c}-0.422 \\
(-3.557)\end{array}$ & & & & $\begin{array}{c}-0.287 \\
(-1.267)\end{array}$ \\
\hline $\begin{array}{l}\text { Industrial output } \\
\text { share }(\log S)\end{array}$ & & $\begin{array}{c}-0.036 \\
(-0.129)\end{array}$ & & & & \\
\hline $\begin{array}{l}\text { Trade } \\
(\log T)\end{array}$ & $\begin{array}{c}0.189 \\
(11.844)\end{array}$ & & & $\begin{array}{c}0.005 \\
(1.062)\end{array}$ & & \\
\hline $\begin{array}{l}\text { FDI } \\
(\log \text { FDI) }\end{array}$ & & & & & $\begin{array}{c}0.054 \\
(2.223) \\
\end{array}$ & \\
\hline $\begin{array}{l}\text { Labor } \\
(\log L)\end{array}$ & $\begin{array}{c}0.463 \\
(24.376) \\
\end{array}$ & & & & & \\
\hline $\begin{array}{l}\text { Capital } \\
(\log K)\end{array}$ & $\begin{array}{c}0.317 \\
(14.594)\end{array}$ & & & & & \\
\hline $\begin{array}{l}\text { State-owned } \\
\text { Enterprises } \\
\text { (log SOE) }\end{array}$ & & $\begin{array}{c}0.372 \\
(4.446)\end{array}$ & & & & \\
\hline $\begin{array}{l}\text { Citizen } \\
\text { Complaints } \\
\text { (log C) }\end{array}$ & & & $\begin{array}{c}0.013 \\
(0.213)\end{array}$ & & & \\
\hline $\begin{array}{l}\text { Education } \\
\text { (log ed) }\end{array}$ & & & $\begin{array}{c}-0.285 \\
(-2.200) \\
\end{array}$ & & & \\
\hline $\begin{array}{l}\text { Population } \\
\text { Density } \\
\text { (log PD) }\end{array}$ & & & $\begin{array}{c}0.091 \\
(2.963)\end{array}$ & & & \\
\hline $\begin{array}{l}\text { Industrial } \\
\text { Share } 1 \\
\left(\log S_{-1}\right)\end{array}$ & & & & $\begin{array}{c}0.921 \\
(54.605)\end{array}$ & & \\
\hline $\begin{array}{l}\text { Investments } \\
(\log V)\end{array}$ & & & & $\begin{array}{c}0.034 \\
(2.439) \\
\end{array}$ & & \\
\hline $\begin{array}{l}\text { Remoteness } \\
(\log R)\end{array}$ & & & & & $\begin{array}{c}-0.654 \\
(-6.786) \\
\end{array}$ & \\
\hline $\begin{array}{l}\text { Exchange rate } \\
(\log E \text { R) }\end{array}$ & & & & & $\begin{array}{c}0.042 \\
(0.135) \\
\end{array}$ & \\
\hline $\begin{array}{l}\text { Tariffs } \\
(\log T N * \log \mathrm{TP})\end{array}$ & & & & & $\begin{array}{c}0.003 \\
(0.053) \\
\end{array}$ & \\
\hline $\begin{array}{l}\text { Cumulative FDI } \\
\left(\log \text { CFDI }_{-1}\right)\end{array}$ & & & & & & $\begin{array}{c}0.354 \\
(3.753)\end{array}$ \\
\hline $\begin{array}{l}\text { Road intensity } \\
(\log \mathrm{TI})\end{array}$ & & & & & & $\begin{array}{c}0.668 \\
(3.106) \\
\end{array}$ \\
\hline $\begin{array}{l}\text { Tax rate } \\
(\log \text { Tax })\end{array}$ & & & & & & $\begin{array}{c}0.084 \\
(0.390) \\
\end{array}$ \\
\hline $\begin{array}{l}\text { GDP per capita } \\
\left(\log _{\text {PGDP }}\right)\end{array}$ & & & & & & $\begin{array}{c}0.639 \\
(2.266) \\
\end{array}$ \\
\hline $\begin{array}{l}\text { Regional } \\
\text { Dummy D }\end{array}$ & & & & $\begin{array}{c}-0.009 \\
(-1.191) \\
\end{array}$ & $\begin{array}{c}0.225 \\
(2.074) \\
\end{array}$ & $\begin{array}{c}0.394 \\
(2.128) \\
\end{array}$ \\
\hline $\begin{array}{l}\text { Time Dummy } \\
\text { DT }\end{array}$ & & & & & $\begin{array}{c}-0.013 \\
(-0.180) \\
\end{array}$ & $\begin{array}{c}-0.851 \\
(-4.316) \\
\end{array}$ \\
\hline $\begin{array}{l}\text { Adjusted } \mathrm{R}^{2} \\
\text { Observations }\end{array}$ & $\begin{array}{l}0.980 \\
252\end{array}$ & $\begin{array}{l}0.574 \\
252\end{array}$ & $\begin{array}{l}0.088 \\
252\end{array}$ & $\begin{array}{l}0.955 \\
252\end{array}$ & $\begin{array}{c}0.911 \\
252\end{array}$ & $\begin{array}{l}0.794 \\
252\end{array}$ \\
\hline
\end{tabular}


Table G-5 Industrial Particle Emissions Case

\begin{tabular}{|c|c|c|c|c|c|c|}
\hline & \multicolumn{3}{|c|}{ Dependent } & \multicolumn{3}{|c|}{ Variable } \\
\hline & $\begin{array}{c}\text { GDP } \\
(\log Y) \\
(1)\end{array}$ & $\begin{array}{l}\text { Particles } \\
(\log E) \\
(2)\end{array}$ & $\begin{array}{c}\text { Levy rate } \\
\text { on IGE } \\
(\log r) \\
\text { (3) }\end{array}$ & $\begin{array}{c}\text { Industrial share } \\
(\log S) \\
(4)\end{array}$ & $\begin{array}{c}\text { Trade } \\
(\log \mathrm{T}) \\
(5)\end{array}$ & $\begin{array}{c}\text { FDI } \\
(\underset{(6)}{\log \text { FDI })}\end{array}$ \\
\hline Constant & $\begin{array}{c}-2.403 \\
(-18.445)\end{array}$ & $\begin{array}{c}-7.248 \\
(-5.214)\end{array}$ & $\begin{array}{c}3.797 \\
(3.835)\end{array}$ & $\begin{array}{c}0.216 \\
(2.936) \\
\end{array}$ & $\begin{array}{c}9.781 \\
(3.823)\end{array}$ & $\begin{array}{c}-0.259 \\
(-1.495)\end{array}$ \\
\hline $\begin{array}{l}\text { GDP } \\
(\log Y)\end{array}$ & & $\begin{array}{c}2.108 \\
(5.434) \\
\end{array}$ & & $\begin{array}{c}-0.020 \\
(-1.632) \\
\end{array}$ & $\begin{array}{c}0.874 \\
(15.880) \\
\end{array}$ & $\begin{array}{c}1.088 \\
(4.819) \\
\end{array}$ \\
\hline $\begin{array}{l}\text { GDP Square } \\
\left(\log ^{2} Y\right)\end{array}$ & & $\begin{array}{c}-0.102 \\
(-2.956) \\
\end{array}$ & & & & \\
\hline $\begin{array}{l}\text { Income } \\
(\log (\mathrm{Y} / \mathrm{P}))\end{array}$ & & & $\begin{array}{c}-0.218 \\
(3.022)\end{array}$ & & & \\
\hline $\begin{array}{l}\text { Emissions } \\
\text { (Particle) (log E) }\end{array}$ & $\begin{array}{c}0.096 \\
(7.595)\end{array}$ & & $\begin{array}{c}-0.114 \\
(-2.908)\end{array}$ & & & \\
\hline $\begin{array}{l}\text { Levy Rate on } \\
\text { IGE }(\log r)\end{array}$ & & $\begin{array}{c}-0.354 \\
(-4.303) \\
\end{array}$ & & & & $\begin{array}{c}-0.287 \\
(-1.267) \\
\end{array}$ \\
\hline $\begin{array}{l}\text { Industrial output } \\
\text { share }(\log S)\end{array}$ & & $\begin{array}{c}1.614 \\
(8.318)\end{array}$ & & & & \\
\hline $\begin{array}{l}\text { Trade } \\
(\log T)\end{array}$ & $\begin{array}{c}0.200 \\
(14.704)\end{array}$ & & & $\begin{array}{c}0.005 \\
(1.062)\end{array}$ & & \\
\hline $\begin{array}{l}\text { FDI } \\
(\log F D I)\end{array}$ & & & & & $\begin{array}{c}0.054 \\
(2.223) \\
\end{array}$ & \\
\hline $\begin{array}{l}\text { Labor } \\
(\log \mathrm{L})\end{array}$ & $\begin{array}{c}0.440 \\
(33.035) \\
\end{array}$ & & & & & \\
\hline $\begin{array}{l}\text { Capital } \\
(\log K) \\
\end{array}$ & $\begin{array}{c}0.293 \\
(14.500) \\
\end{array}$ & & & & & \\
\hline $\begin{array}{l}\text { State-owned } \\
\text { Enterprises } \\
\text { (log SOE) }\end{array}$ & & $\begin{array}{c}1.382 \\
(11.340)\end{array}$ & & & & \\
\hline $\begin{array}{l}\text { Citizen } \\
\text { Complaints } \\
(\log C)\end{array}$ & & & $\begin{array}{c}0.026 \\
(0.423)\end{array}$ & & & \\
\hline $\begin{array}{l}\text { Education } \\
\text { (log ed) }\end{array}$ & & & $\begin{array}{c}-0.319 \\
(-2.270)\end{array}$ & & & \\
\hline $\begin{array}{l}\text { Population } \\
\text { Density } \\
\text { (log PD) }\end{array}$ & & & $\begin{array}{c}0.057 \\
(1.977)\end{array}$ & & & \\
\hline $\begin{array}{l}\text { Industrial } \\
\text { Share }_{-1} \\
\left(\log S_{-1}\right)\end{array}$ & & & & $\begin{array}{c}0.921 \\
(54.605)\end{array}$ & & \\
\hline $\begin{array}{l}\text { Investments } \\
(\log V)\end{array}$ & & & & $\begin{array}{c}0.034 \\
(2.439)\end{array}$ & & \\
\hline $\begin{array}{l}\text { Remoteness } \\
(\log R)\end{array}$ & & & & & $\begin{array}{c}-0.654 \\
(-6.786)\end{array}$ & \\
\hline $\begin{array}{l}\text { Exchange rate } \\
(\log E \text { R) }\end{array}$ & & & & & $\begin{array}{c}0.042 \\
(0.135) \\
\end{array}$ & \\
\hline $\begin{array}{l}\text { Tariffs } \\
(\log T N * \log \mathrm{TP})\end{array}$ & & & & & $\begin{array}{c}0.003 \\
(0.053) \\
\end{array}$ & \\
\hline $\begin{array}{l}\text { Cumulative FDI } \\
\left(\log C^{2} I_{-1}\right)\end{array}$ & & & & & & $\begin{array}{c}0.354 \\
(3.753) \\
\end{array}$ \\
\hline $\begin{array}{l}\text { Road intensity } \\
(\log \mathrm{TI})\end{array}$ & & & & & & $\begin{array}{c}0.668 \\
(3.106) \\
\end{array}$ \\
\hline $\begin{array}{l}\text { Tax rate } \\
(\log \text { Tax })\end{array}$ & & & & & & $\begin{array}{c}0.084 \\
(0.390) \\
\end{array}$ \\
\hline $\begin{array}{l}\text { GDP per capita } \\
\left(\log _{\text {PGDP }} \text { - }\right)\end{array}$ & & & & & & $\begin{array}{c}0.639 \\
(2.266) \\
\end{array}$ \\
\hline $\begin{array}{l}\text { Regional } \\
\text { Dummy D }\end{array}$ & & & & $\begin{array}{c}-0.009 \\
(-1.191) \\
\end{array}$ & $\begin{array}{c}0.225 \\
(2.074) \\
\end{array}$ & $\begin{array}{c}0.394 \\
(2.128) \\
\end{array}$ \\
\hline $\begin{array}{l}\text { Time Dummy } \\
\text { DT }\end{array}$ & & & & & $\begin{array}{c}-0.013 \\
(-0.180) \\
\end{array}$ & $\begin{array}{c}-0.851 \\
(-4.316) \\
\end{array}$ \\
\hline $\begin{array}{l}\text { Adjusted } \mathrm{R}^{2} \\
\text { Observations }\end{array}$ & $\begin{array}{l}0.984 \\
252\end{array}$ & $\begin{array}{l}0.696 \\
252\end{array}$ & $\begin{array}{l}0.080 \\
252\end{array}$ & $\begin{array}{l}0.955 \\
252\end{array}$ & $\begin{array}{l}0.911 \\
252 \\
\end{array}$ & $\begin{array}{l}0.794 \\
252\end{array}$ \\
\hline
\end{tabular}


Table G-6 Industrial Dust Emissions Case

\begin{tabular}{|c|c|c|c|c|c|c|}
\hline & \multicolumn{3}{|c|}{ Dependent } & \multicolumn{3}{|c|}{ Variable } \\
\hline & $\begin{array}{c}\text { GDP } \\
(\log Y) \\
(1)\end{array}$ & $\begin{array}{c}\text { Dust } \\
(\log E) \\
(2)\end{array}$ & $\begin{array}{c}\text { Levy rate } \\
\text { on IGE } \\
(\log r) \\
(3)\end{array}$ & $\begin{array}{c}\text { Industrial share } \\
\qquad(\log S) \\
(4)\end{array}$ & $\begin{array}{c}\text { Trade } \\
(\log \mathrm{T}) \\
(5)\end{array}$ & $\begin{array}{c}\text { FDI } \\
(\log \text { FDI }) \\
(6)\end{array}$ \\
\hline Constant & $\begin{array}{c}-2.225 \\
(-14.308) \\
\end{array}$ & $\begin{array}{c}6.562 \\
(3.347) \\
\end{array}$ & $\begin{array}{c}-0.165 \\
(-0.131) \\
\end{array}$ & $\begin{array}{c}0.216 \\
(2.936) \\
\end{array}$ & $\begin{array}{c}9.781 \\
(3.823) \\
\end{array}$ & $\begin{array}{c}-0.259 \\
(-1.495) \\
\end{array}$ \\
\hline $\begin{array}{l}\text { GDP } \\
(\log Y)\end{array}$ & & $\begin{array}{c}1.197 \\
(2.501)\end{array}$ & & $\begin{array}{c}-0.020 \\
(-1.632)\end{array}$ & $\begin{array}{c}0.874 \\
(15.880)\end{array}$ & $\begin{array}{c}1.088 \\
(4.819)\end{array}$ \\
\hline $\begin{array}{l}\text { GDP Square } \\
\left(\log ^{2} Y\right)\end{array}$ & & $\begin{array}{c}-0.040 \\
(-1.046)\end{array}$ & & & & \\
\hline $\begin{array}{l}\text { Income } \\
(\log (Y / P))\end{array}$ & & & $\begin{array}{c}-0.124 \\
(-1.596) \\
\end{array}$ & & & \\
\hline $\begin{array}{l}\text { Emissions } \\
\text { (Dust) (log E) }\end{array}$ & $\begin{array}{c}0.106 \\
(4.799) \\
\end{array}$ & & $\begin{array}{c}0.119 \\
(2.063) \\
\end{array}$ & & & \\
\hline $\begin{array}{l}\text { Levy Rate on } \\
\text { IGE }(\log r)\end{array}$ & & $\begin{array}{c}0.175 \\
(1.982) \\
\end{array}$ & & & & $\begin{array}{c}-0.287 \\
(-1.267) \\
\end{array}$ \\
\hline $\begin{array}{l}\text { Industrial output } \\
\text { share }(\log \mathrm{S})\end{array}$ & & $\begin{array}{c}-0.526 \\
(-1.862) \\
\end{array}$ & & & & \\
\hline $\begin{array}{l}\text { Trade } \\
(\log T)\end{array}$ & $\begin{array}{c}0.160 \\
(10.100) \\
\end{array}$ & & & $\begin{array}{c}0.005 \\
(1.062) \\
\end{array}$ & & \\
\hline $\begin{array}{l}\text { FDI } \\
(\log \text { FDI })\end{array}$ & & & & & $\begin{array}{c}0.054 \\
(2.223) \\
\end{array}$ & \\
\hline $\begin{array}{l}\text { Labor } \\
(\log L)\end{array}$ & $\begin{array}{c}0.403 \\
(19.107)\end{array}$ & & & & & \\
\hline $\begin{array}{l}\text { Capital } \\
(\log K)\end{array}$ & $\begin{array}{c}0.371 \\
(17.500)\end{array}$ & & & & & \\
\hline $\begin{array}{l}\text { State-owned } \\
\text { Enterprises } \\
\text { (log SOE) }\end{array}$ & & $\begin{array}{c}0.362 \\
(3.009)\end{array}$ & & & & \\
\hline $\begin{array}{l}\text { Citizen } \\
\text { Complaints } \\
(\log C)\end{array}$ & & & $\begin{array}{c}0.049 \\
(0.809)\end{array}$ & & & \\
\hline $\begin{array}{l}\begin{array}{l}\text { Education } \\
\text { (log ed) }\end{array} \\
\end{array}$ & & & $\begin{array}{c}-0.056 \\
(-0.383) \\
\end{array}$ & & & \\
\hline $\begin{array}{l}\text { Population } \\
\text { Density } \\
\text { (log PD) }\end{array}$ & & & $\begin{array}{c}-0.010 \\
(-0.280)\end{array}$ & & & \\
\hline $\begin{array}{l}\text { Industrial } \\
\text { Share }-1 \\
\left(\operatorname{log~S}_{-1}\right) \\
\end{array}$ & & & & $\begin{array}{c}0.921 \\
(54.605)\end{array}$ & & \\
\hline $\begin{array}{l}\text { Investments } \\
(\log V)\end{array}$ & & & & $\begin{array}{c}0.034 \\
(2.439) \\
\end{array}$ & & \\
\hline $\begin{array}{l}\text { Remoteness } \\
(\log \mathrm{R})\end{array}$ & & & & & $\begin{array}{c}-0.654 \\
(-6.786) \\
\end{array}$ & \\
\hline $\begin{array}{l}\text { Exchange rate } \\
(\log E \text { R })\end{array}$ & & & & & $\begin{array}{c}0.042 \\
(0.135) \\
\end{array}$ & \\
\hline $\begin{array}{l}\text { Tariffs } \\
(\log T N * \log T P)\end{array}$ & & & & & $\begin{array}{c}0.003 \\
(0.053) \\
\end{array}$ & \\
\hline $\begin{array}{l}\text { Cumulative FDI } \\
\left(\log \text { CFDI }_{-1}\right)\end{array}$ & & & & & & $\begin{array}{c}0.354 \\
(3.753) \\
\end{array}$ \\
\hline $\begin{array}{l}\text { Road intensity } \\
(\log T I)\end{array}$ & & & & & & $\begin{array}{c}0.668 \\
(3.106) \\
\end{array}$ \\
\hline $\begin{array}{l}\text { Tax rate } \\
(\log \text { Tax }) \\
\end{array}$ & & & & & & $\begin{array}{c}0.084 \\
(0.390) \\
\end{array}$ \\
\hline $\begin{array}{l}\text { GDP per capita } \\
\left(\log _{\left.\text {PGDP }_{-1}\right)}\right.\end{array}$ & & & & & & $\begin{array}{c}0.639 \\
(2.266) \\
\end{array}$ \\
\hline $\begin{array}{l}\text { Regional } \\
\text { Dummy D }\end{array}$ & & & & $\begin{array}{c}-0.009 \\
(-1.191) \\
\end{array}$ & $\begin{array}{c}0.225 \\
(2.074) \\
\end{array}$ & $\begin{array}{c}0.394 \\
(2.128) \\
\end{array}$ \\
\hline $\begin{array}{l}\text { Time Dummy } \\
\text { DT }\end{array}$ & & & & & $\begin{array}{c}-0.013 \\
(-0.180) \\
\end{array}$ & $\begin{array}{c}-0.851 \\
(-4.316) \\
\end{array}$ \\
\hline $\begin{array}{l}\text { Adjusted } \mathrm{R}^{2} \\
\text { Observations }\end{array}$ & $\begin{array}{c}0.982 \\
252 \\
\end{array}$ & $\begin{array}{l}0.542 \\
252 \\
\end{array}$ & $\begin{array}{l}0.071 \\
252\end{array}$ & $\begin{array}{l}0.955 \\
252\end{array}$ & $\begin{array}{l}0.911 \\
252 \\
\end{array}$ & $\begin{array}{l}0.794 \\
252\end{array}$ \\
\hline
\end{tabular}




\section{Vita}

\section{Haixiao Huang}

Haixiao Huang was born on August 27, 1961 in Nancheng, Jiangxi Province, People's Republic of China. In December 1977 he passed the national university entrance examination held for the first time in China since the "Cultural Revolution" and was admitted to Shandong Institute of Mining and Technology (renamed as Shandong University of Science and Technology recently). At this Institute he received a BSc Degree in mine construction and a MSc Degree in mining systems engineering, and worked in that Institute untill 1996. From 1996 to 1997, he was a visiting scholar at the Institute of Chemical Engineering, Fuel and Environmental Technology, Vienna University of Technology, Austria. Since 1997, he has been a PhD student in the Natural Resource Economics Program, West Virginia University. His research has mainly focused on issues in coal production, environmental economics and management, and the relationship between trade and the environment. He is the author of more than ten articles. 